\title{
Kinetic models of sequential initiation events upon polysome formation
}

\author{
Dissertation \\ for the award of the degree \\ "Doctor rerum naturalium" (Dr.rer.nat.) \\ of the Georg-August-Universität Göttingen
}

within the doctoral program IMPRS Molecular Biology

of the Georg-August University School of Science (GAUSS)

submitted by

Irena Andreeva

from Svishtov, Bulgaria

Göttingen 2016

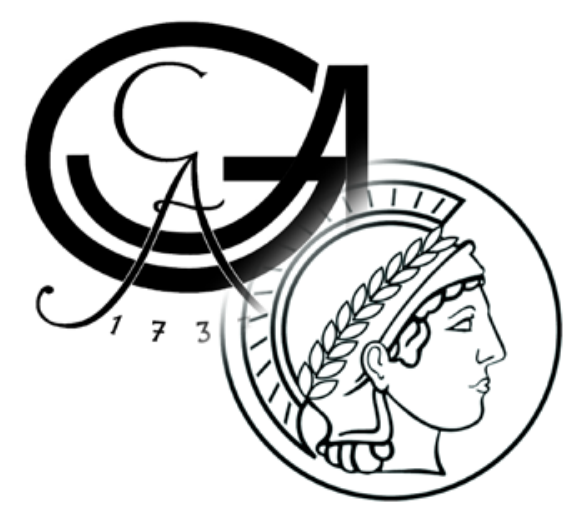




\section{Members of the Examination Board / Thesis Committee}

Prof. Dr. Marina Rodnina ( $1^{\text {st }}$ Referee)

Department of Physical Biochemistry

Max Planck Institute for Biophysical Chemistry

Göttingen, Germany

Prof. Dr. Heinz Neumann ( $2^{\text {nd }}$ Referee)

Department of Applied Synthetic Biology

Göttingen Center for Molecular Biosciences (GZMB)

Göttingen, Germany

Prof. Dr. Holger Stark

Department of Structural Dynamics

Max Planck Institute for Biophysical Chemistry

Göttingen, Germany

\section{Further members of the Examination Board}

Prof. Dr. Markus Bohnsack

Department of Molecular Biology

University Medical Center Göttingen

Göttingen, Germany

Prof. Dr. Kai Tittmann

Department of Molecular Enzymology

Schwann-Schleiden-Forschungszentrum

Göttingen, Germany

Prof. Dr. Ralf Ficner

Department of Molecular Structural Biology

Institute for Microbiology and Genetics

Göttingen, Germany

Date of oral examination: 09.05.2016 


\section{Affidavit}

Herewith I declare, that I prepared the Thesis "Kinetic models of sequential initiation events upon polysome formation" on my own and with no other sources and aids than quoted.

Irena Andreeva

March, 2016

Göttingen, Germany 
Table of Contents

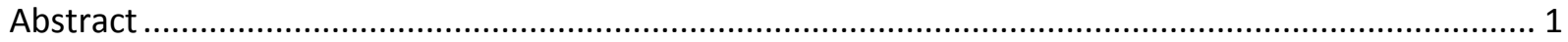

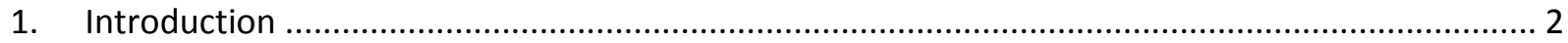

1.1. Dominance of translational regulation in gene expression ..................................................... 2

1.2. Main phases of protein synthesis in bacteria ................................................................... 2

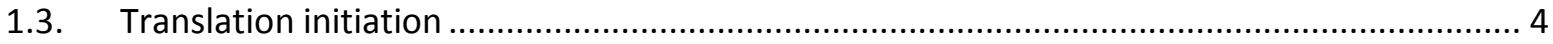

1.4. Efficiency of protein synthesis depends on mRNA sequence determinants ........................ 6

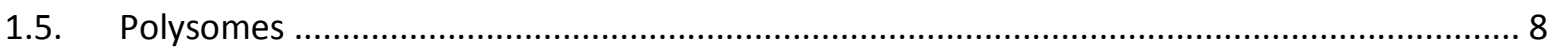

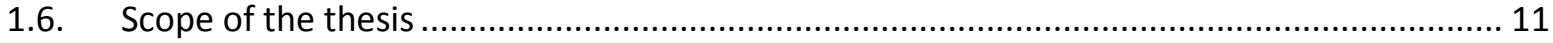

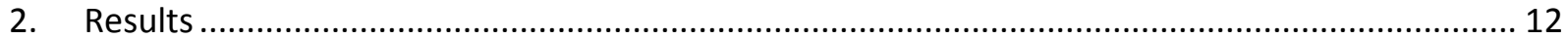

2.1. Design, production and translation initiation potential of novel model 5 '-end labeled mRNAs. 12

2.1.1. Generation of 5 '-end labeled mRNAs with poly(U) extensions .................................... 12

2.1.2. Generation of $5^{\prime}$-end-labeled mRNAs by modified in vitro transcription reaction............ 14

2.2. Rapid kinetics of $30 \mathrm{~S}$ PIC recruitment to various model 5 '-end labeled mRNAs.................... 17

2.2.1. 5 '-end labeled mRNAs with poly $(U)$ extensions recruited the 30S PIC depending on their

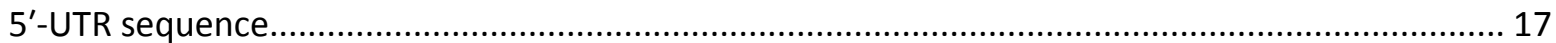

2.2.2. $5 * \mathrm{RBS}_{18 \mathrm{e}}(\mathrm{U})_{250} \mathrm{mRNA}$ changed fluorescence upon $30 \mathrm{~S}$ PIC recruitment ........................ 20

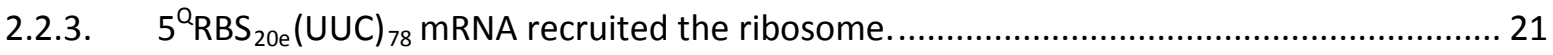

2.3. Timing of the first 30 S PIC binding event with model 5 '-end labeled mRNAs......................... 23

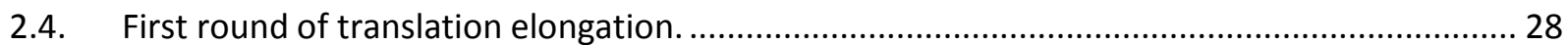

2.5. The first step of polysome formation in vitro in a minimal translation system........................ 32

2.6. Kinetic model of second round initiation............................................................................ 36

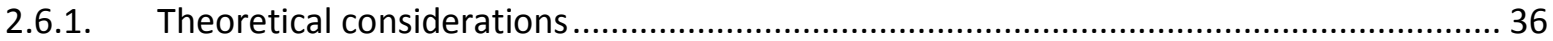

2.6.2. $5^{\mathrm{Q}} \mathrm{RBS}_{20 \mathrm{e}}(\mathrm{U})_{78}$ mRNA recruited the first and the second ribosome with a similar rate .... 39

2.6.3. $5^{\mathrm{Q}} \mathrm{RBS}_{18 \mathrm{e}}(\mathrm{U})_{250}$ mRNA differed in the rates of the first and second 30S PIC recruitment. 41

2.6.4. $5 * \mathrm{RBS}_{18 \mathrm{e}}(\mathrm{U})_{250} \mathrm{mRNA}$ directly visualized the recruitment of the $30 \mathrm{~S}$ PIC........................ 45

2.7. asRNA changed fluorescence upon target RBS hybridization; a novel method for probing a

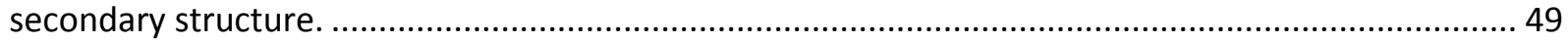

2.7.1. Equilibrium binding of asRNA12* to its target on $\mathrm{RBS}_{20 \mathrm{e}}(\mathrm{UUC})_{78}$ mRNA........................50

2.7.2. asRNA12* changed fluorescence upon target RBS hybridization off the ribosome.......... 51 
2.7.3. asRNA12* as reporter for RBS clearance during the first ribosome elongation.

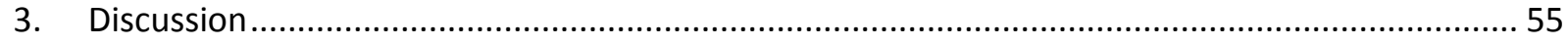

How does the RBS of the mRNA affect the first round of initiation?

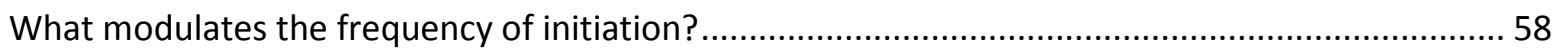

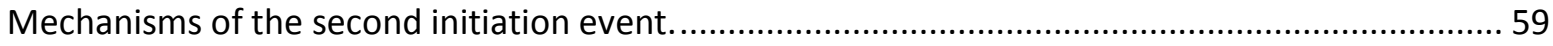

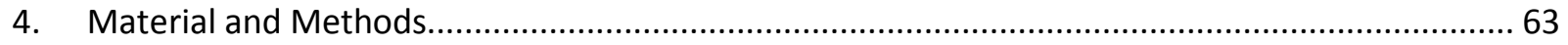

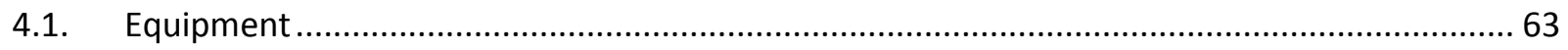

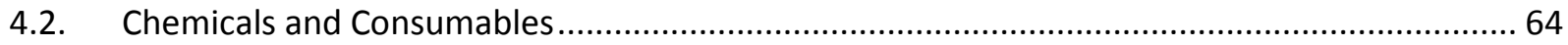

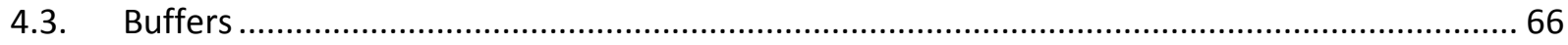

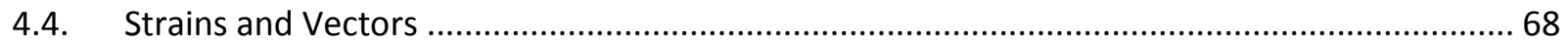

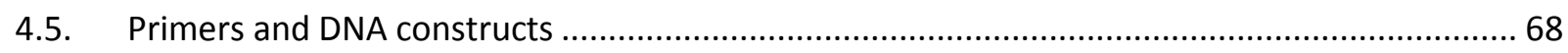

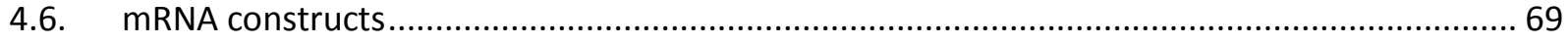

4.7. Generation of model DNA templates for $\mathrm{RBS}_{20 \mathrm{e}}(\mathrm{UUC})_{78 \mathrm{AAA}}$ and $\mathrm{RBS}_{20 \mathrm{e}}(\mathrm{UUC})_{78}$ mRNAs.......... 71

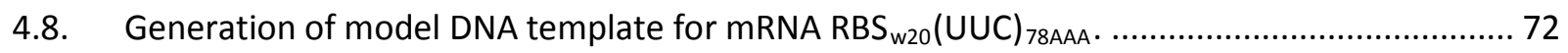

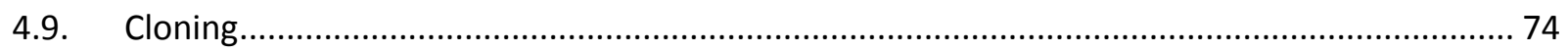

4.10. Bacterial transformation and plasmid DNA preparation ….............................................. 74

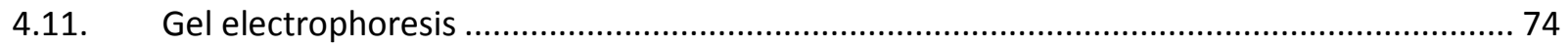

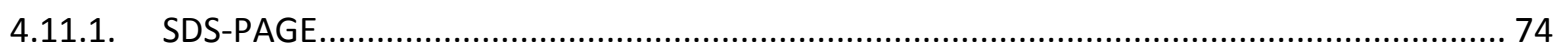

4.11.2. Tris-Tricine polyacrylamide gel preparation. …............................................................ 75

4.11.3. Denaturing urea polyacrylamide electrophoresis........................................................ 75

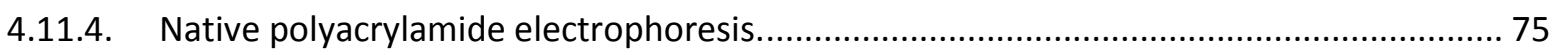

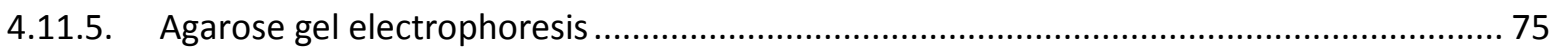

4.12. Modified in vitro T7 RNA-polymerase transcription reaction............................................. 76

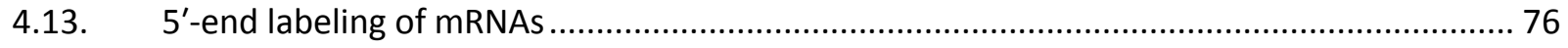

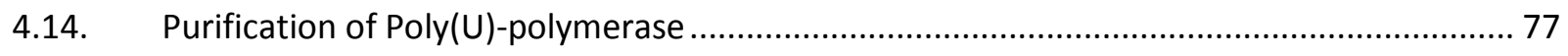

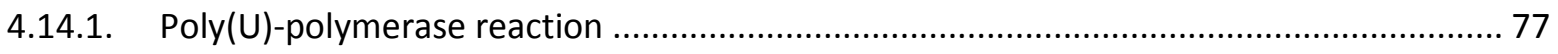

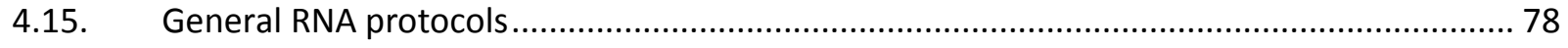

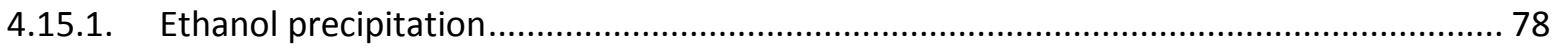

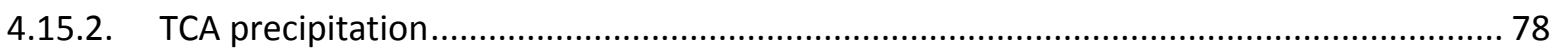

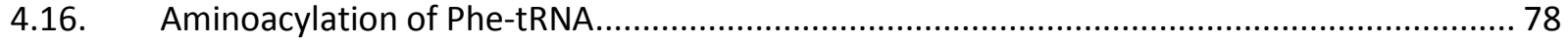

4.17. S13(Alx488) reconstitution to $\Delta 30$ S subunit ribosomal subunits ...................................... 78

4.18. Preparation of components used for in vitro translation ................................................... 79 


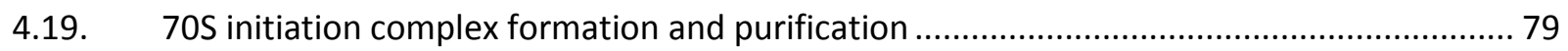

4.19.1. Initiation complex efficiency measured by nitrocellulose filter binding .......................... 79

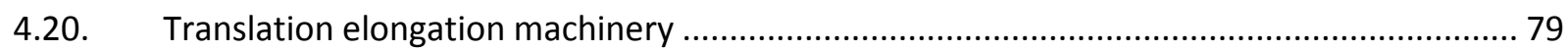

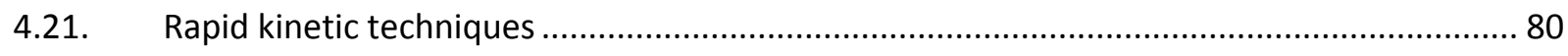

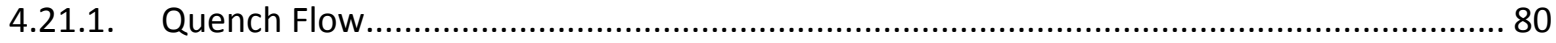

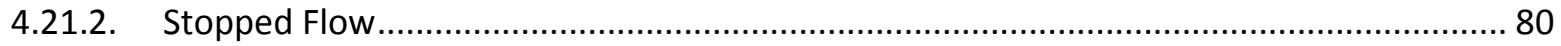

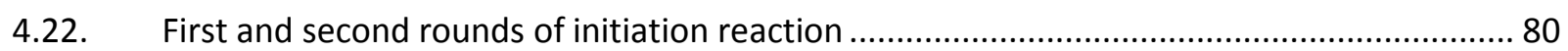

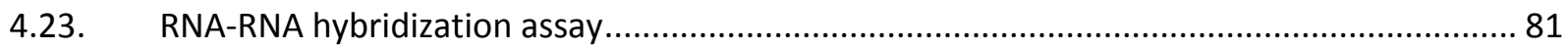

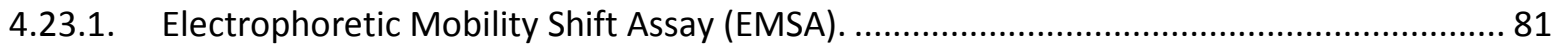

4.23.2. asRNA12*-mRNA association kinetics measured at the stopped flow apparatus ............ 81

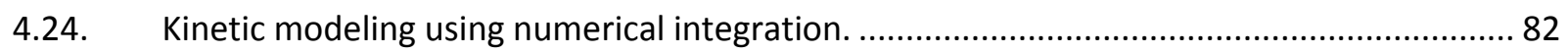

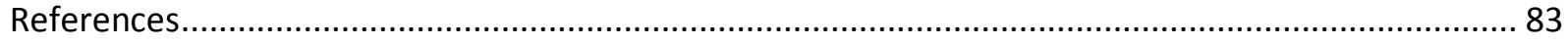

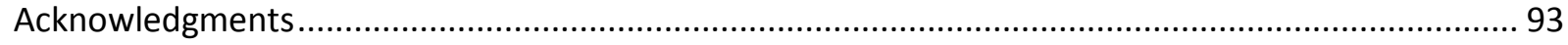

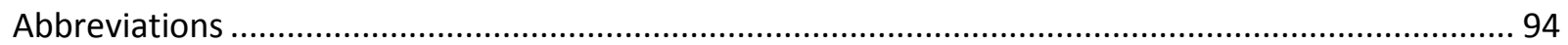

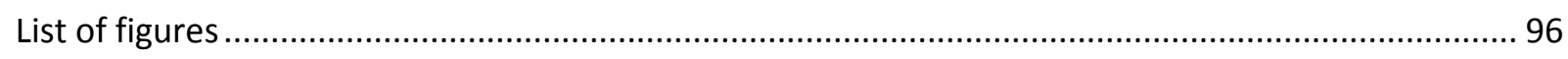

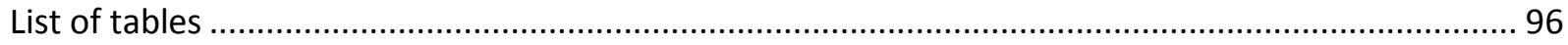

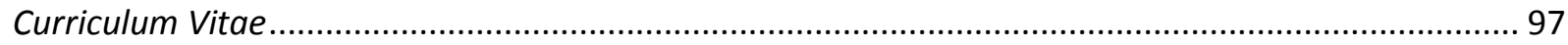




\section{Abstract}

Polysomes are active protein-synthesizing units consisting of multiple ribosomes assembled along one mRNA. The frequency of ribosome loading on the mRNA defines the number of ribosomes per polysome, which is an important regulator of the proteomic output from the transcriptome. The mechanisms that regulate the frequency of ribosome loading on the mRNA, and thus protein abundance are largely unknown. Here we have studied ribosome loading in real-time in vitro employing fluorescence resonance energy transfer (FRET), rapid kinetics, and global fitting approaches. We monitored how the first ribosome in a polysome moves along the mRNA away from the initiation site, whereas the second ribosome starts the initiation on the same mRNA. We established novel approaches for monitoring mRNA recruitment by efficient FRET between the $5^{\prime}$-end of model mRNAs and proteins from the initiation machinery. We recapitulated in vitro the overall mRNA loading frequency reported in vivo and explored how the rate of clearance of the initiation site from the first ribosome and the secondary structures around the ribosome binding site (RBS) affected ribosome loading. We compared the mechanisms of translation initiation of the first and the second ribosomes and measured the initiation and elongation rate constants. We showed that the recruitment of the second ribosome happened co-translationally and was RBS specific. We obtained a set of elemental rates for each model mRNA in the process of the second ribosome recruitment. The analysis revealed that the 30S PIC recruitment followed two kinetically different mechanisms depending on the mRNA used. These results suggested that ribosome recruitment into a polysome may comprise an important regulatory step that defines the frequency of translation of a given mRNA. Taken together, this study provides quantitative new insights into the interactions of the 30S PIC with various mRNAs in the first step of polysome formation. 


\section{Introduction}

\subsection{Dominance of translational regulation in gene expression}

Biological mechanisms involved in shaping the global proteome are extremely complex and poorly understood. In cells, messenger RNA (mRNA) and protein levels are fine-tuned to adjust continuously to cellular demands. The regulation of gene expression in prokaryotes can occur at several stages in the step-wise transfer of information from a gene to protein: transcription, translation and mRNA / protein turnover. Large-scale studies in prokaryotes showed a lack of correlation between mRNA and protein abundances emphasizing the significance of posttranscriptional regulations (Corbin et al., 2003; Lu et al., 2007). Post-transcriptional regulations involve dynamic adaptation of mRNA and protein turnover and also modulation of the efficiency of protein synthesis, hence the density of ribosomes along the mRNA transcript. Translation regulation is proposed to be the main reason for the weak correlation between mRNA and protein expression, rather than processes involved in mRNA or protein turnover (Lee et al., 2003; Mehra et al., 2003). Which particular stage of translation is rate-limiting in determining translation efficiencies is still a matter of debate. mRNA sequence determinants, ribosome-mRNA interactions and the functionality of the gene being expressed may play essential roles. Predicting the desired gene expression is important for medical and biotechnological applications (Keasling, 2010).

\subsection{Main phases of protein synthesis in bacteria}

Ribosomes are the professional translators in cellular life. They are molecular machines that decipher the genetic RNA instructions and provide the environment in which translation takes place. Ribosomes possess two core functional centers: the small ribosomal subunit ( $30 \mathrm{~S}$ in bacteria) has the decoding center where the codon-anticodon base pairing is monitored, whereas the large ribosomal subunit (50S in bacteria) forms the peptidyl transferase center (PTC) catalyzing the peptide bond formation and the hydrolysis of peptidyl-tRNA during termination of protein synthesis (Ramakrishnan, 2002). There are three binding sites for tRNA on the ribosome, the A (acceptor), P (peptidyl), and E (exit) site. The main consecutive phases of translation, initiation, elongation, termination and ribosome recycling, are evolutionary conserved and any perturbation in the cycle could lead to global irreversible changes in the cell (Figure 1).

During initiation, the $30 \mathrm{~S}$ subunit selects the correct mRNA open reading frame (ORF) and recruits the initiator tRNA (fMet-tRNA ${ }^{\mathrm{fMet}}$ ) into the ribosomal $P$ site which base pairs with the start codon of the mRNA. Eubacteria accomplish this task with the help of three non-ribosomal proteins, the initiation factors (IFs) IF1, IF2 and IF3 (Laursen et al., 2005; Milon and Rodnina, 2012). The $50 \mathrm{~S}$ subunit rapidly docks to the $30 \mathrm{~S}$ initiation complex (30S IC) with the IFs, the mRNA and the fMettRNA ${ }^{\text {fMet }}$. The maturation of 70S initiation complex (70S IC) is coupled to GTP hydrolysis by IF2, which leads to the formation of a stable $70 \mathrm{~S} \mathrm{IC} \mathrm{and} \mathrm{the} \mathrm{dissociation} \mathrm{of} \mathrm{the} \mathrm{initiation} \mathrm{factors} \mathrm{(Goyal} \mathrm{et} \mathrm{al.,}$ 2015). The result is a 70S IC ready to enter the next phase of translation.

Elongation refers to the polymerization of the nascent peptide. Successive aminoacyl-tRNAs (aa-tRNAs) are delivered to the ribosome in a ternary complex (TC) with elongation factor Tu (EF-Tu) and GTP. Correct codon-anticodon interaction leads to GTPase activation and GTP hydrolysis, generating GDP and inorganic phosphate. EF-Tu-GDP complex dissociates from the ribosome. EF-Tu- 
GDP is reloaded with GTP in the cytosol by EF-Ts, a specific guanine nucleotide exchange factor (Rodnina and Wintermeyer, 2001).

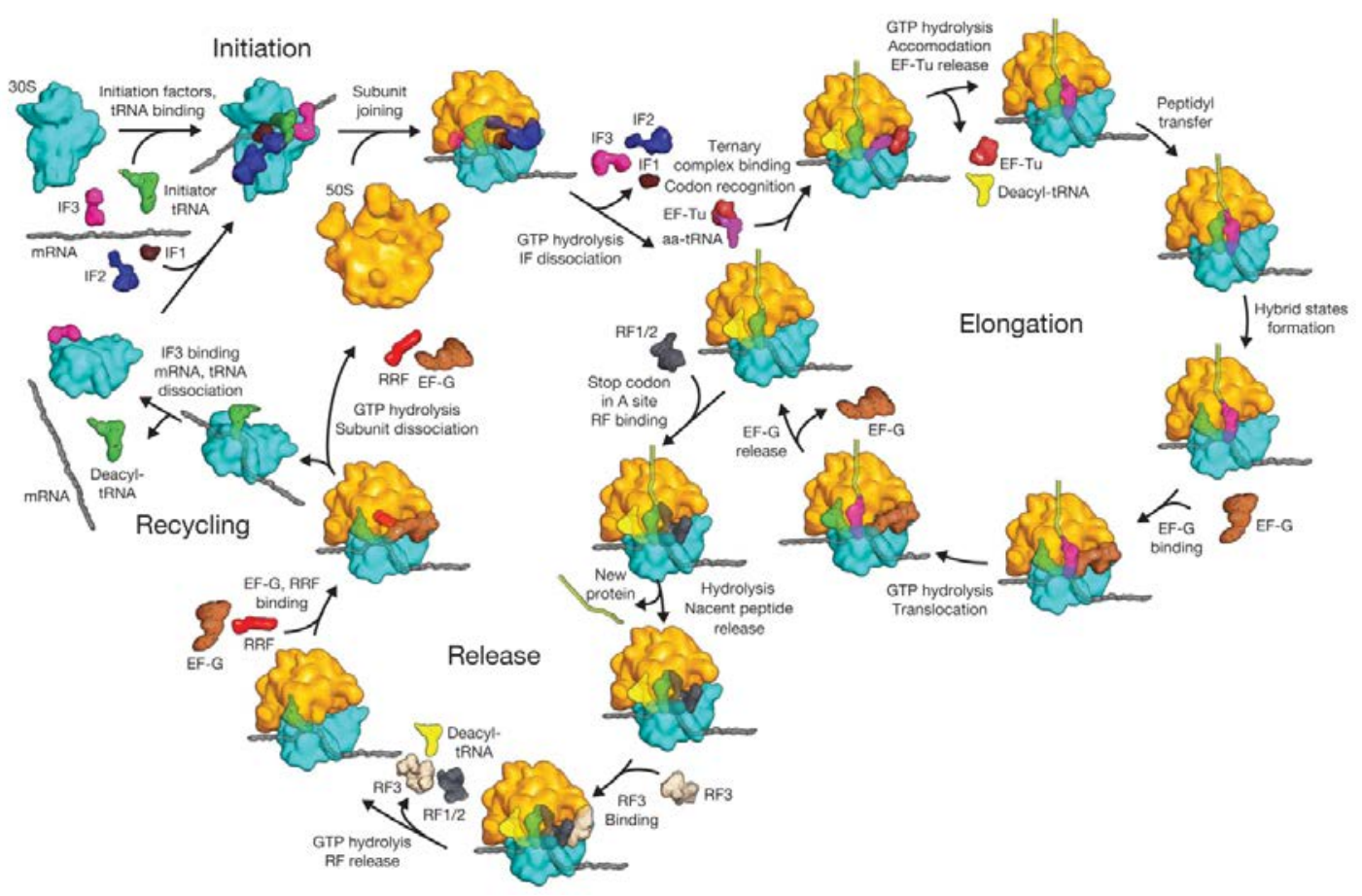

Figure 1. Main phases of translation.

Overview of prokaryotic translation pathway. The main phases, initiation, elongation, termination and recycling, are explained in the text. Abbreviations used in the figure: aminoacyl-tRNA (aa-tRNA,); elongation factor (EF); initiation factor (IF); release factor (RF), ribosome-recycling factor (RRF) (Schmeing and Ramakrishnan, 2009).

Both ribosomal subunits are involved in the step-wise movement of the ribosome precisely one codon at a time in a process called translocation, which brings the next codon in the mRNA into now empty A site to be decoded. Translocation of the tRNAs-mRNA complex is promoted by elongation factor G (EF-G) at the cost of GTP hydrolysis (Rodnina et al., 1997). EF-G, in its active GTP form, is recruited to the ribosome through the interactions with ribosomal protein $L 7 / 12$ from the highly dynamic 50S stalk (Diaconu et al., 2005). Translocation of the tRNAs from their A and P site to the $P$ and $E$ site is coordinated by the rotation of the subunits with respect to each other, the concerted motions of ribosomal subdomains (i.e. $30 \mathrm{~S}$ head and body) and local dynamics of ribosomal proteins (e.g. L1, L9) (Dunkle and Cate, 2010; Rodnina and Wintermeyer, 2011). The nascent peptide moves out of the ribosome through a tunnel in the 50S subunit, which is lined with ribosomal RNA and minor patches of proteins (Voss et al., 2006). The rate of elongation depends on the codon identity and the availability of the aa-tRNA cognate for a specific mRNA codon (Sorensen and Pedersen, 1991). Certain codon sequences may interact with the ribosome and slow it down in a programed or non-programed fashion, leading to a variable speed of ribosomes along the mRNA (Caliskan et al., 2015; Keiler, 2015). Translational pausing in yeast and mammals can also occur due to position-specific interaction of the nascent chain with the peptide exit tunnel at the $5^{\text {th }}$ codon (Han et al., 2014; Heyer and Moore, 2016). 
Termination includes the sequence of events following recognition of the stop codon on the mRNA (UAG, UAA or UGA) by proteins RF1 and RF2 up to the hydrolysis of the peptidyl-tRNA and the consequent release of the nascent chain (Ito et al., 2000). RF1/2 dissociation is accelerated by RF3, a translational GTPase that stimulates the functional cycle of RF1/2 at the expense of GTP hydrolysis (Korostelev, 2011; Youngman et al., 2008). After termination, a deacylated tRNA and the mRNA are still associated with the 70S ribosome. The ribosome recycling factor (RRF) and EF-G in its GTPactivated state bind to the post-termination complex. Hydrolysis of GTP allows dissociation of the 50S subunit. IF3 promotes the release of the deacylated tRNA and the mRNA from the 30S subunit and mediates the next round of initiation (Peske et al., 2005). In the cell, multiple ribosomes simultaneously engage along the sequence of a single mRNA forming a polysomal unit (Miller et al., 1970). Building a polysomal unit demands time and redirects energy from other cellular processes. However, to assemble multiple ribosomes, actively translating along the mRNA sequence, amplify the message encoded in a single transcript to several copies of protein. This ensures highly efficient use of mRNAs and energy resources.

\subsection{Translation initiation}

Initiation of translation in bacteria begins already during transcription, which tightly couples these two cellular processes. Translation initiation is the rate-limiting and most highly regulated phase of the protein biosynthesis (Jacques and Dreyfus, 1990). Kinetic dissection of the translation initiation reveals multiple kinetic checkpoints along the pathway. The process begins with the formation of a transient intermediate $30 \mathrm{~S}$ pre-initiation complex (30S PIC), in which the three IFs, mRNA and fMet-tRNA ${ }^{\text {fMet }}$ assemble on the $30 \mathrm{~S}$ ribosomal subunit. The transition to the mature complex - i.e. the $30 \mathrm{~S} \mathrm{IC} \mathrm{-} \mathrm{is} \mathrm{guided} \mathrm{by} \mathrm{a} \mathrm{conformational} \mathrm{change} \mathrm{in} \mathrm{which} \mathrm{the} \mathrm{start} \mathrm{codon} \mathrm{of} \mathrm{the}$ mRNA specifically interacts with the anticodon of the initiator tRNA in the P site (Milon et al., 2012). Subsequently, the joining of the 50S subunit with the 30S IC leads to the formation of the 70S IC. The mRNA can bind the $30 \mathrm{~S}$ subunit at any step of the translation initiation reaction, either in complex with the IFs or with the IFs plus fMet-tRNA ${ }^{\text {fMet }}$ (Milon et al., 2012; Tsai et al., 2012).

The initiation factors are essential proteins in E.coli and play crucial roles for the accuracy and speed of the multistep process of translation initiation. They induce conformational changes of the $30 \mathrm{~S}$ subunit and affect each other in order to increase or decrease the affinity of the 30S PIC to the proper mRNA (Milon and Rodnina, 2012). IF1 binds at the vicinity of the A site of the 30S subunit where aa-tRNA is expected to bind (Carter et al., 2001; Sette et al., 1997). It stimulates the action of the other initiation factors IF2 and IF3 (Milon et al., 2008). When a 70S IC forms, IF3 dissociates and leaves the place for incoming aminoacyl-tRNAs. IF2 is a GTPase that plays an important role in several aspects of translation initiation. The summarized functions are: (i) increasing the affinity of the $30 \mathrm{~S}$ subunit for IF1, (ii) favoring binding of aa-tRNAs with blocked $\alpha-\mathrm{NH}_{2}$ groups to the $30 \mathrm{~S} \mathrm{IC} \mathrm{(iii)} \mathrm{favoring}$ an interaction with the 50S subunit; upon subunit association the GTPase activity of IF2 is activated, (iv) positioning the MMet-tRNA $^{\text {fMet }}$ in the P site (Gualerzi et al., 1991; Milon et al., 2010). IF3 contains two domains separated by a flexible linker. The structures of both domains have been solved separately by nuclear magnetic resonance (Garcia et al., 1995a, b). The N-terminal domain of the protein is closer to the initiator tRNA while the C-terminal domain is closer to the 16S RNA of the 30S subunit (Julian et al., 2011). Both IF3 domains bind to the 30S subunit independently of one another 
and with different affinities (Sette et al., 1999). Besides its known function to prevent association of the ribosomal subunits during the recycling phase of translation, IF3 has also a proofreading function by destabilizing complexes containing non-initiator tRNA and/or non-start codons (Antoun et al., 2006; Milon et al., 2008; Petrelli et al., 2001). It also interacts with the other initiation factors during the process of $30 \mathrm{~S} \mathrm{PIC} \mathrm{formation.} \mathrm{Its} \mathrm{inherent} \mathrm{dynamics} \mathrm{during} \mathrm{initiation} \mathrm{have} \mathrm{been} \mathrm{extensively}$ examined with single-molecule techniques and pre-steady state kinetics (MacDougall and Gonzalez, 2015; Milon et al., 2012).

The initiator tRNA possesses specific properties that discriminates it from the elongator tRNAs. Its $\alpha-\mathrm{NH}_{2}$ group is blocked with a formyl group, resulting in an fMet-tRNA ${ }^{\mathrm{fMet}}$ molecule, recognized by IF2 rather than EF-Tu (Laursen et al., 2005). Furthermore, fMet-tRNA ${ }^{\text {fMet }}$ binds to the ribosomal $\mathrm{P}$ site, whereas elongator tRNAs enter the ribosome at the A-site and subsequently translocate to the P site. IF2-fMet-tRNA ${ }^{\mathrm{fMet}}$ interactions on the $30 \mathrm{~S}$ subunit are of great significance for accurate selection of the correct initiation site (Boelens and Gualerzi, 2002), the speed and efficiency of both 30S and 70S IC formation (Canonaco et al., 1986) and for the formation of the first peptide bond (La Teana et al., 1996). Aside from the initiation factors and the fMet-tRNA ${ }^{\text {fMet }}$, key roles in the initiation process play the ribosomal subunits. Bacterial and eukaryotic ribosomes share a core composed of RNA and proteins, which is evolutionally conserved and performs essential functions as decoding and peptide synthesis (Figure 2).

(A)

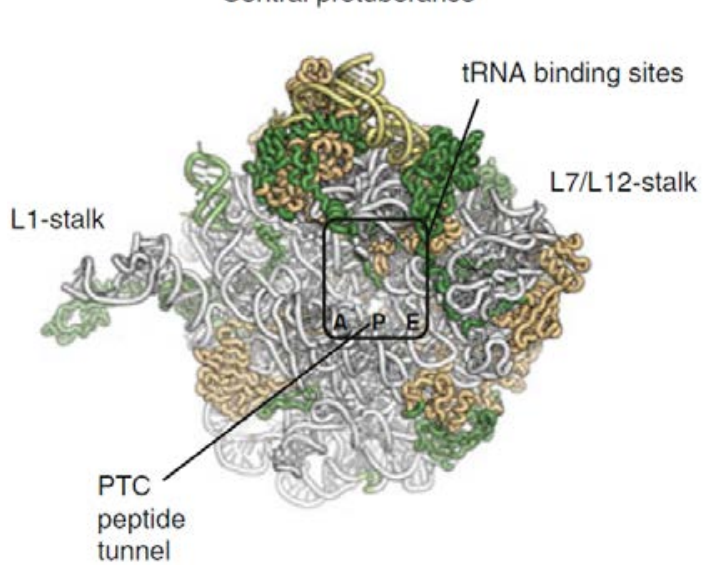

(B)

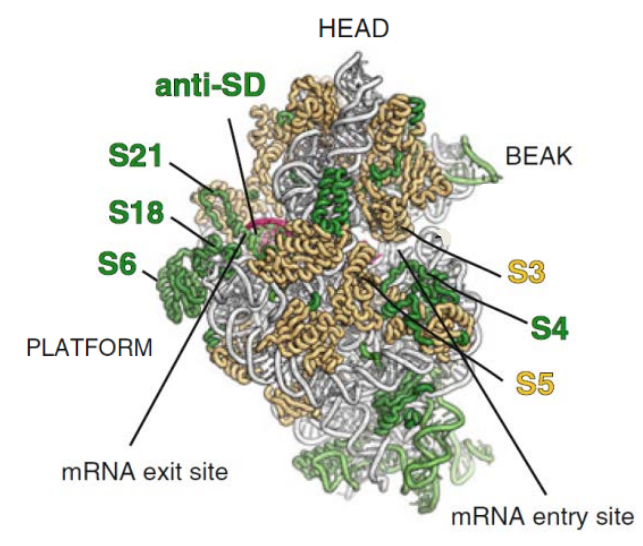

Figure 2. Overall architecture of the $50 \mathrm{~S}$ and $30 \mathrm{~S}$ subunits with bacterial-specific moieties.

(A) The subunit interface of the $50 \mathrm{~S}$ subunit. The evolutionary conserved core of the bacterial ribosome consists of RNA (grey) and proteins (orange). Bacterial-specific moieties are shown in green. The functionally important areas of the $50 \mathrm{~S}$ subunit are depicted, two stalks $\mathrm{L} 1$ and $\mathrm{L} 7 / \mathrm{L} 12$ and the central protuberance. The proteins of the stalks are omitted for simplicity. The tRNA binding sites $(A, P, E)$, the peptidyl transferase center and the peptide tunnel are indicated. (B) Solvent view of the $30 \mathrm{~S}$ subunit. Same color scheme as in (A). The $30 \mathrm{~S}$ subunit binds the mRNA (pink). The landmarks of the $30 \mathrm{~S}$ subunit architecture are indicated as platform, head and beak. The mRNA entry site is surrounded by ribosomal proteins S3, S4 and S5. The mRNA exit site is located between the head and the platform, surrounded by ribosomal proteins S6, S18 and S21. The anti-SD sequence is located at the $3^{\prime}$-end of the 16 S rRNA (Melnikov et al., 2012). 
At the $P$ site of the 30 S subunit, crucial RNA contacts are responsible for the fidelity of translation initiation, facilitating the recognition of the initiation codon by $\mathrm{fMet}^{-t R N A^{\text {fMet }}}$, leading to functional 30S IC and later 70S IC. Structural data reveal the areas which interact with the mRNA bound to the $30 \mathrm{~S}$ subunit, with main contacts occurring through its positively charged platform domain and the 30S neck (Marzi et al., 2007; Ogle et al., 2003; Yusupova et al., 2006). The entry channel of the mRNA is surrounded by ribosomal proteins (S3, S4 and $\mathrm{S} 5$ ) which possess helicase activity and help to unwind mRNA secondary structures (Takyar et al., 2005). Setting the correct reading frame occurs only on a single-stranded region of the mRNAs with a start site (Studer and Joseph, 2007; Yusupova et al., 2001). The mRNA exit channel is surrounded by ribosomal proteins (S1, S6, S7, S11, S18 and S21) which participate in the recruitment of the mRNA during initiation. Also, they are suggested to regulate the mRNA mobility during the elongation phase when the 5 '-end of the mRNA emerges out of the ribosome (Yusupova et al., 2001). Peculiarly structured mRNAs require the action of the essential ribosomal protein - S1 - which contributes to the ribosome's RNAunwinding activity and the recruitment of such mRNAs (Duval et al., 2013). Indeed, structured 5'untranslated regions (UTRs) are commonly found in bacteria and their interactions with the ribosome can modulate initiation rates by over 100-fold (Espah Borujeni et al., 2014). In these cases, the ribosomes can bind at a standby position on the mRNA, upstream of the start site and then slide, in search for the initiation codon (Adhin and van Duin, 1990; de Smit and van Duin, 2003). In vitro experiments suggested that the reaction occurs in two steps. First, the $30 \mathrm{~S}$ subunit rapidly binds to a single stranded region of the mRNA and second a secondary structure is restructured, which requires fMet-tRNA $^{\text {fMet }}$ and the IFs (Studer and Joseph, 2007). If the affinity of the 30S for the mRNA initiation region is high enough, it is possible to melt weak mRNA structures. The mRNA is then transferred from the standby to the decoding site, a process partly induced by the IFs (La Teana et al., 1995). Thus, the accessibility of the ribosome to the start site determines the translational efficiency as strongly structured mRNAs, which unfolds slowly, will also slow down the transition to an active 30S IC. Differential rates of translation initiation, due to intrinsic sequence determinants on the mRNA, are discussed in the next section.

\subsection{Efficiency of protein synthesis depends on mRNA sequence determinants}

To gain understanding of the post-transcriptional regulation in the cell, it is essential to know not only the levels of individual mRNAs, but also the efficiency with which they are being translated into proteins (i.e. mRNA translation state). Translation efficiency is a term defined as a rate of protein production per mRNA (Li, 2015). Various features hidden in the non-coding and coding sequence of the transcripts regulate and induce wide variation in translation efficiencies of genes. The exact role of the parameters modulating the translatability of each mRNA - i.e. length, abundance, secondary structure and life-time - have been partially elucidated; nevertheless, it is still not clear which one is the predominant factor. Codon bias - differential usage of synonymous codons depending on the levels of their corresponding tRNAs in the cell - also have a profound effect on translation efficiencies (Tuller et al., 2010c). Codons with rare tRNAs slow down translation elongation and vice versa. Codon sequence determinants, regulating translation efficiencies, are not further discussed.

The concentration of mRNAs in the cell may vary by several orders of magnitude. In prokaryotes, a result from global, large-scale studies concluded that abundant mRNAs, a result from 
frequent transcription, led to high protein expression (Guimaraes et al., 2014; Passalacqua et al., 2009). This suggests a prime role of transcription as a major determinant for protein expression. However, the abundance of a transcript doesn't represent the abundance of the corresponding protein, hence the proteome (Li et al., 2014; Lu et al., 2007). For example, proteins expressed from an operon - RNA coding for more than one cistron (protein) - can have different translation efficiencies, varying in $>100$-fold, even though they share the same mRNA. Achieving differential translation is crucial during translation of protein complexes with uneven stoichiometry - for example ATPsynthase or 50S subunit's L7/L12 stalk. Fine-tuning of subunit biosynthesis is essential in order to obtain the appropriate protein ratios and most importantly save energy from producing extra, uncomplexed protein (Li et al., 2014). How such differential translation efficiencies are achieved in bacteria is largely unknown.

Genome-wide measurements can partially correlate translation efficiencies of individual mRNAs with key determinants of translation initiation, (i) the $5^{\prime}$-UTR, (ii) the sequence and structure of the ribosome binding site (RBS), (iii) the start codon and, (iv) the presence or absence of enhancer A/U rich sequences (Lu et al., 2007). The 5'-UTR accommodates the RBS and can expand up to 100 nucleotides (nt) away from the start codon, preserving its regulatory function in recruiting the ribosome (Darfeuille et al., 2007). Systematic analysis of the mRNA folding propensity suggested that the folding free energy of the region spanning from -10 to $+35 \mathrm{nt}$ has the largest impact on the prokaryotic translation efficiency independent of the length of the $5^{\prime}$-UTR or the coding sequence downstream of the start codon (Espah Borujeni et al., 2014; Seo et al., 2009). This specific region overlaps with the RBS. The RBS of the majority of bacterial mRNAs extends 20 nt on each side of the translation initiation codon (most frequently AUG) and contains features that distinguish it from any other sequence on the mRNA (Chen et al., 1994). Upstream the start codon the translation initiation region contains the Shine-Dalgarno (SD) sequence - a polypurine-rich sequence (UAAGGAGGU) complementary to a region at the $3^{\prime}$-end of the $16 S$ rRNA, i.e. the anti-SD sequence (Shine and Dalgarno, 1974). The SD region is separated from the start codon by a spacer sequence, which usually spans around $5 \mathrm{nt}$. Not all mRNA signal determinants for initiation are as highly characterized as the RBS. Unconventional initiation on mRNAs that lack a SD sequence, have a GUG or UUG as a start codon or completely lack the 5'-UTR (i.e. leaderless mRNA), can occur quite efficiently (Moll et al., 2004; O'Donnell and Janssen, 2001). In these cases, the strength of the SD:anti-SD region, its distance to the initiation codon and the choice of a start codon are dispensable for recruiting the 30S subunit.

The efficiency of translation and the resulting protein production are determined by translation initiation, elongation, termination and ribosome recycling rates. It is possible that interplay exists between the rate of elongation and the rate of initiation near the mRNA start site. In the three domains of life bacteria, archaea and eukaryotes, the first 30-40 codons of the ORF underwent evolutionary selection for slow early elongation, which resulted in a translational "ramp". The accumulation of slowly translated codons at the beginning of the genes increased the ribosome density at the $5^{\prime}$-end, also seen by ribosome profiling technique - a method detecting ribosome protected mRNA fragments (Ingolia et al., 2012). These observations had led to the "ramp" hypothesis. The "ramp" was attributed to improve the translation efficiency, reducing neighboring ribosomes interference and minimizing traffic jams further down the length of the mRNA sequence (Tuller et al., 2010a). The phenomenon was however not observed in high-resolution polysome 
profiling study in yeast, questioning its relevance for the post-translational regulation of protein abundance (Heyer and Moore, 2016). Genome analysis across many species proposed a scenario where the underlying reason for the enrichment of slowly-translated $\mathrm{N}$-terminal codons was their minor contribution to potential secondary structure near the start site (Bentele et al., 2013). For example, in E. coli rare codons were selected because of their lack of GC content, which disfavored secondary structure propensity and not because they were rare and slowly translated (Goodman et al., 2013). In other bacteria with lower GC content than E. coli ( $50 \%$ GC content) the enrichment of rare codons was not observed (Bentele et al., 2013). Folding of RNA around the RBS also correlated with translation efficiencies for a synthetically generated GFP protein library, but it is worth to note that the proposed strong correlation may differ among natural genes and different cellular conditions (Kudla et al., 2009; Welch et al., 2009). These results suggested that the main driving force for translation efficiency is the folding energy at the translation start site.

Structures around the RBS exerted control over the number of ribosomes loaded on the mRNA, which in turn modulated the abundancy of protein per mRNA (de Smit and van Duin, 1990; Zur and Tuller, 2012). Future biophysical modeling combined with in silico optimization will be able to design completely novel, non-natural RNA sequences with predicted ribosomal affinity and translation initiation rates (Kosuri et al., 2013; Na et al., 2010; Salis et al., 2009). On one hand, boosting only the initiation rates might have a rather negative effect on translation due to misbalance with the rate of elongation and termination, creating traffic jams of ribosomes along the mRNA (Mitarai et al., 2008). On the other hand, elongation might become limiting when the ribosomes fail to clear the initiation region efficiently, blocking the initiation of the next ribosome (Chu et al., 2014). Efficient translation requires both high ribosomal affinity (productive mRNA-30S subunit interactions) and high elongation rate. Translation initiation, as the most strongly regulated phase of protein synthesis, during which an mRNA is selected, has a major influence on the number of ribosomes on the mRNA sequence and the polysome size (Arava et al., 2003; Picard et al., 2012).

\subsection{Polysomes}

Statistical and computational tools, capable of interpreting and integrating genome-wide data, revealed a significant variability in translation efficiencies among different genes in the genome (Dressaire et al., 2009; Lu et al., 2007). One particular mechanism for regulation of gene expression at a translational level is polysome formation (Miller et al., 1970). Polysomes are active proteinsynthesizing units consisting of multiple ribosomes assembled along one mRNA. The number of ribosomes on the mRNA - the polysome size - varies from mRNA to mRNA and over time for the same mRNA (Valleriani et al., 2010). In exponentially growing E. coli 70\% of ribosomes are involved in polysomes while the other $27 \%$ are in monosomes (Jacobson and Baldassare, 1976). The rate at which each ribosome is loaded on the mRNA and the ribosome density along the mRNA sequence (the number of ribosomes per ORF) are key components of translation-level regulation.

Quantifying the number of loaded ribosomes for individual mRNAs correlates with the translational status of this message and provides information about different aspects of translational regulations (Arava, 2009; Ingolia, 2014). Previous studies have investigated frequencies of ribosome loading on the mRNA in vivo in the context of gene expression (Kennell and Riezman, 1977; Sorensen and Pedersen, 1991), by computer simulation algorithms (Kierzek et al., 2001) and by mathematical 
modeling (Mitarai et al., 2008). Only few studies have described high resolution translatome analysis with mRNAs classified with respect to the number of loaded ribosomes by means of DNA microarray or ribosome profiling in yeast (Arava et al., 2003; Heyer and Moore, 2016; Lackner et al., 2007) and by bioinformatics and statistical modeling in bacteria (Picard et al., 2012).

Ribosomes protect 28-30 nt mRNA footprint from nuclease digestion (Ingolia et al., 2012; Steitz and Jakes, 1975). As proposed in yeast and bacteria, the density with which the ribosomes are distributed along each mRNA (1.23 ribosomes per $100 \mathrm{nt}$ mRNA) was below the potential maximum packing density ( 1 ribosome per $30 \mathrm{nt}$ ), consistent with initiation and ribosome loading on the mRNA being the rate-limiting step in protein synthesis (Picard et al., 2012). Similar results were seen in higher eukaryotes where the range of 4 to 6 -fold lower packing of ribosomes, in comparison to the maximum packing density, was observed by means of electron microscopy and high-throughput microarray assay (Christensen and Bourne, 1999; Qin et al., 2007).

Mechanistic kinetic model that took into account all elemental kinetic steps of translation in E. coli, suggested an important role of polysome formation during translation (Zouridis and Hatzimanikatis, 2007). First, the model proposed that the growing polysome size, and the increased number of ribosomes along the mRNA, led to an initial increase of the translation rate until a point where it decreased due to increased crowding. The mathematically modeled self-organization of the ribosomes in the polysome achieved maximum translation rates, consistent with results of structural studies by cryo-electron tomography (CET) (Brandt et al., 2010; Myasnikov et al., 2014). CET and template matching use a combination of biochemical and microscopy techniques to identify individual polysome structures and provide insights into the 3D supramolecular organization of native bacterial and eukaryotic polysomes (Figure 3). The results supported a conserved organization of polysome architecture from bacteria to humans, although prokaryotic and eukaryotic ribosomes differ in their outer architecture and size (Brandt et al., 2010; Brandt et al., 2009; Pfeffer et al., 2012). In all domains of life the neighboring ribosomes were densely packed and exhibited a similar orientation. The advantages of the preferred ribosome topologies within the polysome was physiologically justified as it (i) promoted multiple rounds of translation, (ii) protected the mRNA by ribonucleases degradation and, (iii) optimized the chaperones access to the emerging, folding protein.

The work in prokaryotes could visualize polysomal organization at an intermediate resolution (4 - $5 \mathrm{~nm}$ ) in membrane encapsulated lysates, using both actively translating (mRNA with a stop codon) and stalled mRNA-ribosome complexes (mRNA without a stop codon) (Brandt et al., 2009). The model estimated a distance between the $\mathrm{P}$ sites of adjacent ribosomes of $72 \mathrm{nt}$, corresponding to a difference of 24 residues of nascent peptide emerging in the cytosol. The work in eukaryotes utilized stalled mRNA-ribosome complexes with 28 ribosomes along the transcript in a tightly packed conformation with a distance between each ribosome in the range of 32-39 nt, corresponding to an emerging peptide of 10-13 residues (Myasnikov et al., 2014). The high density of dynamic ribosomes undergoing protein synthesis may suggest that parts of neighboring ribosomes contact and influence each other (Figure 3). Ribosomes interacted with each other mainly via the small ribosomal subunit either through protein-protein or RNA-protein interactions. The polysomal mRNA was prone to curve when bound to each ribosome with approximately $45^{\circ}$ kink between the adjacent codons (Yusupova et al., 2001). A discontinuous mRNA pathway in the polysome unit was proposed to maintain the mRNA unwound and protected (Brandt et al., 2009).Prokaryotic ribosomes exhibited 
parallel orientation within the polysome, pointing to one direction. The eukaryotic polysomes exhibited a similar mRNA path and in addition formed double rows of ribosomes in anti-parallel orientation (Myasnikov et al., 2014). The latter type of structure may be functionally important for the circularization of the eukaryotic polysome, which brings the $5^{\prime}$ - and the 3 '-end of the mRNA close to one another, and renders the polysome unit capable of supporting multiple cycles of initiationtermination-reinitiation. While individual steps of the translation initiation, elongation and termination phases cycles have been dissected kinetically in detail (Milon and Rodnina, 2012; Peske et al., 2005; Rodnina and Wintermeyer, 2011; Wintermeyer et al., 2004), an understanding of how these phases contribute to translation on polysomes is completely lacking.

(A)

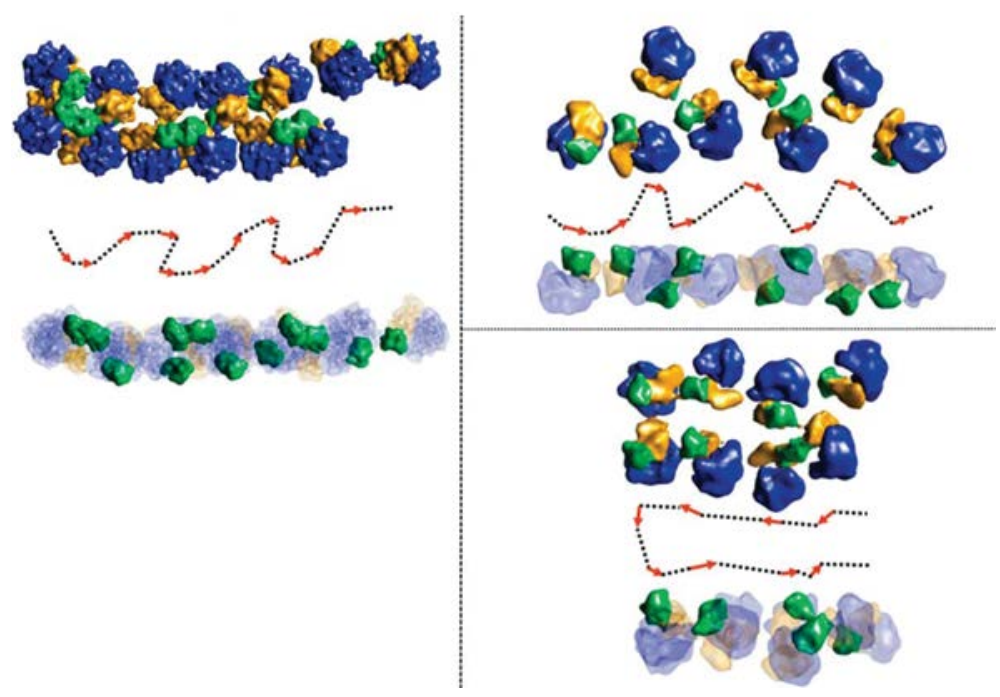

Figure 3. Comparison between prokaryotic and eukaryotic polysomal orientation.

(A) 3D reconstruction of $E$. coli polysomes obtained with cryo-electron tomography and sub-tomogram averaging (Brandt et al., 2009). Modeled mRNA pathway within the ribosome is represented by a dashed line with arrowhead pointing from the entry to the exit site of the mRNA. 50S subunit (blue), $30 \mathrm{~S}$ head (green) $30 \mathrm{~S}$ body (yellow). (B) Same technique as in (A) with eukaryotic polysomes in a parallel (top) or anti-parallel (bottom) orientation (Myasnikov et al., 2014). Adapted from "Ribosomes Structure, Function, and Dynamics", 2011. 


\subsection{Scope of the thesis}

The aim of this work was to design and establish an experimental system to monitor polysome formation in real-time. Using radioactive and fluorescence reporters in rapid kinetic experiments with the help of a fully reconstituted $E$. coli translation system, we were able to:

(i) Design and produce novel, model labeled mRNAs and establish reliable FRET couples to monitor ribosome loading on mRNAs.

(ii) Develop kinetic models which take into account the rate of elongation of the first ribosome in a polysome and the rate of initiation of the second ribosome.

Some of the questions we addressed were:

(i) How does the RBS of the mRNA affect the first and the second round of initiation?

(ii) Does the first ribosome, which has already selected the desired mRNA for translation, alter the subsequent initiation event on the same message? 


\section{Results}

\subsection{Design, production and translation initiation potential of novel, model 5 '-end labeled mRNAs.}

To study the mechanism and efficiency of ribosome loading on mRNAs require an experimental system that allows monitoring specific binding reactions. In addition to monitoring the mRNA binding of the first, leading ribosome in a polysome, we need to monitor the loading of the second, following ribosome, while the leading ribosome is translating the same mRNA. A single, sitespecific label near the RBS of the mRNA is a prerequisite for monitoring frequency of ribosome loading. The mRNA is one of the best targets to place a label, due to the fact that different mRNAs are expected to perform differently in the process of polysome formation. Establishing a tool to specifically label different mRNAs at the $5^{\prime}$-end gives us the flexibility to examine various features of the mRNA that contribute to the process of polysome formation. In order to exclude any effect connected to ribosome pausing during the elongation phase, we designed the mRNA's coding sequence to be simple: decoded by only one amino acid: phenylalanine. This ensures us that the first ribosome will clear the ribosome binding site rapidly and efficiently, so that the arrival of the second ribosome can be monitored under pre-steady state conditions. We designed and optimized two methods for production of model, $5^{\prime}$-end labeled mRNAs with various RBSs and repetitive coding sequence for phenylalanine.

\subsubsection{Generation of $5^{\prime}$-end labeled mRNAs with poly(U) extensions}

The first approach was to enzymatically elongate a short (24 nt), 5'-end labeled mRNAs (with non-fluorescent acceptor ATTO540Q or a fluorescence dye ATTO488) with a poly(U) polymerase enzyme Cid1 (PUP) from Schizoscaccharomyces pombe, which adds a polyuridine stretch at the $3^{\prime}$ end of the primer mRNA in a template-independent manner. The sequences of the short mRNAs used for priming the PUP was altered generating a set of extended mRNAs which differed at their $5^{\prime}$-end sequence but all had a start codon (AUG) and the same coding sequence, UUU, for phenylalanyl (Table 11). The primer mRNAs were chosen to differ in its length of Shine-Dalgarno (SD) sequence and its potential to form secondary structures. The name of the mRNAs reflected the label at the $5^{\prime}$-end, with a superscript for a quencher $(\mathrm{Q})$ or a fluorescent dye $\left({ }^{*}\right)$, length of the $5^{\prime}$-UTR and the features of the RBS as enhanced (e) or weak (w) as subscripts and the approximate number of (U) at the $3^{\prime}$-end (Table 12).

The experimental conditions of the PUP extension reaction differed between the mRNA primers and strongly depended on their sequence and structure (Section 4.14.1). An extensive optimization of the time, concentration of substrates and buffer conditions in the enzymatic reaction for each mRNA primer was necessary in order to achieve efficient quality and quantity of the extended mRNAs. Labeled mRNAs primers: $5^{\mathrm{Q}} \mathrm{RBS}_{18 \mathrm{e}}, 5^{*} \mathrm{RBS}_{18 \mathrm{e}}$ and $5^{\mathrm{Q}} \mathrm{RBS}_{18}$ and their unlabeled counterparts, were extended with $\approx 250 \mathrm{nt}$ for $2 \mathrm{~h}$ at $37^{\circ} \mathrm{C}$. Reducing the time to $45 \mathrm{~min}$ using the same conditions produced an mRNA with a shorter coding region $\left(5^{\mathrm{Q}} \mathrm{RBS}_{18 \mathrm{e}}(\mathrm{U})_{100}\right)$. However, labeled and unlabeled primer mRNAs $5^{\mathrm{Q}} \mathrm{RBS}_{18 \mathrm{w}}$ and $\mathrm{RBS}_{18 \mathrm{w}}$ had to be extended at $49^{\circ} \mathrm{C}$ in the presence of $4 \%$ DMSO. These conditions were necessary to melt the secondary structure, which was occluding the $3^{\prime}$ end of the primer that is essential for the poly(U) polymerization reaction. The enzymatic extension of 
$5^{\mathrm{Q}} \mathrm{RBS}_{18 \mathrm{w}}$ produced a slightly longer poly(U) sequence of $\approx 350 \mathrm{nt}$ due to the increased uridine incorporation rate by the PUP enzyme at higher temperatures. As a result, we could produce preparative amounts of mRNAs with all the desired characteristics: labeled 5'-UTR, desired RBS and a repetitive sequence coding for a single amino acid (Figure 4).

(A)

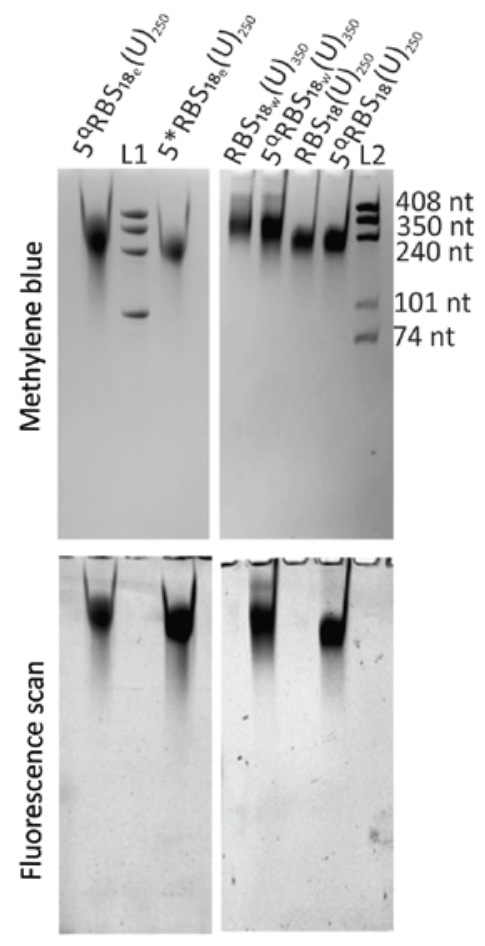

(B)
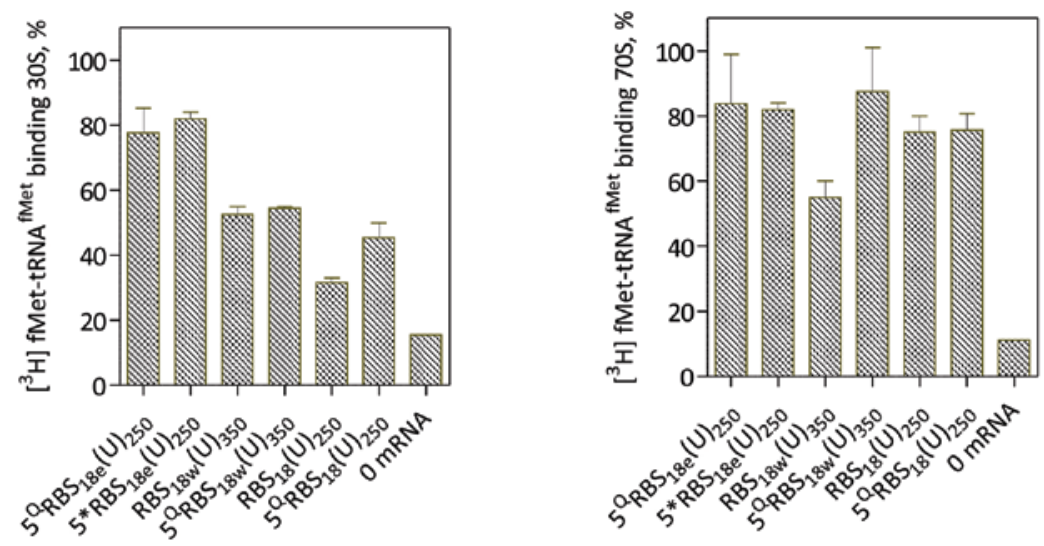

(C)

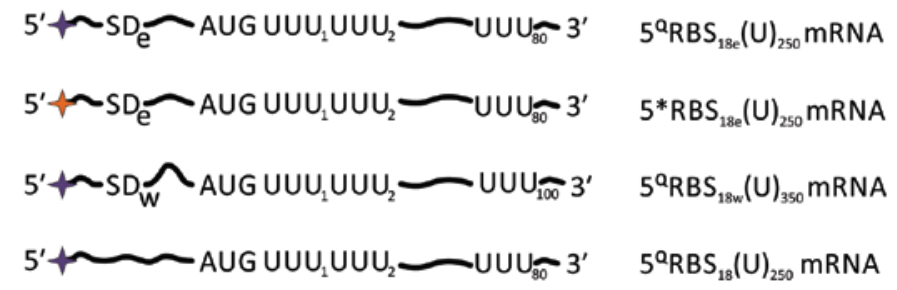

Figure 4. Synthesis and activity testing of the model 5'-end labeled mRNAs.

(A) After preparative PUP enzymatic reaction and RNAeasy midi kit purification (Qiaqen), 20 pmol of the mRNAs were electrophoretically separated on an $8 \%$ urea PAGE gel and visualized by methylene blue staining (top). mRNAs labeled with ATTO540Q or ATTO488 were detected with the Cy3 channel scan $(532 \mathrm{~nm}$ excitation and $580 \mathrm{~nm}$ emission filter) on the fluorescence scanner (bottom). $5^{\mathrm{Q}} \mathrm{RBS}_{18 \mathrm{e}}(\mathrm{U})_{250}$; L1. RNA Ladder (408 nt, $350 \mathrm{nt}$, $240 \mathrm{nt}, 101 \mathrm{nt}) ; 5^{*} \mathrm{RBS}_{18 \mathrm{e}}(\mathrm{U})_{250} ; \mathrm{RBS}_{18 \mathrm{w}}(\mathrm{U})_{350} ; 5^{\mathrm{Q}} \mathrm{RBS}_{18 \mathrm{w}}(\mathrm{U})_{350} ; \mathrm{RBS}_{18}(\mathrm{U})_{250} ; 5^{\mathrm{Q}} \mathrm{RBS}_{18}(\mathrm{U})_{250} ; \mathrm{L2}$. Same ladder as $\mathrm{L1}$ plus a $74 \mathrm{nt} \mathrm{RNA}$. (B) Nitrocellulose filter binding experiments tested the ability of the labeled mRNAs to form ribosomal complexes. The efficiency of ribosome binding was estimated as the ratio between the pmol $\left.\mathrm{f}^{3} \mathrm{H}\right]$ Met-tRNA ${ }^{\mathrm{fMet}}$ calculated from the radioactivity retained on the filter per pmol of ribosome present in the reaction. The column numbers represent different mRNAs used to form the initiation complex and are the same as in (A). In the [0 mRNA] column, everything except the mRNA was mixed and the calculated $\left.\mathrm{f}^{3} \mathrm{H}\right]$ Met-tRNA ${ }^{\text {fMet }}$ radioactivity was used as a background. Error bars represent s.d. 3 independent replicates. (C) Schematics and names of the $5^{\prime}$-end labeled model mRNAs visualized on the fluorescence scanner (A, bottom) (Table 11). mRNAs schematics were designed by Dr. R. Belardinelli.

After preparative PUP extension, the model mRNAs were tested in their ability to form initiation complexes with the $30 \mathrm{~S}$ subunit (30S IC) or the $70 \mathrm{~S}$ ribosomes (70S IC) by nitrocellulose filtration assay (Figure 4B) (Section 4.19.1). The mRNAs that possessed an enhanced Shine-Dalgarno 
sequence $(6 \mathrm{nt})$ and no predicted secondary structure $\left(5^{\mathrm{Q}} \mathrm{RBS}_{18 \mathrm{e}}(U)_{250,} 5^{*} \mathrm{RBS}_{18 \mathrm{e}}(U)_{250}\right)$ could efficiently form 30S IC and 70S IC ( $\geq 80 \%$ ). The $\operatorname{RBS}_{18 \mathrm{w}}(\mathrm{U})_{350}$ and $5^{\mathrm{Q}} \mathrm{RBS}_{18 \mathrm{w}}(\mathrm{U})_{350}$ mRNAs with a weaker SD sequence $(3 \mathrm{nt})$ and predicted secondary structure were able to efficiently form 70 S IC ( $\geq 80 \%)$ but performed only up to $50 \%$ when forming the $30 \mathrm{~S} \mathrm{IC}$. This meant that the 70S IC with this mRNAs was more stable than with the 30S IC. Same effect was observed when we used $\operatorname{RBS}_{18}(U)_{250}$ and $5^{\mathrm{Q}} \mathrm{RBS}_{18}(\mathrm{U})_{250}$ mRNAs with no SD sequence and no potential for secondary structure. In this case the low efficiency of complex formation was due to the lack of stabilization by interactions with the 30S subunit when the mRNA does not possess a SD sequence. The presence of a fluorescence dye on the 5 '-end of the mRNA, regardless of its nature, had no effect on the formation of the ribosome complexes. As a summary, the efficiency of $30 \mathrm{~S} \mathrm{IC} \mathrm{formation} \mathrm{with} \mathrm{the} \mathrm{model} \mathrm{mRNAs} \mathrm{was} \mathrm{highly}$ dependent on the sequence of the $5^{\prime}$-UTR, while the efficiency of 70S IC was high for all of the model mRNAs, making them suitable to form synchronized 70S IC. All poly(U)-extended model mRNAs were screened in Section 2.2 for a fluorescence signal with components of the initiation machinery in a stopped flow apparatus.

\subsubsection{Generation of $5^{\prime}$-end-labeled mRNAs by modified in vitro transcription reaction.}

Establishing a method to produce a model mRNA with a fixed length of the coding region and site specific label at the $5^{\prime}$-end is another prerequisite to monitor polysome formation. In this part of the results we focused on the design, production and testing of a novel model mRNAs produced with a modified in vitro T7 RNA-polymerase transcription reaction. We designed a DNA_UUC template and transcribed it into a model $\mathrm{RBS}_{20 \mathrm{e}}(\mathrm{UUC})_{\text {78AAA }}$ mRNA with the following characteristics (i) large scale production using modified T7 RNA-polymerase in vitro transcription reaction; (ii) accessibility for labeling with a thiol-reactive dye at the $5^{\prime}$-end; (iii) the presence of a SD sequence and a start codon (AUG); (iv) fixed length coding region able to accommodate at least 2-3 translating ribosomes; (v) repetitive coding region for 26 phenylalanyl amino acids decoded by the codon UUC; (vi) a Lys codon after the coding sequence for the poly(Phe) stretch; (vii) the absence of a stop codon. The RBS of this mRNA was chosen to be able to efficiently form 30S IC and 70S IC. The fixed length of coding region was designed to be rapidly decoded to a single amino acid (Phe) followed by a Lys codon, which could be detected in a quantitative approach to estimate the rate of translation elongation. We did not include a stop codon because we could halt the ribosome elongation by varying the concertation of the Phe tRNA ${ }^{\text {Phe }}$ substrate. The name of the mRNAs was similar to the ones used in Section 2.1.1, but here we reflected the the number of nucleotides represented by the codon UUC. The extension AAA at the end of the name indicated that the mRNA possessed a codon for lysine decoded by the codon AAA after the UUC repetitive sequence.

We obtained the designed DNA_UUC template commercially and successfully cloned it into a vector plasmid (Section 4.7). The DNA_UUC template was used either in the subsequent T7 RNApolymerase transcription reaction or treated with a Dral restriction enzyme in order to remove the $3^{\prime}$ end sequence after the last UUC codon, producing a shorter template (DNA_UUC101) which was transcribed to $\mathrm{RBS}_{20 \mathrm{e}}(\mathrm{UUC})_{78}$ mRNA. We could also modify the model DNA_UUC with a site-directed mutagenesis to create another DNA_UUCW template. It was used in a transcription reaction to produce $\mathrm{RBS}_{20 \mathrm{w}}(\mathrm{UUC})_{\text {78AAA }} \mathrm{mRNA}$ that had the same characteristics as $\mathrm{RBS}_{20 \mathrm{e}}(\mathrm{UUC})_{\text {78AAA }} \mathrm{mRNA}$, but 
had a different 5'-UTR (Section 4.8). The following step-by-step optimization of a model mRNA production was also done for the DNA_UUCw template.

The task to produce by PCR amplification a single product from the long repetitive sequence of the DNA_UUC template turned out to be challenging. The optimization of the reaction yielded a single fragment only after a $50 \mathrm{pg}$ of template was added, which is 200 -fold less than a reaction carried out with a non-repetitive DNA template. A PCR-amplified DNA_UUC fragment was then used as a template for the T7 RNA-polymerase transcription reaction (Section 4.12). Taking advantage of the strong preference of the T7 RNA-polymerase for guanosine at the first and second transcript positions (Jia and Patel, 1997), all the in vitro transcription reactions were carried out in the presence of guanosine monophosphate (GMP) or guanosine $5^{\prime}$ ( $\alpha$-thio) monophosphate (GMPS). The guanosine monophosphate nucleotides are incorporated only at the initiation step of transcription and not in the polymerization. The GMPS at the 5 '-end of the mRNAs was subsequently modified in a reaction with a maleimide-coupled non-fluorescent acceptor dye to generate a stable P-S-C linkage and specifically tag the $5^{\prime}$-end of the RNA (Section 4.13) (Figure 22).

The T7 RNA-polymerase was used to transcribe the long repetitive sequence of the $\mathrm{RBS}_{20 \mathrm{e}}(\mathrm{UUC})_{\text {78AAA }}$ mRNA and simultaneously initiate with a modified nucleotide (GMPS or GMP). An optimized ratio between the nucleotides: GMPS:GTP:ATP:CTP:UTP (5:0.5:1:2:5) was needed to achieve a high yield and purity (Figure $5 \mathbf{A}$ ). The successfully produced model mRNAs caring a GMPS at its 5 '-end obtained by the optimized in vitro transcription reaction were purified by MonoQ column and tested in a labeling reaction. The mRNAs were incubated with a 50-fold molar excess of dye ATTO540Q (maleimide) in phosphate buffer (100 mM), pH 7.2, for $2 \mathrm{~h}$ at room temperature. After a

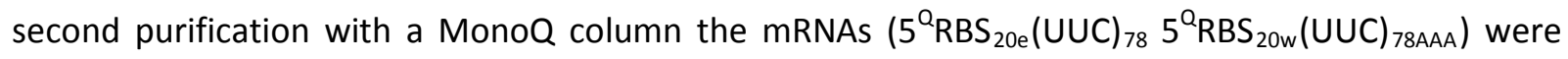
pure and the efficiency of labeling was close to $100 \%$ (Section 4.13 ). The presented method gave us the flexibility to use any thiol reactive group for labeling the mRNA $5^{\prime}$-end. We utilized ATTO540Q as a non-fluorescent acceptor which gave us a considerable adaptability when choosing a FRET donor partner.

We tested the produced fluorescence labeled and unlabeled model mRNAs in their ability to form $30 \mathrm{~S}$ and $70 \mathrm{~S} \mathrm{IC} \mathrm{using} \mathrm{a} \mathrm{nitrocellulose} \mathrm{filter} \mathrm{assay} \mathrm{(Figure} \mathrm{5B).} \mathrm{Model} \mathrm{mRNAs} \mathrm{with} \mathrm{enhanced} \mathrm{SD}$ sequence $\left(\mathrm{RBS}_{20 \mathrm{e}}(\mathrm{UUC})_{78 \mathrm{AAA}}, \mathrm{RBS}_{20 \mathrm{e}}(\mathrm{UUC})_{78}\right.$ and $5^{\mathrm{O}} \mathrm{RBS}_{20 \mathrm{e}}(\mathrm{UUC})_{78}$ ) were able to form $30 \mathrm{~S}$ IC and $70 \mathrm{~S}$ IC with the efficiency of $\geq 80 \%$, independently of their length or $5^{\prime}$-end label. Model mRNAs $\mathrm{RBS}_{20 \mathrm{w}}(\mathrm{UUC})_{\text {78AAA }}$ and $5^{\mathrm{Q}} \mathrm{RBS}_{20 \mathrm{w}}(\mathrm{UUC})_{78 \mathrm{AAA}}$, however, did not form a stable $30 \mathrm{~S}$ IC (20\% binding efficiency), but were performing better in the 70 S IC formation (50\%). This result suggested the presence of a non-optimal ribosome binding site, with a potential secondary structure and an insufficient stabilization by the ribosome. The generation of pure and intact mRNAs enabled us to use them in rapid kinetic and other biophysical assays (Section 2.2). 
(A)
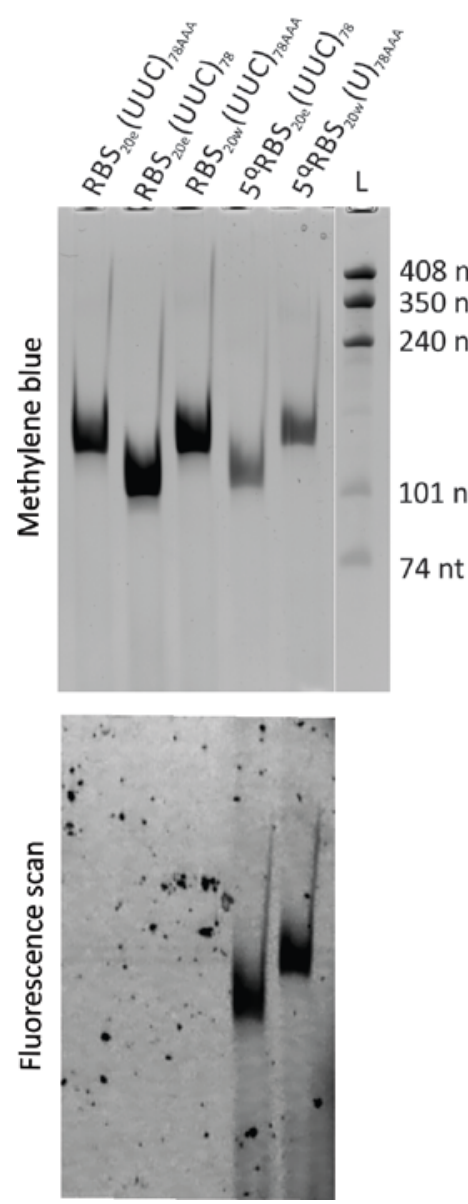

(B)
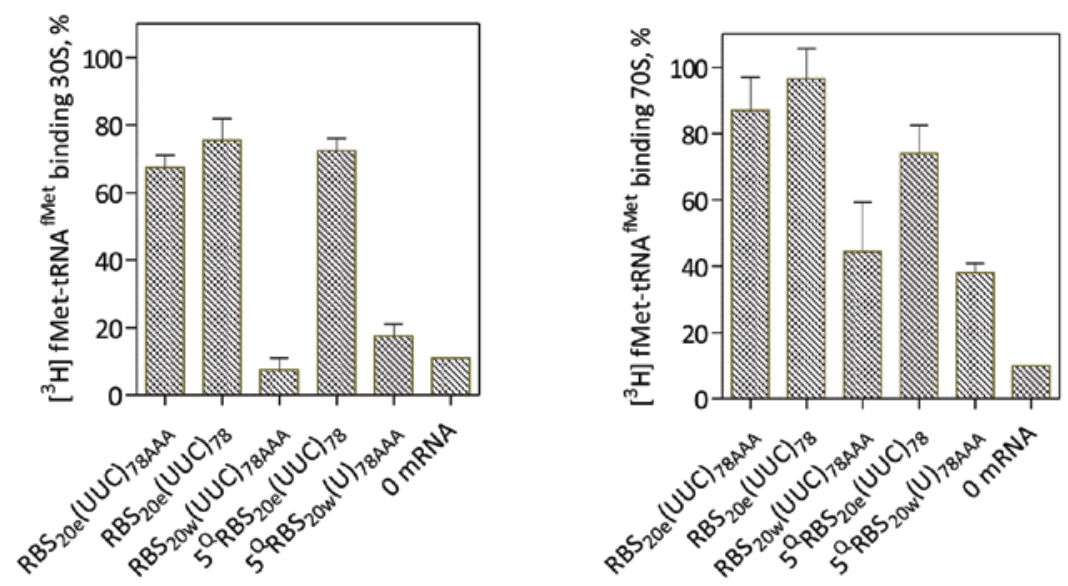

(C)

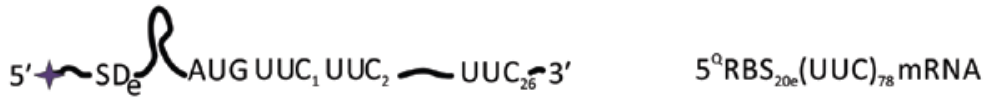

$5^{\prime} \sim \mathrm{SD}_{\mathrm{W}} \bigcap_{\mathrm{AUGUUCO}} \mathrm{UUC}_{2} \sim \mathrm{UUC}_{26} \mathrm{AAA}-3^{\prime} 5^{\mathrm{a}} \mathrm{RBS}_{20 \mathrm{~W}}(\mathrm{UUC})_{78 \mathrm{BAM}} \mathrm{mRNA}$

Figure 5. In vitro transcribed model mRNAs are active in translation initiation.

(A) After in vitro T7 RNA-polymerase transcription, ATTO540Q labeling and MonoQ chromatography, 20 pmol of the labeled mRNAs and 60 pmol of the non-labeled mRNAs were electrophoretically separated on an $8 \%$ urea PAGE. Samples were visualized with a Methylene blue staining (top). Labeled mRNAs with ATTO540Q were detected with the Cy3 channel scan (532 nm excitation and $580 \mathrm{~nm}$ emission filter) on the fluorescence scan (bottom). L. RNA Ladder (408 nt, $350 \mathrm{nt}, 240 \mathrm{nt}, 101 \mathrm{nt}, 74 \mathrm{nt}$ ); $\mathrm{RBS}_{20 \mathrm{e}}(\mathrm{UUC})_{78 \mathrm{AAA}} ; \mathrm{RBS}_{20 \mathrm{e}}(\mathrm{UUC})_{78}$; $\mathrm{RBS}_{20 \mathrm{w}}(\mathrm{UUC})_{78} ; 5^{\mathrm{C}} \mathrm{RBS}_{20 \mathrm{e}}(\mathrm{UUC})_{78} ; 5^{\mathrm{C}} \mathrm{RBS}_{20 \mathrm{w}}(\mathrm{UUC})_{78}$ (B) Nitrocellulose filter binding experiments tested the ability of the labeled mRNAs to form ribosomal complexes. The efficiency of ribosome binding was estimated as the ratio between the pmol $\left.\mathrm{f}^{3} \mathrm{H}\right] \mathrm{Met}-\mathrm{tRNA} \mathrm{f}^{\mathrm{fMet}}$ calculated from the radioactivity retained on the filter per pmol of ribosome present in the reaction. The column numbers represent different mRNAs used to form the initiation complex and are the same as in (A). In the [0 mRNA] column, everything except the mRNA was mixed and calculated as background from the $\left[^{3}{ }^{3} \mathrm{H}\right] \mathrm{Met}^{-t R N A}{ }^{\mathrm{fMet}}$ radioactivity counts. Error bars represent s.d. calculated from 3 independent replicates. (C) Schematics and names of the model mRNAs (Table 11). 


\subsection{Rapid kinetics of 30S PIC recruitment to various model 5 '-end labeled mRNAs.}

Binding and conformational changes of fluorescence-labeled reactants can be studied via Fluorescence Resonance Energy Transfer (FRET), a phenomenon which is strongly distancedependent. For an efficient energy transfer to occur the absorption spectrum of an acceptor molecule must overlap the fluorescence emission spectrum of a donor molecule. The Förster radius $\left(R_{0}\right)$, where the efficiency of transfer is $50 \%$, depends on a multiple factors and is specific for the FRET pair in use (Lakowicz, 2016 ). The donor/acceptor pair used in these experiments (Alx488 as donor, ATTO540Q as acceptor) had a calculated $\left(R_{0}\right)$ of $62 \AA$ assuming a random orientation of the fluorophores.

We screened the produced (Section 2.1) mRNAs for the appearance of a FRET signal upon binding to the 30S PIC containing donor dye-labeled proteins from the initiation machinery or give a fluorescence change upon recruitment to the 30S subunit. We choose IF3 and the 30S subunit with reconstituted labeled S13 because of their central role in mRNA selection and also because of their estimated distance to the $5^{\prime}$-end (Julian et al., 2011; Wimberly et al., 2000). A single cysteine mutant of IF3 was labeled with a donor fluorescence dye (Alx488 maleimide) at position 166 in the $C$ terminal domain (CTD) of IF3, which carries out most functions of the initiation factor (Milon et al., 2012; Petrelli et al., 2001). IF3 is the first initiation factor to bind to the $30 \mathrm{~S}$ subunit in the process of initiation (Milon et al., 2012). Cysteine was introduced at position 112 C-terminal domain (CTD) of S13 protein and labeled with donor fluorescence dye (Alx488) (Cunha et al., 2013). The protein was in vitro reconstituted in 30 S subunit lacking S13 protein (Section 4.17). It is located at the top of the head of the 30 S subunits (Hoang et al., 2004). The CTD of S13 is known to sense key interactions during the process of translation initiation (Cukras and Green, 2005).

We formed 30S PIC in the presence of all initiation factors and GTP either with bound IF3(Alx488) or 30S(Alx488) subunit. We rapidly mixed 30S PIC with the 5'-end-labeled mRNAs (carrying an ATTO540Q fluorophore quencher) in a stopped-flow apparatus. The obtained time courses were fitted with an exponential function to derive the apparent rate constant (kapp) of the reaction. With the appropriately designed controls we were able to assign the observed fluorescence traces to a FRET signal or a fluorescence change.

2.2.1. 5 '-end labeled mRNAs with poly(U) extensions recruited the $30 \mathrm{~S}$ PIC depending on their $5^{\prime}$-UTR sequence.

We tested the labeled mRNAs (Section 2.1.1) for their ability to recruit the $30 \mathrm{~S}$ PIC. Model mRNAs $5^{\mathrm{Q}} \mathrm{RBS}_{18 \mathrm{e}}, 5^{\mathrm{Q}} \mathrm{RBS}_{18 \mathrm{e}}(\mathrm{U})_{100}$ and $5^{\mathrm{Q}} \mathrm{RBS}_{18 \mathrm{e}}(\mathrm{U})_{250}$ could bind to the $30 \mathrm{~S}$ PIC. They have the same $5^{\prime}-$ UTRs accessible for the 30S subunit and a long SD $(6 \mathrm{nt})$ sequence, but have different lengths of poly(U) extensions (i.e. coding region). The change in FRET fluorescence between $5 Q$ mRNAs (quencher) and IF3(Alx488) (fluorescence donor) bound to the 30S PIC was monitored in time (Figure 6A). The biphasic fluorescence signal was fitted exponentially yielding a $k_{\text {app1 }}$ of $7 \mathrm{~s}^{-1}$ and a $k_{\text {app2 }}$ of around $1 \mathrm{~s}^{-1}$. The $k_{\text {app } 1}$ most likely reflected the binding of the 30S PIC to the MRNA while the second, slower rate most likely represents the accommodation of the $5^{\prime}$-end of the mRNA on the 30S subunit. Concentration dependence was necessary to resolve the binding step (Section 2.3). 
(A)

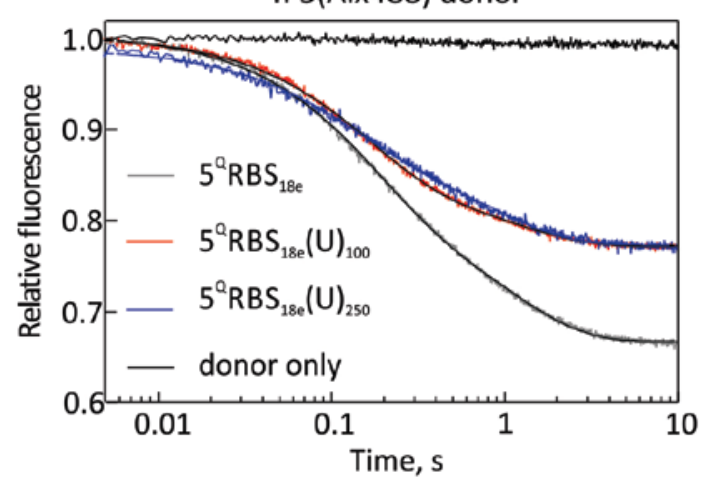

(C)

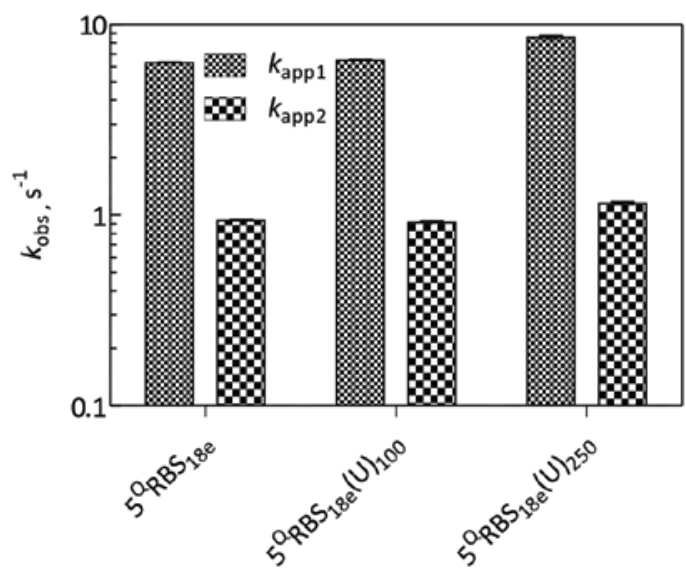

(B) 30S(Alx488) subunit donor

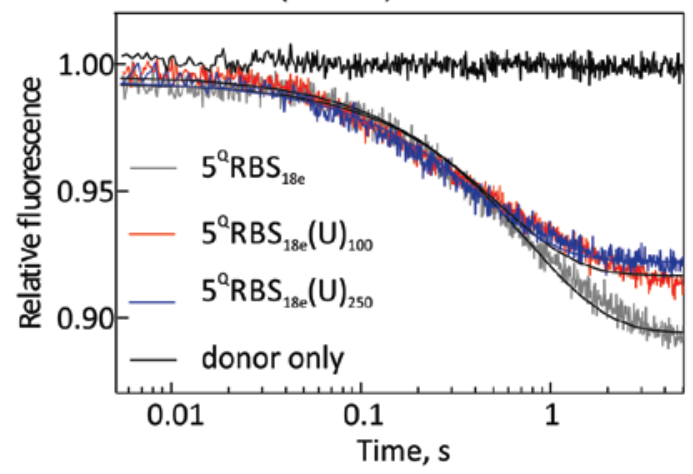

(D)

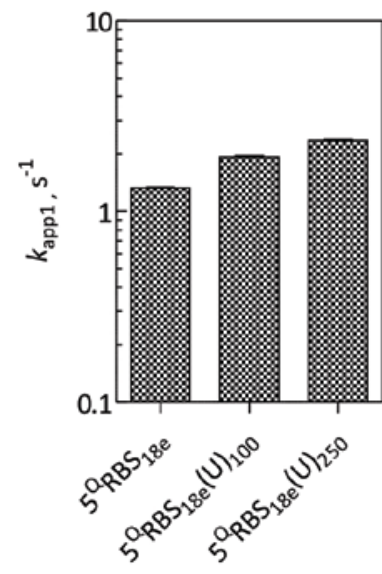

Figure 6. FRET between 5 '-end labeled mRNAs with poly(U) extensions and IF3(Alx488) bound to 30 S PIC or 30S(Alx488) PIC.

(A) FRET between $5^{\prime}$ ATTO540Q labeled mRNAs $5^{\mathrm{a}} \mathrm{RBS}_{18 \mathrm{e}}$ (grey), $5^{\mathrm{a}} \mathrm{RBS}_{18 \mathrm{e}}(\mathrm{U})_{100}$ (red), $5^{\mathrm{Q}} \mathrm{RBS}_{18 \mathrm{e}}(\mathrm{U})_{250}$ (blue) each $(0.05 \mu \mathrm{M})$ and 30S(IF3Alx488) PIC $(0.1 \mu \mathrm{M})$. Non-labeled mRNA was used in the donor-only trace (black). Smooth black lines represent exponential fitting. (B) Same experiment as in (A), but with FRET donor 30S(Alx488) PIC (0.1 $\mu \mathrm{M})$. (C) Exponential fitting of the FRET traces from (A). Two-exponential fitting was used to describe the kinetic behavior yielding two apparent rates: $k_{\text {app } 1}=7.0 \pm 0.1 \mathrm{~s}^{-1}$ and $k_{\text {app2 }}=1.0 \pm 0.1 \mathrm{~s}^{-1}$. Error bars (smaller then symbol size) represent standard error of the fit. (D) Exponential fitting the fluorescence traces from (B). One-exponential fitting yielded $k_{\text {app } 1}=1.5 \pm 0.1 \mathrm{~s}^{-1}$.

The fluorescence amplitude of the reaction was $10 \%$ higher when we used the short mRNA $\left(5^{\mathrm{Q}} \mathrm{RBS}_{18 \mathrm{e}}\right)$ of $24 \mathrm{nt}$-long mRNA (30\% amplitude) in comparison to its extended counterpart $\left(5^{\mathrm{C}} \mathrm{RBS}_{18 \mathrm{e}}(\mathrm{U})_{250}\right)(20 \%$ amplitude). This may reflect the different efficiencies with which a short mRNA versus a long $m R N A$ is recruited to the $30 \mathrm{~S}$ subunit, with a higher probability for the 30S subunit to encounter the mRNA away from the RBS for the longer mRNA. Decreasing the length of the poly(U) extensions to $\approx 100$ uridines $\left(5^{\mathrm{O}} \mathrm{RBS}_{18 \mathrm{e}}(\mathrm{U})_{100}\right)$ did not change the rate or the amplitude of the observed binding in comparison to $5^{\mathrm{Q}} \mathrm{RBS}_{18 \mathrm{e}}(\mathrm{U})_{250}$ mRNA. No fluorescence change of the donor IF3(Alx488) occurred when we used an unlabeled mRNA in the reaction confirming that the FRET pair was highly specific, with the signal change solely due to $30 \mathrm{~S}$ PIC binding to the $5^{\prime}$-end of the model mRNAs. 
These results confirmed that the $30 \mathrm{~S}$ PIC complex formation with model mRNAs: $5^{\mathrm{Q}} \mathrm{RBS}_{18 \mathrm{e}}$, $5^{\mathrm{Q}} \mathrm{RBS}_{18 \mathrm{e}}(\mathrm{U})_{100}$ and $5^{\mathrm{Q}} \mathrm{RBS}_{18 \mathrm{e}}(\mathrm{U})_{250}$ was rapid and efficient.

In order to have a direct observation of the mRNA recruitment to the 30S subunit we used labeled, active in initiation $30 \mathrm{~S}$ subunits reconstituted with S13(Alx488). We mixed model mRNAs $5^{\mathrm{Q}} \mathrm{RBS}_{18 \mathrm{e}}, 5^{\mathrm{Q}} \mathrm{RBS}_{18 \mathrm{e}}(\mathrm{U})_{100}$ and $5^{\mathrm{Q}} \mathrm{RBS}_{18 \mathrm{e}}(\mathrm{U})_{250}$ with an accessible $5^{\prime}$ UTR, long SD sequence and different length of coding region with $30 \mathrm{~S}$ (Alx488) PIC and followed the signal in time (Figure 6B). The donor fluorescence on the $30 \mathrm{~S}$ subunit was quenched in a single step upon interaction, yielding an apparent rate constant $k_{\mathrm{app} 1}=1 \mathrm{~s}^{-1}$ when fitted with one-exponential equation. Similar fluorescence amplitude (10\%) was detected when a shorter 24 nt-long mRNA primer $\left(5^{\mathrm{Q}} \mathrm{RBS}_{18 \mathrm{e}}\right)$ was used instead of its poly(U)-extended derivative $\left(5^{\mathrm{C}} \mathrm{RBS}_{18 \mathrm{e}}(\mathrm{U})_{250}\right)(8 \%)$. The signal was not present when we used a nonlabeled mRNA in the reaction confirming absence of fluorescence change of S13(Alx488) upon mRNA recruitment. The rate $1 \mathrm{~s}^{-1}$ most likely reflects the binding of the 3OS PIC to the $5^{\prime}$-end labeled mRNAs. A concentration dependence was necessary to assign the association step and calculate the rate constants (Section 2.3).

Labeled mRNAs bearing non-optimal 5'-UTRs, e.g. with potential for secondary structures and without a SD sequence, did not result in a FRET change when IF3(Alx488) and 30S(Alx488) subunits were employed as FRET donors. No FRET change was observed after mixing mRNAs $5^{\mathrm{Q}} \mathrm{RBS}_{18}$; $5^{\mathrm{Q}} \mathrm{RBS}_{18}(\mathrm{U})_{250} ; 5^{\mathrm{Q}} \mathrm{RBS}_{18 w} ; 5^{\mathrm{Q}} \mathrm{RBS}_{18 \mathrm{w}}(\mathrm{U})_{350}$ with $30 \mathrm{~S}$ (IF3Alx488) PIC or alternatively, with 30S(Alx488) PIC. When protruding from the ribosomal mRNA exit site these $5^{\prime}$-UTRs might adopt an orientation which does not bring the reporters into a FRET distance. Alternatively, the binding and stabilization of these mRNAs to the $30 \mathrm{~S}$ subunit might be impaired due to a low affinity and transient dynamics of the mRNA binding to the $30 \mathrm{~S}$ subunit. The present results are in good agreement with the low efficiency of $30 \mathrm{~S} \mathrm{IC}$ formation with these mRNAs measured by nitrocellulose filter technique (Figure $4 B)$. In the case of $5^{\mathrm{Q}} \mathrm{RBS}_{18 \mathrm{w}}(\mathrm{U})_{350} \mathrm{mRNA}$, a secondary structure simulation of the sequence around the RBS (15 nt upstream and $15 \mathrm{nt}$ downstream from the start codon) predicted a free energy score of $\Delta G^{\circ}=-1 \mathrm{kcal} / \mathrm{mol}$, which might be sufficient to destabilize the mRNA on the 30S subunit. With the combination of a shorter SD sequence of $3 \mathrm{nt}$ this potential secondary structure affected the mechanism with which the $30 \mathrm{~S}$ subunit recruits such mRNAs.

In the case of $5^{\mathrm{Q}} \mathrm{RBS}_{18}(\mathrm{U})_{250}$ the predicted positive free energy score of the RBS: $\Delta \mathrm{G}^{\circ}=+3.5$ $\mathrm{kcal} / \mathrm{mol}$ pointed to a very open, unstructured sequence. However, this mRNA lacked the SD sequence needed to stabilize the mRNA in the mRNA entry channel of the 30S subunit. This is an interesting observation, considering the fact that a high percentage of all mRNA in $E$. coli do not possess a SD at all, but are efficiently expressed (Chang et al., 2006; Nakagawa et al., 2010; Skorski et al., 2006). How efficient the translation in the absence of a functional SD sequence is still unknown. Unfortunately, we could not find a FRET-donor labeled proteins, as IF1 and IF2 were not in a FRET distance to the $5^{\prime}$ end, or labeled $\mathrm{fMet}$-tRNA ${ }^{\mathrm{fMet}}$ that would give a signal on the stopped flow with

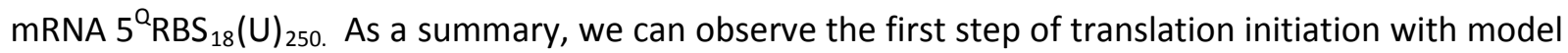
mRNAs $5^{\mathrm{Q}} \mathrm{RBS}_{18 \mathrm{e}}, 5^{\mathrm{Q}} \mathrm{RBS}_{18 \mathrm{e}}(\mathrm{U})_{100}$ and $5^{\mathrm{Q}} \mathrm{RBS}_{18 \mathrm{e}}(\mathrm{U})_{250}$ with two FRET partners (i) IF3(Alx488) bound to the 30 S PIC and (ii) 30S(Alx488) PIC. 


\subsection{2. $5 * \mathrm{RBS}_{18 \mathrm{e}}(U)_{250} \mathrm{mRNA}$ changed fluorescence upon $30 \mathrm{~S}$ PIC recruitment}

$5 * \mathrm{RBS}_{18 \mathrm{e}}(\mathrm{U})_{250}$ mRNA, in contrast to all other model mRNAs, has a fluorescence dye (ATTO488), instead of a quencher at its $5^{\prime}$ end. In this case we were able to directly visualize the $30 \mathrm{~S}$ subunit binding to the very $5^{\prime}$-end of the model mRNA (Figure 7). We used non-labeled components of the initiation machinery to form $30 \mathrm{~S} \mathrm{PIC}$ and mixed them rapidly with $5^{*} \mathrm{RBS}_{18 \mathrm{e}}(U)_{250}$ mRNA which has an open $5^{\prime}$-UTR, a long SD sequence (6 nt) and a poly(U) extension as a coding sequence.

We observed a monophasic decrease in the fluorescence of the reporter at the $5^{\prime}$-end due to binding to the 30S PIC. This was due to a change in the environment surrounding the fluorophore, e.g. if hydrophobic protein residues near the MRNA channel quench the ATTO488 reporter. The observed fluorescence change was fitted with one-exponential equation and the rate was $k_{\mathrm{app} 1}=1.5 \mathrm{~s}^{-1}$. The fluorescence amplitude was $10 \%$. The mRNA did not interact with any other translation initiation component present in the reaction (IF1, IF2, IF3) apart from the 30S subunit (Figure 7-black). It was expected that $5^{*} \mathrm{RBS}_{18 \mathrm{e}}(\mathrm{U})_{250}$ has the same rate of binding to the $30 \mathrm{~S}$ PIC as $5^{\mathrm{a}} \mathrm{RBS}_{18 \mathrm{e}}(\mathrm{U})_{250}$ due to their identical sequence and length of coding sequence. Indeed, $5^{\mathrm{Q}} \mathrm{RBS}_{18 \mathrm{e}}(U)_{250}$ was also recruited by 30S(Alx488) subunit with a $k_{\mathrm{app} 1}$ of $1 \mathrm{~s}^{-1}$ confirming that the activity of labeled and unlabeled components in mRNA recruitment was similar. $5^{*} \mathrm{RBS}_{18 \mathrm{e}}(\mathrm{U})_{250} \mathrm{mRNA}$ is an excellent candidate for monitoring ribosome loading, because we can focus on the mRNA flexibility and dynamics during the process.

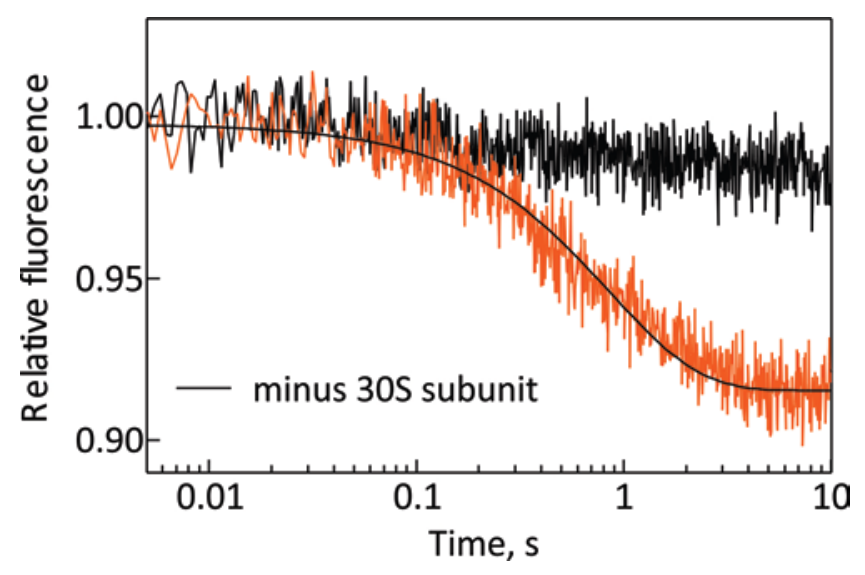

Figure 7. Fluorescence change of $5^{*} \mathrm{RBS}_{18 \mathrm{e}}(\mathrm{U})_{250}$ mRNA upon binding to the $30 \mathrm{~S}$ PIC.

A fluorescence change occurred when the $5^{*} \mathrm{RBS}_{18 \mathrm{e}}(\mathrm{U})_{250}$ mRNA $(0.025 \mu \mathrm{M})$ was mixed with $30 \mathrm{~S}$ PIC $(0.1 \mu \mathrm{M})$ (orange). No fluorescence change occurred when in the same reaction the 30S subunit were omitted (black trace). Smooth black lines represent exponential fitting. One-exponential equation was used to estimate the apparent rate of $k_{\mathrm{app} 1}=1.5 . \pm 0.1 \mathrm{~s}^{-1}$. Error was the s.e.m. of the fit. 
2.2.3. $5^{\mathrm{a}} \mathrm{RBS}_{20 \mathrm{e}}(\mathrm{UUC})_{78} \mathrm{mRNA}$ recruited the ribosome.

In comparison to the model mRNAs with poly(U) extensions examined in Section 2.2.1 and 2.2.2, the mRNAs described in this section have a fixed length of coding region and the codon utilized to decode phenylalanine is UUC instead of UUU (Table 11). $5^{\mathrm{Q}} \mathrm{RBS}_{20 \mathrm{e}}(\mathrm{UUC})_{78} \mathrm{mRNA}$ has the same $5^{\prime}$ UTR as the model mRNA $5^{\mathrm{Q}} \mathrm{RBS}_{18 \mathrm{e}}(\mathrm{U})_{250}$ with the exception of two guanine nucleotides at the $5^{\prime}$ end, making the $5^{\prime}$-UTR $20 \mathrm{nt}$ long instead of $18 \mathrm{nt}$. The guanines at the $5^{\prime}$-end were essential for the in vitro T7 RNA-polymerase transcription reaction. Furthermore, the main difference between the two mRNAs was their predicted folding energies around the RBS: $5^{\mathrm{Q}} \mathrm{RBS}_{18 \mathrm{e}}(\mathrm{U})_{250}$ with a positive delta free energy score $\left(\Delta G^{\circ}=+0.5 \mathrm{kcal} / \mathrm{mol}\right)$, implying a more unstructured sequence, while $5^{\mathrm{Q}} \mathrm{RBS}_{20 \mathrm{e}}(U U \mathrm{UC})_{78}$ mRNA with a negative delta free energy score $\left(\Delta \mathrm{G}^{\circ}=-4 \mathrm{kcal} / \mathrm{mol}\right)$ suggesting a more structured RBS contributed by the coding sequence UUC of the first $15 \mathrm{nt}$ after the AUG (Table 12). Thus the designs of the mRNAs will allow us to focus on their initiation potential, keeping the same translation product of the elongation phase (fMet-poly(Phe) peptide). The $5^{\mathrm{a}} \mathrm{RBS}_{20 \mathrm{w}}(\mathrm{UUC})_{78}$ mRNA was similar to the $5^{\mathrm{Q}} \mathrm{RBS}_{18 \mathrm{w}}(\mathrm{U})_{350}$ mRNA having the same $5^{\prime}$-UTR sequence, with weak SD sequence of $3 \mathrm{nt}$. As in the previous example, $5^{\mathrm{Q}} \mathrm{RBS}_{20 \mathrm{w}}(\mathrm{UUC})_{78}$ mRNA had a 2 nt longer $5^{\prime}$-UTR than $5^{\mathrm{Q}} \mathrm{RBS}_{18 \mathrm{w}}(\mathrm{U})_{350}$ and UUC repeats in the coding sequence instead of UUU. However, both mRNAs had an unchanged folding energy score around the RBS $\left(\Delta G^{\circ}=-1 \mathrm{kcal} / \mathrm{mol}\right)$. In this case only the influence of $5^{\prime}-U T R$ sequence was examined in the process of 30S PIC recruitment.

We tested the binding between $5^{\mathrm{Q}} \mathrm{RBS}_{20 \mathrm{e}}(\mathrm{UUC})_{78}$ mRNA and 30S(IF3Alx488) PIC or 30S(Alx488) PIC in the stopped flow apparatus (Figure 8). When IF3(Alx488) was used as a donor, the fluorescence signal changed in a biphasic fashion, which could be fitted with a two-exponential equation (Figure 8A). The $k_{\text {app1 }}$ was $0.7 \mathrm{~s}^{-1}$, while the $k_{\text {app2 }}$ was $0.2 \mathrm{~s}^{-1}$. The $k_{\mathrm{app} 1}$ likely reflected the binding of the 30S PIC to the mRNA. The second, slower rate might represent the accommodation of the $5^{\prime}$-end of the mRNA on the $30 \mathrm{~S}$ subunit. The fluorescence amplitude was $10 \%$. When we used $30 S(A \mid x 488$ ) subunit as a donor, the decrease in the FRET signal was fitted with a one-exponential equation yielding an apparent rate of $k_{\text {app } 1} 0.1 \mathrm{~s}^{-1}$ and a fluorescence amplitude of $2 \%$. Concentration dependence was needed to resolve the association step in the recruitment of $5^{\mathrm{a}} \mathrm{RBS}_{20 \mathrm{e}}(\mathrm{UUC})_{78} \mathrm{mRNA}$ to the 30S PIC (Section 2.3). Overall, the result obtained with $5^{{ }^{a}} \mathrm{RBS}_{20 e}(U U C)_{78}$ mRNA reflected a scenario in which the 30S PIC was impaired in mRNA recruitment, even though the mRNA possessed a proper RBS with long SD (6 nt) sequence, spacer and AUG codon. This fact was likely due to a presence of a secondary structure, preventing a rapid initial recruitment. Considering that the labeled and unlabeled $5^{\mathrm{Q}} \mathrm{RBS}_{20 \mathrm{e}}(\mathrm{UUC})_{78}$ mRNAs were active in forming $30 \mathrm{~S} \mathrm{IC} \mathrm{(Figure} \mathrm{5B)} \mathrm{we} \mathrm{can} \mathrm{exclude} \mathrm{the}$ effect of the dye at the $5^{\prime}$-end in the overall translation initiation reaction.

In addition, we tested the $5^{\mathrm{Q}} \mathrm{RBS}_{20 \mathrm{w}}(\mathrm{UUC})_{78}$ mRNA which has a lower propensity to form secondary structure $\left(\Delta \mathrm{G}^{\circ}=-1 \mathrm{kcal} / \mathrm{mol}\right)$ in comparison to $5^{\mathrm{Q}} \mathrm{RBS}_{20 \mathrm{e}}(U U \mathrm{UC})_{78}\left(\Delta \mathrm{G}^{\circ}=-4 \mathrm{kcal} / \mathrm{mol}\right)$, but has a weaker SD sequence of ( $3 \mathrm{nt}$ ). When we mixed it with the IF3(Alx488) bound to the 30S PIC or 30S(Alx488) subunit we did not observe a FRET signal. In line with previous results, the different conformation and position of the $5^{\prime}$-end depended on the sequence of the $5^{\prime}$-UTR as for $5^{\mathrm{Q}} \mathrm{RBS}_{18 \mathrm{w}}(\mathrm{U})_{350}$ (Section 2.2.1). We focused on $5^{\mathrm{a}} \mathrm{RBS}_{20 \mathrm{e}}(U U C)_{78}$ mRNA and analyzed in detail its kinetic behavior upon 30S PIC recruitment in Section 2.3. 

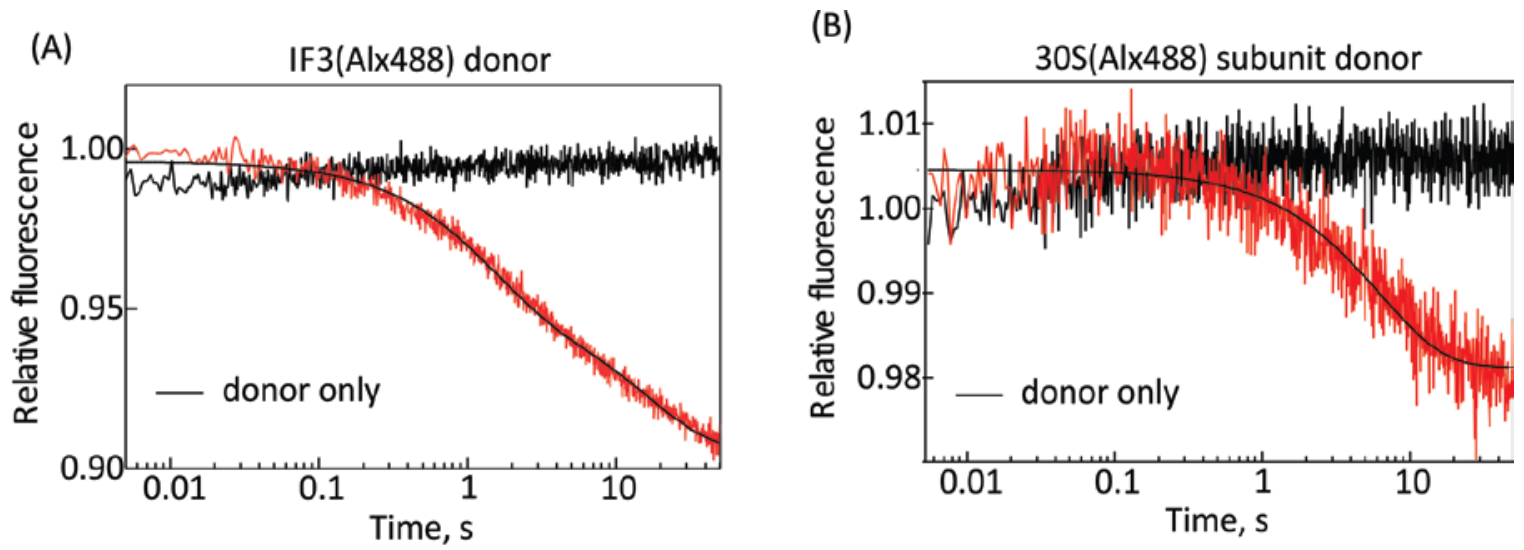

(C)

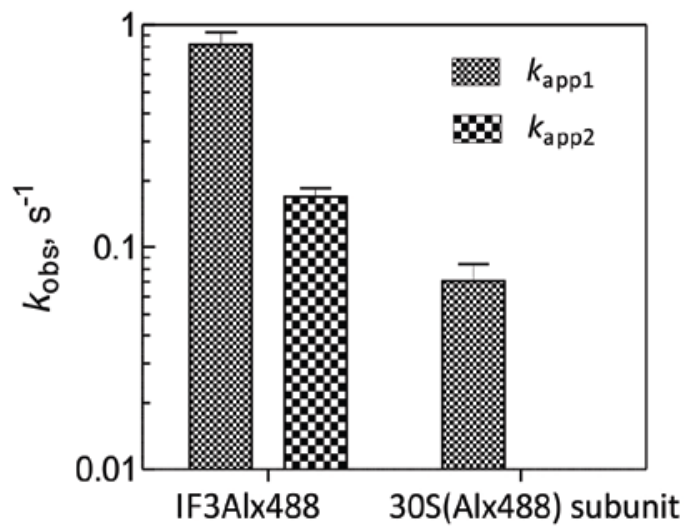

Figure 8. FRET between $5^{\mathrm{a}} \mathrm{RBS}_{20 \mathrm{e}}$ (UUC) ${ }_{78}$ mRNA and IF3(Alx488) bound to the $30 \mathrm{~S}$ PIC or $30 \mathrm{~S}$ (Alx488) PIC.

(A) FRET between $5^{\prime}$ ATTO540Q labeled $5^{\mathrm{C}_{\text {RBS }}}{ }_{20 \mathrm{e}}(\mathrm{UUC})_{78}(0.05 \mu \mathrm{M})$ and 30S(IF3Alx488) PIC (0.1 $\left.\mu \mathrm{M}\right)$. Nonlabeled mRNA was used in the donor-only trace (black). Smooth black line represent exponential fitting. (B) Same experiment as in (A), but the fluorescence donor was 30S(Alx488) PIC $(0.1 \mu \mathrm{M})$ and dark IF3 factor was used $(0.2 \mu \mathrm{M})$. Non-labeled mRNA was used in the donor only trace (black). (C) Exponential fitting of the fluorescence traces from (A) and (B). The reaction with IF3(Alx488) as a donor was fitted with a two-exponential fitting yielding two apparent rates. $k_{\mathrm{app} 1}=0.74 \pm 0.02 \mathrm{~s}^{-1}$ and $k_{\mathrm{app} 2}=0.20 \pm 0.05 \mathrm{~s}^{-1}$. The fluorescence trace shown in (B) was fitted with a one-exponential equation yielding an apparent rate of $k_{\text {app } 1}=0.10 \pm 0.01 \mathrm{~s}^{-1}$. Error bars represent s.d. calculated from 3 independent replicates.

In summary, we established a toolbox of fluorescence observables dedicated to monitor the 30S PIC recruitment to the RBS on model mRNAs. The approach was successful only with a subset of labeled mRNAs, but it allowed us to screen any desired mRNA independent of its coding sequence. A detailed global fitting approach was used in the next section in order to precisely discriminate between different elemental steps occurring during $30 \mathrm{~S}$ subunit binding to the $5^{\prime}$-end labeled mRNAs. In the following sections we only used the mRNAs that gave a FRET signal, $5^{\mathrm{Q}} \mathrm{RBS}_{18 \mathrm{e}}(\mathrm{U})_{250}$ and $5^{\mathrm{Q}} \mathrm{RBS}_{20 \mathrm{e}}(\mathrm{UUC})_{78}$, or fluorescence change, $5^{*} \mathrm{RBS}_{18 \mathrm{e}}(\mathrm{U})_{250}$, when forming the $30 \mathrm{~S}$ PIC. 


\subsection{Timing of the first 30S PIC binding event with model 5 '-end labeled mRNAs.}

In this part of the results, we studied the initiation on the first ribosome with the help of FRET, rapid kinetics, exponential and global fitting approaches. After we screened various $5^{\prime}$-end labeled mRNAs for their potential to give a FRET signal with fluorescence components of the initiation machinery or change fluorescence (Section 2.2), we aimed at solving the pre-steady state kinetics and identifying the timing of the $30 \mathrm{~S}$ PIC recruitment to three model mRNAs, $5^{\mathrm{a}} \mathrm{RBS}_{18 \mathrm{e}}(\mathrm{U})_{250}$, $5^{*} \mathrm{RBS}_{18 \mathrm{e}}(\mathrm{U})_{250}$ and $5^{\mathrm{Q}} \mathrm{RBS}_{20 \mathrm{e}}(\mathrm{UUC})_{78}$. These model mRNAs had different recruitment rates to the $30 \mathrm{~S}$ PIC, which reflected their different mechanism of translation initiation. A detailed kinetic mechanism was needed to discriminate between the different fluorescence intermediates that contribute to each step of this process. The results presented here describe the kinetic behavior of these mRNAs during the first round of initiation, without a leading ribosome translating the sequence. This makes it possible to later compare the kinetics with those of the second round of initiation (Section 2.5), where a translating ribosome was present along the mRNA sequence.

The experimental setup was similar to the one used in Section 2.2. We monitored the FRET or the fluorescence change of the 5'-end of the mRNA upon rapid mixing with the $30 \mathrm{~S} \mathrm{PIC}$ in the stopped-flow apparatus. 30S(Alx488) PIC was formed with a 2-fold molar excess of translation initiation factors and $0.25 \mathrm{mM}$ GTP in TAKM7 buffer for $30 \mathrm{~min}$. Each reaction was monitored under conditions where the 30S(Alx488) subunit was at least in a 3-fold molar excess over the mRNA. In all of the following reactions, the elongation machinery (ternary complex of EF-Tu-Phe-tRNA ${ }^{\text {Phe }}-\mathrm{GTP}$, EF$\mathrm{G}$ and EF-Ts) was supplemented, in order to simulate a molecular crowding effect also present in the experiments done for the second round initiation (Section 2.5).

One-exponential fitting was sufficient to evaluate the time courses of binding of the three model mRNAs $5^{\mathrm{Q}} \mathrm{RBS}_{18 \mathrm{e}}(\mathrm{U})_{250}, 5^{\mathrm{Q}} \mathrm{RBS}_{20 \mathrm{e}}(\mathrm{UUC})_{78}$ and $5^{*} \mathrm{RBS}_{18 \mathrm{e}}(\mathrm{U})_{250}$ to $30 \mathrm{~S}$ (Alx488) subunit or nonlabeled 30S PIC (Figure 9). The dependence of the apparent rate constants on the concentration of $30 \mathrm{~S}$ subunit was linear. In such cases the slope is equal to the association rate constant $\left(\mathrm{k}_{\text {on }}\right)$ and the intercept of the $\mathrm{Y}$-axis indicates the dissociation rate constant $\left(\mathrm{k}_{\text {off }}\right)$. We calculated the association rate $\left(k_{\text {on }}\right)$ with the use of linear regression analysis suggesting a bimolecular binding step. $k_{\text {off }}$ was poorly defined. We did not expect the dissociation of any of the mRNAs to be preferred, because they possess all the requirements for an efficient $30 \mathrm{SIC}$ formation. $5^{\mathrm{Q}} \mathrm{RBS}_{18 \mathrm{e}}(\mathrm{U})_{250} \mathrm{mRNA}$ associated to the $30 \mathrm{~S}$ PIC with a $k_{\text {on }}=27 \mu \mathrm{M}^{-1} \mathrm{~s}^{-1}$ while $5^{*} \mathrm{RBS}_{18 \mathrm{e}}(\mathrm{U})_{250} \mathrm{mRNA}$, which showed a change in fluorescence upon non-labeled 30S PIC binding, associated with $\mathrm{k}_{\text {on }}=14 \mu \mathrm{M}^{-1} \mathrm{~s}^{-1}$ (Figure 9A-D). The two mRNAs differed only in the nature of the label attached to the $5^{\prime}$-end (ATTO488 or ATTO540Q) and hence have similar, but not identical association rates to the $30 \mathrm{~S} \mathrm{PIC.} 5^{\mathrm{Q}} \mathrm{RBS}_{20 \mathrm{e}}(\mathrm{UUC})_{78} \mathrm{mRNA}$ associated to the $30 \mathrm{~S}$ PIC with a $k_{\text {on }}=1.4 \mu \mathrm{M}^{-1} \mathrm{~s}^{-1}$ which was an order of magnitude slower than $5^{\mathrm{Q}} \mathrm{RBS}_{18 \mathrm{e}}(\mathrm{U})_{250}$ mRNA even though they both possess the same long SD (6 nt) and AUG codon, but differ due to the length and the sequence of the coding region, while maintaining the same polypeptide product (Figure 9E-F). This strong reduction in the association rate of the $30 \mathrm{~S} \mathrm{PIC} \mathrm{was} \mathrm{due} \mathrm{to} \mathrm{the} \mathrm{masking} \mathrm{of}$ the SD region by the predicted secondary structure (Table 12). The apparent rates of 30S PIC binding the mRNAs are summarized in Table 1. 
(A)

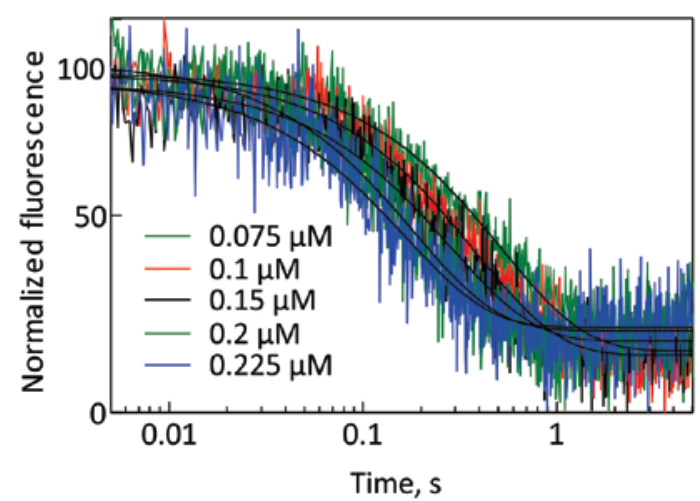

(C)

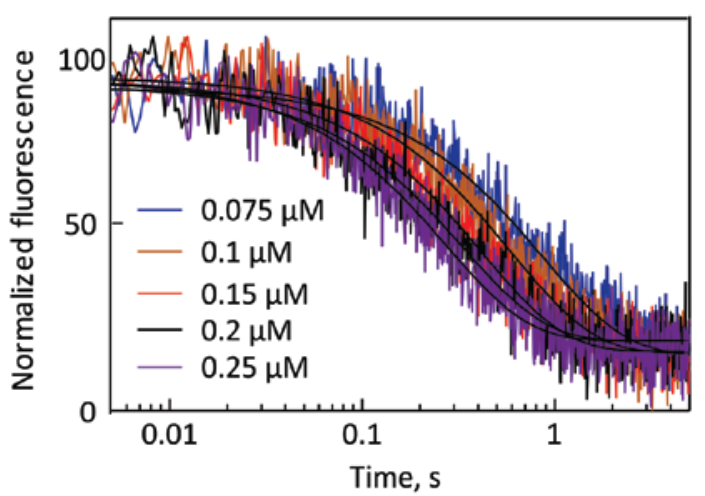

(E)

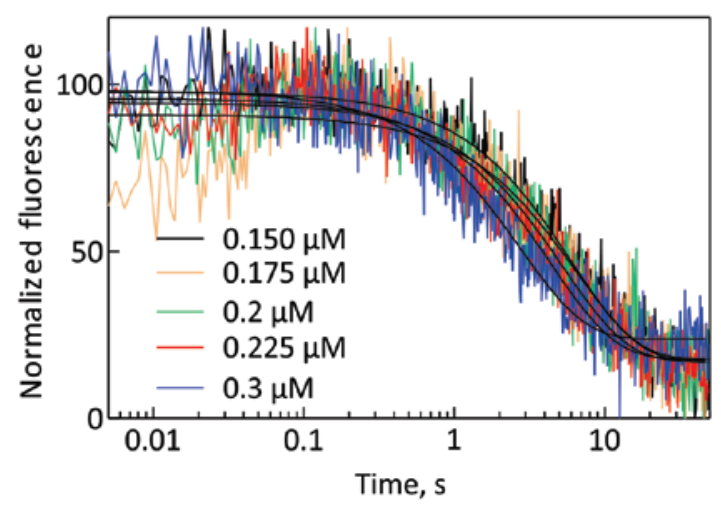

(B)

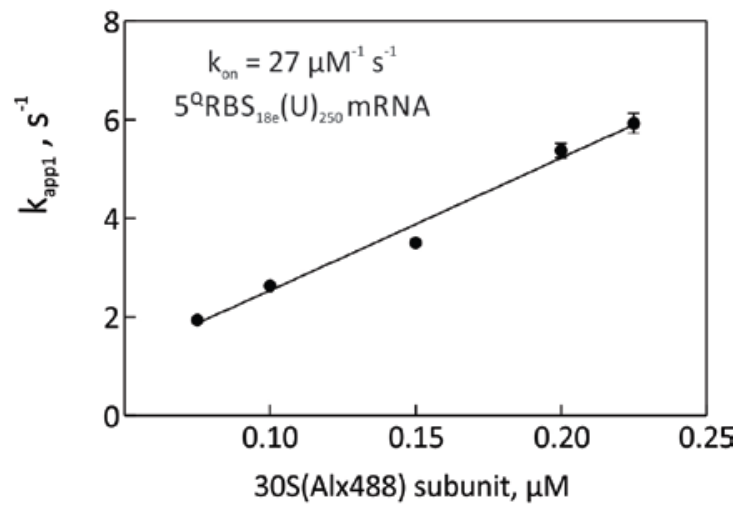

(D)

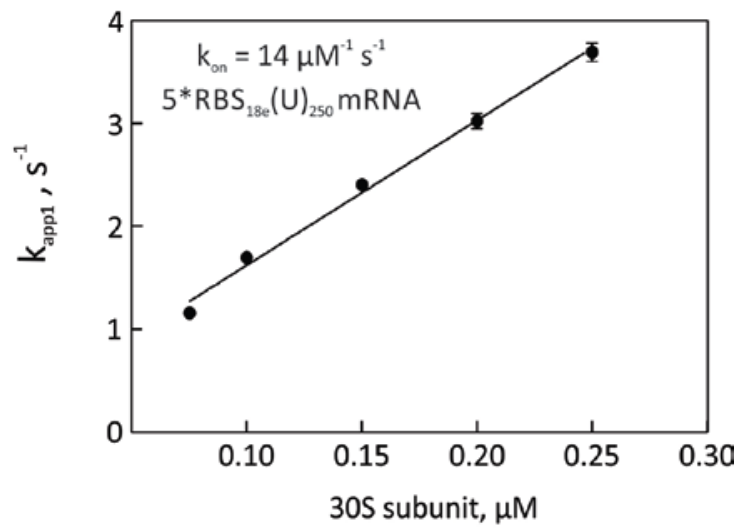

(F)

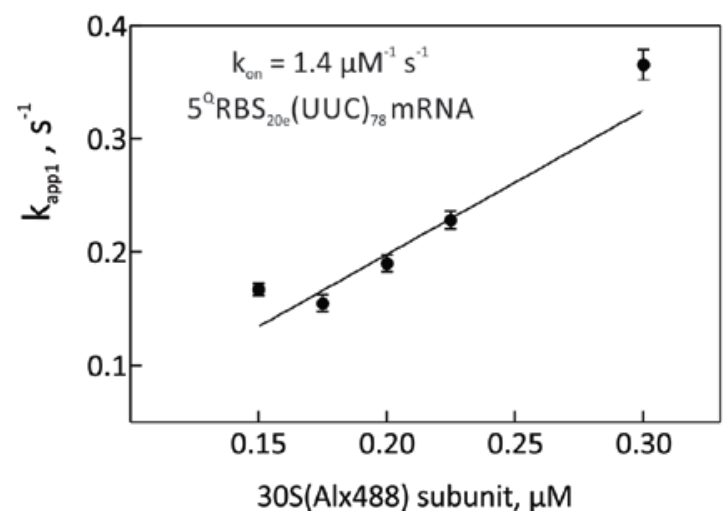

Figure 9. Binding of $5^{\prime}$-end labeled mRNAs to the $30 \mathrm{~S}$ PIC.

(A) Increasing concentrations of $30 \mathrm{~S}(\mathrm{Alx} 488)$ subunit $(0.075 \mu \mathrm{M}-0.225 \mu \mathrm{M})$ were used to form $30 \mathrm{~S}$ PIC, combined with the elongation machinery right before mixing with $5^{\mathrm{Q}} \mathrm{RBS}_{18 \mathrm{e}}(U)_{250} \mathrm{mRNA}(0.025 \mu \mathrm{M})$.(B) Apparent rate constant from exponential fits of (A). Linear regression analysis of $k_{\text {app } 1}$ gave a $k_{\text {on }}=27 \pm 2 \mu \mathrm{M}^{-1} \mathrm{~s}^{-}$ ${ }^{1}$. (C) 30S subunit $(0.075 \mu \mathrm{M}-0.225 \mu \mathrm{M})$ were used to form 30S PIC, combined with the elongation machinery added immediately before mixing with $5^{*} \operatorname{RBS}_{18 \mathrm{e}}(\mathrm{U})_{250}$ mRNA $(0.025 \mu \mathrm{M})$.(D) Apparent rate constant from an exponential fits of (C). Linear regression analysis of $k_{\text {app1 }}$ gave a $k_{\text {on }}=14 \pm 1 \mu \mathrm{M}^{-1} \mathrm{~s}^{-1}$. (E) Same as (A) with $5^{\mathrm{Q}} \mathrm{RBS}_{20 \mathrm{e}}(\mathrm{UUC})_{78}$ mRNA $(0.05 \mu \mathrm{M})$.(F) Apparent rate constant from exponential fits of (E). Linear regression analysis of $k_{\text {app } 1}$ revealed a $k_{\text {on }}=1.4 \pm 0.2 \mu \mathrm{M}^{-1} \mathrm{~s}^{-1}$. Error was the s.e.m. of the fit. 
Table 1. Summary of association rate constants between 30 S PIC and $5^{\prime}$-end labeled mRNAs.

The apparent association rate constants $k_{\text {on }}\left(\mu \mathrm{M}^{-1} \mathrm{~s}^{-1}\right)$ were estimated by linear fitting of the concentration dependence of the $k_{\text {app } 1}$ values from the time courses of Figure 9. Error was the s.e.m. of the fit.

\begin{tabular}{|c|c|}
\hline mRNA, name & $\boldsymbol{k}_{\text {on }}\left(\boldsymbol{\mu \mathrm { M } ^ { - 1 } \boldsymbol { s } ^ { - 1 } )}\right.$ \\
\hline $5^{\mathrm{Q}} \mathrm{RBS}_{18 \mathrm{e}}(\mathrm{U})_{250}$ & $27 \pm 2$ \\
\hline $5^{*} \mathrm{RBS}_{18 \mathrm{e}}(\mathrm{U})_{250}$ & $14 \pm 1$ \\
\hline $5^{\mathrm{Q}} \mathrm{RBS}_{20 \mathrm{e}}(\mathrm{UUC})_{78}$ & $1.4 \pm 0.2$ \\
\hline
\end{tabular}

We could also fit the traces from Figure 9 with a simple, one-step global fit model, in order to refine the association step of the mRNAs to the 30S PIC (Section 4.24). Using a one-step model that represented a reversible, bimolecular binding reaction between 30S(Alx488) PIC and the mRNAs we obtained 2 elemental rate constants; $k_{+1}$ and $k_{-1}$, which depicted the mRNA binding and dissociation step, respectively (Table 2). The values obtained for the mRNA binding step were similar to the ones with the exponential fit (Table 1). With the global fit model we could obtain a value for the dissociation rate $k_{-1}$, albeit with low confidence of the estimated value (Table 2 ).

Table 2. Summary of the elemental rate constants of interaction between 30S PIC and 5'-end labeled mRNAs.

Global fitting of time traces from Figure 9. The elemental rate constants were derived from a one-step global fit model. Error was the s.e.m. of the fit.

\begin{tabular}{|c|c|c|}
\hline mRNA, name & $\begin{array}{c}k_{+1}\left(\mu \mathrm{M}^{-1} \mathrm{~s}^{-1}\right) \\
\text { mRNA } \\
\text { binding }\end{array}$ & $\begin{array}{c}k_{-1}\left(s^{-1}\right) \\
\text { mRNA } \\
\text { dissociation }\end{array}$ \\
\hline $5^{\mathrm{Q}} \mathrm{RBS}_{18 \mathrm{e}}(U)_{250}$ & $25 \pm 1$ & $0.2 \pm 0.1$ \\
\hline $5 * \mathrm{RBS}_{18 \mathrm{e}}(U)_{250}$ & $15 \pm 1$ & $0.2 \pm 0.1$ \\
\hline $5^{\mathrm{Q}} \mathrm{RBS}_{20 \mathrm{e}}(\mathrm{UUC})_{78}$ & $1.1 \pm 0.1$ & $0.006 \pm 0.006$ \\
\hline
\end{tabular}

As a summary, using rapid kinetics and a combination of exponential and global fitting approaches we calculated the association step for three model mRNAs to the $30 \mathrm{~S} \mathrm{PIC} .5^{\mathrm{Q}} \mathrm{RBS}_{18 \mathrm{e}}(\mathrm{U})_{250}$ and $5^{*} \mathrm{RBS}_{18 \mathrm{e}}(\mathrm{U})_{250}$ mRNAs associated with a rate of 25 and $15 \mu \mathrm{M}^{-1} \mathrm{~s}^{-1}$ while $5^{\mathrm{Q}} \mathrm{RBS}_{20 \mathrm{e}}(\mathrm{UUC})_{78} \mathrm{mRNA}$ had a 10-fold slower rate of association $-1.1 \mu \mathrm{M}^{-1} \mathrm{~s}^{-1}$. With the FRET donor 30S(Alx488) subunit we could isolate the binding step. This step is essential for the efficiency with which the mRNA is translated, with faster associating mRNAs with the $30 \mathrm{~S}$ subunit potentially outcompeting the slowly associating mRNAs. The fact that all of the model mRNAs have the same coding sequence for Phe incorporation allowed us to focus preferentially on their initiation properties when investigating the polysome formation. We can therefore ask how the 30S PIC recruits an mRNA, when a leading ribosome moves along its sequence.

As we have examined in Section 2.2, IF3(Alx488) on the 30S PIC also gave a signal when the later was mixed with the $5^{\prime}$-end labeled mRNAs. In contrast to $30 \mathrm{~S}$ (Alx488) subunit, previously used as a FRET donor in the first round of initiation, when we employed 30S(IF3Alx488) PIC and increasing concentrations of the mRNAs, we observed a multi-phasic fluorescence quenching (Figure 10). We used a global fitting approach, instead of an exponential fit, in order to better estimate the steps that 
occur when the 30S(IF3AIx488) PIC recruited the mRNAs. Numerical integration is the best option for extracting accurate individual rate constants from multi-phase traces, because each step is represented by a fluorescence amplitude and rate, stringent to the model input we assign (Section 4.24). Time courses obtained for each reaction at increasing mRNA concentrations, were collectively fitted using a numerical integration to derive the elemental rate constants of each step (Table $\mathbf{3}$ ).

(A)

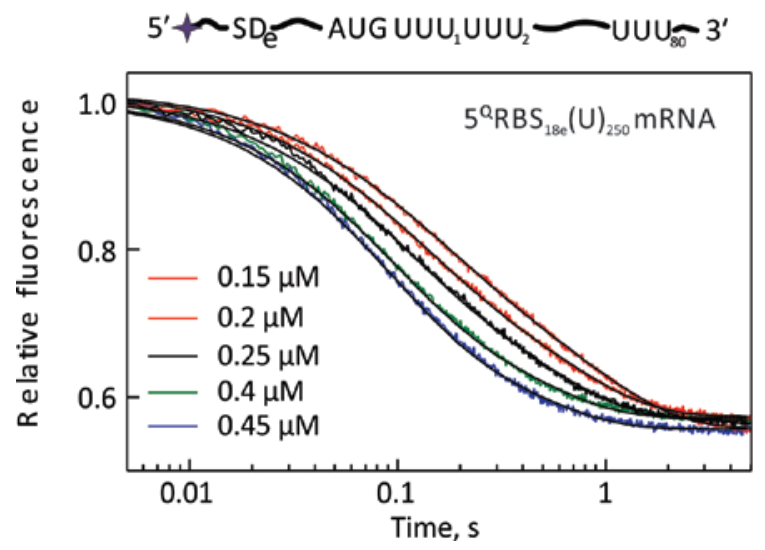

(B)

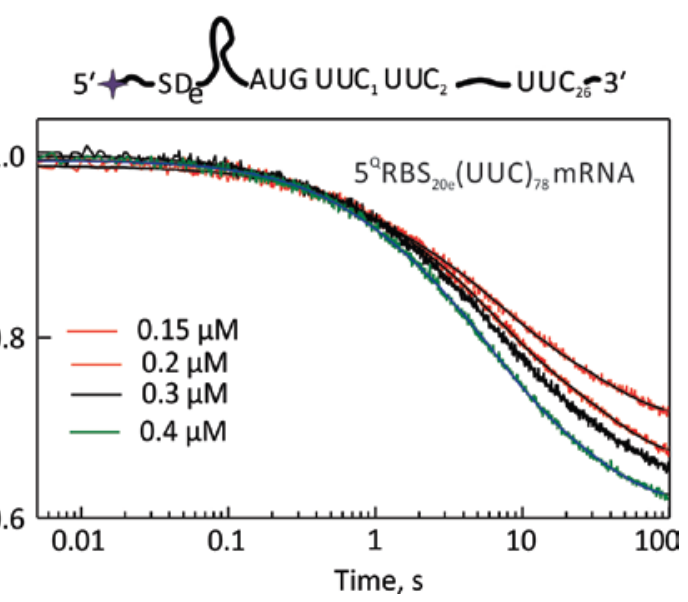

Figure 10. Binding of the 5 '-end labeled mRNAs to the 30S(IF3Alx488) PIC.

(A) FRET between IF3(Alx488) bound to the $30 \mathrm{~S}$ PIC and $5^{\mathrm{Q}} \mathrm{RBS}_{18 \mathrm{e}}(\mathrm{U})_{250}$ mRNA. 30S(IF3AIx488) PIC (0.1 $\left.\mu \mathrm{M}\right)$ was supplemented with the elongation machinery and rapidly mixed with increasing concentrations of $5^{\mathrm{Q}} \mathrm{RBS}_{18 \mathrm{e}}(\mathrm{U})_{250} \mathrm{mRNA}(0.15 \mu \mathrm{M}-0.45 \mu \mathrm{M})$.(B) Same experimental set up as in (A) but increasing concentrations of $5^{\mathrm{a}} \mathrm{RBS}_{20 \mathrm{e}}(\mathrm{UUC})_{78} \mathrm{mRNA}$ (from $0.15 \mu \mathrm{M}$ to $0.4 \mu \mathrm{M}$ ) were used. Smooth black lines represent the global fit. Schematics of the mRNAs used are shown on top.

When we mixed the $30 \mathrm{~S}$ (IF3Alx488) PIC with increasing concentrations of $5^{\mathrm{a}} \mathrm{RBS}_{18 \mathrm{e}}(\mathrm{U})_{250}$ mRNA we observed a biphasic fluorescence trace (Figure 10A). The amplitude of the signal remained constant for all mRNA concentrations (40\%). A two-step global fit model resulted in $k_{+1}$ of $24 \mu \mathrm{M}^{-1} \mathrm{~s}^{-1}$, $k_{-1}$ of $3.0 \mathrm{~s}^{-1}$ and a $k_{+2}$ of $4.0 \mathrm{~s}^{-1}$, with the first binding step accounting for $85 \%$ of the overall amplitude, while the remaining amplitude (15\%) accounted for the second step. The slower second step might reflect various aspects of the pre-initiation step on the open, unstructured RBS of $5^{\mathrm{Q}} \mathrm{RBS}_{18 \mathrm{e}}(\mathrm{U})_{250} \mathrm{mRNA}$, such as adjustment in the mRNAs channel, base paring with the anti-SD sequence, or a more global rearrangement of IF3 on the 30S PIC subunit in the presence of the other IFs. The association step with of $5^{\mathrm{Q}} \mathrm{RBS}_{18 \mathrm{e}}(\mathrm{U})_{250}$ mRNA with FRET donor 30S(IF3Alx488) PIC $k_{+1}$ of 24 $\mu \mathrm{M}^{-1} \mathrm{~s}^{-1}$ was similar to the one obtained with $30 \mathrm{~S}$ (Alx488) subunit, $k_{+1}$ of $25 \mu \mathrm{M}^{-1} \mathrm{~s}^{-1}$ (Table 2).

When we mixed the $30 \mathrm{~S}$ (IF3Alx488) PIC with increasing concentrations of $5^{\mathrm{C}} \mathrm{RBS}_{20 \mathrm{e}}(\mathrm{UUC})_{78}$ mRNA we observed a triphasic fluorescence trace (Figure 10B). The amplitude of the signal varied slightly between the lowest and highest concentration of the mRNA. A three-step global fit model resolved the association and dissociation steps: $k_{+1}=5 \mu \mathrm{M}^{-1} \mathrm{~s}^{-1}, k_{-1}=0.13 \mathrm{~s}^{-1}$, accounting for $30 \%$ of the overall amplitude, and two slower steps: $k_{+2}=0.2 \mathrm{~s}^{-1}$ with $40 \%$ contribution and $k_{+3}=0.03 \mathrm{~s}^{-1}$ with $30 \%$ contribution. We assigned the second step as IF3 rearrangement and the third step as a slow IF3 rearrangement. The appearance of the third step which was not present in the reaction with the 
$5^{\mathrm{Q}} \mathrm{RBS}_{18 \mathrm{e}}(\mathrm{U})_{250}$ mRNA $\left(k_{+3}=0.03 \mathrm{~s}^{-1}\right)$ may reflect the slow dynamics of the $30 \mathrm{~S}$ PIC while unwinding the mRNA RBS in search for the SD sequence and the start codon.

Table 3. Summary of the elemental rate constants of interaction between 30S(IF3Alx488) PIC and 5'-end labeled mRNAs.

Global fitting of time traces form Figure 10. The elemental rate constants were derived from a two or three-step global fit models. The bimolecular step resulted in $k_{+1}$ and $k_{-1}$, assigned as mRNA binding and mRNA dissociation, respectively. The second step was assigned as IF3 rearrangement $\left(k_{+2}\right)$ followed by a third step $\left(k_{+3}\right)$ only for $5^{\mathrm{Q}} \mathrm{RBS}_{20 \mathrm{e}}(\mathrm{UUC})_{78}$ mRNA assigned as IF3 slow rearrangement. Percentages in brackets next to the rate represent the fluorescence contribution of the step from the overall amplitude. Error was the s.e.m. of the fit. N.O (not observed).

\begin{tabular}{|c|c|c|c|c|}
\hline $\begin{array}{c}\text { mRNA, } \\
\text { name }\end{array}$ & $\begin{array}{c}\boldsymbol{k}_{+1}\left(\mu \mathbf{M}^{-1} \mathbf{s}^{-1}\right) \\
\text { mRNA binding }\end{array}$ & $\begin{array}{c}\boldsymbol{k}_{-1}\left(\mathbf{s}^{-1}\right) \\
\text { mRNA } \\
\text { dissociation }\end{array}$ & $\begin{array}{c}\boldsymbol{k}_{+2}\left(\mathbf{s}^{-1}\right) \\
\text { IF3 } \\
\text { rearrangement }\end{array}$ & $\begin{array}{c}\boldsymbol{k}_{+3}\left(\mathbf{s}^{-1}\right) \\
\text { IF3 slow } \\
\text { rearrangement }\end{array}$ \\
\hline $5^{\mathrm{Q}} \mathrm{RBS}_{18 \mathrm{e}}(\mathrm{U})_{250}$ & $24 \pm 1(85 \%)$ & $3.0 \pm 0.1$ & $4.0 \pm 0.1(15 \%)$ & $\mathrm{N} .0$ \\
\hline $5^{\mathrm{Q}} \mathrm{RBS}_{20 \mathrm{e}}(\mathrm{UUC})_{78}$ & $5.0 \pm 0.4(27 \%)$ & $0.13 \pm 0.03$ & $0.2 \pm 0.01(40 \%)$ & $\begin{array}{c}0.03 \pm 0.001 \\
(34 \%)\end{array}$ \\
\hline
\end{tabular}

In summary, we dissected the binding kinetics of three model mRNAs to the 30S PIC with either labeled or unlabeled 30 S subunits and labeled IF3. A global fitting approach helped us to assign the rate constants of the stepwise process of initiation of the model mRNAs. The result confirmed a different mechanism of 30S PIC selection of mRNAs with an unfavorable conformation around the RBS, which caused a 10-fold reduction of the association step (Milon et al., 2012; Studer and Joseph, 2006). Our next aim was to monitor the second round of initiation with model mRNAs which differ in their first round of initiation, and dissect the influence of structured RBS in the process of ribosome loading on mRNAs. We addressed the question of whether the first ribosome that has already selected the RBS can influence the rate of following initiation events. 


\subsection{First round of translation elongation.}

Protein synthesis is a dynamic process and the kinetics of ribosome movement along mRNAs is rapid. To monitor the frequency of ribosome loading on model mRNAs we need to attain another requirement in the in vitro translation system, the translation elongation velocity of the first ribosome must be rapid enough for the pre-steady-state analysis of the subsequent ribosome recruitment. Labeled $5^{\mathrm{Q}} \mathrm{RBS}_{18 \mathrm{e}}(\mathrm{U})_{250}, 5^{*} \mathrm{RBS}_{18 \mathrm{e}}(\mathrm{U})_{250}$ and $5^{\mathrm{Q}} \mathrm{RBS}_{20 \mathrm{e}}(\mathrm{UUC})_{78}$ mRNAs efficiently form $70 \mathrm{~S}$ initiation complexes which could be purified through sucrose cushion (Section 4.19). The production of these synchronized $70 S$ complexes formed with an mRNA carrying a fluorescence label and a radioactivelabeled initiator tRNA $\left[{ }^{3} \mathrm{H}\right] \mathrm{fMet}-\mathrm{tRNA}{ }^{\mathrm{fMet}}$ positioned at the start codon, were utilized in the following experiments.

We measured the rate of elongation upon translation of $5^{\mathrm{C}} \mathrm{RBS}_{18 \mathrm{e}}(\mathrm{U})_{250}$ mRNA by mixing in a quench flow apparatus the $70 \mathrm{~S} I \mathrm{C}\left(5^{\mathrm{Q}} \mathrm{RBS}_{18 \mathrm{e}}(\mathrm{U})_{250} \mathrm{mRNA}\right)$ with the elongation machinery (ternary complexes (TC) formed with labeled $\left[{ }^{14} \mathrm{C}\right]$ Phe-tRNA ${ }^{\text {Phe }}, \mathrm{EF}-\mathrm{G}$ and EF-Ts) (Figure 11). At each time point $(0.01 s-100 s)$ the reaction was chemically quenched, the peptides were precipitated with TCA and the incorporated radioactivity was assessed by scintillation counting (Section 4.21.1). The ratio between pmol $\left[{ }^{14} \mathrm{C}\right] \mathrm{Phe} / \mathrm{pmol}\left[{ }^{3} \mathrm{H}\right] \mathrm{fMet}$ was plotted against time. There was a constant background of 3-5 amino acids, which was the minimum length of precipitated peptide in the assay (Yvon et al., 1989). We calculated the rate of polypeptide elongation using a one-exponential fitting (Section 4.21.2). The rate $k_{\mathrm{e}} 1^{\text {st }} \mathrm{UUU}=4$ aa $\mathrm{s}^{-1}$, where the subscript at the rate constant indicated that this was the rate of elongation (e) of the first 70S ribosome $\left(1^{\mathrm{st}}\right)$ with an mRNA decoding phenylalanine with a UUU codon (UUU). The $5^{\mathrm{Q}} \mathrm{RBS}_{18 \mathrm{e}}(\mathrm{U})_{250}$ mRNA preparations resulted in a rather narrow length distribution poly $(U)(\approx 250 \mathrm{nt})$, as estimated from a high-resolution urea PAGE-gel, which code for around 80 Phe (Figure 4A). However, under the present experimental conditions we could only detect the incorporation of a maximum of 50-55 Phe, which resulted in enough translated codons to study ribosome loading frequencies, as the first ribosome moved sufficiently far away from the initiation site along the mRNA.

$5^{*} \mathrm{RBS}_{18 \mathrm{e}}(\mathrm{U})_{250}$ mRNA has similar length and sequence of the coding region as $5^{\mathrm{Q}} \mathrm{RBS}_{18 \mathrm{e}}(\mathrm{U})_{250}$ mRNA, but differ by the presence of a fluorescence dye rather than a non-fluorescent quencher at its $5^{\prime}$ end. $70 \mathrm{~S} \mathrm{IC}\left(5^{*} \mathrm{RBS}_{18 \mathrm{e}}(\mathrm{U})_{250} \mathrm{mRNA}\right)$ were mixed with the elongation machinery and at defined time points (5 s $-10 \mathrm{~min}$ ) the reaction was quenched and electrophoretically separated (Section 4.11.2). We visualized the product of translation on a Tricine-SDS PAGE gel, using a fluorescence label from the initiator tRNA (BodipyFL[ $\left.{ }^{3} \mathrm{H}\right] \mathrm{Met}^{-\mathrm{RRNA}}{ }^{\mathrm{fMet}}$ ) with which the 70S IC was formed (Figure 11B). This method not only allowed us to estimate the rate of elongation of this mRNA, but also showed the homogeneity of the translated labeled *Met(Phe) 80 peptide. A homogeneous fluorescence band, indicating the full-length product, appeared on the gel already after $30 \mathrm{~s}$. Based on the estimated length of the poly $(U)$ extensions for $5^{*} \mathrm{RBS}_{18 \mathrm{e}}(\mathrm{U})_{250}$ mRNA (Figure 4A) we could predict that 80 Phe were incorporated, which meant that the rate of elongation of this mRNA was $k_{\mathrm{e}} 1^{\text {st }} \mathrm{UUU}=3$ aa $\mathrm{s}^{-1}$. The rates of elongation of the two mRNAs presented here were similar, due to their similar coding sequence. 
(A)
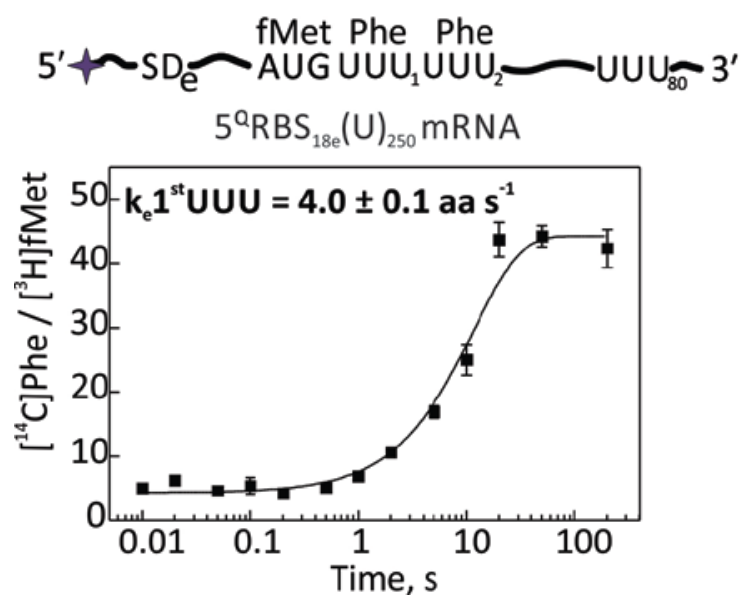

(B)

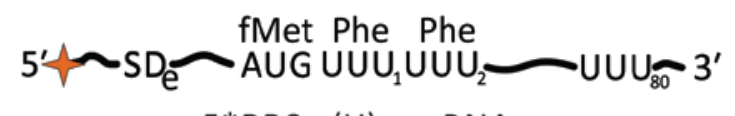

$$
5 * \mathrm{RBS}_{18 \mathrm{e}}(\mathrm{U})_{250} \mathrm{mRNA}
$$

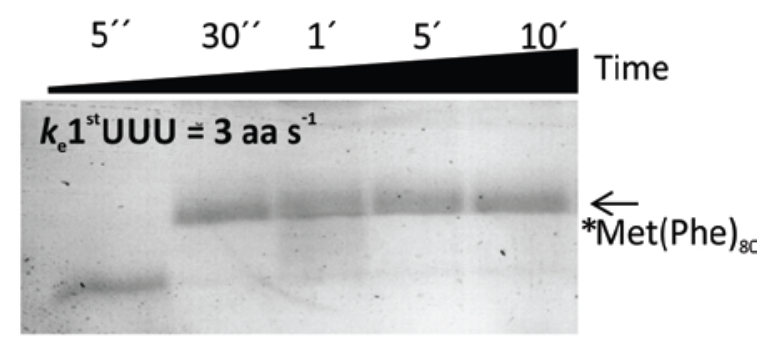

Figure 11. In vitro translation of $5^{\mathrm{Q}} \mathrm{RBS}_{18 \mathrm{e}}(\mathrm{U})_{250}$ and $5^{*} \mathrm{RBS}_{18 \mathrm{e}}(\mathrm{U})_{250} \mathrm{mRNAs}$.

(A) $70 \mathrm{~S} \mathrm{IC} \mathrm{programmed} \mathrm{with} 5^{\mathrm{O}} \mathrm{RBS}_{18 \mathrm{e}}(\mathrm{U})_{250}$ mRNA $(0.05 \mu \mathrm{M})$ and $\left[{ }^{3} \mathrm{H}\right] \mathrm{fMet}-\mathrm{RRNA}{ }^{\text {fMet }}$ were rapidly mixed with the elongation machinery with a TC labeled with $\left[{ }^{14} \mathrm{C}\right] \mathrm{Phe}-\mathrm{RRNA}{ }^{\text {Phe }}$. The ratio between pmol $\left[{ }^{14} \mathrm{C}\right] \mathrm{Phe} / \mathrm{pmol}\left[{ }^{3} \mathrm{H}\right] \mathrm{fMet}$ was plotted against time. The data were fitted with a one-exponential equation. The rate obtained was multiplied by the length of the end peptide and yielded $4.0 \pm 0.1$ aa s $\mathrm{s}^{-1}$. Error represents s.e.m. (B) $70 \mathrm{~S} \mathrm{IC}$ programmed with $5^{*} \mathrm{RBS}_{18 \mathrm{e}}(\mathrm{U})_{250}$ mRNA $(0.02 \mu \mathrm{M})$ and BodipyFL[ $\left.{ }^{3} \mathrm{H}\right] \mathrm{Met}-\mathrm{tRNA}{ }^{\mathrm{fMet}}$ were reacted with the elongation machinery at time points $(5 \mathrm{~s}-10 \mathrm{~min})$. The product was detected through the $\mathrm{N}$-terminal incorporation of fluorescence label attached at BodipyFL[ $\left.{ }^{3} \mathrm{H}\right] \mathrm{Met}-\mathrm{RRNA}{ }^{\mathrm{fMet}}$ with which the 7OS IC was formed. Tricine-SDS-PAGE gel was scanned on a Phosphorimager (Fla 9000). Schematics of the mRNAs used and their respected translated amino acid are shown on top.

In summary, we calculated the rates of elongation of $5^{\mathrm{Q}} \mathrm{RBS}_{18 \mathrm{e}}(U)_{250}$ and $5^{*} \mathrm{RBS}_{18 \mathrm{e}}(\mathrm{U})_{250}$ mRNAs by quantitative radioactive and qualitative (Tricine-SDS PAGE) methods. Both mRNAs were translated efficiently and were long enough to accommodate more than one translating ribosome, which made them excellent candidates for monitoring ribosome loading during polysome formation. Another advantage of these mRNAs was that since they were so long, we could uncouple the influence of the first elongating ribosome from the initiation by the second ribosome by allowing the first ribosome to move by 50-80 codons away from the initiation start.

Similar methodologies as above were used to characterize the rate of elongation of model mRNAs produced by the modified T7 RNA-polymerase in vitro transcription method and bearing fixed-length coding region ( $R B S_{20 e}(U U C)_{78 A A A} m R N A$ and $\left.5^{{ }^{\circ}} R_{B S} S_{20 e}(U U C)_{78} m R N A\right)$. Our first goal was to estimate the efficiency of full product synthesis. We probed the incorporation of a Lys residue $\left(28^{\text {th }}\right.$ position) preceded by methionine and 26 phenylalanine codons in a peptide with the help of a radioactive approach (Figure 12A). We mixed purified 70S IC ( $R B_{20 e}(U U C)_{78 A A A}$ mRNA) with the elongation machinery consisting of Phe-tRNA ${ }^{\text {Phe }}$ and labeled $\left[{ }^{14} \mathrm{C}\right]$ Lys-tRNA ${ }^{\text {Lys }}$ at different time points. The ratio between pmol $\left[{ }^{14} \mathrm{C}\right]$ Lys $/ \mathrm{pmol}\left[{ }^{3} \mathrm{H}\right] \mathrm{fMet}$ was 1 after $60 \mathrm{~s}$. This strongly indicated the commitment of the ribosome to reach the end of the repetitive sequence. The experimental setup was not only rapid, with translation rates comparable to those in vivo, but also robust, with very little or no ribosome drop-off. 
(A)

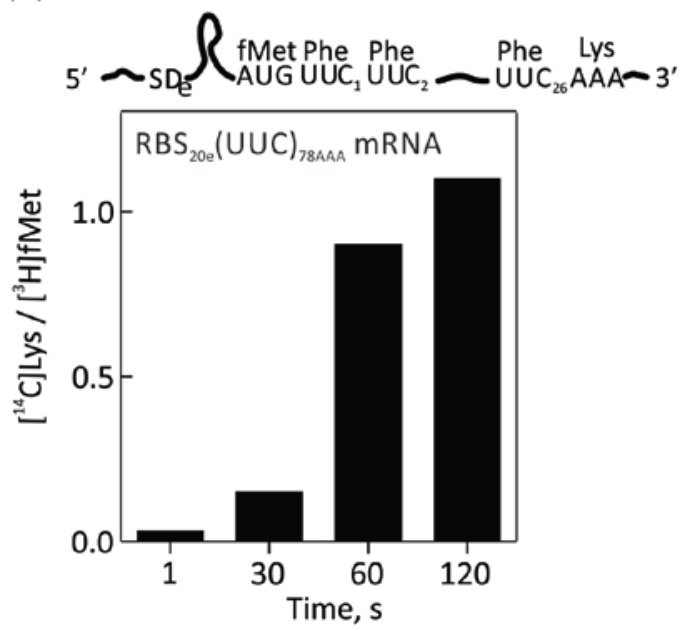

(C)

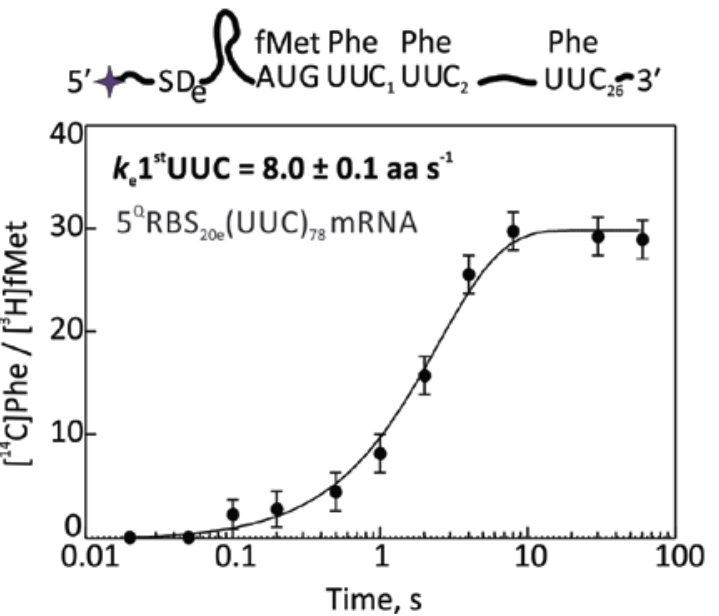

(B)

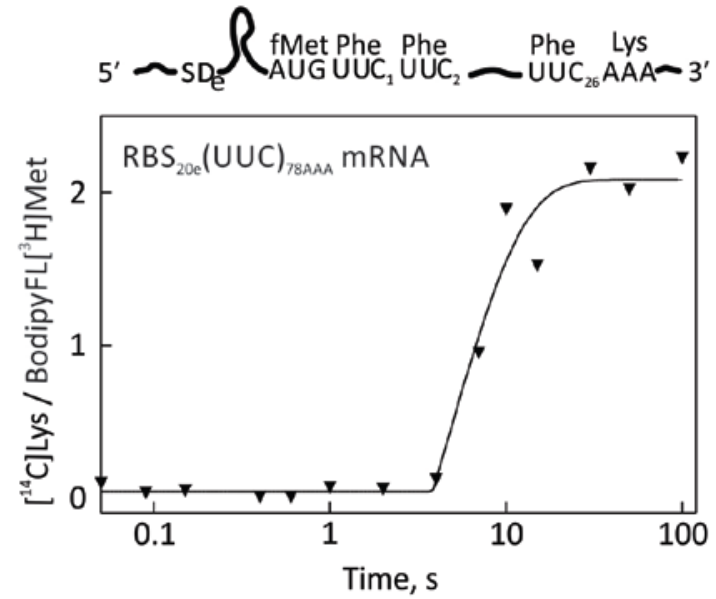

(D)

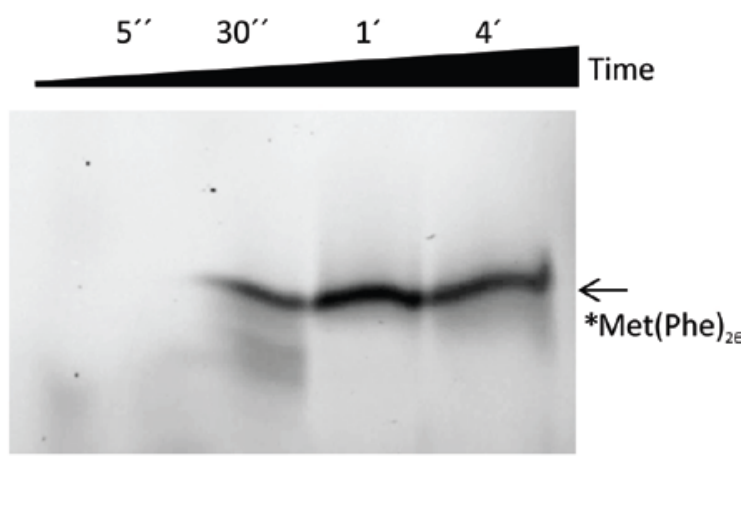

Figure 12. In vitro translation of $\mathrm{RBS}_{20 \mathrm{e}}(\mathrm{U})_{78 A A A}$ and $5^{\mathrm{Q}} \mathrm{RBS}_{20 \mathrm{e}}(\mathrm{U})_{78} \mathrm{mRNAs}$.

(A) In vitro translation of $\mathrm{RBS}_{20 \mathrm{e}}(\mathrm{UUCC})_{78 \text { AAA. }}$. The model mRNA was translated until the end of the 26th UUC codon as detected by the incorporation of a Lys (AAA codon). 70S IC $(0.16 \mu \mathrm{M})$ programed with $\mathrm{RBS}_{20 \mathrm{e}}(\mathrm{UUC})_{\text {78AAA }}$ and $\left[{ }^{3} \mathrm{H}\right] \mathrm{fMet}$-tRNA ${ }^{\mathrm{fMet}}$ were mixed with the elongation machinery with $\left.{ }^{14} \mathrm{C}\right]$ Lys-tRNA ${ }^{\text {Lys }}(0.24$ $\mu \mathrm{M})$ and unlabeled Phe-tRNA ${ }^{\text {Phe }}(8 \mu \mathrm{M})$. The ratio between pmol $\left[{ }^{14} \mathrm{C}\right]$ Lys $/ \mathrm{pmol}\left[{ }^{3} \mathrm{H}\right] \mathrm{fMet}$ was plotted against time. Cartoon of the $\mathrm{RBS}_{20 \mathrm{e}}(\mathrm{UUC})_{\text {78AAA }}$ mRNA (top). (B) $\mathrm{RBS}_{20 \mathrm{e}}(\mathrm{UUC})_{\text {78AAA }}$ mRNA translation in a quench flow apparatus. Same experimental set up as (A) except that unpurified 70S IC $(0.3 \mu \mathrm{M})$ programmed with $\mathrm{RBS}_{20 \mathrm{e}}(\mathrm{UUC})_{\text {78AAA }}$ and BodipyFL[ $\left.{ }^{3} \mathrm{H}\right]$ Met-tRNA ${ }^{\text {fMet }}$ were used. The ratio between pmol $\left[{ }^{14} \mathrm{C}\right]$ Lys / pmol Bodipy $\left.\mathrm{LL}^{3} \mathrm{H}\right]$ Met was plotted against time. The data was fitted to a model in which a delay preceding a oneexponential increase. The experiment was conducted by Dr. Wolf Holtkamp. (C) $5{ }^{{ }^{a} B S_{20 e}}(U U C)_{78} m R N A$ translation in a quench flow apparatus. $70 \mathrm{~S} I \mathrm{C}(0.015 \mu \mathrm{M})$ programmed with $5^{\mathrm{Q}} \mathrm{RBS}_{20 \mathrm{e}}(\mathrm{UUC})_{78} \mathrm{mRNA}$ and $\left[{ }^{3} \mathrm{H}\right]$ fMet-tRNA ${ }^{\text {fMet }}$ were mixed with the elongation machinery containing a TC with $\left[{ }^{14} \mathrm{C}\right]$ Phe-tRNA ${ }^{\text {Phe }}(8 \mu \mathrm{M})$. The ratio between pmol $\left[{ }^{14} \mathrm{C}\right]$ Phe $/ \mathrm{pmol}\left[{ }^{3} \mathrm{H}\right] \mathrm{fMet}$ was plotted against time. The data were evaluated with a oneexponential equation. The rate obtained was multiplied by the length of the final peptide, which yielded $8.0 \pm$ 0.1 aa s$^{-1}$. Error represents s.e.m. Cartoon of the $5^{\mathrm{C}} \mathrm{RBS}_{20 \mathrm{e}}(\mathrm{UUC})_{78}$ mRNA (top). (D) The mRNA $5^{\mathrm{Q}} \mathrm{RBS}_{20 \mathrm{e}}(\mathrm{UUC})_{78}$ was efficiently translated after $30 \mathrm{~s}$ to one homogeneous peptide ( $\left.{ }^{*} \mathrm{Met}(\mathrm{Phe}){ }_{26}\right)$. $70 \mathrm{~S} \mathrm{IC}(0.05 \mu \mathrm{M})$ programmed with $5^{\mathrm{Q}} \mathrm{RBS}_{20 \mathrm{e}}(\mathrm{U})_{78}$ mRNA and BodipyFL[ $\left.{ }^{3} \mathrm{H}\right]$ Met-tRNA ${ }^{\mathrm{fMet}}$ were mixed with the elongation machinery. The peptide was detected through the fluorescence label attached at BodipyFL $\left[{ }^{3} \mathrm{H}\right]$ Met-tRNA ${ }^{\text {fMet }}$ with which the $70 \mathrm{~S}$ IC was formed. Tricine-SDS-PAGE gel scanned on a Phosphorimager (Fla 9000). Schematics of the mRNAs used and their respected translated amino acid are shown on top. 
If we focus on the incorporation of the Lys at the end of the Phe coding sequence, a delay would be needed for the fast translation of the 26 Phe codons before the Lys would be decoded. A pre-steady steady state approach using the same experimental set up as above but with unpurified 70S IC with $\mathrm{RBS}_{20 \mathrm{e}}(\mathrm{UUC})_{\text {78AAA }}$ mRNA and BodipyFL[ $\left.{ }^{3} \mathrm{H}\right]$ Met-tRNA ${ }^{\mathrm{fMet}}$ resolved the delay time and the rate of Lys incorporation at codon $28^{\text {th }}$ (Figure $12 \mathrm{~B}$ ). The ratio between $\left[{ }^{14} \mathrm{C}\right]$ Lys $/ \mathrm{pmol}$ Bodipy $F\left[{ }^{3} \mathrm{H}\right]$ Met in this experimental set up reached $\approx 2$. This probably originated from non-initiated BodipyFL $\left.{ }^{3} \mathrm{H}\right]$ Met-tRNA ${ }^{\text {fMet }}$ precipitated on the filter when unpurified complexes were used. After $4 \mathrm{~s}$ the phenylalanine sequence had been translated, and the ribosome decoded the $\left[{ }^{14} \mathrm{C}\right] \mathrm{Lys}$-tRNA ${ }^{\text {Lys }}$ with a rate of $0.20 \pm 0.05 \mathrm{~s}^{-1}$.

A pre-steady state kinetics was essential to resolve the rapid poly(Phe) elongation rates of the $5^{\mathrm{Q}} \mathrm{RBS}_{20 \mathrm{e}}(\mathrm{UUC})_{78}$ mRNA. We mixed in a quench flow apparatus the $70 \mathrm{~S} \mathrm{IC}\left(5^{\mathrm{Q}} \mathrm{RBS}_{20 \mathrm{e}}(\mathrm{UUC})_{78} \mathrm{mRNA}\right)$ with TC containing labeled $\left[{ }^{14} \mathrm{C}\right]$ Phe-tRNA ${ }^{\text {Phe }}$ (Figure 12C). At each time point samples were collected, TCA precipitated and radioactively counted. The pmol $\left[{ }^{14} \mathrm{C}\right]$ Phe/pmol $\left[{ }^{3} \mathrm{H}\right] \mathrm{fMet}$ ratio was plotted against time. The rate of translation was fitted with a one-exponential equation. The resulted rate of $k_{\mathrm{e}} 1^{\text {st } U U C}=8$ aa s $^{-1}$, indicated that the ribosome binding site was efficiently cleared and ready for a subsequent ribosome recruitment. We visualized the peptide product of $70 \mathrm{~S}$ IC $\left(5^{\mathrm{Q}} \mathrm{RBS}_{20 \mathrm{e}}(\mathrm{UUC})_{78}\right.$ mRNA) translation on a Tricine-SDS PAGE gel, using a fluorescence label from the initiator tRNA (BodipyFL $\left[{ }^{3} \mathrm{H}\right] \mathrm{fMet}-\mathrm{tRNA}{ }^{\mathrm{fMet}}$ ) with which the 70S IC was formed (Figure 12D). A homogeneous fluorescence peptide, ${ }^{*}$ Met(Phe) ${ }_{26}$, appeared on the gel after $30 \mathrm{~s}$ confirming that the mRNA was translated efficiently.

Table 4. Summary of rates of poly(Phe) synthesis.

\begin{tabular}{|c|c|}
\hline mRNA, name & $\boldsymbol{k}_{\mathrm{e}} \mathbf{1}^{\text {st }}$, aa s $^{-1}$ \\
\hline $5^{\mathrm{Q}} \mathrm{RBS}_{18 \mathrm{e}}(\mathrm{U})_{250}$ & $4 \pm 0.1$ \\
\hline $5^{*} \mathrm{RBS}_{18 \mathrm{e}}(\mathrm{U})_{250}$ & 3 \\
\hline $5^{\mathrm{Q}} \mathrm{RBS}_{20 \mathrm{e}}(\mathrm{UUC})_{78}$ & $8.0 \pm 0.1$ \\
\hline
\end{tabular}

As a summary, all the 70S IC formed with model the mRNAs were translated efficiently to the respective peptides. The rate of elongation of all mRNAs was expected to be similar due to their similar elongation rates measured in vitro and in vivo (Rudorf et al., 2014). However, the $5^{\mathrm{Q}} \mathrm{RBS}_{18 \mathrm{e}}(\mathrm{U})_{250}$ and $5^{\mathrm{Q}} \mathrm{RBS}_{18 \mathrm{e}}(\mathrm{U})_{250}$ were translated nearly 2-fold slower than the mRNA with a fixed length and UUC coding sequence. The reason can be that the $5^{\mathrm{Q}} \mathrm{RBS}_{18 \mathrm{e}}(\mathrm{U})_{250}$ and $5^{\mathrm{Q}} \mathrm{RBS}_{18 \mathrm{e}}(\mathrm{U})_{250}$ have an undefined length of coding sequence, which was 3 -fold longer than the $5^{\mathrm{Q}} \mathrm{RBS}_{20 \mathrm{e}}(\mathrm{UUC})_{78} \mathrm{mRNA}$ or that decoding of UUC codons was faster than of UUU (Gromadski et al., 2006). It might be challenging to precisely define the number of codons translated with the present approach. Nonetheless, a single codon resolution of the in vitro translation system was not a prerequisite to monitor ribosome loading during polysome formation. The essential feature in this experiment was to show that the elongating 70S complexes rapidly and efficiently liberated the RBS, to allow the next initiation to proceed. 


\subsection{The first step of polysome formation in vitro in a minimal translation system.}

One of the main goals of the present study was to monitor the arrival of the second 30S PIC to the ribosome binding site while the first $70 \mathrm{~S}$ elongating complex was translating the mRNA. In section 2.4 we examined how the first ribosome moves forward in translation by detecting a single peptide per ribosome with the help of a quantitative radioactive approach and a qualitative TricineSDS PAGE gel. In this part, we aimed to establish a system where we can monitor not only the peptide from the first ribosome, but also the peptide synthesized by the following ribosome translating the same mRNA (Figure 13A). Translation elongation is a fast, continuous process. The availability of aminoacylated tRNA (aa-tRNA) substrate is crucial for the rate with which the protein synthesis proceeds. In order to avoid substrate depletion, a recharging Phe-tRNA ${ }^{\text {Phe }}$ aminoacylation system was introduced to the in vitro translation system (Section 4.16). Phenylalanyl-tRNA synthetase (PheRS) catalyzes the rapid transfer of phenylalanine to the respective tRNA ${ }^{\text {Phe }}$. The formation of a charged with Phe tRNA occurs in two steps: aminoacyl-adenylate intermediate is formed in an ATP-dependent manner followed by a aminoacyl transfer (Baltzinger and Holler, 1982).

We mixed 70S IC formed with model $\mathrm{RBS}_{20 \mathrm{e}}(\mathrm{UUC})_{\text {78AAA }}$ mRNA and $\left[^{3} \mathrm{H}\right] \mathrm{fMet}$-tRNA ${ }^{\text {fMet }}$ with a recharging aminoacylation system for Phe-tRNA ${ }^{\text {Phe }}$ delivering the needed substrate for the ongoing elongation. A mix of all the needed components for amino acylation were pre-incubated with a radioactively labeled $\left[{ }^{14} \mathrm{C}\right] \mathrm{Phe}$ amino acid, which was subsequently charged on the tRNA ${ }^{\text {Phe }}$ with the help of PheRS in vitro (Figure 13A). The successful aminoacylation was detected by the pmol $\left[{ }^{14} \mathrm{C}\right] \mathrm{Phe}$ / pmol $\left[{ }^{3} \mathrm{H}\right] \mathrm{fMet}$ ratio incorporated in the peptide over time. In order to detect the product from the following ribosomes we included in the same mix all the needed components for initiation, 30S subunits, 50 S subunits, fMet-tRNA ${ }^{\text {fMet }}$, IFs and GTP. The initiator tRNA was not labeled, so that the formation of the peptides from the following ribosomes were detected as an increase of the $\left[{ }^{14} \mathrm{C}\right] \mathrm{Phe}$ counts while the $\left[{ }^{3} \mathrm{H}\right] \mathrm{fMet}$ counts - delivered by the first ribosome - remained constant. We could predict from the coding sequence of the model mRNA (27 aa) and the footprint of the ribosome (10 aa) that at least three ribosomes can be accommodated on the mRNA. Given the absence of recycling factors and a stop codon, when the ribosome has decoded all the 26 Phe codons, it remained stalled at the end of the UUC sequence, freeing the RBS for another round of initiation and elongation. We detected over time an increase of the $\left[{ }^{14} \mathrm{C}\right]$ Phe counts over the $\left[{ }^{3} \mathrm{H}\right] \mathrm{fMet}$. After subtracting the length of the first peptide, assuming all ribosomes reached the end of the coding sequence, we calculated the $\left[{ }^{14} \mathrm{C}\right]$ Phe contribution from the following ribosomes to be $15-20$ Phe codons.

This assay clearly indicated that $\mathrm{RBS}_{20 \mathrm{e}}(\mathrm{UUC})_{78 \mathrm{AA}} \mathrm{mRNA}$ was active in poylsome formation and could accommodate at least two translating ribosomes. The result also demonstrated that, (i) the amino acylation recharging system delivered the required amounts of the Phe-tRNA ${ }^{\text {Phe }}$ substrate for the elongation and, (ii) the components of the reconstituted in vitro translation system were active in elongation and initiation. This approach, however, did not allow us to calculate the exact length of the following peptide nor the exact number of translating ribosomes ( 2 or 3 ) due to an intrinsic limitation of the detection method (TCA precipitation) (Section 4.15.2), which fails to account for very short peptides. 
(A)

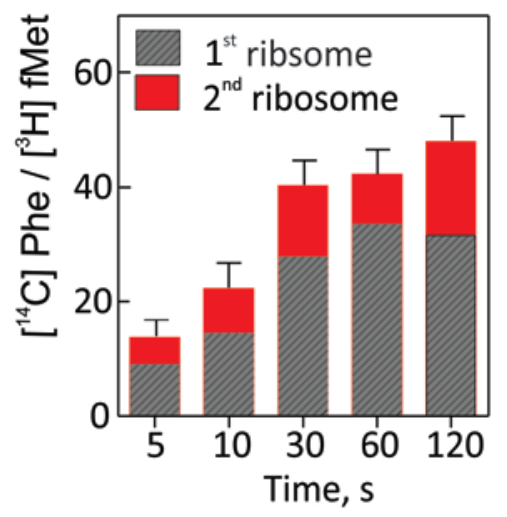

(C)

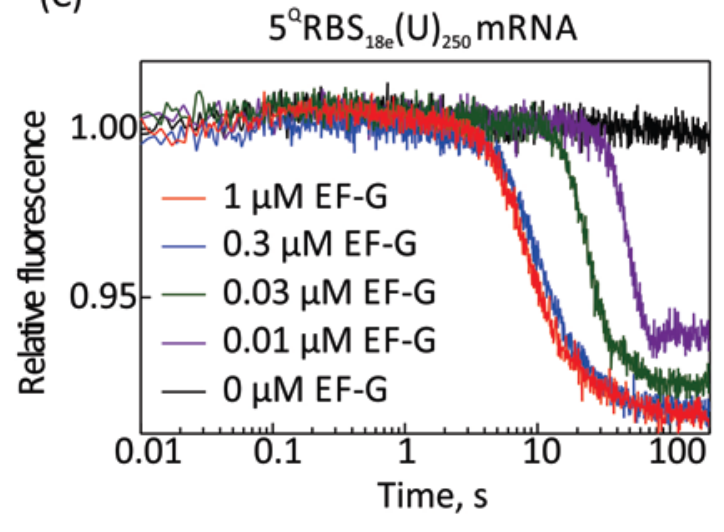

(E)

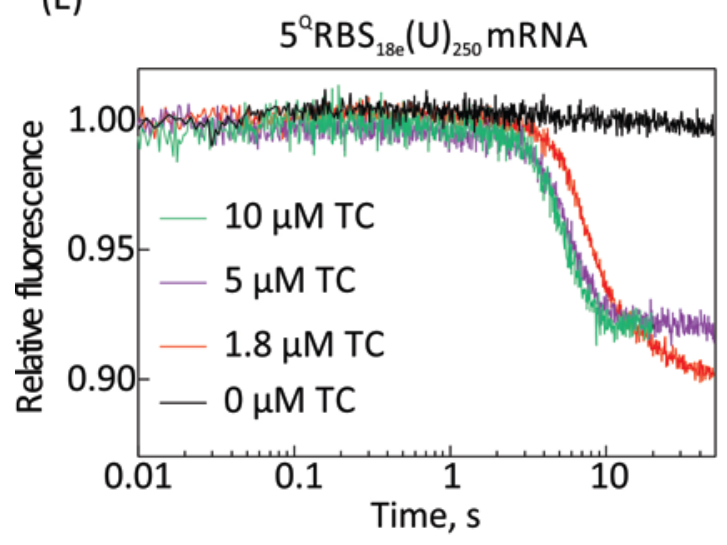

(B)

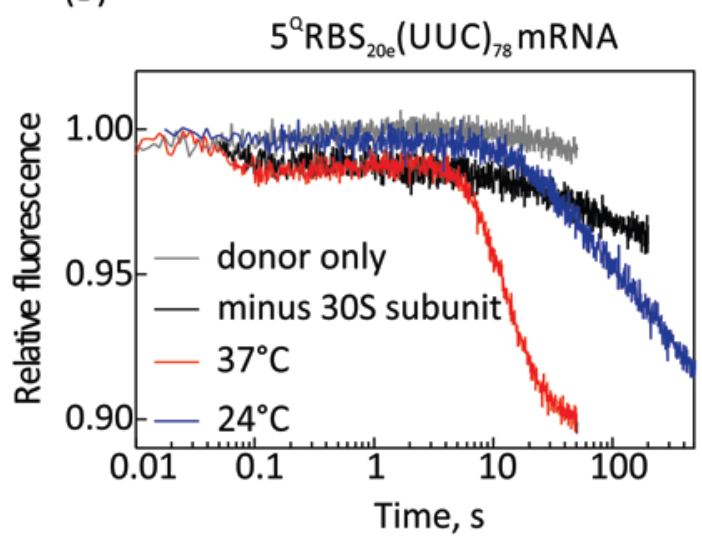

(D)

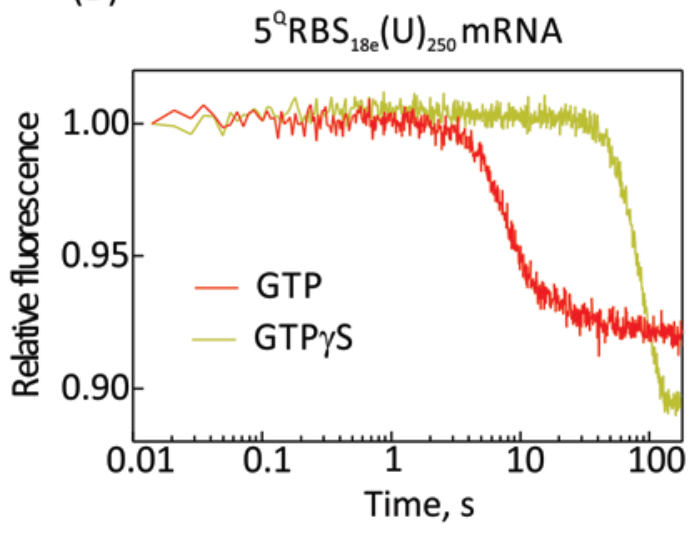

(F)

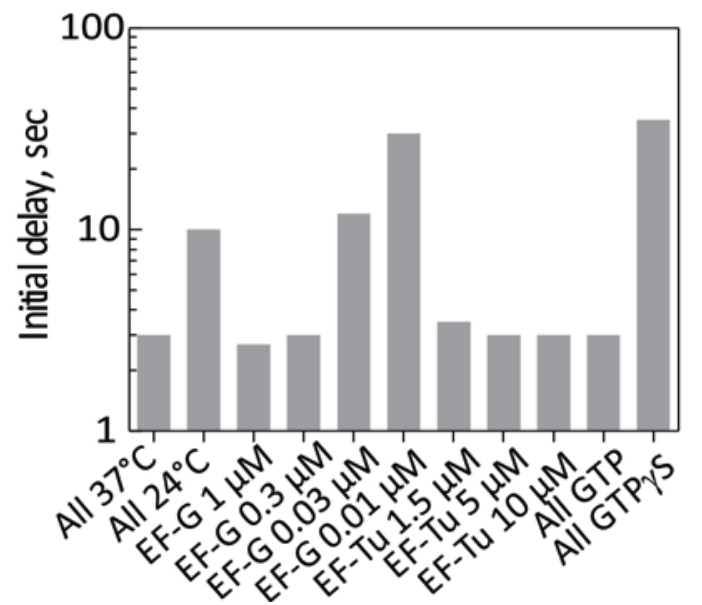

Figure 13. The first step of polysome formation in vitro in a minimal translation system

(A) Protein synthesis by the $1^{\text {st }}$ and $2^{\text {nd }}$ ribosome translating $R_{B S}$ 20e $(U U C)_{78 A A A}$ mRNA. 70S IC $(0.03 \mu M)$ programmed with $\mathrm{RBS}_{20 \mathrm{e}}(\mathrm{UUC})_{78 \mathrm{AAA}}$ and $\left[^{3} \mathrm{H}\right] \mathrm{fMet}-\mathrm{tRNA}{ }^{\text {fMet }}$ was mixed with the elongation machinery and the recharging aminoacylation machinery. The only labeled component was $\left[{ }^{14} \mathrm{C}\right]$ Phe $(30 \mu \mathrm{M})$. The ratio between pmol $\left[{ }^{14} \mathrm{C}\right] \mathrm{Phe} / \mathrm{pmol}\left[{ }^{3} \mathrm{H}\right] \mathrm{fMet}$ was compared in the absence (grey bars, $1^{\text {st }}$ ribosome) or presence (red bars, $2^{\text {nd }}$ ribosome) of $30 \mathrm{~S}$ subunits, 50S subunits, fMet-tRNA ${ }^{\text {fMet }}$, IFs and GTP ready to initiate and elongate. Error bars represent s.d. from 3 independent replicates. (B) Second initiation event taking place on an mRNA being 
translated. $70 \mathrm{~S} \mathrm{IC}\left(5^{\mathrm{Q}} \mathrm{RBS}_{20 \mathrm{e}}(\mathrm{UUC})_{78}\right.$ mRNA, $\left.0.05 \mu \mathrm{M}\right)$ mixed with the elongation machinery and 30S(IF3Alx488) PIC $(0.1 \mu \mathrm{M})$ at $37^{\circ} \mathrm{C}$ (red) or at $24^{\circ} \mathrm{C}$ (blue). No FRET signal change was observed when $30 \mathrm{~S}$ subunit was omitted from the reaction (black). Donor only control contained same components but the 70S IC was formed with a non-labeled $\mathrm{RBS}_{20 \mathrm{e}}(\mathrm{UUC})_{78}$ mRNA (grey). (C) The length of the delay preceding the FRET reaction was dependent on the concentration of EF-G. Same reaction as in (B) was monitored but the 70S IC was programmed with $5^{\mathrm{Q}} \mathrm{RBS}_{18 \mathrm{e}}(\mathrm{U})_{250}$ mRNA. EF-G concentrations ranged from $0.01 \mu \mathrm{M}$ to $1 \mu \mathrm{M}$, no EF-G present (black). (D) The in vitro translation could be globally slowed down by replacing the GTP (1 mM, red ), with a slowly-hydrolyzable GTP analog, i.e. GTP $\gamma \mathrm{S}(1 \mathrm{mM}$, yellow trace). (E) Same reaction monitored as in (C) with EF$\mathrm{G}(1 \mu \mathrm{M})$ but with different concentrations of TC (EF-Tu-GTP-Phe-tRNA ${ }^{\text {Phe }}$ ), $10 \mu \mathrm{M}$ (green), $5 \mu \mathrm{M}$ (purple), or 1.8 $\mu \mathrm{M}$ (red). No signal change was observed when no TC was added (black). (F) Analysis of the length of initial delay preceding the FRET change observed in Figure 13B-E. The prefix ALL before the reaction means that all the components needed for the second round initiation were present (Section 4.22).

Our next aim was to monitor in real-time, using a stopped flow apparatus, the arrival of the second ribosome to the RBS just cleared by the elongating, first ribosome. To examine the influence of single components from the elongation machinery, in the following experiment we did not include the recharging aminoacylation system, rather we utilized purified Phe-tRNA ${ }^{\text {Phe }}$. We combined the advantages of FRET and rapid mixing approaches to focus on the 30S PIC binding to the mRNA after the first ribosome moved forward in translation (Figure 13B-E). We used purified 70S ICs, where the first ribosome covers the RBS of the $5^{\prime}$ ATTO540Q mRNA. These complexes were rapidly mixed with the complete elongation machinery (EF-Tu, Phe-tRNA ${ }^{\text {Phe }}$, EF-G, EF-Ts and GTP) and with 30 S PIC formed with IF3(Alx488), to best simulate the first step of polysome formation in vitro in a minimal translation system (Figure 13B-E). The fluorescence signal between the non-fluorescent acceptor on the $5^{\prime}$-end of the $5^{\mathrm{Q}} \mathrm{RBS}_{20 \mathrm{e}}(\mathrm{UUC})_{78}$ mRNA and the donor IF3(Alx488) bound to the $30 \mathrm{~S}$ subunit was followed in time (Figure 13B). Upon translation, no signal change was observed for about $3 \mathrm{~s}$, followed by a decrease in FRET. The decrease of fluorescence intensity after the delay meant that the 5 '-end bearing the quencher has become accessible for interaction. The only compound caring fluorescence in the reaction was the 30S(IF3Alx488) PIC. Therefore, we could conclude that the decrease of fluorescence represented binding of the 30S PIC near the quencher at the 5 '-end of the mRNA. This could only happen after the clearance of the ribosome binding site which took place during translation elongation. The maximum fluorescence amplitude was around $10 \%$, with the final fluorescence stable over a $30 \mathrm{~s}$ time range. IF3(Alx488) did not change fluorescence in the absence of non-fluorescent acceptor (donor only), or in the absence of $30 \mathrm{~S}$ subunit recruiting the mRNA (Figure 13B-grey and black). Upon translation at $24^{\circ} \mathrm{C}$, we observed that the initial delay was 4 -fold longer and the reaction was overall slowed down (Figure 13B-blue). This fundamental controls ensured that the FRET signal change was solely due to recruitment of the second 30S(IF3Alx488) PIC, confirming the specificity of the FRET pair in a crowded environment. The delay preceding the fluorescence signal change was likely to represent the time needed for the RBS clearance from the first ribosome to occur. We tested this hypothesis by modulating the speed of translation elongation of the first ribosome. The FRET signal between $5^{\mathrm{Q}} \mathrm{RBS}_{18 \mathrm{e}}(\mathrm{U})_{250} \mathrm{mRNA}$ and $30 \mathrm{~S}(\mathrm{IF3AIx488)}$ PIC was followed in real time. When we supplemented the reaction with limiting amounts of EF-G $(0.01 \mu \mathrm{M})$ (Figure 13Cpurple), a dramatic slowdown of translation elongation increased the duration of the initial delay (10fold) in comparison to a reaction where a higher concentration of EF-G $(1 \mu \mathrm{M})$ was used (Figure 13Cred). As a result, the timing of the second ribosome initiation was also 10-fold slower. When the 
system was deprived of EF-G which is an essential factor for translation, the FRET signal assigned to the second round of initiation, was not observed, supporting the conclusion that the initial delay represented the first 70S elongating complex moving forward along the mRNA (Figure 13C-black). A similar phenomenon was observed when we formed the TC with the slowly-hydrolysable analog of GTP (i.e. GTP $y$ S). Again, more than 10-folds increase in the length of the delay was observed with GTP $\gamma S$ in comparison to a reaction with GTP (Figure 13D), slowing down the timing of the second round initiation by more than $30 \mathrm{~s}$ in comparison to $3 \mathrm{~s}$ with GTP. Likely GTP was also present in the system, bound to purified EF-G. Varying the concentration of Phe-tRNA ${ }^{\text {Phe }}$ in a TC with EF-Tu and GTP over a wide range $(1.5-10 \mu \mathrm{M}$, Figure 13E), in the presence of saturating amounts of EF-G and GTP, did not dramatically affected the fluorescence delay $(3 \mathrm{~s})$ whereas the absence of TC abolished the FRET signal. We observed that the frequency of initiation (the delay) could not have been speed up as drastically as it was slowed down (Figure 13F), which may suggest that there is a maximum frequency of initiation (3-4 s) under saturating condition of the elongation machinery or a maximum speed of elongation in the in vitro translation system.

In summary, these experiments monitored in real-time the loading of the second 30S PIC on two model mRNAs, $5^{\mathrm{Q}} \mathrm{RBS}_{20 \mathrm{e}}(\mathrm{UUC})_{78}$ and $5^{\mathrm{C}} \mathrm{RBS}_{18 \mathrm{e}}(\mathrm{U})_{250}$, during translation. The time needed for the ribosome clearance to occur and the second ribosome to initiate binding was 3-4 s for either mRNAs. This result is in agreement with in vivo data obtained by two independent approaches where the successive ribosomes were loaded on the mRNA with an interval of 2-4 s (Kennell and Riezman, 1977; Sorensen and Pedersen, 1991). We conclude that the frequency of ribosome recruitment was dependent on the translation elongation speed of the first ribosome. A detailed kinetic analysis is needed to address the interplay between the rate of elongation and initiation in the model system and the rate of second initiation event between different model mRNAs. 


\subsection{Kinetic model of second round initiation.}

\subsubsection{Theoretical considerations}

The rate at which each ribosome is loaded on the mRNA and the ribosome density along the mRNA sequence are key components of the regulation on the translation level. While individual steps of the translation elongation and initiation cycles have been kinetically dissected, a global understanding of how these phases proceed together in polysomes is unknown. In this section we present a kinetic model that solves the kinetic mechanism of translation elongation on the first ribosome and the translation initiation by the second ribosome simultaneously by a global fitting approach. The model is based solely on the mRNAs experimental designs possessing (i) efficient, labeled initiation region, which reports the recruitment of the 30S PIC and (ii) repetitive coding sequence, reporting the rate of elongation of the first ribosome. As showed in Section 2.5, a typical signal for the second round initiation contained kinetic information which was divided into two main processes: the first one - corresponding to the delay preceding the FRET change - was assigned to the translation elongation of the first ribosome; whereas the second one - represented by the decrease in the FRET signal - was assigned to the arrival of the 30S PIC to the 5'-end of the mRNA being translated. In the next section, the two parts of the global fit model are described separately, but belong to the same global kinetic model (M1) (Figure 14).

The first part of the global fit model (Figure 14-M1.1) was based upon the experimental data and minimal theoretical assumptions. The combination of experimental design and detail characterization of $70 \mathrm{~S}\left(5^{\mathrm{Q}} \mathrm{RBS}_{20 \mathrm{e}}(\mathrm{UUC})_{78}\right.$ mRNA) elongation complexes allowed us to model each translated UUC codon by the first ribosome with the same elemental rate $\left(k_{\mathrm{e}} 1^{\text {st } U U C)}\right.$. We consider that no programmed ribosomal pausing and no secondary structures are present in the coding region. The elongation of UUC codons proceeds only in the forward direction, since we utilize only cognate Phe-tRNA ${ }^{\text {Phe }}$, no dissociation of the ternary complex is considered $\left(k_{-} 1^{1 \text { st } U U C=0}\right)$. Assuming an elongation rate of 8 aa $\mathrm{s}^{-1}$ and the length of the mRNA, which maximally accommodates 26 Phe codons (Figure 12C), in a 3-4 s time range, the first ribosome will translate 24-26 aa. We infer that the ribosome is committed to translate till the end the repetitive UUC sequence, considering that a Lys codon incorporation into the end of the poly(Phe) peptide chain (i.e. position 28) occur efficiently also after 3-4 s (Figure 12B). Given these experimental observations, we included in the first part of the kinetic model (M1.1) 26 identical irreversible steps corresponding to the delay preceding the FRET change, representing the irreversible translation of the poly(UUC) sequence into a poly(Phe) peptide. 
(M1.1)

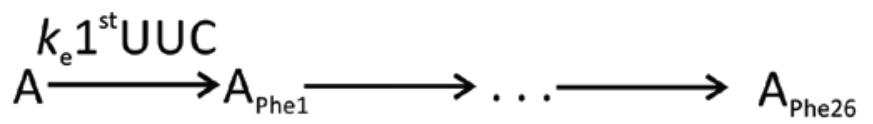

(M1.2)

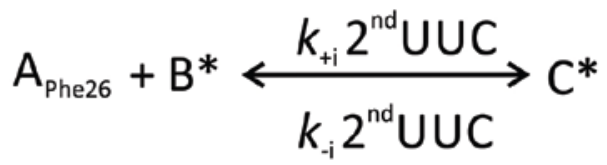

(M2)

$$
\mathrm{A}_{\text {Phe26 }} \text { Post }+\mathrm{B}^{*} \underset{k_{\mathrm{i}} 2^{\text {nd }} \text { UUCPost }}{\stackrel{k_{\mathrm{fi}} 2^{\text {nd }} U \text { UCPost }}{\longrightarrow}} \mathrm{C}^{*}
$$

(M3)

$$
\mathrm{A}_{\text {phe }} \text { Post }+\mathrm{B}^{*} \underset{k_{\mathrm{i}} 2^{\text {nd }} \text { UUUPost }}{\stackrel{k_{+2} 2^{\text {nd }} \text { UUUPost }}{\longrightarrow}} \mathrm{C} * \underset{k_{\mathrm{i}} 2^{\text {nd }} \text { UUUPost2 }}{\stackrel{k_{+1} 2^{\text {nd }} \text { UUUPost2 }}{\longrightarrow}} \mathrm{D}^{*}
$$

\section{Figure 14. Kinetic models for second round initiation.}

We implemented the following steps occurring in the minimal in vitro translation system with the help of global kinetic modeling. (M1.1) Translation starts with synchronized 70S IC (A) and its elongation $\left(k_{\mathrm{e}} 1^{\text {st }} \mathrm{UUC}\right)$ proceeds only in the forward reaction $\left(k_{-e} 1^{\text {st }} \cup U C=0\right)$, decoding one UUC codon after another $\left(A_{\text {phe1 }}\right.$ to $\left.A_{\text {phe26 }}\right)$, and yielding a Phe polypeptide. (M1.2) 30S PIC (B*) finds the available $5^{\prime}$-end of the mRNA and binds the RBS with a rate constant $k_{+} 2^{\text {nd }} U U C$ and dissociates with rate constant $k_{-i} 2^{\text {nd }} U U C$. The process ends with an mRNA carrying a $70 S$ in the elongation phase and a $30 \mathrm{~S}$ subunit in the initiation phase $\left(\mathrm{C}^{*}\right)$. Observables denoted with a $\left(^{*}\right)$ carry fluorescence reporters. Model (M2) represents the 30S PIC recruitment to a post-translational complex ( $A_{\text {Phe26 }}$ Post), comprised of a $70 \mathrm{~S}$ ribosome which has already translated the entire poly(UUC) sequence. Association and dissociation constants are expressed as $k_{+i} 2^{\text {nd }} U U C P o s t$ and $k_{-i} 2^{\text {nd }} U U C P o s t$, respectively. Model (M3) represents the 30S PIC recruitment to a post-translational complex ( $A_{\text {phe }}$ Post), comprised of a $70 \mathrm{~S}$ ribosome which has already translated the entire poly(UUU) sequence. Association and dissociation constants are expressed as $k_{++2} 2^{\text {nd }}$ UUUPost and $k_{-i} 2^{\text {nd }}$ UUUPost, respectively. The complex rearranges with elemental rates $k_{+} 2^{\text {nd }}$ UUUPost2 and $k_{-i} 2^{\text {nd }}$ UUUPost2 to complex (D*).

We modeled the second part of the FRET signal as the arrival of the 30S PIC to the 5 '- end of the mRNA being translated (Figure 14-M1.2). Translation initiation is a very well characterized multistep process (Milon and Rodnina, 2012). Our model simplifies this process to one particular step, the arrival of the 30S PIC to the RBS to reversibly initiate translation. This reaction was modeled as a bimolecular binding between the RBS of an mRNA being translated $\left(A_{\text {Phe26 }}\right)$ and the initiating 30S PIC $\left(\mathrm{B}^{*}\right)$ with elemental rates $k_{+\mathrm{i}} 2^{\text {nd }} \mathrm{UUC}$ and $k_{-\mathrm{i}} 2^{\text {nd }} \mathrm{UUC}$, respectively. The final product of the reaction is an mRNA carrying one 70S elongating ribosome and a 30S PIC in its initiation phase (C*) (Figure 14M1.2). Later steps in the translation initiation pathway (i.e. initiator tRNA accommodation or subunit joining) have not been considered during this study, but can potentially be measured and included into the model. Modulating the number of steps (adding or removing) preceding the bimolecular reaction, which reflects the number of codons translated from the first ribosome, did not affect the 
value for the elemental rate of $k_{+_{i}} 2^{\text {nd }}$ UUC. Overall, the presented kinetic model (M1) allows us to calculate the rate of the first step in polysome formation with different mRNAs, focusing on the initiation phase of translation. We can also test whether the first ribosome, which has already selected and translated the desired mRNA alter the rate of subsequent initiation event on the same message. For this purpose we modeled the reaction where the first ribosome that has already translated the mRNA, and the resulting 70S Post elongation complex ( $A_{\text {Phe26 }}$ Post) recruit the 30S PIC $\left(\mathrm{B}^{*}\right)$ in a reversible manner with elemental rates $k_{+_{\mathrm{i}}} 2^{\text {nd }}$ UUCPost and $k_{-i} 2^{\text {nd }}$ UUCPost, respectively (Figure 14-M2). Comparison between $k_{+_{i}} 2^{\text {nd }}$ UUC and $k_{+_{i}} 2^{\text {nd }}$ UUCPost elemental rates provides an estimate for the influence of ongoing translation elongation on the second initiation event.

Model 3 was designed for mRNAs: $5^{\mathrm{Q}} \mathrm{RBS}_{18 \mathrm{e}}(\mathrm{U})_{250}$ and $5^{*} \mathrm{RBS}_{18 \mathrm{e}}(\mathrm{U})_{250}$, which possess long poly(U) extensions as coding sequences. For simplicity we used the same abbreviations as above, i.e. UUU replaces UUC in the name of the elemental rates (i.e. $k_{+_{i}} 2^{\text {nd }}$ UUU). When we utilized complexes with $5^{*} \mathrm{RBS}_{18 \mathrm{e}}(U)_{250}$ mRNA we added a $\left({ }^{*}\right)$ next to the name of the rate (i.e. $k_{+_{\mathrm{i}}} 2^{\text {nd }} \mathrm{UUU}$ and $k_{+} 2^{\text {nd }}$ UUUPost*). The 70S Post elongation complex is expected to incorporate roughly 50 or 80 Phe when we use mRNAs $5^{\mathrm{Q}} \mathrm{RBS}{ }_{18 \mathrm{e}}(\mathrm{U})_{250}$ or $5^{*} \mathrm{RBS}_{18 \mathrm{e}}(\mathrm{U})_{250}$, respectively (Figure 11). That is why in Model (M3) we abbreviate the complex ( $A_{\text {Phe }}$ Post) without a specification of the number of Phe translated (Figure 14-M3). The reversible binding of a $30 \mathrm{~S} \mathrm{PIC}\left(B^{*}\right)$ to the $\left(A_{\text {Phe }}\right.$ Post) will result in elemental rates $k_{+_{\mathrm{i}}} 2^{\text {nd }}$ UUUPost and $k_{-\mathrm{i}} 2^{\text {nd }}$ UUUPost. We added a rearrangement step after the bimolecular binding reaction ( $\left.D^{*}\right)$, when we use $30 \mathrm{~S}(\mathrm{IF} 3 \mathrm{~A} / \mathrm{lx} 488) \mathrm{PIC}$, resulting in elemental rates $\left(k_{\mathrm{t}_{i}} 2^{\text {nd }}\right.$ UUUPost2 and $k_{\text {. }}$ $2^{2}$ Ud UUUPost2). In this case, we consider the examined kinetic behavior of IF3(Alx488) on the $30 \mathrm{~S}$ subunit upon the first mRNA recruitment which resulted in a multiphasic fluorescence trace (Figure 10). In all the following results we assumed that all the complexes are stable and set the values of the dissociation rate constants to 0 in the global fitting models.

In the next sections we apply the global kinetic models in order to solve the rate constants that govern polysome formation in a minimal in vitro translation system with three different mRNAs. A major emphasis was given to the differences between the elemental rates of co- and posttranslational 30S PIC recruitment of the MRNA, in comparison to the same ones obtained with an mRNA during the first initiation event. Considering that the model mRNAs possess different mechanism of the first recruitment event, contributed by the sequence around the RBS, we also examined how the first ribosome affects the conformation of the $5^{\prime}$-end of the mRNA upon RBS clearance. 
2.6.2. $5^{\mathrm{Q}} \mathrm{RBS}_{20 \mathrm{e}}(\mathrm{U})_{78}$ mRNA recruited the first and the second ribosome with a similar rate

Here we tested the recruitment of $30 \mathrm{~S}(\mathrm{Al} \times 488)$ subunit to the $5^{\mathrm{a}} \mathrm{RBS}_{20 \mathrm{e}}(\mathrm{U})_{78}$ mRNA during ongoing translation by the leading ribosome. As determined from the first recruitment event, this mRNA has a predicted secondary structure around the RBS which affected its initiation rate (Figure 8). Because we start with synchronized $70 S$ IC, we are confident that the first ribosome was recruited to the RBS in order to position the initiator tRNA properly. During translation, the mRNA will exit out of the mRNA channel and may start folding back to its initial conformation or to an alternative conformation induced by the first ribosome. We used the same experimental set up as in Section 2.5, as we rapidly mixed $70 \mathrm{~S} \mathrm{IC}\left(5^{\mathrm{a}} \mathrm{RBS}_{20 \mathrm{e}}(\mathrm{U})_{78} \mathrm{mRNA}\right)$ with the elongation machinery and the $30 \mathrm{~S}$ (Alx488) PIC. The fluorescence signal obtained was similar to that shown in Figure 13, with a delay of 3-4 $\mathrm{s}$, followed by a decrease in fluorescence (Figure 15A-red). The FRET signal was fitted with model M1 (Figure 14). Important information contained in the delay preceding the FRET signal change was its duration (abbreviated as $t_{\mathrm{f}} 2^{\text {nd }}$ ). It represents the time the first ribosome needs to translate a certain number of codons, sufficient to clear the region surrounding the AUG start, which allows the second round initiation to begin. When we compared the fluorescence signal describing the arrival of the $30 \mathrm{~S}$ PIC to the 5 '-end of the mRNA with the radioactive signal reporting on the rate of translation elongation of Phe codons by the first ribosome, we observed that after 3-4 s the first ribosome has translated the full peptide (Figure 15A). This timing was matching with the frequency of second round initiation, namely the beginning of the FRET signal decrease. Taking into account the measured rate of first ribosome translation (i.e. 8 aa s$^{-1}$ ) we can estimate that in a time range of 3-4 s (i.e. the length of the delay preceding the FRET change) 24-26 Phe have been incorporated, as the mRNA ends after the $26^{\text {th }}$ UUC codon. This result is in agreement with structural and in vivo data estimating one ribosome every 24 aa (72 nt) in prokaryotes (Brandt et al., 2009).

Another process that occurs during the in vitro translation was the recruitment of the second 30 S PIC to the 5'-end of the mRNA. The decrease of FRET signal can only occur after the first ribosome has cleared the surrounding of the RBS. We fitted the obtained FRET signal with the minimally constructed model (Figure 14M1.1) and derived two elemental rates. $k_{\mathrm{e}} 1^{\text {st }} \mathrm{UUC}$ describing 26 repetitive irreversibly steps was 5 aa $\mathrm{s}^{-1}$. The last step - represented by a bimolecular binding reaction in model (Figure 14M1.2) - resulted in the association rate constant $k_{\mathrm{t}_{\mathrm{i}}}{ }^{\text {nd }} \mathrm{UUC}=0.5 \mu \mathrm{M}^{-1} \mathrm{~s}^{-}$ ${ }^{1}$. This rate was best described with one step, as determined in the first recruitment assay with the same mRNA (Figure 9F). 


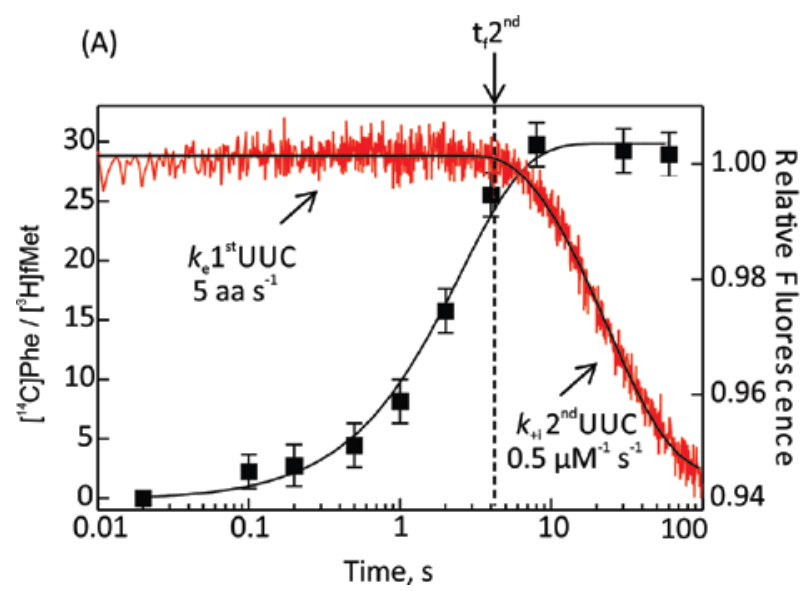

(B)

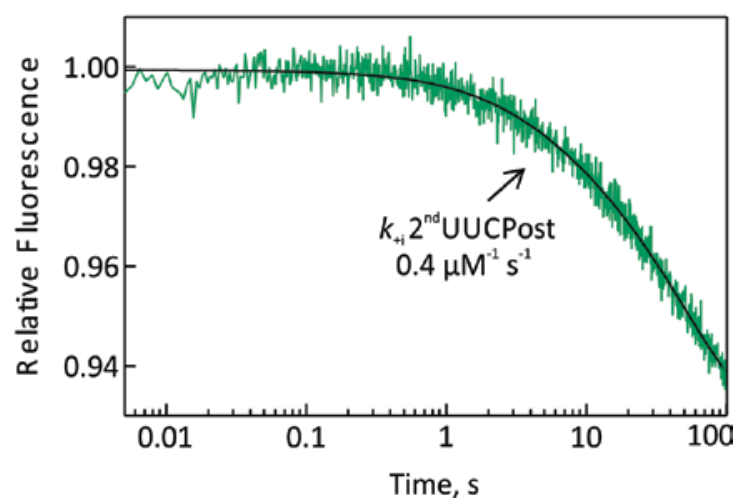

Figure 15. Co- and post- translational monitoring of 30 (Alx488) PIC recruitment to $5{ }^{\mathrm{Q}} \mathrm{RBS}_{20 \mathrm{e}}\left(\mathrm{UUC} \mathrm{C}_{78} \mathrm{mRNA}\right.$.

(A) FRET between a non-fluorescent acceptor on the $5^{\prime}$-end of the MRNA and donor on the 30S (Alx488) subunit was followed in time in a stopped flow apparatus (red trace). We mixed $\left.70 \mathrm{~S} \mathrm{IC} \mathrm{(} 5^{\mathrm{Q}_{\text {RBS }}} \mathrm{Ce}_{20}(\mathrm{UUC})_{78} \mathrm{mRNA}\right)(0.05$ $\mu \mathrm{M})$ with the elongation machinery and the $30 \mathrm{~S}(\mathrm{Alx} 488) \mathrm{PIC}(0.1 \mu \mathrm{M})$. The black squares represent time points of Phe incorporation of $70 \mathrm{~S} \mathrm{IC} \mathrm{programed} \mathrm{with} \mathrm{the} \mathrm{same} \mathrm{mRNA:}\left(5^{\mathrm{Q}} \mathrm{RBS}_{20 \mathrm{e}}(\mathrm{UUC})_{78}\right)$ fitted with single exponential equation, data from as Figure $12 \mathrm{C}$. Elemental rate constants $k_{\mathrm{e}} 1^{\text {st }} \mathrm{UUC}\left(5 \pm 0.2\right.$ aa $\left.s^{-1}\right)$ and $k_{+_{i}} 2^{\text {nd }}$ UUC $\left(0.5 \pm 0.2 \mu \mathrm{M}^{-1} \mathrm{~s}^{-1}\right)$ were obtained using model (M1) (Figure 14). Smooth black line represents the global fit. $\mathrm{t}_{\mathrm{f}} 2^{\text {nd }}$ $=$ translation initiation frequency depicted as a dashed line. (B) $70 S$ IC $\left(5^{{ }^{a}} R_{B S} S_{20 e}(U U C)_{78}\right.$ mRNA $)(0.05 \mu M)$ cleared the RBS after mixing with the elongation machinery and incubation for $2 \mathrm{~min}$ at $37^{\circ} \mathrm{C}$. The resulting $70 \mathrm{~S}$ post-translation complex was mixed with the 30S(Alx488) PIC $(0.1 \mu \mathrm{M})$. The elemental rate constant $k_{+}{ }^{2}{ }^{\text {nd }}$ UUCPost $\left(0.40 \pm 0.02 \mu \mathrm{M}^{-1} \mathrm{~s}^{-1}\right)$ was obtained with model M2 (Figure 14). Smooth black line represents the global fit

The post-translational state of the mRNA RBS was probed with an assay where we allowed the 70S IC to translate the $5^{\mathrm{Q}} \mathrm{RBS}_{20 \mathrm{e}}(\mathrm{UUC})_{78}$ mRNA untill the end, supplying it with all necessary elongation machinery and incubating the reaction for $2 \mathrm{~min}$ at $37^{\circ} \mathrm{C}$. This ensured that the first ribosome had liberated the ribosome binding site. The resulting $70 \mathrm{~S}$ post translation complex was mixed with the 30S(Alx488) PIC. We observed a fluorescence signal representing the binding the $30 \mathrm{~S}$ PIC to the 5 '-end bearing the non-fluorescent acceptor (Figure 15B). We globally fitted the signal with Model (M2) (Figure 14). The calculated rate of 30S PIC recruitment to the translated mRNA $k_{+_{\mathrm{i}}} 2^{\text {nd }}$ UUCPost $=0.4 \mu \mathrm{M}^{-1} \mathrm{~s}^{-1}$ was similar to that estimated for an mRNA being translated $k_{\mathrm{i}} 2^{\text {nd }} \mathrm{UUC}=$ $0.5 \mu^{-1} \mathrm{~s}^{-1}$. This result suggested that the $30 \mathrm{~S}$ PIC was recruited with a similar rate to $5^{\mathrm{a}} \mathrm{RBS}_{20 \mathrm{e}}(\mathrm{UUC})_{78}$ mRNA containing a stalled $70 \mathrm{~S}$ ribosome 26 Phe away from the RBS and to $5^{\mathrm{Q}} \mathrm{RBS}_{20 \mathrm{e}}(\mathrm{UUC})_{78} \mathrm{mRNA}$ being actively translated. The elemental rate of the first recruitment to the free $5^{\mathrm{Q}} \mathrm{RBS}_{20 \mathrm{e}}(U \cup C)_{78} \mathrm{mRNA}$ was also similar, $1.1 \mu \mathrm{M}^{-1} \mathrm{~s}^{-1}$ (Table 2). This can be explained by the fact that the RBS of $5^{\mathrm{Q}} \mathrm{RBS}_{20 \mathrm{e}}(\mathrm{UUC})_{78}$ mRNA already translated and possessing a ribosome along its sequence has returned to its initial state and it is ready for another cycle of initiation. 
2.6.3. $5^{\mathrm{a}} \mathrm{RBS}_{18 \mathrm{e}}(\mathrm{U})_{250}$ mRNA differed in the rates of the first and second $30 \mathrm{~S}$ PIC recruitment.

It is expected that the frequencies of translation initiation events will vary for different mRNAs. To test this contention, we used the established translation system with the $5^{\mathrm{a}} \mathrm{RBS}_{18 \mathrm{e}}(\mathrm{U})_{250}$ and $5 * \mathrm{RBS}_{18 \mathrm{e}}(\mathrm{U})_{250}$ mRNAs labeled with a non-fluorescent acceptor and with a fluorescence dye, respectively. They possess undefined length of Phe codons (UUU). These mRNAs recruited the $30 \mathrm{~S}$ PIC 10-fold faster than the $5^{\mathrm{Q}} \mathrm{RBS}_{20 \mathrm{e}}$ (UUC) 78 mRNA due to their open RBS (Figure 9A-D). On one hand, the $5^{\mathrm{Q}} \mathrm{RBS}_{18 \mathrm{e}}(\mathrm{U})_{250}$ and $5 * \mathrm{RBS}_{18 \mathrm{e}}(\mathrm{U})_{250} \mathrm{mRNAs}$ length did not restrict the first ribosome at exactly $24-26$ aa away from the RBS, but rather allowed it to elongate at least 2-fold further along on the mRNA, keeping the same repetitive, coding potential as $5^{a} \mathrm{RBS}_{20 \mathrm{e}}(U U C)_{78}$ mRNA. On the other hand, the rate of elongation by the first ribosome was more undefined since these mRNAs does not have a fixed length of the $3^{\prime}$ end (Section 2.4). In order to simulate the first step of polysome formation on these mRNAs, we mixed the 70S IC $\left(5^{\mathrm{Q}} \mathrm{RBS}_{18 \mathrm{e}}(\mathrm{U})_{250}\right)$ with the elongation machinery and 30S PIC formed with either IF3(Alx488) or 30S(Alx488) subunit in a stopped flow apparatus (Figure 16). We measured FRET between the non-fluorescent acceptor at the 5 '-end of the mRNA and the fluorescence components from the initiation machinery. The FRET signals were similar to the one obtained in Section 2.5, with a delay followed by the fluorescence decrease, which was assigned to the translation elongation of the first ribosome and to the recruitment of the 30S PIC to the 5'-end of the MRNA, respectively (Figure 16A and $\mathrm{C}$ ). We overlaid the signal representing the rate of Phe translation with this MRNA with the FRET depicting the second round initiation (Figure 16A). We observed that in this case the FRET signal, and thus the 30S PIC binding, happened when the first ribosome had translated between 15 and 30 Phe codons. Taking into account the estimated rate of elongation by the first ribosome ( 4 aa $\mathrm{s}^{-}$ $\left.{ }^{1}\right)$ we can estimate that for 3-4 $\mathrm{s}$ a number of 12 to 16 Phe will be incorporated into a protein. This number of codons was less than what we calculated with $5^{\mathrm{Q}} \mathrm{RBS}_{20 \mathrm{e}}(\mathrm{UUC})_{78} \mathrm{mRNA}$ with fixed length(26 aa).

We then used the global kinetic model described in Section 2.6.1 (M1) for $5^{{ }^{a}} \mathrm{RBS}_{20 \mathrm{e}}(\mathrm{UUC})_{78}$ mRNA to fit the traces we obtained with $5^{\mathrm{Q}} \mathrm{RBS}_{18 \mathrm{e}}(\mathrm{U})_{250}$ mRNA. We reasoned that (i) the two mRNAs had a similar frequency of initiation $t_{f} 2^{\text {nd }}$, i.e. $3-4 \mathrm{~s}$ and (ii) both mRNAs code for Phe, albeit by UUU codon in $5^{\mathrm{a}} \mathrm{RBS}_{18 \mathrm{e}}(\mathrm{U})_{250}$ and $\mathrm{UUC}$ codon in $5^{\mathrm{a}} \mathrm{RBS}_{20 \mathrm{e}}(\mathrm{U})_{78}$, which implied that they should have overall similar rates of translation elongation of the first ribosome, even though they have a 2-fold difference in the rate of GTPase activation step during the process of Phe-tRNA ${ }^{\text {Phe }}$ selection (Gromadski et al., 2006). Because the rate of elongation of $5^{\mathrm{Q}} \mathrm{RBS}_{20 \mathrm{e}}(U)_{78} \mathrm{mRNA}$ was better defined than that of $5^{\mathrm{O}} \mathrm{RBS}_{18 \mathrm{e}}(\mathrm{U})_{250} \mathrm{mRNA}$, and we experimentally confirmed that the delay phase depended on the elongation of the first ribosome (Figure 13C-D), we can approximate that they would also have a similar rate of translation in the stopped flow experiments. We can exclude that the initial fluorescence delay depends on the RBS sequence, because the two mRNA have different RBS but similar frequency of initiation. Reducing the number of steps in the model (M1.1) (Figure 14) to 16 equivalent to the incorporation of 16 Phe - reduced the elongation rate $\left(k_{\mathrm{e}} 1^{\text {st }} \mathrm{UUU}\right)$ nearly 2 -folds but it did not affect the calculated rate of the 30 S PIC recruitment $\left(k_{+_{\mathrm{i}}} 2^{\text {nd }} \mathrm{UUU}\right)$, associated with the decrease of FRET signal. 
(A)

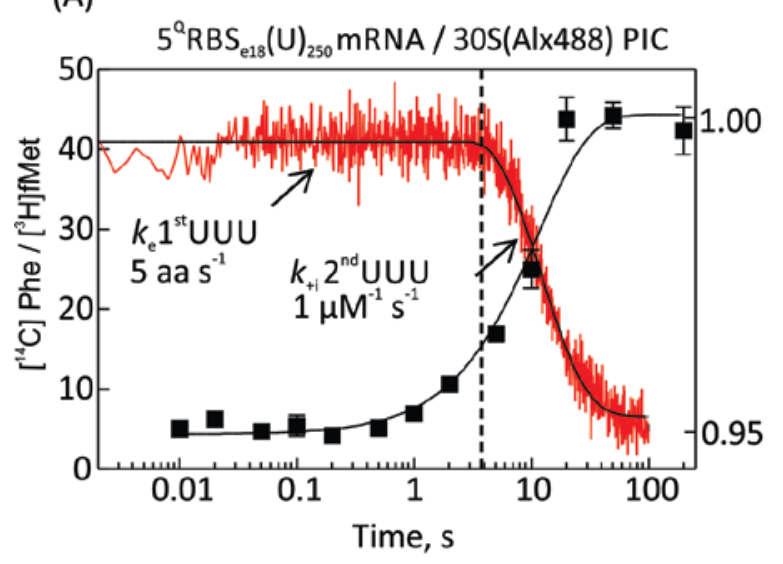

(C)

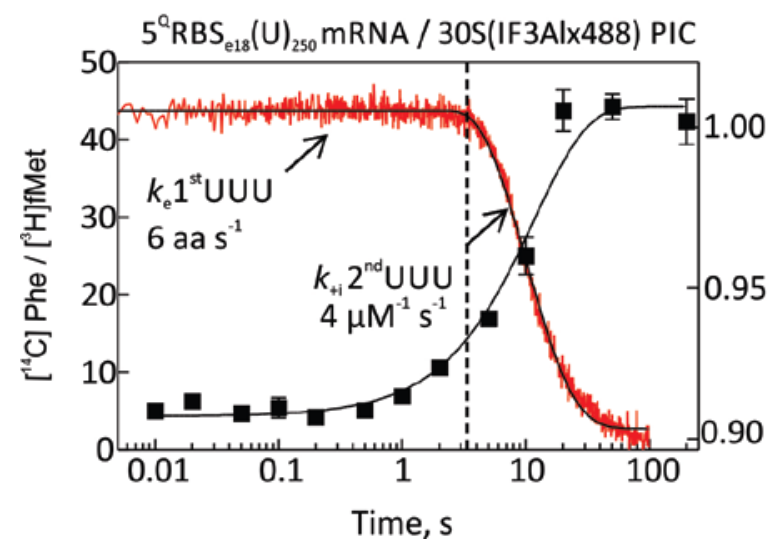

(B)

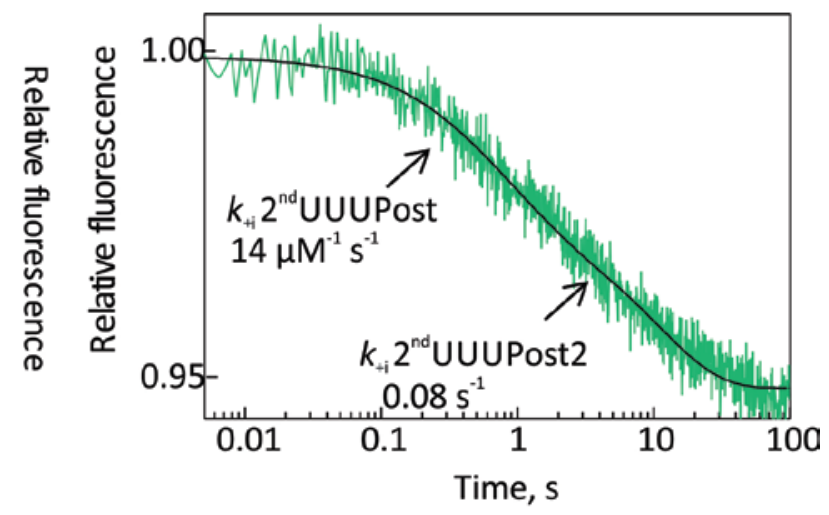

(D)

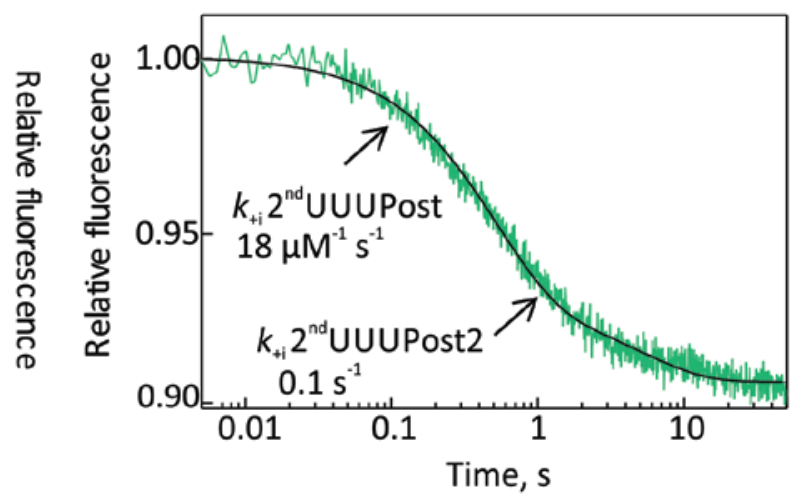

Figure 16. Co- and post- translational monitoring of $30 \mathrm{~S} \mathrm{PIC}$ recruitment to $5{ }^{\mathrm{Q}} \mathrm{RBS}_{18 \mathrm{e}}(\mathrm{U})_{250}$ mRNA.

(A) FRET between a non-fluorescent acceptor on the $5^{\prime}$-end of the mRNA and a donor 30S(Alx488) was followed in time in a stopped flow machine (red trace). We mixed $70 \mathrm{~S} \mathrm{IC}\left(5^{{ }^{\mathrm{O}}} \mathrm{RBS}_{18 \mathrm{e}}(\mathrm{U})_{250} \mathrm{mRNA}\right)(0.05 \mu \mathrm{M})$ with the elongation machinery and the $30 \mathrm{~S}$ (Alx488) PIC $(0.1 \mu \mathrm{M})$. The elemental rate constants $k_{\mathrm{e}} 1^{\text {st }} \mathrm{UUU}\left(5 \pm 0.3\right.$ aa $\left.s^{-1}\right)$ and $k_{+_{i}} 2^{\text {nd }}$ UUU $\left(1.1 \pm 0.3 \mu \mathrm{M}^{-1} \mathrm{~s}^{-1}\right)$ were obtained with model M1.1 and M1.2 (Figure 14). Smooth black line represents the global fit. The black squares represent time points of Phe incorporation of 70S IC programed with the same mRNA: $5^{\mathrm{Q}} \mathrm{RBS}_{18 \mathrm{e}}(\mathrm{U})_{250}$ fitted with a single exponential equation: same as (Figure 11A). (B) $70 \mathrm{~S}$ IC $\left(5^{\mathrm{O}} \mathrm{RBS}_{18 \mathrm{e}}(\mathrm{U})_{250} \mathrm{mRNA}\right)(0.05 \mu \mathrm{M})$ cleared the RBS after mixing it with the elongation machinery and incubating for $2 \mathrm{~min}$ at $37^{\circ} \mathrm{C}$. Afterwards, the $70 \mathrm{~S}$ post-translation complex was mixed with the 30S(Alx488) PIC (0.1 $\left.\mu \mathrm{M}\right)$. The elemental rate constants $k_{+_{i}} 2^{\text {nd }}$ UUUPost $\left(14 \pm 2 \mu \mathrm{M}^{-1} \mathrm{~s}^{-1}\right)$ and $k_{\mathrm{t}_{i}}{ }^{\text {nd }}$ UUUPost2 $\left(0.08 \pm 0.02 \mathrm{~s}^{-1}\right)$ were obtained using model M3 (Figure 14). Smooth black line represents the global fit. (C) Same reaction observed in (A) but with 30S(IF3AIx488) PIC (0.1 $\mu \mathrm{M})$ as a FRET donor. Elemental rate constants $k_{\mathrm{e}} 1^{\text {st }} \mathrm{UUU}\left(6 \pm 0.2\right.$ aa s$\left.{ }^{-1}\right)$ and $k_{+_{\mathrm{i}}} 2^{\text {nd }} \mathrm{UUU}\left(4.0 \pm 0.2 \mathrm{~s}^{-1}\right)$ were obtained using models M1.1 and M1.2 (Figure 14) (D) Same reaction as (B) but with 30S(IF3Alx488) PIC (0.1 $\mu \mathrm{M})$ as a FRET donor. The elemental rate constants ${k_{+_{\mathrm{i}}}}{ }^{\text {nd }}$ UUUPost $\left(18 \pm 1 \mu \mathrm{M}^{-1} \mathrm{~s}^{-1}\right)$ and $k_{+_{\mathrm{i}}} 2^{\text {nd }}$ UUUPost2 $\left(0.10 \pm 0.02 \mathrm{~s}^{-1}\right)$ were obtained using model M3 (Figure 14). Smooth black line represents the global fit. 
When we globally fitted the second round initiation FRET with 30S(Alx488) PIC we obtained a value for the rate constant of the first ribosome elongation $k_{\mathrm{e}} 1^{\text {st }} \mathrm{UUU}=5$ aa s $\mathrm{s}^{-1}$ and the rate for second ribosome recruitment $k_{+_{i}} 2^{\text {nd }} \mathrm{UUU}=1 \mu \mathrm{M}^{-1} \mathrm{~s}^{-1}$ (Figure 16A). A similar set of rate constants was obtained when we used a 30S(IF3Alx488) PIC as a FRET donor, $k_{\mathrm{e}} 1^{\text {st }} \mathrm{UUU}=6$ aa $\mathrm{s}^{-1}$ and a rate constant of the second ribosome recruitment $k_{+_{i}} 2^{\text {nd }} \mathrm{UUU}=4 \mu \mathrm{M}^{-1} \mathrm{~s}^{-1}$ (Figure 16C). Only one step for the second initiation recruitment was resolved $\left(k_{+_{\mathrm{i}}} 2^{\text {nd }} \mathrm{UUU}=4 \mu \mathrm{M}^{-1} \mathrm{~s}^{-1}\right)$, even though the FRET pair $30 \mathrm{~S}$ (IF3Alx488) PIC - $5^{\mathrm{Q}} \mathrm{RBS}_{18 \mathrm{e}}(\mathrm{U})_{250} \mathrm{mRNA}$ resulted in a biphasic fluorescence time course in the first initiation event (Figure 10A). The lack of the second phase suggested that IF3(Alx488) undergone a different rearrangement in the first and second 30S PIC, when it recruited an mRNA being translated. Furthermore, when we compared the rates of recruitment of the $30 \mathrm{~S}$ PIC to the free $5^{\mathrm{Q}} \mathrm{RBS}_{18 \mathrm{e}}(\mathrm{U})_{250}$ mRNA during the initiation of the first ribosome (Section 2.3), with $k_{+1}$ (30S(Alx488) PIC $=25 \mu M^{-1} \mathrm{~s}^{-1}$ and $\mathrm{k}_{+1}\left(30 \mathrm{~S}\right.$ (IF3Alx488) $\left.\mathrm{PIC}=24 \mu \mathrm{M}^{-1} \mathrm{~s}^{-1}\right)$, it turned out that those rates were much higher than the rates of co-translational recruitment. $k_{t_{i}} 2^{\text {nd }} \mathrm{UUU}(30 \mathrm{~S}(\mathrm{Alx} 488) \mathrm{PIC})=1 \mu \mathrm{M}^{-1} \mathrm{~s}^{-1}$ and $k_{\mathrm{i}} 2^{\text {nd }} \mathrm{UUU}$ (30S(IF3Alx488) PIC $=4 \mu \mathrm{M}^{-1} \mathrm{~s}^{-1}$ ) were slowed down by 6-25-fold. A scenario where the first ribosome slows down the second initiation event on an mRNA possessing open and rapidly initiating RBS was surprising. To understand whether the rate constants of the 30S PIC recruitment were modulated after elongation of the first ribosome or not, we tested the recruitment with the post translation assay. We allowed the $70 S$ IC to translate the $5^{\mathrm{Q}} \mathrm{RBS}_{18 \mathrm{e}}(\mathrm{U})_{250}$ mRNA by mixing it with the complete elongation machinery and incubating the mix for $2 \mathrm{~min}$ at $37^{\circ} \mathrm{C}$. The resulting $70 \mathrm{~S}$ post complex was rapidly mixed with the 30S(Alx488) PIC or 30S(IF3Alx488) PIC. The FRET change was biphasic and was globally fitted with Model (M3) (Figure 14). The first step $\left(k_{+_{i}} 2^{\text {nd }}\right.$ UUUPost) was assigned to the binding reaction between the 30S PIC and the mRNA while the second step $\left(k_{+_{i}} 2^{\text {nd }}\right.$ UUUPost2) was assigned to a conformational rearrangement occurring on an mRNA carrying a 70S complex along its sequence (Figure 16B). When we used $30 \mathrm{~S}(\mathrm{Al} \times \mathrm{x} 488$ ) subunit as a FRET donor, the rate of recruitment was $k_{+} 2^{\text {nd }}$ UUUPost $=14 \mu \mathrm{M}^{-1} \mathrm{~s}^{-1}$, followed by a rearrangement occurring with a rate of $k_{\mathrm{i}} 2^{\text {nd }}$ UUUPost2= $0.08 \mathrm{~s}^{-1}$. The second step was not observed when we dissected the first binding between FRET pair $30 \mathrm{~S}$ (Alx488) subunit and $5^{\mathrm{C}} \mathrm{RBS}_{18 \mathrm{e}}(\mathrm{U})_{250}$ mRNA, which suggested that the slow step was induced by the presence of a 70S stalled complex along the mRNA sequence. Another explanation could be that the translation elongation was not completely synchronized, due to the undefined length of the poly $(U)$ extension, which resulted in a population of 705 complexes positioned too close to the RBS.

With a FRET donor 30S(IF3AIx488) PIC the rate of recruitment was $k_{+_{i}} 2^{\text {nd }}$ UUUPost $=18 \mu M^{-1} \mathrm{~s}^{-}$ ${ }^{1}$ followed by a rearrangement occurring with a rate of $k_{+_{i}} 2^{\text {nd }}$ UUCPost2 $=0.1 \mathrm{~s}^{-1}$ and a $50 \%$ fluorescence contribution (Figure 16D). Not surprisingly, the second slower step was assigned to IF3 rearrangement also present in the first initiation event between FRET couples 30S(IF3AIx488) PIC and $5^{\mathrm{Q}} \mathrm{RBS}_{18 \mathrm{e}}(\mathrm{U})_{250}$ mRNA (Table 3), however, significantly slowed down $\left(\mathrm{k}_{+2}=4 \mathrm{~s}^{-1}\right)$. It can be interpreted as a rearrangement of the factor influenced by the global movements of the 30S PIC on an RBS already being translated. However, given the highly dynamic nature of IF3, it is difficult to evaluate how the recruitment of 30S PIC to an mRNA with a 70S elongating complex along its sequence could 
influences the dynamics of IF3(Alx488). Nevertheless, when we compared the calculated elemental rates of 30S PIC recruitment to $5^{\mathrm{a}} \mathrm{RBS}_{18 \mathrm{e}}(\mathrm{U})_{250}$ mRNA (Section 2.3), we observed that the rates of first ribosome recruitment $k_{+1}\left(30 \mathrm{~S}\right.$ (Alx488) PIC $=25 \mu \mathrm{M}^{-1} \mathrm{~s}^{-1}$ and $k_{+1}$ (30S (IF3Alx488) PIC = $24 \mu \mathrm{M}^{-1} \mathrm{~s}^{-}$ ${ }^{1}$ were in the same range as the elemental rates $k_{+_{i}}{ }^{\text {nd }}$ UUUPost $\left(14 \mu \mathrm{M}^{-1} \mathrm{~s}^{-1}\right.$ and $\left.18 \mu \mathrm{M}^{-1} \mathrm{~s}^{-1}\right)$ determined after the first ribosome has translated the mRNA. This result confirmed that the $70 \mathrm{~S}$ elongating complex had liberated the RBS and the mRNA had returned to its initial conformation. However, this mRNA conformation was not the same as the one measured by the co-translational recruitment $k_{+_{i}} 2^{\text {nd }} U U U$, as indicated by a difference in the elemental rates of recruitment. This suggests an interference of the first ribosome with the second initiation event which was RBS specific, because no significant reduction (2-fold) of the rate of 30S PIC recruitment was observed with $5^{\mathrm{Q}} \mathrm{RBS}_{20 \mathrm{e}}(\mathrm{UUC})_{78} \mathrm{mRNA}$ (Section 2.6.2). This result points to an important regulatory effect of the polysome formation, as different RBS sequences of the mRNA adopt different structures while emerging from the mRNA exit channel. This effect would be elongation-independent, as elongation rates were similar for all mRNAs.

As a summary, we could kinetically describe the second round initiation observed with $5^{\mathrm{Q}} \mathrm{RBS}_{18 \mathrm{e}}(\mathrm{U})_{250}$ mRNA and two FRET donor-labeled proteins from the initiation machinery. We compared the calculated set of elemental rate constants from global kinetic models and observed differences between the rates of recruitment of a ribosome-free mRNA, co-translationally and posttranslationally recruited $30 \mathrm{~S}$ PIC. 


\subsection{4. $5^{*} \mathrm{RBS}_{18 \mathrm{e}}(\mathrm{U})_{250}$ mRNA directly visualized the recruitment of the $30 \mathrm{~S}$ PIC.}

Until now we monitored the second round initiation only through an mRNA labeled at the 5'end with a non-fluorescent acceptor and with fluorescence components of the initiation machinery. This approach focused on the 30S PIC recruitment, seen from either IF3 or the ribosome itself and disregarded the dynamics of the mRNA $5^{\prime}$-end. We then explored the second round initiation reaction from the point of view of an mRNA labeled with a fluorescence dye ATTO488 placed at the $5^{\prime}$-end. As we have seen in Section 2.2.2, $5 * \mathrm{RBS}_{18 \mathrm{e}}(\mathrm{U})_{250}$ mRNA changed fluorescence upon biding to the $30 \mathrm{~S}$ PIC (Figure 7). The fluorescence decreased likely due to the presence of hydrophobic residues surrounding the mRNA cleft. We visualized the dynamics of the $5^{\prime}$-end of the mRNA upon translation in the presence or absence of the 30S PIC. First, we mixed the $70 \mathrm{SIC}\left(5^{*} \mathrm{RBS}_{18 \mathrm{e}}(\mathrm{U})_{250} \mathrm{mRNA}\right)$ with the elongation machinery (Figure 17-red). We recorded a rapid biphasic increase of the fluorescence (10\%) followed by $a \approx 3 \%$ decrease of fluorescence amplitude. The signal change was dependent on the translation elongation on the first ribosome, because it was abolished when no Phe-tRNA ${ }^{\text {Phe }}$ was present. By including $30 \mathrm{~S}$ PIC in the reaction we observed the same rapid fluorescence increase, followed this time by a decrease in fluorescence, which almost completely recovered the overall fluorescence change. We could assign the fluorescence quenching to the second 30S PIC recruited to the available $5^{\prime}$-end of the mRNA being translated, because a similar quenching occurred in the first mRNA recruitment (Figure 7).

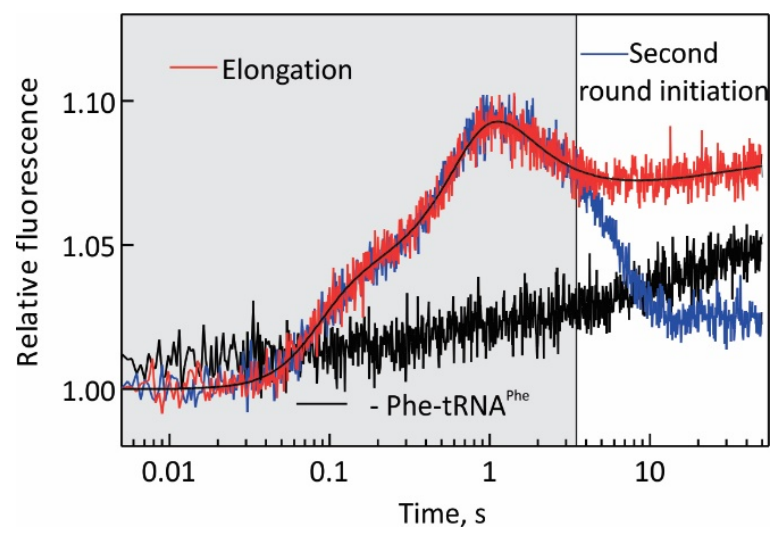

Figure 17. Visualizing the 5'-end-labeled mRNA during elongation and second round of initiation.

The fluorescence change of $5 * \mathrm{RBS}_{18 \mathrm{e}}(U)_{250}$ mRNA during translation and second round initiation was followed over time on a stopped flow apparatus. Purified 70S IC $(0.05 \mu \mathrm{M})$ were mixed with the elongation machinery in the absence (red) or the presence of 30S PIC $(0.1 \mu \mathrm{M})$ (blue). A slow fluorescence change (3-4\%) occurred when we omitted the Phe-tRNA ${ }^{\text {Phe }}$ from the elongation machinery (black). The smooth black line represents a fit obtained with Table Curve software (Systat Software). The grey area represented the elongation of the first ribosome while the rest of the figure represented the second round initiation. 
The complicated kinetic behavior of the initial fluorescence increase was simplified by background subtraction in order to resolve the later steps. We first obtained an arbitrary ideal fit for the signal representing the first ribosome translation (Section 4.21.2). Second, we subtracted this fit from the fluorescence trace in order to minimize the background. Lastly, we subtracted the refined fluorescence trace from the fluorescence signal representing the second round initiation and obtained the signal which was due solely to the 30S PIC recruitment (Figure 18A). As a result we could focus only at the fluorescence quenching represented by the 30S PIC recruitment to the mRNA. Interestingly, the modified signal resembled the previously observed second round initiation reactions fit with an initial delay, followed by a decrease in the fluorescence (Figure 16).

(A)

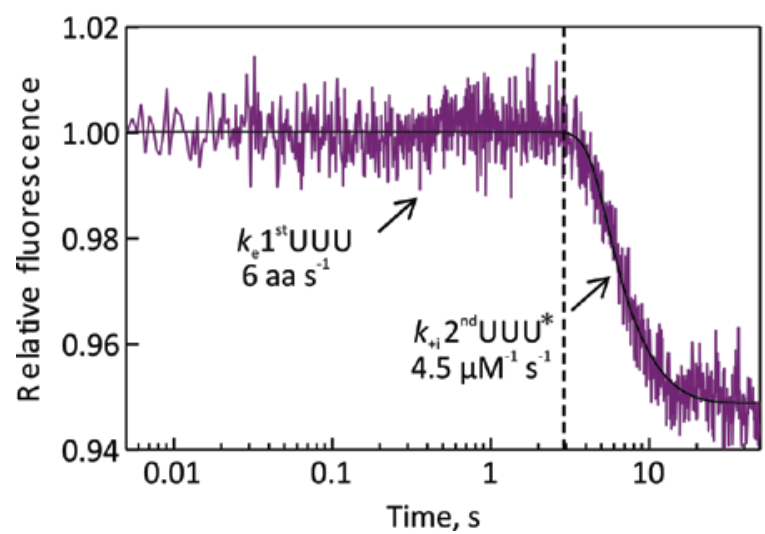

(B)

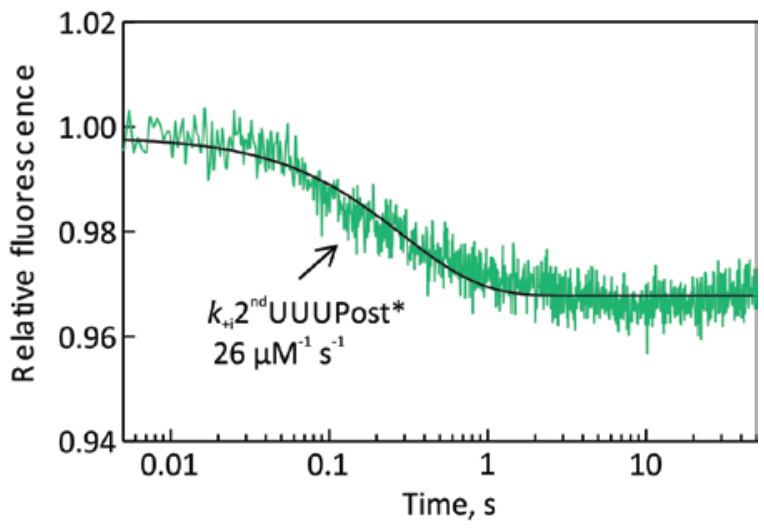

Figure 18. Co-and post translationally recruitment to the $30 \mathrm{~S}$ PIC to the $5^{*} \mathrm{RBS}_{18 \mathrm{e}}(\mathrm{U})_{250}$ mRNA.

(A) Mathematically derived time course from Figure 17 (purple). The trace representing the elongation of the first ribosome (red) was subtracted from the trace representing the second ribosome binding (blue) (Figure 17). Elemental rates $k_{\mathrm{e}} 1^{\mathrm{st}} \mathrm{UUU} *\left(6.0 \pm 0.3\right.$ aa s $\left.\mathrm{s}^{-1}\right)$ and $k_{+i} 2^{\text {nd }} \mathrm{UUU}^{*}\left(4.5 \pm 0.7 \mu \mathrm{M}^{-1} \mathrm{~s}^{-1}\right)$ were obtained with model (M1.1 and M1.2) (Figure 14). Smooth black line represents the global fit. (B) Recruitment of the 30S PIC to the $5 * \mathrm{RBS}_{18 \mathrm{e}}(\mathrm{U})_{250} \mathrm{mRNA}$ after the first ribosome had liberated the RBS. We allowed the first ribosome $70 \mathrm{~S} \mathrm{IC}$ $\left(5^{*} \mathrm{RBS}_{18 \mathrm{e}}(\mathrm{U})_{250} \mathrm{mRNA}\right)(0.05 \mu \mathrm{M})$ to translate by mixing it with the elongation machinery for $2 \mathrm{~min}$ at $37^{\circ} \mathrm{C}$. The $70 S$ post-translation complex was mixed rapidly with the 30S PIC. Smooth black line represents the global fit obtained with model M3 (Figure 14) with a single bimolecular step resulting in $k_{+i} 2^{\text {nd }}$ UUUPost* $=26 \pm 2 \mu \mathrm{M}^{-1} \mathrm{~s}^{-1}$.

We used the global kinetic model (M1.1 and M2) (Figure 14) to calculate the elemental steps of translation elongation of the first ribosome and the recruitment of the second 30S PIC to the $5^{\prime}$ end of the mRNA. The rate of elongation by the first ribosome was $k_{\mathrm{e}} 1^{\text {st }} \mathrm{UUU}=6$ aa $\mathrm{s}^{-1}$. The rate was similar to the one obtained with $5^{\mathrm{Q}} \mathrm{RBS}_{18 \mathrm{e}}(\mathrm{U})_{250}$ mRNA. The rate of second ribosome recruitment was $k_{+_{\mathrm{i}}} 2^{\text {nd }} \mathrm{UUU}^{*}=4.5 \mu \mathrm{M}^{-1} \mathrm{~s}^{-1}$, which was in the same range as the same step observed with $5^{\mathrm{Q}} \mathrm{RBS}_{18 \mathrm{e}}(\mathrm{U})_{250}$ mRNA with FRET donors 30S(Alx488) and IF3Alx488 $\left(k_{+_{i}} 2^{\text {nd }}\right.$ UUU $\left.=1-4 \mu \mathrm{M}^{-1} \mathrm{~s}^{-1}\right)$. However, $k_{+_{i}} 2^{\text {nd }} U U^{*}$ $=4.5 \mu^{-1} \mathrm{~s}^{-1}$ was nearly 3 -fold slower than the rate of the first ribosome recruitment measured with the same mRNA $k_{+1}=15 \mu \mathrm{M}^{-1} \mathrm{~s}^{-1}$ (Table 2). We then used the post translation assay to test if the first ribosome had influenced the mRNA structure after RBS liberation. We allowed the 70S IC to translate the mRNA by mixing it with the complete elongation machinery for $2 \mathrm{~min}$ at $37^{\circ} \mathrm{C}$. Simplified Model (M3) (Figure 14), with a single bimolecular step, was sufficient to account for the fast fluorescence 
quenching $k_{+_{i}} 2^{\text {nd }}$ UUUPost $*=26 \pm 2 \mu \mathrm{M}^{-1} \mathrm{~s}^{-1}$ (Figure 18B). The post recruitment fluorescence trace had a smaller amplitude change (4\%) in comparison to the reaction occurring co-translationally (6\%). The slight reduction of the amplitude might be due to the loss of sensitivity of the fluorophore during the 2 min incubation with the crowded elongation machinery. When we compared the elemental rates of $30 \mathrm{~S} \mathrm{PIC} \mathrm{recruitment} \mathrm{with} 5 * \mathrm{RBS}_{18 \mathrm{e}}(\mathrm{U})_{250}$ mRNA from Section 2.3, we observed that the rate constant of the first ribosome recruitment $k_{+1}=15 \mu \mathrm{M}^{-1} \mathrm{~s}^{-1}$ was in the same range as the elemental rates $k_{\mathrm{i}} 2^{\text {nd }}$ UUUPost ${ }^{*}=26 \mu \mathrm{M}^{-1} \mathrm{~s}^{-1}$ observed in the post reaction. This result confirmed that the first $70 \mathrm{~S}$ elongating complex had liberated the RBS and the mRNA had returned to its initial state. We again obtained a lower rate constant of the second initiation event compared to the first one, similar to the effect seen in the FRET assay with $5^{\mathrm{Q}} \mathrm{RBS}{ }_{18 \mathrm{e}}(\mathrm{U})_{250}$ mRNA and donor-dye labeled proteins from the initiation machinery. However, the magnitude of the rate reduction was only $3-f o l d$, whereas that seen with 30S(Alx488) subunit was 25-fold, because we visualized the recruitment of the very end of the $5^{\prime}$-end of the mRNA.

In summary, we visualized simultaneously (i) the 5'-end mRNA dynamics during translation of the first ribosome (ii) the second 30S PIC recruitment to the same mRNA after RBS clearance had occurred. We observed the mRNA exit dynamics most likely representing various interactions with ribosomal proteins S7, S11, S18. The 5'-end of the mRNA with an open RBS was accessible for second initiation after 2-3 $\mathrm{s}$ in the same range seen with two other model mRNAs (Sections 2.6.2 and 2.6.3). 
Table 5. Summary of elemental rate constants obtained with global fit models from Figure 14.

All rates and standard errors are derived from global fitting using numerical integration; n.o. - not observed. Percentages in brackets next to the rate represent the fluorescence contribution of the step from the overall amplitude.

\begin{tabular}{|c|c|c|c|c|}
\hline & \multicolumn{4}{|c|}{ Elemental rates } \\
\hline FRET pair & Model 1.1 & Model 1.2 & Model 2 & Model 3 \\
\hline & $\begin{array}{l}k_{\mathrm{e}} 1^{\text {st }} U U C \\
\left(\text { aa s }^{-1}\right)\end{array}$ & $\begin{array}{l}k_{+i} 2^{\text {nd }} \cup U C \\
\left(\mu M^{-1} s^{-1}\right)\end{array}$ & $\begin{array}{c}k_{+\mathrm{i}} 2^{\text {nd }} \text { UUCPost } \\
\left(\mu \mathrm{M}^{-1} \mathrm{~s}^{-1}\right)\end{array}$ & \\
\hline $\begin{array}{c}5^{\mathrm{Q}} \mathrm{RBS}_{20 \mathrm{e}}(\mathrm{U})_{78} \mathrm{mRNA} / \\
30 \mathrm{~S}(\mathrm{Al} \times 488) \mathrm{PIC}\end{array}$ & $5 \pm 0.2$ & $0.5 \pm 0.2$ & $0.40 \pm 0.02$ & N.O. \\
\hline & $\begin{array}{l}k_{\mathrm{e}} 1^{\mathrm{st}} \mathrm{UUU} \\
\left(\text { aa s s }^{-1}\right)\end{array}$ & $\begin{array}{l}k_{++2^{n d}} 2^{\text {nd U }} \\
\left(\mu \mathrm{M}^{-1} \mathrm{~s}^{-1}\right)\end{array}$ & $\begin{array}{c}k_{+i} 2^{\text {nd }} \text { UUUPost } \\
\left(\mu \mathrm{M}^{-1} \mathrm{~s}^{-1}\right)\end{array}$ & $\begin{array}{c}k_{+\mathrm{i}} 2^{\text {nd }} \text { UUUPost } \\
2 \\
\left(\mathrm{~s}^{-1}\right)\end{array}$ \\
\hline $\begin{array}{c}5^{\mathrm{Q}} \mathrm{RBS}_{18 \mathrm{e}}(\mathrm{U})_{250} \mathrm{mRNA} / \\
30 \mathrm{~S}(\mathrm{Al} \times 488) \mathrm{PIC}\end{array}$ & $5 \pm 0.3$ & $1.1 \pm 0.1$ & $\begin{array}{l}14 \pm 2 \\
(55 \%)\end{array}$ & $\begin{array}{c}0.08 \pm 0.02 \\
(45 \%)\end{array}$ \\
\hline $\begin{array}{c}5^{\mathrm{Q}} \mathrm{RBS}_{18 \mathrm{e}}(\mathrm{U})_{250} \mathrm{mRNA} / \\
30 \mathrm{~S}(\mathrm{IF} 3 \mathrm{Al} \times 488) \mathrm{PIC}\end{array}$ & $6 \pm 0.2$ & $4.0 \pm 0.2$ & $\begin{array}{l}18 \pm 1 \\
(50 \%)\end{array}$ & $\begin{array}{c}0.1 \pm 0.02 \\
(50 \%)\end{array}$ \\
\hline & $\begin{array}{c}k_{\mathrm{e}} 1^{\text {st }} U U^{*} \\
\left(\text { aa s s }^{-1}\right)\end{array}$ & $\begin{array}{c}k_{++2^{n d}} 2^{\text {d }} U^{*} \\
\left(\mu \mathrm{M}^{-1} s^{-1}\right)\end{array}$ & $\begin{array}{c}k_{+\mathrm{i}} \mathrm{2}^{\text {nd }} \text { UUUPost } \\
* \\
\left(\mu \mathrm{M}^{-1} \mathrm{~s}^{-1}\right) \\
\end{array}$ & \\
\hline $\begin{array}{c}5 * \mathrm{RBS}_{18 \mathrm{e}}(\mathrm{U})_{250} \mathrm{mRNA} / \\
30 \mathrm{~S} \text { PIC }\end{array}$ & $6.0 \pm 0.3$ & $4.5 \pm 0.7$ & $26 \pm 2$ & N.O. \\
\hline
\end{tabular}

This study is the first attempt to reconstitute polysomes in vitro and follow the initiation frequency on bacterial mRNAs during translation in real-time. The combination of rapid kinetics and global modelling succeeded in monitoring efficiency and timing of ribosome loading on model mRNAs. Utilizing a single kinetic model (M1) we calculated the rate of translation of the first, leading ribosome and the rate of recruitment of the following one for three model mRNAs, with two different RBS. Such approach allowed us to address the mechanisms of translation regulation during polysome formation, by using a completely reconstituted in vitro translational system. All three model mRNAs had similar frequency of loading of the second ribosome of 2-4s and rates of elongation on the first ribosome $\left(k_{\mathrm{e}} 1^{\mathrm{st}}\right)$. However, the mRNA differed in the rates of $30 \mathrm{~S}$ PIC recruitment depending on whether they were obtained during the second initiation event $\left(k_{\mathrm{i}} 2^{\text {nd }}\right)$, post translationally $\left(k_{\mathrm{i}} 2^{\text {nd }}\right.$ Post) or during the first initiation event (Section 2.3) without a ribosome. Taken together, these results give new insights into how the mRNA sequence around the RBS governs the rate of second round initiation. 


\section{7. asRNA changed fluorescence upon target RBS hybridization; a novel method for probing a secondary structure.}

The combination of rapid kinetics and fluorescence-based techniques successfully led us to monitor the efficiency and timing of ribosome loading on model mRNAs in real-time and kinetically dissect the process (Section 2.6). Moreover, this approach allowed us to address the mechanisms of translation regulation during polysome formation, by focusing on translation initiation. A major question remains: does a translating ribosome exert control over the second initiation event if elongation is not limiting? As we showed in Section 2.6, $5^{\mathrm{Q}} \mathrm{RBS}_{20 \mathrm{e}}(\mathrm{UUC})_{78}$ mRNA showed similar elemental rates of $30 \mathrm{~S}$ PIC recruitment (i) off the ribosome, (ii) while being translated, or (iii) when a stalled 705 elongated complex was bound at the end of its coding sequence. These results suggested that if there is a potential restructuring of the RBS during the first ribosome elongation it is too rapid or transient to be resolved with $30 \mathrm{~S}(\mathrm{Al} \times 488)$ and the $5^{\prime}$-end labeled mRNA as fluorescence observables. Interestingly, the $5^{\mathrm{Q}} \mathrm{RBS}_{20 \mathrm{e}}(\mathrm{UUC})_{78} \mathrm{mRNA}$ has a predicted secondary structure around the RBS, which contributed to the rate of 30S PIC recruitment (Figure 9E-F) (Table 12). Therefore, establishing a method to probe directly the structure that occluded the RBS sequence is a major challenge. We designed a fluorescence, single stranded anti-sense RNA observable (asRNA12) and took advantage of the processes of RNA-RNA duplex formation. As we know from the literature, most regulatory small RNAs base pair in the 5'-UTR of the target mRNAs near the ribosome binding site (Storz et al., 2011). We aimed at probing the dynamics around the RBS of $\mathrm{RBS}_{20 \mathrm{e}}(U U C)_{78}$ mRNA using a short (12 nt), anti-sense RNA oligonucleotide, which is fully complementary to a specific region of the RBS, i.e. covers half of the SD sequence, the spacer region and the AUG codon of $5^{\mathrm{Q}} \mathrm{RBS}_{20 \mathrm{e}}(\mathrm{UUC})_{78} \mathrm{mRNA}$. The oligonucleotide was predicted to restructure its target sequence upon hybridization by (i) forming an RNA-RNA duplex covering $50 \%$ of the RBS, (ii) leaving the mRNA $5^{\prime}$-end free, and (iii) not interfering with the coding region of the mRNA (Figure 19C). Labeled with an Alx488 dye at the $3^{\prime}$-end asRNA12* was obtained commercially and used in the following sections. 
2.7.1. Equilibrium binding of asRNA12* to its target on $\mathrm{RBS}_{20 \mathrm{e}}(\mathrm{UUC})_{78} \mathrm{mRNA}$.

First, we measured the equilibrium binding constant of asRNA12* to the RBS of $\mathrm{RBS}_{20 \mathrm{e}}(\mathrm{UUC})_{78}$ mRNA (from now on called target RBS) by Electrophoretic Mobility Shift Assay (EMSA) (Section 4.23.1). We mixed constant concentrations of the labeled asRNA12* with increasing concentration of unlabeled $\mathrm{mRNA}$ and incubated for $30 \mathrm{~min}$ at $37^{\circ} \mathrm{C}$, subsequently separating the complexes from non-bound asRNA12* on a native PAGE (Section 4.11.4). As expected, at increasing concentrations of asRNA12*, we observed the appearance of a slower-migrating fluorescence band, corresponding to the RNA-RNA duplex (Figure 19A). The asRNA12* formed a complex with its target mRNA with a $K_{d}$ of $0.12 \pm 0.03 \mu \mathrm{M}$ (Figure 19B). The complex was stable for more than $30 \mathrm{~min}$ at $37^{\circ} \mathrm{C}$. The complex migrated as one homogeneous fluorescence band, indicating that under native conditions the oligonucleotide stabilized a single mRNA structure.

(A)

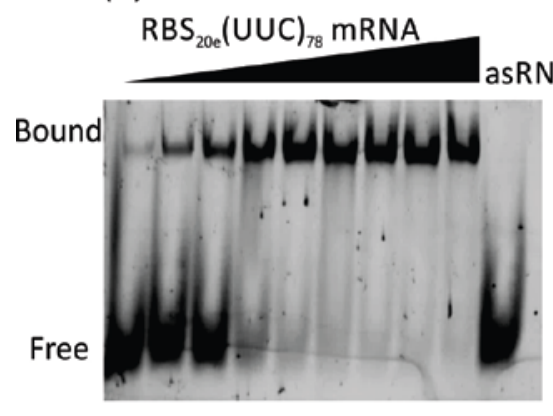

(B)

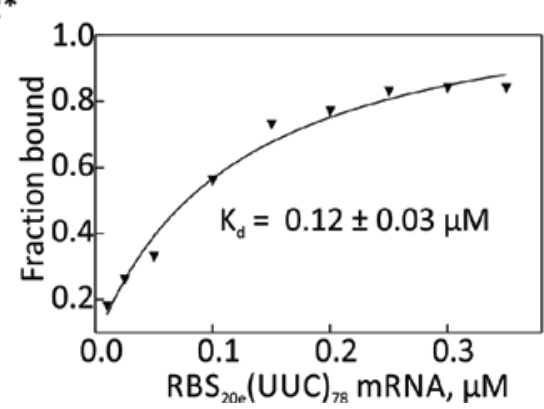

(C)

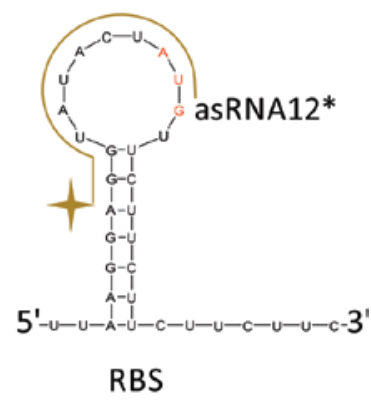

Figure 19. Binding of asRNA12* to $\mathrm{RBS}_{20 \mathrm{e}}(\mathrm{UUC})_{78}$ mRNA by EMSA.

(A) Constant concentrations of asRNA12* $(0.05 \mu \mathrm{M})$ were incubated with increasing concentrations of target mRNA RBS $20 \mathrm{e}(\mathrm{UUC})_{78}(0.01 \mu \mathrm{M}-0.4 \mu \mathrm{M})$ incubated for $30 \mathrm{~min}$ at $37^{\circ} \mathrm{C}$ and separated on a native PAGE gel. (B) ImageJ analysis of the gel from (A). Fraction bound was plotted against target mRNA concentration. The equilibrium binding constant was estimated by one site binding equation: $K_{d}=0.12 \pm 0.04 \mu \mathrm{M}$ (Graph Pad Prism). Error was the s.e.m. of the fit. (C) Schematic of the predicted structure of the target RBS of $\mathrm{RBS}_{20 \mathrm{e}}(\mathrm{UUC})_{78} \mathrm{mRNA}$ (mfold) and the complementary binding site of asRNA12* (gold) with a fluorophore at the $3^{\prime}$-end (gold star).

In the next section, we used the asRNA12* to visualize its recruitment to the target RBS sequence on the mRNA (i) off the ribosome, (ii) during the first ribosome elongation, (iii) after the first ribosome elongation, and (iv) in competition with the 30S PIC. 
2.7.2. asRNA12* changed fluorescence upon target RBS hybridization off the ribosome.

In order to use the asRNA12* as a reliable observable of the RBS dynamics in the following reactions, we first studied the kinetics of its interaction with the target RBS in a stopped flow apparatus. The Alexa 488 dye at the $3^{\prime}$ end of the $12 \mathrm{nt}$ RNA oligonucleotide contributed an additional net negative charge to the RNA sequence, expected to minimally interfere with its native structure. We observed a fluorescence change of the asRNA12* upon binding to unlabeled $\mathrm{RBS}_{20 \mathrm{e}}(\mathrm{UUC})_{78} \mathrm{mRNA}$ (Figure 20A). A fluorescence change upon RNA-RNA hybridization was expected due to the highly flexible nature of RNA and the drastic environment change from a free state to a hybridized state measured in the reaction.

(A)

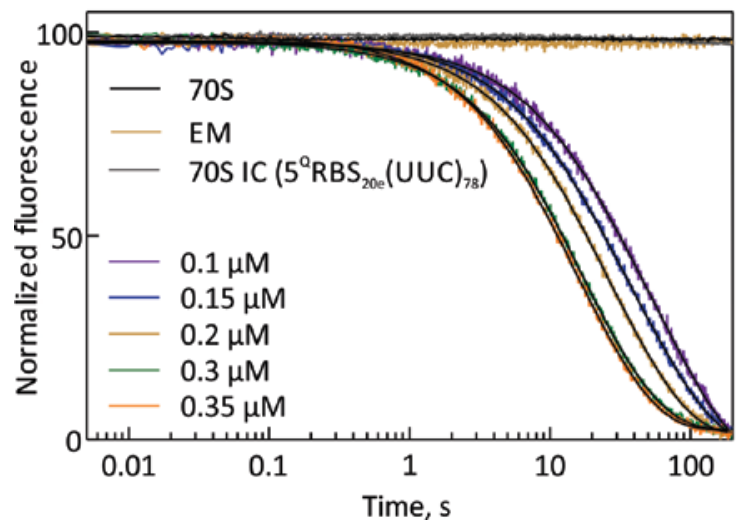

(B)

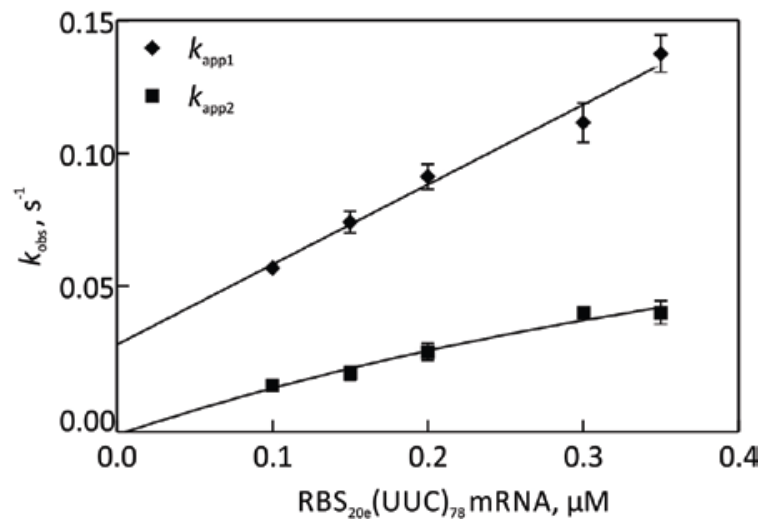

Figure 20. Fluorescence change of asRNA12* upon $\mathrm{RBS}_{20 \mathrm{e}}(\mathrm{UUC})_{78} \mathrm{mRNA}$ binding.

(A) We mixed asRNA12* $(0.05 \mu \mathrm{M})$ and increasing concentration of $\mathrm{RBS}_{20 \mathrm{e}}(\mathrm{UUC})_{78}$ mRNA $(0.1 \mu \mathrm{M}-0.35 \mu \mathrm{M})$ (purple to orange) in a stopped flow apparatus. The fluorescence change of asRNA12* upon target RBS hybridization was followed in time. No signal was observed when $70 \mathrm{~S}$ ribosomes (black), EM (elongation machinery) (gold) or $70 \mathrm{~S} \mathrm{IC}\left(5^{\mathrm{a}} \mathrm{RBS}_{20 \mathrm{e}}(\mathrm{UUC})_{78} \mathrm{mRNA}\right)$ (grey) were used instead. (B) Apparent rate constants of asRNA12* binding to $\mathrm{RBS}_{20 \mathrm{e}}(\mathrm{UUC})_{78} \mathrm{mRNA}$. The $k_{\text {app } 1}$ rate increased with increasing concentration of the mRNA. Linear regression analysis revealed a $k_{\text {on }}=0.30 \pm 0.02 \mu \mathrm{M}^{-1} \mathrm{~s}^{-1}$ and $k_{\text {off }}=0.030 \pm 0.001 \mathrm{~s}^{-1}$. The fit for $k_{\text {app } 2}$ was poorly defined saturating at $0.09 \pm 0.08 \mathrm{~s}^{-1}$. Error bars were s.e.m. of the fit.

Upon mixing asRNA12* with increasing concentrations of $\mathrm{RBS}_{20 \mathrm{e}}(\mathrm{UUC})_{78} \mathrm{mRNA}$, we observed a biphasic fluorescence quenching, which we fitted with a two-exponential equation (Figure 20A). The fluorescence decreased by $20 \%$. Given the high stability of the fluorescence signal (amplitude variation of $3 \%$ ) and its large overall amplitude, we normalized the traces from the smallest value in each data set as $(0 \%)$ to the highest value for each data set $(100 \%)$. The $k_{\mathrm{app} 1}$ increased linearly with increasing concentrations of the target mRNA, indicating the binding step, while $k_{\text {app2 }}$ was saturating (Figure 20B). Linear regression analysis of $k_{\mathrm{app} 1}$ revealed an association rate constant $k_{\text {on }}=0.3 \mu \mathrm{M}^{-1} \mathrm{~s}^{-1}$ and dissociation rate constant $k_{\text {off }}$ of $0.03 \mathrm{~s}^{-1}$. The estimated $\mathrm{K}_{\mathrm{d}}=0.1 \mu \mathrm{M}$ from the apparent rates $\left(k_{\text {off }}\right.$ $\left(k_{\text {on }}\right)$, measured at the stopped flow was similar to the one measured in equilibrium (Figure 19B). The second rate $-k_{\text {app } 2}=0.09 \mathrm{~s}^{-1}$ was estimated by hyperbolic fitting, was poorly defined with a high associated error. The slower step might be assigned to a restructuring of the RNA-RNA hybrid after the binding or represent a fraction of duplexes behaving differently than the majority. The behavior 
of the probe was further examined for potential unspecific RNA:RNA interactions in the crowded in vitro system utilized in the next section. Indeed, no fluorescence change was observed when we added asRNA12* to 70S ribosomes or the elongation machinery. As expected, when we used a purified 70S IC formed with the $5^{\mathrm{Q}} \mathrm{RBS}_{20 \mathrm{e}}(\mathrm{UUC})_{78} \mathrm{mRNA}$, no fluorescence change was observed, as the target sequence was occluded by the ribosome (Figure 20A).

In summary, we measured the binding of the asRNA12* to the target RBS of $\mathrm{RBS}_{20 \mathrm{e}}(\mathrm{UUC})_{78}$ mRNA in the absence of the ribosome. In this way we gained understanding of the rate and specificity of duplex asRNA12-target RBS formation. The probe provided direct information on local dynamics of the RBS specifically due to its different fluorescence state in free and target sequence hybridization states. In the next section we included the asRNA12* probe in a reaction where we now probe RBS accessibility during translation of purified $70 \mathrm{~S} I \mathrm{C}$ bearing $5^{\mathrm{Q}} \mathrm{RBS}_{20 \mathrm{e}}(\mathrm{UUC})_{78} \mathrm{mRNA}$.

\subsection{3. asRNA12* as reporter for RBS clearance during the first ribosome elongation}

After we had characterized the binding reaction between the asRNA12* and $\mathrm{RBS}_{20 \mathrm{e}}(\mathrm{UUC})_{78}$ mRNA in equilibrium and at pre-steady-state conditions (Figure 19 and Figure 20), we concluded that it binds to the mRNA efficiently: with apparent association constant of $0.3 \mu \mathrm{M}^{-1} \mathrm{~s}^{-1}$ and it changes specifically fluorescence upon target RBS hybridization. In this part of the results, we included the asRNA12* as an observable of RBS clearance during the first ribosome elongation. Opposite to previously examined signals, where we always observed the recruitment of the second 30S PIC to the 5 '-end labeled mRNAs by FRET or fluorescence change (Section 2.6), we now focused on the fluorescence change of asRNA12* upon target RBS hybridization.

We used purified 70S IC with $5^{\mathrm{Q}} \mathrm{RBS}_{20 \mathrm{e}}(\mathrm{UUC})_{78} \mathrm{mRNA}$, where the first ribosome occluded the RBS and was ready to elongate. These complexes were supplemented with asRNA12*and rapidly mixed with the complete elongation machinery. We predicted that the asRNA12* target sequence will become accessible for hybridization only after the $70 \mathrm{~S}$ elongation complex had moved forward in translation. From previous data we know that asRNA12* did not interact with non-translating complexes (i.e. 70S IC) thus, we did not expect any fluorescence change until the RBS clearance occurred (Figure 20A). Indeed, upon translation no signal was observed until the RBS became accessible for hybridization, causing a $25 \%$ decrease in asRNA12* fluorescence. 
(A)

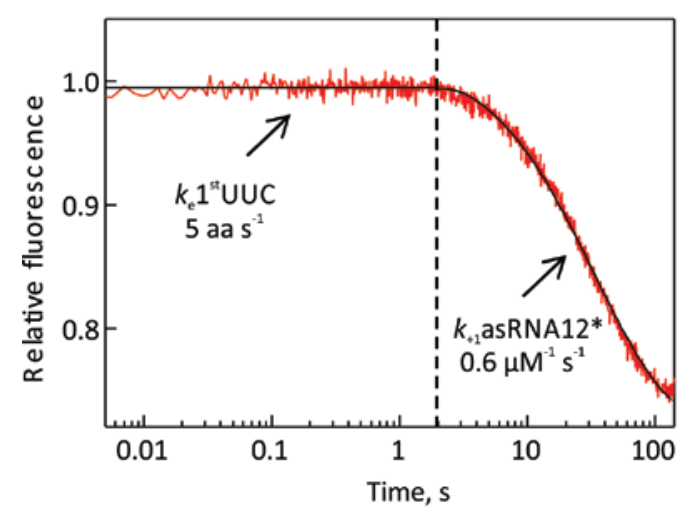

(B)

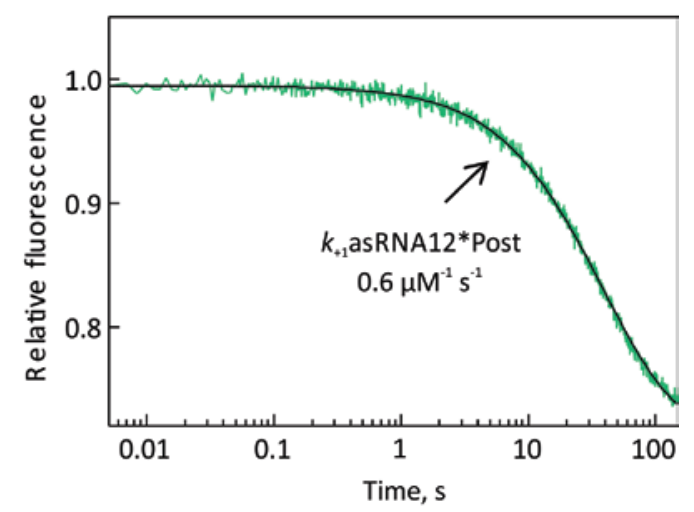

(C)

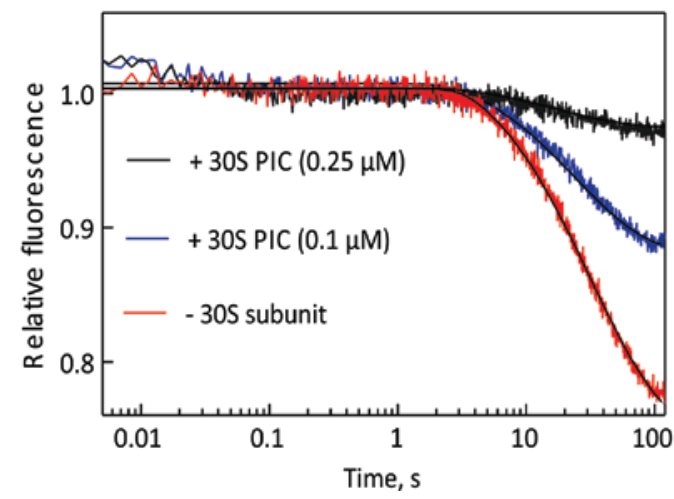

Figure 21. Co-and post translationally recruitment of asRNA12* to the $5^{\mathrm{a}} \mathrm{RBS}_{20 \mathrm{e}}(\mathrm{UUC})_{78}$ mRNA.

(A) The RBS became available for asRNA12* binding only after the 705 ribosome had moved along in translation. Fluorescence change of asRNA12* upon RBS binding was followed in time upon mixing 70S IC $\left(5^{\mathrm{Q}} \mathrm{RBS}_{20 \mathrm{e}}(\mathrm{UUC})_{78}\right)(0.05 \mu \mathrm{M})$ and asRNA12* $(0.025 \mu \mathrm{M})$ with the elongation machinery. The signal was fitted with modified Model (M1) (Figure 14) in which $k_{\mathrm{e}} 1^{\text {st }} \mathrm{UUC}$ was fixed to 5 aa $\mathrm{s}^{-1}$ whereas $k_{+1}$ asRNA12* was let free and resulted in $0.60 \pm 0.01 \mu \mathrm{M}^{-1} \mathrm{~s}^{-1}$. (B) $70 \mathrm{~S} \mathrm{IC}\left(5^{\mathrm{Q}} \mathrm{RBS}_{20 \mathrm{e}}(\mathrm{UUC})_{78} \mathrm{mRNA}\right)(0.05 \mu \mathrm{M})$ translated the mRNA by mixing it with the elongation machinery for $2 \mathrm{~min}$ at $37^{\circ} \mathrm{C}$. The $70 \mathrm{~S}$ post-translation complex was subsequently rapidly mixed with the asRNA12* $(0.025 \mu \mathrm{M})$. The fluorescence change of asRNA12* was followed in time. The signal was fitted with a global fit model M2 (Figure 14) and yielded $k_{+1}$ asRNA12*Post $=0.6 \pm 0.01 \mu \mathrm{M}^{-1} \mathrm{~s}^{-1}$. (C) Same reaction as in (A) but in the presence of the $30 \mathrm{~S} \mathrm{PIC}(0.1 \mu \mathrm{M})$ (blue) and $(0.25 \mu \mathrm{M})$ (black) or no $30 \mathrm{~S}$ subunit (red).

As in previous reactions, where multiple kinetic steps were involved, a global fitting approach was necessary to characterize the kinetics of interactions. We saw similarities between the observed signals and previously examined and kinetically dissected FRET signals depicting the second round of initiation (Section 2.6). The initial delay was due to the movement of the first ribosome along the mRNA, while the fluorescence quenching was due to the asRNA12*-RBS hybridization. Considering the fact that we are using the same $70 S I C\left(5^{{ }} \mathrm{RBS}_{20 \mathrm{e}}(\mathrm{UUC})_{78} \mathrm{mRNA}\right)$ and the same concentration of elongation machinery, the elongation rate of the first ribosome should remain the same as the one observed in the Section 2.6.2, $k_{\mathrm{e}} 1^{\text {st }} \mathrm{UUC}=5 \mathrm{aa} \mathrm{s}^{-1}$. The presence of the asRNA12* would not interfere with the elongation cycle, due to its confirmed specificity (Section 2.7.2). Consequently, we built a model where the elongation rate of each step was restrained to $k_{\mathrm{e}} 1^{\text {st }} \mathrm{UUC}=5$ aa s $\mathrm{s}^{-1}$. The model was 
very similar to the $M 1$ (Figure 14), but instead of $\left(A_{\text {Phe26 }}\right)$ we could accommodate 15 irreversible steps of UUC decoding in the initial fluorescence delay $\left(A_{\text {phe15 }}\right)$ and the fluorescence component $\left(B^{*}\right)$ was the asRNA12* instead of the 30S PIC. The abbreviation of the rates also was similar with the extension asRNA12* (i.e. $k_{+1}$ asRNA12*, $k_{+1}$ asRNA12Post*). The number of elongation steps required for the fit was less than 26 , because we now monitored directly the accessibility of the RBS and not the 30S PIC recruitment. The rate constant of asRNA12* binding to the RBS was $k_{+1}$ asRNA12 $=0.6 \mu \mathrm{M}^{-}$ ${ }^{1} \mathrm{~s}^{-1}$. When we allowed the $70 \mathrm{~S} I \mathrm{C}$ to translate the mRNA for $2 \mathrm{~min}$ at $37^{\circ} \mathrm{C}$ and then mixed with asRNA12* we observed a monophasic fluorescence decrease (Figure 21B). The fluorescence trace was fitted with Model (M2) yielding only single elemental rate of $k_{+1}$ asRNA12Post $=0.6 \mu \mathrm{M}^{-1} \mathrm{~s}^{-1}$. No second step was found in comparison to the recruitment of the oligonucleotide to the mRNA off the ribosome which yielded two rates $\mathrm{k}_{\mathrm{app} 1}$ and $\mathrm{k}_{\mathrm{app} 2}$ (Figure 20B). It could be hypothesized that the disappearance of the second step resulted from remodeling of the mRNA structure by the first ribosome, leading to a single binding step.

The comparison between the obtained elemental rate constants with asRNA12* upon target RBS binding revealed slightly faster elemental rate of asRNA12* binding to the RBS during or post translation $\left(k_{\text {on }}=0.6 \mu \mathrm{M}^{-1} \mathrm{~s}^{-1}\right)$, than to an mRNA off the ribosome $\left(k_{\text {on }}=0.3 \mu \mathrm{M}^{-1} \mathrm{~s}^{-1}\right)$. This effect suggested that the conformation of the mRNA RBS induced by the first ribosome differed from that of the free mRNA and was not detectable with the 30S PIC. Alternatively, free mRNA may entail two (or more) different populations with different propensity to bind asRNA12*, which on average yield $k_{\text {on }}=$ $0.3 \mu \mathrm{M}^{-1} \mathrm{~s}^{-1}$. Translation by the leading ribosome may remodel the mRNA in favor of more readily binding conformation(s). When we included the $30 \mathrm{~S} \mathrm{PIC} \mathrm{in} \mathrm{the} \mathrm{in} \mathrm{vitro} \mathrm{translation} \mathrm{reaction} \mathrm{with}$ asRNA12* we could reduce the fluorescence change amplitude from $25 \%$ until nearly $2 \%$, confirming a competition between the ribosome and the asRNA12* for the RBS (Figure 21C). The approach of including a fluorescence oligonucleotide aiming for the RBS and the start codon sequence of the mRNA during and post translation proved to be a novel method of observing local RBS dynamics. 


\section{Discussion}

During the directional process of protein synthesis, multiple ribosomes simultaneously engage along the sequence of a single mRNA forming a polysomal unit. The process is strongly dependent on the timing of initiation, elongation and termination of each ribosome on the mRNA sequence. Here we have studied the second round translation initiation kinetics during on-going translation in a minimal in vitro reconstituted system. We followed the initiation frequency in realtime with the help of fluorescence observables and fast kinetic approaches. We determined the initiation and elongation rate constants. The high sensitivity and specificity of fluorescence and FRET reporters contributed to unraveling the structural and biochemical events occurring around the RBS of the mRNA, either free or recruited by the ribosome. The mRNA was chosen as an observable because different mRNAs are expected to perform differently in ribosome loading during polysome formation. Therefore, methods that enable efficient, site-specific labeling of various mRNAs are a prerequisite for the characterization of the in vitro ribosome recruitment rates.

How does the RBS of the mRNA affect the first round of initiation?

The use of fluorescently labeled mRNAs in translation so far included (i) 3'-end labeled short mRNAs (14-30 nt) monitoring 30S subunit recruitment or mRNA movement during translocation (Cunha et al., 2013; Milon et al., 2012; Savelsbergh et al., 2003; Studer and Joseph, 2006), (ii) functionally modified nucleosides with emissive properties within the RBS monitoring the elongation cycle (Liu et al., 2013), and (iii) 5'-end fluorescence labeled mRNAs used to monitor IF3 association kinetics to the 30S PIC (Milon et al., 2012). Typically, these mRNAs are short in order to allow monitoring one or very few events in translation. In contrast, we developed and optimized novel methods for production of long, 5'-end labeled mRNAs with different initiation determinants and identical coding sequence (Section 2.1). As the only variable in the canonical translation initiation pathway, the mRNA sequence is predicted to play a major role in the process of polysome formation. Indeed, the design of model mRNAs to uncouple the synergistic effect of initiation and elongation during polysome formation was of great importance. We focused our efforts on the optimization of approaches to produce mRNAs which differed in their overall length, 5'-UTR sequence, the presence and strength of the SD-anti-SD interaction and the propensity of the RBS to form secondary structures. Reducing the coding capacity of the mRNA to only two amino acids - the initiator fMet and phenylalanine - simplified the experimental set up and the following kinetic modeling. By using this approach we additionally synchronized the translation elongation speed and focused only at the initiation region of the mRNAs.

Two enzymatic reactions were modified and optimized for the production of the model mRNAs. Using the enzymatic extension reaction of short, labeled primer mRNAs with a Poly(U)polymerase allowed us to vary the $5^{\prime}$-UTR sequence of the mRNA, while retaining the desired coding sequence, i.e. UUU. An alternative approach utilized a template-directed T7 RNA-polymerase transcription of model mRNAs using a thiol reactive nucleotide incorporated at the 5 '-end of the mRNA. The flexibility of such approach is enormous, because any maleimide reactive dye can be used to label the $5^{\prime}$-end of the transcript if it starts with a guanine nucleotide, which is a prerequisite for priming the efficient in vitro transcription. 
The RBS sequence and structure were both important for the selection of an mRNA for translation, as we observed when testing the model mRNAs in their ability to form 30S IC and 70S IC (Section 2.1). The presence of an enhanced SD region proved to have a stabilizing effect in the process of initiation in agreement with the previous data (reviewed in (Gualerzi and Pon, 2015). Shortening or removing the SD sequence reduced the efficiency of $30 \mathrm{~S} \mathrm{IC} \mathrm{formation,} \mathrm{suggesting} \mathrm{a}$ different affinity of the ribosome to such mRNAs, independent of the coding sequence. The predicted free energies of folding around the RBS did not fully correlate with the efficiencies of $30 \mathrm{~S} \mathrm{IC}$ formation. We observed that the sequence of 5'-UTR had a more drastic effect on the efficiency of the 30 S IC formation and in particular the presence of an enhanced (6 nt-long) SD sequence. For example, an mRNA with a predicted negative $\Delta G^{\circ}$ score (i.e. strongly structured) and enhanced SD had a higher $30 \mathrm{~S} I \mathrm{C}$ efficiency than an mRNAs with a predicted less negative $\Delta \mathrm{G}^{\circ}$ score (i.e. weakly structured) and with shorter SD or no SD sequence. This result agrees with the fact that the $30 \mathrm{~S}$ subunit itself can unfold weak RNA secondary structures in the initiation region if the affinity to the mRNA is high enough (Studer and Joseph, 2006). Moreover, the presence of a fully accessible and unstructured RBS does not counteract an overall low affinity of the 305 subunit to an mRNA. The presence of the $50 \mathrm{~S}$ subunit stabilized all mRNAs upon formation of the 70S IC, independent of their sequence and structure, confirming that later steps along the pathway of initiation also play a role in determining whether an mRNA will enter the pool of translating ribosomes (Milon and Rodnina, 2012).

A great amount of work has been focused on how the RNA re-folding around the start site influence translation efficiencies (Goodman et al., 2013; Kudla et al., 2009; Tuller et al., 2010b). Furthermore, various online calculators use a combination of structure prediction algorithms and limited set of biophysical experiments to estimate the efficiency of translation initiation by correlating it with RNA structure (RBS calculator, UTR designer, RBS designer) (Espah Borujeni et al., 2014; Na et al., 2010; Seo et al., 2013). Computational analyses using prediction algorithms of RNA structures based on its underlying sequence are reasonably accurate (Zuker, 2003). For example, an exchange of only two nucleotides in the RBS caused a decrease in the folding energy from $-4.8 \mathrm{kcal} / \mathrm{mol}$ to -1.4 $\mathrm{kcal} / \mathrm{mol}$ and affected the initiation mechanism of the mRNAs in vitro (Studer and Joseph, 2006). Similarly, $5^{\mathrm{Q}} \mathrm{RBS}_{20 \mathrm{e}}(\mathrm{U})_{250} \mathrm{mRNA}$ and $5^{\mathrm{a}} \mathrm{RBS}_{20 \mathrm{e}}(\mathrm{UUC})_{78}$ mRNA resulted in different predicted free energies $\left(\Delta G^{\circ}\right)$ even though they possessed the same SD and spacer sequence but differed at the codon sequence identity. The presence of repetitive UUC instead of UUU, which left the product of the mRNA unchanged, showed different contribution to the overall folding energy of the RBS. Despite a progress in predicting the efficiency of initiation and mRNA folding in silico there is a need for a better mechanistic understanding of translation initiation with different mRNAs.

The timing and kinetics of the first initiation event was a specific feature of each MRNA and depended on the RBS. We used FRET to study 30 S PIC recruitment to various labeled mRNAs in the presence of all the initiation factors and GTP (Section 2.2). In order to isolate the first association step in the initiation pathway, we excluded the initiator tRNA which is known to be part of later steps in the process - i.e. start codon recognition and accommodation (Milon et al., 2008). IF3(Alx488) and S13(Alx488) reconstituted into the $30 \mathrm{~S}$ subunit as observables reported the $5^{\prime}$ ATTO540Q mRNAs recruitment. IF3 is one of the first factors to bind to the 30S PIC with an association rate of $k_{\text {on }}$ about 
$1000 \mu \mathrm{M}^{-1} \mathrm{~s}^{-1}$ and with very high affinity $-\mathrm{K}_{\mathrm{d}}<0.1 \mathrm{nM}$ (Milon et al., 2012). The reported high affinity made IF3 bound to the 30S subunit an excellent candidate to monitor mRNA binding.

We screened ten different 5 '-end labeled mRNAs for a FRET signal appearing upon mRNA binding to the 30S PIC carrying IF3(Alx488) or 30S(Alx488) PIC. It turned out that only the mRNAs with strong (6 nt) SD sequence gave a change in FRET signal upon binding, independent of their predicted free energy of RBS folding or length. The appearance of FRET not only indicated that the mRNA was recruited to the $30 \mathrm{~S}$ PIC, but also pointed to distance dependent events occurring during the process, localizing the flexible $5^{\prime}$-end within the $\mathrm{R}_{0}$ of the FRET labels (62 $\AA$ ). The mRNAs with short ( $3 \mathrm{nt}$ ) or no SD sequence resulted in the absence of stabilization of these mRNAs seen during the 30S IC formation, reducing their efficiency in the process. Even if the biding of these mRNAs to the 30S PIC was only transient, we would still expect to detect a FRET signal, however no such was observed between the $5^{\prime}$-end of these mRNAs and IF3 or S13. We interpreted the lack of FRET signal as an indication that the position of the $5^{\prime}$-end was far greater than the $\mathrm{R}_{0}$ of the FRET pair. Crystallography had mapped the exact pathway of the mRNA in the 70S initiation complex suggesting that mRNAs lacking SD have a different exit path from the ribosome during elongation than an mRNA possessing a SD (Yusupova et al., 2006). However, the exact position of the sequence upstream of the SD sequence is expected to vary between different mRNA and due to RNA flexibility and it is challenging to exactly locate.

As alternative to the FRET pairs in use (i.e. mRNA-IF3 and mRNA-30S subunit), $5 * R^{2} S_{18 \mathrm{e}}(U)_{250}$ mRNA enriched our fluorescence-based toolbox by adding another point of view on the mRNA recruitment process, because it was labeled with a fluorescent dye instead of a dark, non-fluorescent acceptor. The analysis of the fluorescence change observed upon binding of the mRNA to label-free 30S PIC, reported a rate constant for the mRNA recruitment $\left(15 \mu \mathrm{M}^{-1} \mathrm{~s}^{-1}\right)$ similar to the rate determined with labeled components $\left(25 \mu \mathrm{M}^{-1} \mathrm{~s}^{-1}\right.$ and $\left.24 \mu \mathrm{M}^{-1} \mathrm{~s}^{-1}\right)$, confirming the specificity and efficiency of the FRET system. A kinetic model of the 30S IC assembly by Milon et al. revealed the exact timing and choreography of the events. In the absence of mRNA the 30S subunit recruited the initiation factors and fMet-tRNA ${ }^{\mathrm{fMet}}$ very rapidly, within about $130 \mathrm{~ms}$. The arrival time of the mRNA was a specific feature of each mRNA. We performed a kinetic analysis of the recruitment of the mRNAs and as a result of detailed exponential and global kinetic fitting approaches, we resolved the association rate of 30S PIC to the model mRNAs with two different RBS, but same coding potential (Section 2.3). FRET between the $5^{\prime}$-end labeled mRNAs and 30S(Alx488) subunit reported a single association step for the $5^{\mathrm{a}} \mathrm{RBS}_{18 \mathrm{e}}(\mathrm{U})_{250}$ and $5^{\mathrm{Q}} \mathrm{RBS}_{20 \mathrm{e}}(\mathrm{UUC})_{78}$ mRNAs. The association rate constants of the mRNAs with the 30S PIC correlated with the predicted RBS free energies of folding. In our study a difference from $+0.5 \mathrm{kcal} / \mathrm{mol}$ to $-4 \mathrm{kcal} / \mathrm{mol}$ in the $\Delta G^{\circ}$ caused more than $10-$ fold reduction in the association rate constant between $5^{\mathrm{Q}} \mathrm{RBS}_{18 \mathrm{e}}(\mathrm{U})_{250}\left(25 \mu \mathrm{M}^{-1} \mathrm{~s}^{-1}\right)$ and $5^{\mathrm{Q}} \mathrm{RBS}_{20 \mathrm{e}}(\mathrm{UUC})_{78}\left(1.1 \mu \mathrm{M}^{-1} \mathrm{~s}^{-1}\right)$ mRNA (Table 2). We could exclude that the observed difference was due to the different length of the mRNAs, since reducing the length of $5^{\mathrm{a}} \mathrm{RBS}_{18 \mathrm{e}}(\mathrm{U})_{250}$ mRNA did not affect the rate of recruitment to the $30 \mathrm{~S}$ PIC. The fact that the $5^{\prime}$-end of $5^{\mathrm{Q}} \mathrm{RBS}_{20 \mathrm{e}}(\mathrm{UUC})_{78}$ mRNA was longer with two additional nucleotides - each contributing $6 \AA$ to the length of the mRNA - might have an effect on the positioning of the ATTO540Q dye further away from the donor dye, thereby altering the FRET efficiency. We also reported that the fluorescent amplitudes of the recruitment with $5^{\mathrm{Q}} \mathrm{RBS}_{20 \mathrm{e}}(\mathrm{UUC})_{78}$ mRNA and 30S(Alx488) subunit or IF3(Alx488) were 2-5-fold lower than the same reaction observed 
with $5^{\mathrm{Q}} \mathrm{RBS}_{18 \mathrm{e}}(U)_{250}$ mRNA. The base pairing predicted within the $5^{\mathrm{a}} \mathrm{RBS}_{20 \mathrm{e}}(U \mathrm{UC})_{78} \mathrm{mRNA}$ did not involve the extreme $5^{\prime}$-end of the mRNA but rather the SD region and the first codons after the start codon. We therefore assumed that the 5 '-end was free to interact with the 30 s subunit and not involved directly in any secondary structure.

30S(Alx488) subunit and IF3(Alx488) bound on the 30 S subunit gave different perspective on the process of mRNA recruitment. IF3 proved to be more dynamic on the 30S PIC in comparison to S13. Multiple steps were observed upon mRNAs recruitment when the initiation factor was used. The factor discriminated between different mRNA utilized. For example, a minimum of three elemental steps were needed to resolve the kinetic behavior of IF3(Alx488) upon $5^{{ }^{a}} \mathrm{RBS}_{20 \mathrm{e}}(\mathrm{UUC})_{78} \mathrm{mRNA}$ binding (Figure 10B). It is tempting to speculate that the factor senses the movements of the $30 \mathrm{~S}$ subunit. As a consequence the steps after the binding might be assigned to the mRNA restructuring during the process of initiation. It is not excluded that the observed dynamics of IF3 were more global and connected to the interplay between IF1 and IF2 on the 30S subunit, rather than correlated with direct mRNA adjustments.

What modulates the frequency of initiation?

In prokaryotes, proteins are synthesized in vivo at a rate of $10-20$ aa $\mathrm{s}^{-1}$ at $37^{\circ} \mathrm{C}$ under exponential growth (Dennis and Bremer, 1974). The apparent translation initiation rate can vary for each mRNAs in the range of 25 -fold $\left(0.2\right.$ to $5 \mathrm{~s}^{-1}$ ) (Chu et al., 2014). The relative role of initiation versus elongation rates in setting the protein abundance profile is an actively discussed topic. The sequential character of protein synthesis demands interdependence of initiation, elongation, termination and de novo initiation on the same mRNA. Clearance of the start site was suggested to be a novel control mechanism in yeast, where slowly decoded codons at the beginning of the mRNA sequence lower the frequency of loading of the following ribosomes (Chu et al., 2014). As a result of biochemical and computer simulation experiments codon usage was directly linked to translation initiation. Alternatively, faster initiation than elongation would lead to ribosome queuing along the sequence and slow down elongation (Mitarai et al., 2008). In our system we aimed at synchronizing the elongation rate and uncouple the effects of codon usage as a potential modulator of polysome formation. Using pre-steady state kinetics we measured the rates of clearance of the initiation region from the first ribosome on the model mRNAs (Section 2.4). Using a FRET approach we revealed the minimum initiation frequency of ribosomes loaded on model mRNAs $-t_{\mathrm{f}} 2^{\text {nd }}$ (Section 2.5). The time needed for the ribosome clearance to occur and the second ribosome to initiate binding was estimated to be 3-4 s measured in vitro in a minimal translation system. The result is in very good agreement with data measured in vivo in the context of gene expression (Kennell and Riezman, 1977), by computer simulation algorithms (Kierzek et al., 2001) and by mathematical modeling (Mitarai et al., 2008).

In order to assess whether the kinetics of elongation by the first ribosome affected the following initiation event we modulated its speed by varying the concentrations of essential components of rapid translation, TC, EF G, and GTP (Figure 13). The ternary complex EF-Tu-GTP-PhetRNA $^{\text {Phe }}$ supplied the needed substrate for protein synthesis-appreciated with both in vitro aminoacylation reaction and purified charged Phe-tRNA ${ }^{\text {Phe }}$. The $t_{\mathrm{f}} 2^{\text {nd }}$ depended on EF-G translocation 
on the first ribosome. We could slow down 10-fold the second recruitment event by limiting the elongation of the first ribosome by reducing EF-G concentration. Increasing the concentration of EF-G did not accelerate the $t_{f} 2^{\text {nd }}$ more than 2-4 s. A similar effect was observed when we utilized GTP $\gamma \mathrm{S}$ in the reaction. The frequency of second initiation event was delayed in the presence of GTP $\mathrm{S}$ compared to GTP. Slowly hydrolysable analogs of GTP still sustain translocation, however more than 50-fold slower (Rodnina et al., 1997). They are known to reduce the rates of the GTPase of both EF-Tu and EF-G, which are crucial for rapid elongation. The frequency of second round initiation depended on the rate of clearance of the start site and not on the nature of the RBS of the mRNA being translated. All three mRNAs tested resulted in a similar frequency of second ribosome initiation, suggesting translation elongation near the star site as primary regulator of ribosome loading in polysomes.

Mechanisms of the second initiation event.

This work provided the first quantitative insight into the process of the second round initiation by building a kinetic model based on the fluorescence signals obtained with a pre-steady state approach (Section 2.6). We used the mRNAs that (i) were efficiently recruited to the 30S PIC and (ii) had repetitive coding sequence that made it easy to calculate the rate of elongation by the first ribosome. Because we start with synchronized 70S IC that are positioned at the start codon, the RBS was not structured at the beginning of the experiment. Our model simplified the initiation pathway to a single step, the recruitment of the 30S PIC to the $5^{\prime}$-end of the model mRNA. Later steps along the pathway of $30 \mathrm{~S} \mathrm{IC} \mathrm{formation,} \mathrm{such} \mathrm{as} \mathrm{mRNA} \mathrm{unwinding} \mathrm{and} \mathrm{fMet-tRNA}{ }^{\text {fMet }}$ accommodation are also considered important checkpoints to competent complex formation (Milon et al., 2012). However, as we use mRNAs with optimal SD and start codon, the rearrangements during the maturation of the 30S IC may be rapid compared to the recruitment step. In fact, the rate constants of mRNA association with the $30 \mathrm{~S}$ subunit, 5 to $25 \mu_{\mathrm{M}}^{-1} \mathrm{~s}^{-1}$ were lower than those reported for the model mRNAs by Milon et al., 2012, suggesting that the association step may be the rate-limiting step for the mRNA constructs used here. Kinetic modeling allowed us to investigate the peptide elongation on the first ribosome and the recruitment of the second ribosome. We excluded any effect of pausing due to codon bias, positively charged amino acid interacting with the protein exit channel or secondary structures along the coding region because we utilize a repetitive codon sequence, which allowed us to assume that every step of elongation proceeds with the same rate. Translation of 24-26 codons, leading to the movement of the ribosome by 72-78 nt away from the start codon, was sufficient for the recruitment of the following ribosome. Interestingly, this distance between the ribosomes was much larger than expected based on the 10-12 codons covered in the mRNA tunnel of the ribosome (Steitz and Jakes, 1975). With an elongation rate of the first ribosome of 8 aa s${ }^{-1}$, the first ribosome would leave the RBS after $1.5 \mathrm{~s}$, which was significantly less than the experimentally observed loading frequency of 3-4 s. Thus, the distance between the two adjacent ribosomes, and the time of loading, were larger than theoretically possible based on the ribosome footprint alone and may be caused by the proximity and dynamics of outer parts of the ribosome, e.g. ribosome stalks comprised by proteins L7/12 or L1. 
During translation, the mRNA exits the mRNA channel and may start folding back to a conformation that it assumes free in solution or to an alternative conformation induced by the first ribosome. The timing of the structuring events may affect the recruitment of the second ribosome. By implementing the kinetic model we obtained a set of elemental rates, which revealed that the 30S PIC recruitment followed two kinetically different mechanism depending on the mRNA used. The first type of mechanism was exemplified by the mRNA with a predicted secondary structure $\left(5^{\mathrm{Q}} \mathrm{RBS}_{20 \mathrm{e}}(\mathrm{UUC})_{78} \mathrm{mRNA}\right)$. In this case, the recruitment of the second 30S PIC was not affected by the presence of the first ribosome and proceeded with the same rate as the first recruitment event. A scenario where the RBS restructuring occurred could not be excluded, but the RBS folding could occur faster than the 30S PIC recruitment. Our data differ from the observation obtained in a cell-free translation system where the elemental rate of initiation on polysomes was 3-fold faster than that on free mRNA, without a ribosome along the sequence (Underwood et al., 2005). The cause of this acceleration was suggested to depend on the opening of the RBS sequence by the first ribosome, which facilitated the following initiation event. However, in the same system the frequency of ribosome loading was found to occur every $60 \mathrm{~s}$, leaving 90 aa (270 nt) between two adjacent ribosomes. Such distances minimize any kind of interaction between ribosomes, thus questioning the nature of the observed acceleration.

Contrary to $5^{\mathrm{Q}} \mathrm{RBS}_{20 \mathrm{e}}(\mathrm{UUC})_{78} \mathrm{mRNA}$, the kinetic analysis with $5^{\mathrm{Q}} \mathrm{RBS}_{18 \mathrm{e}}(\mathrm{U})_{250}$ mRNA revealed differences between the elemental rates of the first and the second 30S PIC recruitment. The main difference between the two mRNAs was the nature of the repetitive codon sequence, contributing to the overall folding energy of the RBS. Depending on the observable we utilized, the 30S(Alx488) subunit, IF3(Alx488) or the 5 '-end fluorescence change, we determined that the second recruitment event was slower ( 3 to 25 -fold) when compared to the first initiation event. The great difference between the rates might be due to the fact that the utilized observables capture different dynamic conformations of the emerging mRNA. While the first initiation event depends solely on the RBS availability, mRNA abundance and conformational rearrangements in the $30 \mathrm{~S} \mathrm{IC} \mathrm{due} \mathrm{to} \mathrm{initiation}$ factors dynamics, the second initiation events, which occurs co-translationally, may depend on the first ribosome elongating on the message. The flexible nature of the $5^{\prime}$-end emerging from the mRNA channel might adopt various non-optimal conformations hindering the second ribosome recruitment due to a steric clash with the flexible periphery of actively translating ribosomes. Such potential interaction might also be present in the case of a slowly initiating RBS ( $\left.5^{a} R S_{20 e}(U U C)_{78} m R N A\right)$. The exact magnitude of the effect depended on the sequence details of the mRNA.

Structural data indicated that the $70 \mathrm{~S}$ ribosome preserves contacts with the $5^{\prime}$-UTR of the mRNA even after the elongation cycle has begun (Yusupova et al., 2006). Crucial RNA-RNA base paring at the SD sequence contribute to the stability of this complex. In this case, the availability of the $5^{\prime}$-end may correlate with the rate of translation of the first ribosome. To study the fate of the mRNA $5^{\prime}$-end, we followed the dynamic changes of the mRNA environment utilizing $5^{\mathrm{a}} \mathrm{RBS}_{\mathrm{e} 18}(\mathrm{U})_{250}$ mRNA. Although we can only speculate about the exact nature of the fluorescence change, it proved to be a reliable and specific observable of the process of second 30S PIC recruitment. We detected that the RBS of the mRNA released the potential contacts with the first ribosome after 2-3 s, giving a chance for a second ribosome to initiate. This delay time was again longer than expected for the ribosome to clear its initial footprint on the RBS. Thus, also the availability of the mRNA 5 '-end for 
interactions with other ligands was delayed upon ongoing translation. We could assess the post elongation state of the RBS by letting the first ribosome translate the mRNA, free the RBS and then halt at the end of the sequence. We then measured the recruitment of the second ribosome to the mRNA. In this assay we aimed at decoupling the effects of the first ribosome proximity to the RBS from the second ribosome attempting to initiate. For all the mRNAs utilized the post state of 30S PIC recruitment was similar to the first initiation event, which meant that after the first elongating ribosome cleared the start codon and moved sufficiently away from the RBS the 5 '-end returned to its initial state. This initial state however was not the same as the one induced by the first ribosome cotranslationally, enhancing the notion that the mRNA can adopt multiple conformations during elongation.

One remaining question was how fast the mRNA emerging from the first ribosome cotranslationally assumes its secondary structure. Ribosome progression along a transcript unwinds mRNA secondary structures which could either identically reform after its transit or adopt a different conformation. RNA folding happens in the microsecond time range and it is difficult to capture in combination with some biological processes which happen in the millisecond-to-second time range (Lee et al., 2007; Porschke, 1974). However, duplex formation of nucleic acids (RNA-RNA, DNA-RNA or DNA-DNA) has been observed with stopped-flow approach and was found to proceed in the millisecond time range (Rauzan et al., 2013; Zuo et al., 1990). Such approach can resolve more ensemble kinetic events during the complementary base pairing reaction, such as binding, global restructuring and formation of new hydrogen bonds between the nucleic acids.

We designed an assay where we can observe the time evolution of an RNA-RNA duplex formation. We aimed to establish a method to probe directly the structure around the RBS sequence of $\mathrm{RBS}_{20 \mathrm{e}}(\mathrm{UUC})_{78} \mathrm{mRNA}$ : off the ribosome, during the first ribosome elongation and after the first ribosome elongation (Section 2.7). We chose $R_{B S} S_{20 e}(U U C)_{78} m R N A$ due to its predicated secondary structure potential around the RBS and due to the fact we have dissected kinetically the recruitment of the first and the second ribosome with donor-dye labeled proteins from the initiation machinery. A short (12 nt) anti-sense RNA oligonucleotide, fully complementary to the RBS sequence next to the start codon, bound its target sequence and stabilized a single conformation on the mRNA as seen under native conditions. Furthermore, the labeled asRNA12* provided direct information on the local dynamics of the RBS due to its different intrinsic fluorescence states when free or hybridized to its target sequence. The binding of the short fluorescence-labeled RNA oligonucleotide to its target was specific and not affected by the crowded environment resulting from the presence of the translation machinery in the reaction mixture. We included it to the current fluorescence toolbox as an observable to report on the availability of the RBS right after the clearance of the translation initiation region by the leading ribosome. Using global fitting approach we resolved that after 15 aa, translated by the ribosome, the target sequence became available for hybridization. The rate of cotranslationally asRNA12* recruitment was slightly faster (2-fold) in comparison to the same rate off the ribosome. Interestingly, the post state of the RBS was recruited by the asRNA12* with the same rate, suggesting a mechanism in which the first ribosome had restructured the RBS upon its progression along the mRNA. These subtle differences in conformational features could only be detected by asRNA12*. When we included in the reaction the 30 S PIC it competed with the asRNA12* for binding the RBS. Notably, most small RNAs are anti-sense RNAs, which exhibit their action by 
competing with the ribosome for the translation initiation region, inactivating the mRNA for further expression (Wagner and Flardh, 2002). As a summary, we established a novel tool to monitor RBS dynamics during a single round translation elongation of the first ribosome. The advantages of including an oligonucleotide complementary to the target RBS included the specificity of the fluorescence change, precision of the binding localization, feasibility, and simplicity of the experimental setup. The asRAN12* provided direct information on local dynamics of the RBS during initiation site clearance.

In summary, the approaches described in this thesis allowed us to simultaneously resolve the elemental rates of translation elongation and initiation and to dissect the complexity of the process of polysome formation in vitro. In perspectives, the characterized kinetic models can be further enriched with the later steps in the process of second round initiation, namely codon-anticodon interactions and $50 \mathrm{~S}$ subunit joining. Variable model and natural RBS can be labeled and tested in the in vitro translation system, including leaderless mRNAs, whose initiation mechanism is still under investigation. Collecting a larger set of rate constants might help distinguish the rate-limiting step (s) during the process of polysome formation, expecting that various mRNA will differ in their ribosome loading potential. Including natural mRNAs with non-uniform translation elongation rates would require more comprehensive models able to calculate the number of elongation steps needed for RBS clearance and their individual rates. Because the ribosomes are located on average not far apart on mRNAs, they might interact with each other and influence each other's functions and dynamics. In the future it might be possible to visualize in real-time interactions across neighboring ribosomes, for example between the mobile, periphery stalks or the 30 s subunits heads. In line with these thoughts, detailed map of mRNA dynamic conformations induced by the elongating ribosomes might provide important regulatory steps during translation. 


\section{Material and Methods}

\subsection{Equipment}

Table 6. List of equipment.

\begin{tabular}{|c|c|}
\hline Instrument & Manufacturer \\
\hline Äkta Purifier Plus & GE Healthcare \\
\hline Avanti J-26S XP centrifuge & Beckman Coulter GmbH, Krefeld, Germany \\
\hline Avanti J-30 I centrifuge & Beckman Coulter GmbH, Krefeld, Germany \\
\hline Branson Sonifier & Emerson, St. Louis, USA \\
\hline Centrifuge 5424 & Eppendorf AG, Hamburg, Germany \\
\hline Centrifuge 5810R & Eppendorf AG, Hamburg, Germany \\
\hline Innova 44 shaker & Eppendorf AG, Hamburg, Germany \\
\hline Intelli Mixer RM-2 & Elmi Ltd,Riga, Latvia \\
\hline Milli-Q water purification system & Merck KGaA, Darmstadt, Germany \\
\hline $\begin{array}{l}\text { Mini-PROTEAN Tetra Vertical } \\
\text { Electrophoresis Cell }\end{array}$ & California, USA \\
\hline $\begin{array}{l}\text { NanoDrop 2000c UV-Vis } \\
\text { Spectrophotometer }\end{array}$ & Thermo Fisher Scientific, Karlsruhe, Germany \\
\hline Optima MAX-XP ultracentrifuge & Beckman Coulter GmbH, Krefeld, Germany \\
\hline PeqLab UV transilluminator & VWR International GmbH, Darmstadt, Germany \\
\hline $\begin{array}{l}\text { PerfectBlue Dual Gel System Twin } \\
\text { ExW S }\end{array}$ & VWR International GmbH, Darmstadt, Germany \\
\hline PerfectBlue Gel system Mini S & VWR International GmbH, Darmstadt, Germany \\
\hline $\begin{array}{l}\text { Phosphorimager Fuji Film Fla } \\
7000 / 9000\end{array}$ & GE Healthcare, Germany \\
\hline $\begin{array}{l}\text { QUANTUM 26MX Gel documentation } \\
\text { system }\end{array}$ & VWR International GmbH, Darmstadt, Germany \\
\hline Quench Flow & KIN-TEK Laboratories, Texas, USA \\
\hline SX-20MV stopped-flow apparatus & Applied Photophysics, Leatherhead, UK \\
\hline Thermo-cycler PeqStar & VWR International GmbH, Darmstadt, Germany \\
\hline Thermomixer comfort & Eppendorf AG, Hamburg, Germany \\
\hline Tri-Carb 3110 TR Counter & PerkinElmer GmbH, Rodgau, Germany \\
\hline Vortex Genie 2 & Scientific Industries, Inc., Bohemia, NY, USA \\
\hline
\end{tabular}




\subsection{Chemicals and Consumables}

Table 7. List of chemicals and consumables.

\begin{tabular}{|c|c|}
\hline Compounds/kits & Manufacturer \\
\hline$\left[{ }^{14} \mathrm{C}\right]$ Phenylalanine & Perkin Elmar - Massachusetts, USA \\
\hline$\left[{ }^{3} \mathrm{H}\right]$ Methionine & Perkin Elmar - Massachusetts, USA \\
\hline Acetic acid & Merck KGaA, Darmstadt, Germany \\
\hline Acrylamide $4 x$ & SERVA electrophoresis GmbH, Heidelberg, Germany \\
\hline $\begin{array}{l}\text { Acrylamide/Bis Solution } 40 \% \mathrm{w} / \mathrm{v}(19: 1 \\
\text { and } 29: 1)\end{array}$ & SERVA electrophoresis GmbH, Heidelberg, Germany \\
\hline Agar-agar & Carl Roth GmbH, Karlsruhe, Germany \\
\hline Agarose SERVA for DNA electrophoresis & SERVA electrophoresis GmbH, Heidelberg, Germany \\
\hline Alexa 488 maleimide (Alx488) & Life Technologies - Darmstadt, Germany \\
\hline Ammonium chloride & Merck KGaA, Darmstadt, Germany \\
\hline Ammonium peroxodisulfate (APS) & Merck KGaA, Darmstadt, Germany \\
\hline Ampicillin & Sigma-Aldrich Chemie GmbH, Steinheim, Germany \\
\hline Antarctic Phosphatase with 10x buffer & New England BioLabs GmbH, Frankfurt am Main, Germany \\
\hline ATP lyophilized & Jena Bioscience GmbH, Jena, Germany \\
\hline ATTO540Q maleimide & ATTO-TEC, Siegen, Germany \\
\hline Beckman Coulter Tube & Beckman Coulter GmbH, Krefeld, Germany \\
\hline Bis-Tris & Sigma-Aldrich Chemie GmbH, Steinheim, Germany \\
\hline Boric acid & Merck KGaA, Darmstadt, Germany \\
\hline Bromphenol Blue sodium salt & Merck KGaA, Darmstadt, Germany \\
\hline Coomassie Blue G250 & Merck KGaA, Darmstadt, Germany \\
\hline $\begin{array}{l}\text { Deoxyribonucleotide (dNTP) solution } \\
\text { mix }\end{array}$ & New England BioLabs GmbH, Frankfurt am Main, Germany \\
\hline Dimethylformamide (DMF) & Merck KGaA, Darmstadt, Germany \\
\hline $\begin{array}{l}\text { Disodium hydrogen phosphate } \\
\text { dihydrate }\end{array}$ & Merck KGaA, Darmstadt, Germany \\
\hline DMSO & Merck KGaA, Darmstadt, Germany \\
\hline DNase I & Sigma-Aldrich Chemie GmbH, Steinheim, Germany \\
\hline Dodecylsulphate-Na-salt pellets & SERVA electrophoresis GmbH, Heidelberg, Germany \\
\hline Dpnl & New England BioLabs GmbH, Frankfurt am Main, Germany \\
\hline Dral & New England BioLabs GmbH, Frankfurt am Main, Germany \\
\hline DTT Biochemica & AppliChem GmbH, Darmstadt, Germany \\
\hline D-Tube Dialyzers & Merck KGaA, Darmstadt, Germany \\
\hline EcoRI-HF & New England BioLabs GmbH, Frankfurt am Main, Germany \\
\hline Ethanol & Merck KGaA, Darmstadt, Germany \\
\hline Ethylenediaminetetraacetic acid (EDTA) & Merck KGaA, Darmstadt, Germany \\
\hline
\end{tabular}




\begin{tabular}{|c|c|}
\hline Glycerol & Merck KGaA, Darmstadt, Germany \\
\hline Glycine & Merck KGaA, Darmstadt, Germany \\
\hline GMP - Iyophilized & Jena Bioscience GmbH, Jena, Germany \\
\hline GTP & Sigma-Aldrich Chemie GmbH, Steinheim, Germany \\
\hline $\begin{array}{l}\text { Guanosine 5'-O-[y-thio]triphosphate } \\
\text { (GTPYS) }\end{array}$ & Jena Bioscience $\mathrm{GmbH}$, Jena, Germany \\
\hline Guanosine-5'-0-monophosporothioate & BioLog, Bremen, Germany \\
\hline HEPES & Sigma-Aldrich Chemie GmbH, Steinheim, Germany \\
\hline HindIII-HF & New England BioLabs GmbH, Frankfurt am Main, Germany \\
\hline HiTrap Q columns ( $1 \mathrm{ml}$ or $5 \mathrm{ml})$ & GE Healthcare, Germany \\
\hline Hydrochloric acid & Merck KGaA, Darmstadt, Germany \\
\hline Imidazole & Merck KGaA, Darmstadt, Germany \\
\hline IPTG & Carl Roth GmbH, Karlsruhe, Germany \\
\hline Kanamycin sulfate & SERVA electrophoresis GmbH, Heidelberg, Germany \\
\hline $\begin{array}{l}\text { Macharey-Nagel Plasmid Preparation } \\
\text { Kit }\end{array}$ & MACHEREY-NAGEL GmbH \& Co. KG, Düren, Germany \\
\hline Magnesium chloride hexahydrate & Merck KGaA, Darmstadt, Germany \\
\hline Methanol & Merck KGaA, Darmstadt, Germany \\
\hline Methylene Blue & Merck KGaA, Darmstadt, Germany \\
\hline N,N' Methylene Bisacrylamide $2 x$ & SERVA electrophoresis GmbH, Heidelberg, Germany \\
\hline NEB2 Buffer (10x) & New England BioLabs GmbH, Frankfurt am Main, Germany \\
\hline $\mathrm{Ni}^{2+-}$ Agarose & Qiaqen, Hilden, Germany \\
\hline NTPs & Jena Bioscience GmbH, Jena, Germany \\
\hline NucleoSpin Gel and PCR clean up & Macherey Nagel GmbH, Düren, Germany \\
\hline NucleoSpin Plasmid kit & Macherey Nagel GmbH, Düren, Germany \\
\hline Pefablock & Sigma-Aldrich Chemie GmbH, Steinheim, Germany \\
\hline Phosphoenolpyruvate & Sigma-Aldrich Chemie GmbH, Steinheim, Germany \\
\hline $\begin{array}{l}\text { Phusion High Fidelity DNA Polymerase } \\
\text { provided with } 5 x \text { HF buffer }\end{array}$ & New England BioLabs GmbH, Frankfurt am Main, Germany \\
\hline Potassium acetate & Merck KGaA, Darmstadt, Germany \\
\hline Potassium chloride & Merck KGaA, Darmstadt, Germany \\
\hline Potassium dihydrogen phosphate & Merck KGaA, Darmstadt, Germany \\
\hline Potassium hydroxide & Merck KGaA, Darmstadt, Germany \\
\hline Putrescine dihydrochloride & Sigma-Aldrich Chemie GmbH, Steinheim, Germany \\
\hline Pyrophosphatase & Sigma-Aldrich Chemie GmbH, Steinheim, Germany \\
\hline Pyruvate kinase from rabbit muscle & $\begin{array}{l}\text { Roche Diagnostics Deutschland GmbH, Mannheim, } \\
\text { Germany }\end{array}$ \\
\hline QIAEX II Gel Extraction Kit & Qiaqen, Hilden, Germany \\
\hline Quick T4 DNA Ligase provided with $2 x$ & New England BioLabs GmbH, Frankfurt am Main, Germany \\
\hline
\end{tabular}




\begin{tabular}{|ll|}
\hline quick ligation buffer & \\
\hline RNAeasy (mini,midi,maxi) kit & Qiaqen, Hilden, Germany \\
\hline RNase inhibitor & Promega GmbH, Mannheim, Germany \\
\hline Scintillation cocktail Quickszint 361 & Zinsser analytic - Maidenhead, U.K \\
\hline SERVA DNA Stain G & SERVA electrophoresis GmbH, Heidelberg, Germany \\
\hline SmartLadder & Eurogentec Deutschland GmbH, Köln, Germany \\
\hline Sodium acetate & Merck KGaA, Darmstadt, Germany \\
\hline Sodium bicarbonate & Merck KGaA, Darmstadt, Germany \\
\hline Sodium carbonate & Merck KGaA, Darmstadt, Germany \\
\hline Sodium chloride & Merck KGaA, Darmstadt, Germany \\
\hline Sodium hydroxide & Merck KGaA, Darmstadt, Germany \\
\hline Spermidine trihydrochloride & Sigma-Aldrich Chemie GmbH, Steinheim, Germany \\
\hline Sucrose & Merck KGaA, Darmstadt, Germany \\
\hline TCA & Merck KGaA, Darmstadt, Germany \\
\hline TEMED & Sigma-Aldrich Chemie GmbH, Steinheim, Germany \\
\hline Tricine & Sigma-Aldrich Chemie GmbH, Steinheim, Germany \\
\hline Tris(hydroxymethyl)aminomethane & Merck KGaA, Darmstadt, Germany \\
\hline Tryptone & Carl Roth GmbH, Karlsruhe, Germany \\
\hline Urea & Merck KGaA, Darmstadt, Germany \\
\hline Xylene cyanol FF & Merck KGaA, Darmstadt, Germany \\
\hline $\boldsymbol{\beta}$-mercaptoethanol & Sigma-Aldrich Chemie GmbH, Steinheim, Germany \\
\hline
\end{tabular}

\subsection{Buffers}

Table 8. List of buffers.

\begin{tabular}{|c|c|}
\hline Buffer/media & Composition \\
\hline \multicolumn{2}{|l|}{ Media } \\
\hline LB medium & $10 \mathrm{~g} / \mathrm{L} \mathrm{NaCl}, 10 \mathrm{~g} / \mathrm{L}$ tryptone, $5 \mathrm{~g} / \mathrm{L}$ yeast extract \\
\hline \multicolumn{2}{|l|}{ Reaction buffers } \\
\hline TAKM $_{7}$ & $50 \mathrm{mM}$ Tris pH 7.5, $70 \mathrm{mM} \mathrm{NH}_{4} \mathrm{Cl}, 30 \mathrm{mM} \mathrm{KCl}, 7 \mathrm{mM} \mathrm{MgCl} 2$ \\
\hline 5x Transcription buffer & $200 \mathrm{mM}$ Tris- $\mathrm{HCl} \mathrm{pH}$ 7.5, $75 \mathrm{mM} \mathrm{MgCl}$, $10 \mathrm{mM}$ spermidine, $50 \mathrm{mM} \mathrm{NaCl}$ \\
\hline HiFi & $\begin{array}{l}50 \mathrm{mM} \text { Tris- } \mathrm{HCl}, \mathrm{pH} 7.5,50 \mathrm{mM} \mathrm{NH}{ }_{4} \mathrm{Cl}, 50 \mathrm{mM} \mathrm{KCl}, 3.5 \mathrm{mM} \mathrm{MgCl}{ }^{2}, 0.5 \\
\mathrm{mM} \text { spermidine, } 8 \mathrm{mM} \text { putrescine, } 2 \mathrm{mM} \text { DTT }\end{array}$ \\
\hline \multicolumn{2}{|l|}{ Gel buffers } \\
\hline 6x DNA loading dye & $\begin{array}{l}30 \%(\mathrm{v} / \mathrm{v}) \text { glycerol, } 0.25 \%(\mathrm{w} / \mathrm{v}) \text { bromophenol blue, } 0.25 \%(\mathrm{w} / \mathrm{v}) \text { xylene } \\
\text { cyanol FF }\end{array}$ \\
\hline 2x Urea loading dye & $8 \mathrm{M}$ Urea, 50\% glycerol in TBE \\
\hline $\begin{array}{l}2 \times \text { Tricine-SDS-PAGE } \\
\text { sample buffer }\end{array}$ & $\begin{array}{l}100 \mathrm{mM} \text { Tris- } \mathrm{HCl} \mathrm{pH} 6.8,24 \% \mathrm{w} / \mathrm{v} \text { glycerol, } 2 \% \text { v/v } \beta \text {-mercaptoethanol, } \\
7 \% \mathrm{w} / \mathrm{v} \text { SDS }\end{array}$ \\
\hline
\end{tabular}




\begin{tabular}{|c|c|}
\hline $\begin{array}{l}\text { 3x Gel buffer for } \\
\text { Tris-tricine PAGE }\end{array}$ & $3 \mathrm{M}$ Tris $\mathrm{pH} 8.9,0.3 \% \mathrm{w} / \mathrm{v}$ SDS \\
\hline $\begin{array}{l}\text { Anode buffer } \\
\text { (Tris-tricine PAGE) }\end{array}$ & 200 mM Tris-HCl pH 8.9 \\
\hline $\begin{array}{l}\text { Cathode buffer } \\
\text { (Tris-tricine PAGE) }\end{array}$ & $100 \mathrm{mM}$ Tris, $100 \mathrm{mM}$ Tricine, 0.1\% w/v SDS \\
\hline SDS sample buffer & $\begin{array}{l}50 \mathrm{mM} \text { Tris- } \mathrm{HCl} \mathrm{pH} 6.8,2 \% \mathrm{w} / \mathrm{v} \text { SDS, } 4 \% \mathrm{v} / \mathrm{v} \text { glycerol, } 0.8 \% \mathrm{v} / \mathrm{v} \beta- \\
\text { mercaptoethanol, } 0.025 \% \mathrm{w} / \mathrm{v} \text { bromphenol blue }\end{array}$ \\
\hline SDS running buffer & 25 mM Tris, 200 mM glycine, $1 \mathrm{~g} / \mathrm{L} \mathrm{SDS}$ \\
\hline $\begin{array}{l}\text { Staining buffer (SDS- } \\
\text { PAGE) }\end{array}$ & $10 \%$ etanol, $5 \%$ acetic acid, $1 \mathrm{ml}$ of $0.25 \%$ Coomassie Blue G250. \\
\hline $\begin{array}{l}\text { Destaining buffer (SDS- } \\
\text { PAGE) }\end{array}$ & $10 \%$ etanol, $5 \%$ acetic acid, \\
\hline TAE buffer & $40 \mathrm{mM}$ Tris pH 8.4, $20 \mathrm{mM}$ Acetate, $1 \mathrm{mM}$ EDTA \\
\hline $\begin{array}{l}\text { Loading buffer (Native } \\
\text { PAGE) }\end{array}$ & 1x TBE Buffer, 50\% Glycerol \\
\hline TBE buffer & $89 \mathrm{mM}$ Tris $\mathrm{pH} 8.3,89 \mathrm{mM}$ boric acid, $2 \mathrm{mM}$ EDTA \\
\hline \multicolumn{2}{|l|}{$\begin{array}{l}\text { Purification/labeling } \\
\text { buffers }\end{array}$} \\
\hline Lysis Buffer & $\begin{array}{l}20 \mathrm{mM} \text { Tris- } \mathrm{HCl}, \mathrm{pH} 8,0.5 \mathrm{M} \mathrm{NaCl}, 25 \mathrm{mM} \text { Imidazole, } 6 \mathrm{mM} \text { DTT, } 5 \% \\
\text { Glycerol }\end{array}$ \\
\hline Elution Buffer & $\begin{array}{l}20 \mathrm{mM} \text { Tris- } \mathrm{HCl}, \mathrm{pH} 8,0.5 \mathrm{M} \mathrm{NaCl}, 500 \mathrm{mM} \text { Imidazole, } 6 \mathrm{mM} \mathrm{DTT}, 5 \% \\
\text { Glycerol }\end{array}$ \\
\hline Storage Buffer & $\begin{array}{l}20 \mathrm{mM} \text { Tris- } \mathrm{HCl}, \mathrm{pH} 6.8,100 \mathrm{mM} \mathrm{KCl}, 1 \mathrm{mM} \mathrm{MgCl}, 1.5 \mathrm{mM} \mathrm{DTT}, 50 \% \\
\text { Glycerol }\end{array}$ \\
\hline Phosphate buffer & $0.1 \mathrm{M}, \mathrm{pH} 7.2,1 \mathrm{~L}, 68.4 \mathrm{ml}$ of $1 \mathrm{M} \mathrm{NaH}_{2} \mathrm{PO}_{4} / 31.6 \mathrm{ml}$ of $1 \mathrm{M} \mathrm{Na}_{2} \mathrm{HPO}_{4}$ \\
\hline
\end{tabular}




\subsection{Strains and Vectors}

Table 9. List of strains and vectors.

\begin{tabular}{|c|c|c|}
\hline Strain/vector & Properties & Use \\
\hline \multicolumn{3}{|l|}{ Strains } \\
\hline $\begin{array}{l}\text { NovaBlue } \\
\text { (in house prepared) }\end{array}$ & K12 strain, high transformation efficiency & Plasmid propagation \\
\hline $\begin{array}{l}\text { BL21 (DE3) } \\
\text { (in house prepared) }\end{array}$ & Deficient in lon and ompT proteases & Protein expression \\
\hline $\begin{array}{l}\text { One Shot TOP10 (Life } \\
\text { Technologies) }\end{array}$ & $\begin{array}{l}\text { Efficient transformation of methylated DNA } \\
\text { from genomic preparations }\end{array}$ & $\begin{array}{l}\text { High-efficiency cloning } \\
\text { and plasmid propagation }\end{array}$ \\
\hline \multicolumn{3}{|l|}{ Vectors } \\
\hline pUC19 & High copy number, ampicillin resistance & $\begin{array}{l}\text { Cloning and site- directed } \\
\text { mutagenesis }\end{array}$ \\
\hline
\end{tabular}

\subsection{Primers and DNA constructs}

Table 10. List of DNA primers and DNA_UUC template.

\begin{tabular}{|lll|}
\hline Name & Sequence, $\mathbf{5}^{\prime} \rightarrow \mathbf{3}^{\prime}$ & $\mathbf{T}_{\mathbf{m}}{ }^{\mathbf{1}}$ \\
\hline DNA_UUC & CGGGATTCCTCGATAACAATTTAAAGAAGAAGAAGAAGAAGAAGAAGAA & \\
& GAAGAAGAGAAGAAGAAGAAGAAGAAGAGAAGAAGAAGAAGAAGAAG & \\
& AACATAGTATACCTCCTTAAGTGCCTATAGTGAGTCGTATTAAAGCTTATG & \\
\hline T7UUCFor & CATAAGCTTTAATACGACTCACTATAGG & 57.6 \\
\hline T7UUCRev & CGGGAATTCCTCGATAACAA & 56.4 \\
\hline pUC19 For Seq & GTTGGGAAGGGCGATCGG & 54.9 \\
\hline $\begin{array}{l}\text { pUC19 Reverse } \\
\text { Seq }\end{array}$ & GCAATTAATGTGAGTTAGCTC & 48.5 \\
\hline DistalUUC For & CATAGTATACCTCCTTGTTAACCTATAGTGAGTCGTATTAAAGC & 63.5 \\
\hline DistalUUC Rev & CGACTCACTATAGGTTAACATACTATGTTCTTCTTC & 64.5 \\
\hline ProximalUUC int $\mathbf{F}$ & GAACATAGTATACATACCTGTTAACCTATAGTGAGTCGTATTAAAG & 62.6 \\
\hline ProximalUUC int $\mathbf{R}$ & CTCACTATAGGTTAACAGGTATGTATACTATGTTCTTCTTCTTCTT & 62.5 \\
\hline ProxyUUC For & GAAGAACATAGTATGTATACCTGTTAACCTATAGTGAGTCG & 61 \\
\hline ProxyUUC Rev & CTCACTATAGGTTAACAGGTATCAATACTATGTTCTTCTTCTTC & 61.3 \\
\hline
\end{tabular}

${ }^{1}$ The melting temperature was calculated by Lasargene SeqBuilder Software (Madison, USA). 


\section{6. mRNA constructs}

Table 11. List of mRNAs.

The following table provides the nomenclature, length, type of modification and sequence of the mRNAs used in the thesis. The Shine-Dalgarno sequence is underlined, the AUG start codon is in red. The mRNA nomenclature for the in vitro transcribed model mRNAs indicated the label at the $5^{\prime}$-end, the length of $5^{\prime}$-UTR, and the features of the RBS, e.g. enhanced (e) or weak (w), and the number of nucleotides represented by the codon UUC. The extension AAA at the end of the name indicated that the mRNAs possess a codon for lysine decoded by the codon AAA after the UUC repetitive sequence. The mRNA nomenclature of the commercially ordered short mRNAs (24 nt) and their corresponding poly(U) derivatives indicated the label at the $5^{\prime}$-end, the length of $5^{\prime}$-UTR, the features of the RBS and the approximate number of uridines at the $3^{\prime}$-end. For example, $5^{\mathrm{Q}} \mathrm{RBS}_{18 \mathrm{e}}(\mathrm{U})_{250}$ meant that an mRNA with an $18 \mathrm{nt}$ long $5^{\prime}$-UTR which carried an ATTO540Q non-fluorescent acceptor at its $5^{\prime}$-end and had an enhanced ribosome binding site (e) was extended with approximately 250 uridines.

\begin{tabular}{|c|c|c|c|}
\hline $\begin{array}{l}\text { mRNA, } \\
\text { Name }\end{array}$ & $\begin{array}{l}\text { Length, } \\
\text { nt }\end{array}$ & Modification & $\begin{array}{l}\text { Sequence, } \\
5^{\prime} \rightarrow 3^{\prime}\end{array}$ \\
\hline $\mathrm{RBS}_{20 \mathrm{e}}(\mathrm{UUC})_{\text {78AAA }}$ & 124 & - & $\begin{array}{l}\text { GGCACUUAAGGAGGUAUACUAUGUUCUUCUUCUUCUUC } \\
\text { UUCUUCUUCUUCUUCUUCUUCUUCUUCUUCUUCUUCUU } \\
\text { CUUCUUCUUCUUCUUCUUCUUCUUUAAAUUGUUAUCGA } \\
\text { GGAAUUCCCG }\end{array}$ \\
\hline RBS $_{20 \mathrm{e}}(\mathrm{UUC})_{78}$ & 101 & - & \multirow{2}{*}{$\begin{array}{l}\text { GGCACUUAAGGAGGUAUACUAUGUUCUUCUUCUUCUUC } \\
\text { UUCUUCUUCUUCUUCUUCUUCUUCUUCUUCUUCUUCUU } \\
\text { CUUCUUCUUCUUCUUCUUCUUCUUU }\end{array}$} \\
\hline $5^{\mathrm{Q}} \mathrm{RBS}_{20 \mathrm{e}}(\mathrm{UUC})_{78}$ & 101 & 5'ATTO540Q & \\
\hline RBS $_{20 \mathrm{w}}(\mathrm{UUC})_{\text {78AAA }}$ & 124 & - & \multirow{2}{*}{$\begin{array}{l}\text { GGUUAACAGGUAUACAUACUAUGUUCUUCUUCUUCUUC } \\
\text { UUCUUCUUCUUCUUCUUCUUCUUCUUCUUCUUCUUCUU } \\
\text { CUUCUUCUUCUUCUUCUUCUUCUUCUUUAAAUUGUUA } \\
\text { UCGAGGAAUUCCCG }\end{array}$} \\
\hline $\begin{array}{l}5^{\mathrm{Q}} \mathrm{RBS}_{20 \mathrm{w}}(\mathrm{UUC})_{78 \mathrm{AA}} \\
\mathrm{A}\end{array}$ & 124 & 5'ATTO540Q & \\
\hline $\mathrm{RBS}_{18 \mathrm{e}}$ & 24 & - & \multirow{3}{*}{ CACUUAAGGAGGUAUACUAUGUUU } \\
\hline $5^{\mathrm{Q}} \mathrm{RBS}_{18 \mathrm{e}}$ & 24 & 5'ATTO540Q & \\
\hline $5^{*} \mathrm{RBS}_{18 \mathrm{e}}$ & 24 & 5'ATTO488 & \\
\hline $\mathrm{RBS}_{18 \mathrm{w}}$ & 24 & - & \multirow[b]{2}{*}{ UUAACAGGUAUACAUACUAUGUUC } \\
\hline $5^{\mathrm{Q}} \mathrm{RBS}_{18 \mathrm{w}}$ & 24 & 5'ATTO540Q & \\
\hline $\mathrm{RBS}_{18}$ & 24 & - & \multirow[b]{2}{*}{ UUAAUCCCUUCUUAUACUAUGUUC } \\
\hline $5^{\mathrm{Q}} \mathrm{RBS}_{18}$ & 24 & 5'ATTO540Q & \\
\hline $\mathrm{RBS}_{18 \mathrm{e}}(\mathrm{U})_{250}$ & $\approx 250$ & - & \multirow{3}{*}{ CACUUAAGGAGGUAUACUAUGUUU $(U)_{\mathrm{n} 250}$} \\
\hline $5^{*} \mathrm{RBS}_{18 \mathrm{e}}(\mathrm{U})_{250}$ & $\approx 250$ & 5'ATTO488 & \\
\hline $5^{\mathrm{Q}} \mathrm{RBS}_{18 \mathrm{e}}(\mathrm{U})_{250}$ & $\approx 250$ & 5'ATTO540Q & \\
\hline $5^{a}$ RBS $_{18 \mathrm{e}}(\mathrm{U})_{100}$ & $\approx 100$ & 5'ATTO540Q & CACUUAAGGAGGUAUACUAUGUUU $(U)_{n 100}$ \\
\hline $\mathrm{RBS}_{18 \mathrm{w}}(\mathrm{U})_{350}$ & $\approx 350$ & - & \multirow[b]{2}{*}{ UUAACAGGUAUACAUACUAUGUUC(U) $)_{\mathrm{n} 350}$} \\
\hline $5^{\mathrm{Q}} \mathrm{RBS}_{18 \mathrm{w}}(\mathrm{U})_{350}$ & $\approx 350$ & 5'ATTO540Q & \\
\hline $\mathrm{RBS}_{18}(\mathrm{U})_{250}$ & $\approx 250$ & - & \multirow[b]{2}{*}{ UUAAUCCCUUCUUAUACUAUGUUC(U) $)_{\mathrm{n} 250}$} \\
\hline $5^{\mathrm{Q}} \mathrm{RBS}_{18}(\mathrm{U})_{250}$ & $\approx 250$ & 5'ATTO540Q & \\
\hline
\end{tabular}


Table 12. $\Delta G^{\circ}$ free energy calculations of RBS from model mRNAs.

Extended RBS (Ext. RBS) was defined as the full length $5^{\prime}$-UTR and $15 \mathrm{nt}$ from the coding sequence. The extended RBS (Ext.RBS) length varied depending on the mRNA used, since the length of the 5'UTR was different for most of the mRNAs. RBS was defined as $15 \mathrm{nt}$ upstream and $15 \mathrm{nt}$ downstream from the start codon. All the calculated combinations of free energy values were obtained with mfold (Zuker, 2003). The Shine-Dalgarno sequence is underlined. The AUG start codon is in red.

\begin{tabular}{|c|c|c|c|c|}
\hline $\begin{array}{l}\text { mRNA, } \\
\text { Name }\end{array}$ & $\begin{array}{l}\text { Length, } \\
\text { nt }\end{array}$ & $\begin{array}{l}\mathrm{RBS}, \Delta \mathrm{G}^{\circ}, \\
\mathrm{kcal} / \mathrm{mol}^{2}\end{array}$ & $\begin{array}{l}\text { Ext. RBS, } \\
\Delta \mathrm{G}^{\circ}, \\
\mathrm{kcal} / \mathrm{mol}\end{array}$ & $\begin{array}{l}\text { Sequence } \\
5^{\prime} \rightarrow 3^{\prime}\end{array}$ \\
\hline $\mathrm{RBS}_{20 \mathrm{e}}(\mathrm{UUC})_{78}$ & 101 & $\begin{array}{l}-4.00 \\
-3.90 \\
-3.50 \\
-3.20\end{array}$ & $\begin{array}{l}-4.00 \\
-3.90 \\
-3.50 \\
-3.20\end{array}$ & $\begin{array}{l}\text { GGCACUUAAGGAGGUAUACUAUGUUCUU } \\
\text { CUUCUUCUUCUUCUUCUUCUUCUUCUUC } \\
\text { UUCUUCUUCUUCUUCUUCUUCUUCUUCU } \\
\text { UCUUCUUCUUCUUCUUU }\end{array}$ \\
\hline $\mathrm{RBS}_{20 \mathrm{w}}(\mathrm{UUC})_{\text {78AAA }}$ & 124 & $\begin{array}{l}-1.00 \\
-0.90\end{array}$ & -3.60 & $\begin{array}{l}\text { GGUUAACAGGUAUACAUACUAUGUUCUU } \\
\text { CUUCUUCUUCUUCUUCUUCUUCUUCUUC } \\
\text { UUCUUCUUCUUCUUCUUCUUCUUCUUCU } \\
\text { UCUUCUUCUUCUUCUUCUUUAAAUUGUU } \\
\text { AUCGAGGAAUUCCCG }\end{array}$ \\
\hline $5^{\mathrm{a}} \mathrm{RBS}_{18 \mathrm{e}}(\mathrm{UUU})_{250}$ & 250 & $\begin{array}{l}+0.5 \\
+0.6\end{array}$ & $\begin{array}{l}-0.20 \\
+0.50 \\
+0.60\end{array}$ & CACUUAAGGAGGUAUACUAUGUUU(U) $)_{n 250}$ \\
\hline $5^{\mathrm{Q}} \mathrm{RBS}_{18 \mathrm{w}}(\mathrm{UUU})_{350}$ & 350 & -1.00 & -2.30 & UUAACAGGUAUACAUACUAUGUUC(U) \\
\hline $5^{Q} \mathrm{RBS}_{18}(\mathrm{UUU})_{250}$ & 250 & $\begin{array}{l}+3.50 \\
+3.70 \\
+4.30\end{array}$ & $\begin{array}{l}+3.10 \\
+3.50 \\
+3.70 \\
+4.00\end{array}$ & UUAAUCCCUUCUUAUACUAUGUUC(U $)_{n 250}$ \\
\hline
\end{tabular}




\subsection{Generation of model DNA templates for $\mathbf{R B S}_{20 \mathrm{e}}(\mathrm{UUC})_{\text {78AAA }}$ and RBS $_{20 e}(U U C)_{78}$ mRNAs.}

Single stranded DNA (DNA_UUC, $10.6 \mathrm{nmol}$, Table 10) was ordered from IBA (Göttingen, Germany). The single stranded DNA_UUC was purified from denaturing acrylamide/bis-acrylamide (8\%) polyacrylamide gel (Section 4.11.3) with the help of QIAEX II gel extraction kit following the manufactures protocol. Two step polymerase chain reaction (PCR) protocols were utilized to produce a double stranded DNA_UUC. PCR was done on Thermo-cycler PeqStar. In the first step (Table 13), only one primer was used (T7UUCFor, Table 10). A $50 \mu \mathrm{l}$ amplification reaction mixture consisted of 1X HF buffer with $\mathrm{MgCl}_{2}(1.5 \mathrm{mM})$, T7UUCFor primer $(0.15 \mu \mathrm{M})$, dNTP mix (0.2 mM), Phusion DNApolymerase $(0.02$ units $/ \mu \mathrm{l})$ and single stranded DNAUUC as template $(0.1 \mathrm{ng} / \mu \mathrm{l})$. In the second step, the reaction mix from the first step was used as a template without any further purification. Same reaction components were used, except this time two primers were utilized: T7UUCFor $(0.5 \mu \mathrm{M})$ and T7UUCRev $(0.5 \mu \mathrm{M})$ (Table 10). The thermo-cycle program conditions were accordingly modified (Table 14). The PCR product was purified by NucleoSpin Gel and PCR clean-up. The concentration and the purity of the amplified fragment were assessed by measuring the absorption at 260nm with NanoDrop, followed by electrophoretic analysis on 1.2\% agarose gel (Section 4.11.5). The amplified fragment was cloned into a vector producing pUC19_UUC plasmid (Section 4.9).

PCR amplified (Table 14) and purified DNA_UUC template $(1 \mu \mathrm{g})$ was incubated with a Dral restriction enzyme $(0.4 \mathrm{U} / \mu \mathrm{l})$ in NEB4 buffer and BSA $(0.1 \mathrm{mg} / \mathrm{ml})$ over night at $24 \mathrm{C}$ in order to remove the $3^{\prime}$ end sequence after the last GAA triplet, producing a shorter template (DNA_UUC101). The reaction was purified by NucleoSpin Gel and PCR clean up. The concentration and the purity of the fragment were assessed in the same way as for the previous template. The purified DNA templates were used in subsequent T7 RNA- transcription reaction (Section 4.12). 
Table 13. Thermo-cycler program conditions for single stranded DNA_UUC.

\begin{tabular}{|l|c|c|c|}
\hline Cycle step & Temperature, $^{\circ} \mathbf{C}$ & Time, s & Cycles \\
\hline Initial denaturation & 98 & 30 & 1 \\
\hline Denaturation & 98 & 15 & 1 \\
Annealing & 57 & 20 & \\
Extension & 72 & 15 & 1 \\
\hline Final extension & 72 & 120 & \\
\hline
\end{tabular}

Table 14. Thermo-cycler program conditions for double stranded DNA_UUC.

\begin{tabular}{|l|c|c|c|}
\hline Cycle step & Temperature, $^{\circ} \mathbf{C}$ & Time, $^{\mathbf{s}}$ & Cycles \\
\hline Initial denaturation & 98 & 60 & 1 \\
\hline Denaturation & 98 & 15 & 25 \\
Annealing & 57 & 20 & \\
Extension & 72 & 15 & 1 \\
\hline Final extension & 72 & 300 & \\
\hline
\end{tabular}

\subsection{Generation of model DNA template for mRNA $\operatorname{RBS}_{\mathrm{w20}}(\mathrm{UUC})_{\text {78AAA. }}$}

Three-stage site-directed mutagenesis was used on pUC19_UUC vector in order to mutate 10 non-consecutive nucleotides (Table 15). Forward and reverse primers were designed to be complementary to pUC19_UUC plasmid and carry the desired mutations (Table 10) by using Seqbuilder software (Lasergene) and were purchased from IBA GmbH (Göttingen, Germany). The first step of two-step mutagenic PCR was performed with forward and reversed primers in two separate tubes, accordingly. A $75 \mu \mathrm{l}$ amplification reaction mixture consisted of $1 \mathrm{X} \mathrm{HF}$ buffer with $\mathrm{MgCl}_{2}(1.5$ $\mathrm{mM})$, forward or reverse primers $(0.5 \mu \mathrm{M})$, dNTP $\operatorname{mix}(0.2 \mathrm{mM})$, Phusion DNA-polymerase $(0.02$ units $/ \mu \mathrm{l})$ and plasmid template $(0.5 \mathrm{ng} / \mu \mathrm{l})$ (Table 16). For the second step PCR, the two reactions were mixed and further amplified (Table 17). After confirmation of pUC19_DNA_UUCW plasmid amplification on an agarose gel (Section 4.11.5) the reaction mix was treated with $1 \mu$ l of Dpnl (NEB) for $2 \mathrm{~h}$ at $37^{\circ} \mathrm{C}$ and subsequently purified by NucleoSpin Gel and PCR clean-up and transformed into bacteria (Section 4.10). 
Table 15. Three-stage site-directed mutagenesis.

\begin{tabular}{|c|c|c|c|}
\hline Template plasmid & Primer pairs & Annealing, $\mathbf{T}^{\circ} \mathbf{C}$ & Product plasmid \\
\hline pUC19_UUC & $\begin{array}{c}\text { DistalUUC For } \\
\text { DistalUUC Rev }\end{array}$ & 60 & $\begin{array}{c}\text { pUC19_UUC } \\
\text { distal mut }\end{array}$ \\
\hline $\begin{array}{c}\text { pUC19_UUC distal } \\
\text { mut }\end{array}$ & $\begin{array}{c}\text { ProximalUUC int F } \\
\text { ProximalUUC int R }\end{array}$ & 57 & $\begin{array}{c}\text { pUC19_UUC } \\
\text { proxy int }\end{array}$ \\
\hline $\begin{array}{c}\text { pUC19_UUC proxy } \\
\text { int }\end{array}$ & $\begin{array}{c}\text { ProxyUUC For } \\
\text { ProxyUUC Rev }\end{array}$ & 54 & pUC19_UUCw \\
\hline
\end{tabular}

Table 16. First step of thermo-cycler program conditions for site-directed mutagenesis.

\begin{tabular}{|l|c|c|c|}
\hline Cycle step & Temperature, $^{\circ} \mathbf{C}$ & Time, $^{\mathbf{s}}$ & Cycles \\
\hline Initial denaturation & 95 & 180 & 1 \\
\hline Denaturation & 95 & 30 & 5 \\
Annealing & See Table 15 & 60 & \\
Extension & 72 & 180 & 1 \\
\hline Final extension & 72 & 180 & \\
\hline
\end{tabular}

Table 17. Second step of thermo-cycler program conditions for site-directed mutagenesis.

\begin{tabular}{|l|c|c|c|}
\hline Cycle step & Temperature, $^{\circ} \mathbf{C}$ & Time, $^{\mathbf{s}}$ & Cycles \\
\hline Initial denaturation & 95 & 60 & 1 \\
\hline Denaturation & 95 & 30 & 16 \\
Annealing & See Table 15 & 60 & \\
Extension & 72 & 300 & 1 \\
\hline Final extension & 72 & 300 & \\
\hline
\end{tabular}




\subsection{Cloning}

The PCR produced DNA_UUC amplicon $(0.5 \mu \mathrm{g}$ ) (Section 4.7) and the vector plasmid pUC19 (2 $\mu \mathrm{g}$ ) (Table 9) were subjected to endonuclease digestion with HindIII-HF (0.5 U/ $\mu \mathrm{l})$ and EcoRI-HF $(0.5$ $\mathrm{U} / \mu \mathrm{l}$ ) for $3 \mathrm{~h}$ at $37^{\circ} \mathrm{C}$ in buffer NEB2. The digested DNA was purified by NucleoSpin Gel and PCR cleanup. The digested plasmid was dephosphorylated for $60 \mathrm{~min}$ at $37^{\circ} \mathrm{C}$ with Antarctic phosphatase (5 units) in $1 x$ Antarctic phosphatase buffer following incubation for $5 \mathrm{~min}$ at $65^{\circ} \mathrm{C}$. The linearized and dephosphorylated pUC19 plasmid was loaded on a 1.2\% agarose gel (Section 4.11.5). The plasmid was visualized under a PeqLab UV transilluminator and excised with the help of a clean scalpel. Further purification step was performed with the help of NucleoSpin Gel and PCR clean-up kit. The plasmid recovery from the agarose gel was 65\%. For the ligation step $50 \mathrm{ng}$ of pUC19 vector and 3fold molar excess of insert DNA were combined with $1 \mu \mathrm{l}$ of Quick T4 DNA Ligase in ligation buffer. The reaction was incubated $5 \mathrm{~min}$ at $25^{\circ} \mathrm{C}$ and used for subsequent transformation (Section 4.10). pUC19 For Seq and pUC19 Reverse Seq were used for sequencing SeqLab (Goettingen, Germany) (Table 10).

\subsection{Bacterial transformation and plasmid DNA preparation}

Competent bacterial cells $(50 \mu \mathrm{l}$ ) (Table 9) were thawed on ice. $5 \mathrm{ng}$ of the ligation mixture (Section 4.9) was gently added to the cells and incubated on ice for $20 \mathrm{~min}$. The mix was then heat shocked for $30 \mathrm{~s}$ at $42^{\circ} \mathrm{C}$. Afterwards, $950 \mu \mathrm{l}$ of room temperature LB media was added to the cells and they were placed in a thermomixer comfort $(600 \mathrm{rpm})$ for $60 \mathrm{~min}$ at $37^{\circ} \mathrm{C}$. After the incubation, $50-100 \mu \mathrm{l}$ of the mix was plated on LB agar plates containing ampicillin $(0.1 \mathrm{mg} / \mathrm{ml})$ or kanamycin $(0.05 \mathrm{mg} / \mathrm{ml})$ depending on the resistance of the vector in use (Table 9). After an overnight incubation at $37^{\circ} \mathrm{C}$, single colony were selected and used to inoculate $5 \mathrm{ml}$ of LB media supplemented with the respective antibiotic. Cultures were left shaking over night at $37{ }^{\circ} \mathrm{C}$ and $300 \mathrm{rpm}$ (Innova 44 shaker). Bacteria were harvested by centrifugation for $15 \mathrm{~min}$ at $4000 \mathrm{rpm}$ (Eppendorf Centrifuge 5810R). Plasmids were purified using the Macherey-Nagel Plasmid Preparation Kit (Mini, Midi or Maxi-scale) according to the manufacturer's instructions. The concentration of the plasmids was assessed by measuring the absorption at $260 \mathrm{~nm}$ with NanoDrop. All insert sequence was confirmed by sequencing from SeqLab (Goettingen, Germany).

\subsection{Gel electrophoresis}

\subsubsection{SDS-PAGE}

Separating gel of $10 \mathrm{ml}$ contained different final concentrations (10\%, $15 \%$ and $16 \%$ ) of Acrylamide/Bis-acrylamide (29:1), 40\%, TRIS-HCl (300 mM), pH 8.8, SDS (0.1\%), APS (10\%) (1/100, $\mathrm{v} / \mathrm{v}$ ) and TEMED (1/1000, v/v). Stacking gel of $5 \mathrm{ml}$ contained 4.8\% Acrylamide/Bis-acrylamide (29:1), 40\%, TRIS-HCI 6.8 (0.125 mM), SDS (0.1\%), APS (10\%) (1/100, v/v) and TEMED (1/1000, v/v) (Shapiro et al., 1967). Samples were incubated after the addition of SDS-PAGE sample buffer for 5 min $60{ }^{\circ} \mathrm{C}$ (Laemmli, 1970). Gels were run at room temperature in SDS-PAGE running buffer (TRIS- $\mathrm{HCl}(25 \mathrm{mM})$, Glycine $(200 \mathrm{mM})$, SDS (0.1\%)), at $130 \mathrm{~V}$ for $30 \mathrm{~min}$ and $200 \mathrm{~V}$ for $1.5-2 \mathrm{~h}$. Gels were run on a MiniPROTEAN Tetra Cell vertical electrophoresis system (BioRad). The gel was incubated with staining 
solution at room temperature for $4 \mathrm{~h}$. The staining solution was discarded and $40 \mathrm{ml}$ destaining solution was added to the gel and incubated overnight on a shaker at room temperature.

\subsubsection{Tris-Tricine polyacrylamide gel preparation.}

Tricine-SDS-PAGE was composed of three parts containing, respectively, the following final concentration of acrylamide/bis-acrylamide (49\% T, 3\% C): separating gel (16.5\%), spacer gel (10\%) and stacking gel (4\%). Gels were prepared in Tris- $\mathrm{HCl}(1 \mathrm{M}) \mathrm{pH} 8.45$ and SDS (0.1\%); in addition, separating gel was supplemented with glycerol (13\%). Gels were polymerized with APS (10\%) (1/100, $\mathrm{v} / \mathrm{v})$ and TEMED (1/1000, v/v). Samples were incubated with Tricine-SDS-PAGE sample buffer for 30 min at $40^{\circ} \mathrm{C}$ and then loaded on the gradient gel. Gels were run on a PerfectBlue Dual Gel System Twin ExW S (PeqLab) at $30 \mathrm{~V}$ for $1 \mathrm{~h}$; once the samples had completely entered the stacking gel, the voltage was raised to $150 \mathrm{~V}$ and the run was continued for 2-3 $\mathrm{h}$. Two distinct buffers were used for the anode (i.e. $0.2 \mathrm{M}$ Tris- $\mathrm{HCl}, \mathrm{pH} 8.9$ ) and for the cathode (i.e. $0.1 \mathrm{M}$ Tris- $\mathrm{HCl}, \mathrm{pH} 8.25,0.1 \mathrm{M}$ tricine and $0.1 \%$ SDS) (Schagger and von Jagow, 1987). Pictures of the gels were taken at Phosphorimager Fuji Film Fla 7000 or Fla 9000 (GE Healthcare, Germany)

\subsubsection{Denaturing urea polyacrylamide electrophoresis.}

Urea PAGE used in the experiments contained different final concentrations of acrylamide/bis-acrylamide (19:1), urea (8 M), TBE buffer, APS (10\%), (1/100, v/v) and TEMED (1/1000, $\mathrm{v} / \mathrm{v})$. Samples were incubated for $3 \mathrm{~min}$ at $90{ }^{\circ} \mathrm{C}$ before loading with urea loading dye. Gels were run on a Mini-PROTEAN Tetra Cell vertical electrophoresis system (BioRad). A pre-run at room temperature was done at 130V, 20 min in 0.5X TBE buffer followed by run for $1.5 \mathrm{~h}-2.5 \mathrm{~h}, 150-200 \mathrm{~V}$. Gels were fixed with acetic acid (10\%) for $10 \mathrm{~min}$ and then stained with a methylene blue $(0.04 \%)$ (Sigma) in NaOAc (2 M) pH 5.0 solution for 20 min. Gels were de-stained in water by gentle shaking. Pictures of the gels were taken at PeqLab UV transilluminator (PeqLab).

\subsubsection{Native polyacrylamide electrophoresis.}

Native PAGE used in the experiments contained different final concentrations of acrylamide/bis-acrylamide (19:1), TBE buffer, APS (10\%), (1/100, v/v) and TEMED (1/1000, v/v). Gels were run on a PerfectBlue Dual Gel System Twin ExW S (PeqLab) at $80 \mathrm{~V}$ for $2.5 \mathrm{~h}$ at $4^{\circ} \mathrm{C}$. Pictures of the gels were taken at Phosphorimager Fuji Film Fla 7000 (GE Healthcare, Germany).

\subsubsection{Agarose gel electrophoresis}

Agarose gel electrophoresis was used for the separation of DNA fragments. Gels used in the experiments contained different percentage of agarose (w/v) in TAE buffer. Gels were supplemented with Stain G (1:50000 dilution) and run at a Perfect Blue Gel system (PeqLab). Electrophoresis was carried out in running buffer $1 x$ TAE at $100 \mathrm{~V}$ for $1 \mathrm{~h}$, room temperature. Pictures of the gels were taken at PeqLab UV transilluminator (PeqLab). 


\subsection{Modified in vitro T7 RNA-polymerase transcription reaction.}

T7 RNA-polymerase (200 units/ $\mu$ l) was kindly supplied by Dr. D. Burakovsky. Guanosine-5'-Omonophosporothioate (GMPS) was purchased from BioLog as powder. The nucleotide was dissolved in water. The templates used for the in vitro transcription reaction were obtained by PCR amplification of pUC19_UUC, pUC19_UUCw vectors as described in sections 4.7 and 4.8 . DNA_UUC101 was prepared as in section 4.7. In vitro transcription reaction mix contained: $1 \mathrm{x}$ transcription buffer, DTT (10 mM), DNA template $(0.05 \mu \mathrm{M})$, pyrophosphatase $(0.01$ units $/ \mu \mathrm{l})$, RNase inhibitor (0.2 units/ $\mu \mathrm{l})$, T7 RNA-polymerase (1.6 units/ $\mu \mathrm{l}), \mathrm{MgCl}_{2}(3.5 \mathrm{mM}), \mathrm{NEB} 4$ buffer $(0.5 \mathrm{x})$ and optimized ratio of nucleotides GMPS:GTP:ATP:CTP:UTP (5:0.5:1:2:5). GMP was used instead of GMPS when the mRNA was not going to be subsequently labeled. Reactions were incubated for $4 \mathrm{~h}$ at $37^{\circ} \mathrm{C}$ and purified by HiTrap $5 \mathrm{ml}$ column (GE Healthcare) on Äkta Purifier Plus. The eluted mRNA fractions were pooled and ethanol precipitated (Section 4.15.1). The pure mRNAs were subsequently labeled (Section 4.13) or kept at $-20^{\circ} \mathrm{C}$ for biochemical reactions.

\subsection{5 '-end labeling of mRNAs}

The $\mathrm{RBS}_{20 \mathrm{e}}(\mathrm{UUC})_{78}$ and $\mathrm{RBS}_{20 \mathrm{w}}(\mathrm{UUC})_{\text {78AAA }}$ mRNAs were transcribed in the presence GMPS (Section 4.12). $1 \mathrm{mg}$ of ATTO540Q maleimide $\left(\varepsilon_{542}\right.$ ATTO540Q dye $\left.=105000 \mathrm{M}^{-1} \mathrm{~cm}^{-1}\right)$ was dissolved in $20 \mu \mathrm{l}$ DMF. The labeling reaction was carried out in phosphate buffer $(0.1 \mathrm{M}), \mathrm{pH} 7.2$ with a 50 -fold molar excess of the dye over mRNA. After $2 \mathrm{~h}$ incubation at room temperature protected from light, the labeling reaction was stopped by ethanol precipitation (Section 4.15.1). After 5 consecutive reprecipitation steps the samples were purified by HiTrap Q HP $5 \mathrm{ml}$ column (GE Healthcare). Absorption of the eluted fractions at $260 \mathrm{~nm}$ and $542 \mathrm{~nm}$ was checked and mRNAs were visualized by urea-PAGE scanned with a Phsophorimager (532 nm excitation and $580 \mathrm{~nm}$ emission filter). Fractions were combined and further ethanol precipitated. The degree of labeling was around $100 \%$, as determined spectrophotometrically. The integrity of the mRNA was assessed by urea PAGE (Section 4.11.3).

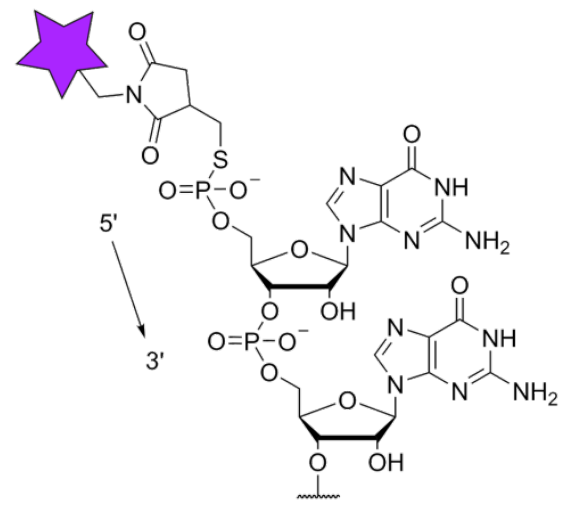

Figure 22. Structure of the $5^{\prime}$-end labeled model mRNAs produced by modified in vitro transcription reaction.

Final product of modified T7 RNA-polymerase in vitro reaction: mRNA carrying an unnatural nucleotide: guanosine-5'-O-monophosporothioate (GMPS) at the 5'-end subsequently reacted with ATTO540Q (purple star) in a thioester bond. Cartoon was made in ChemSketch software (Advanced Chemistry Development, Inc., Ontario, Canada). Figure by Alexander Rabe. 


\subsection{Purification of Poly(U)-polymerase}

pET28a_Cid1 plasmid was a kind gift from Prof M. Wickens. The plasmid ( $5 \mathrm{ng}$ ) was incubated for $30 \mathrm{~min}$ on ice and transformed into E.coli BL21(DE3) chemically competent cells (in-house) by heath shock for $35 \mathrm{~s}$ at $42^{\circ} \mathrm{C}$. After $1 \mathrm{~h}$ at $37^{\circ} \mathrm{C}$ incubation the cells were grown overnight at the same temperature on LB agar plates containing $30 \mu \mathrm{g} / \mathrm{ml}$ kanamycin. A single colony was used to inoculate $30 \mathrm{~mL}$ of LB-media as pre-culture, which was incubated over night at $37^{\circ} \mathrm{C}, 180 \mathrm{rpm}$ shaking. $5 \mathrm{~mL}$ of this pre-culture was used to inoculate $6 \mathrm{~L}$ of LB-media containing $30 \mu \mathrm{g} / \mathrm{ml}$ kanamycin. The main culture was grown at $37^{\circ} \mathrm{C}, 180 \mathrm{rpm}$. After an $\mathrm{OD}_{600}$ of 0.9 was reached, the protein expression was induced by adding isopropyl-B-D-thiogalactopyranoside (IPTG) to a final concentration of $0.25 \mathrm{mM}$. After 4 hours of induction the cells were harvested for $25 \mathrm{~min}, 5.000 \mathrm{rpm}$ at $4^{\circ} \mathrm{C}$ (Beckman J6, $6 \times 1 \mathrm{~L}$ rotor). Cell pellets were washed by resuspension with $50 \mathrm{ml}$ lysis buffer (Table 8) and centrifuged, 45 min, $5000 \mathrm{rpm}$ (Eppendorf Centrifuge 5810R). After this washing step, the cells were finally resuspended in the same buffer $(1.5 \mathrm{ml}$ per gram of cell pellet), flash-frozen in liquid nitrogen and stored at $-80^{\circ} \mathrm{C}$.

Upon addition of $100 \mathrm{mM}$ Pefablock protease inhibitor the cells were thawed on ice and opened by applying $6 \times 20$-s pulses at $20 \%$ amplitude using a Branson Sonifier. Sonication was carried out at $4^{\circ} \mathrm{C}$ as all the other purification steps unless stated otherwise. The cell lysate was then incubated $30 \mathrm{~min}$ with $D$ Nase I $(10 \mu \mathrm{g} / \mathrm{ml})$ and subsequently centrifuged for $45 \mathrm{~min}$ at $20000 \mathrm{rpm}$ in a preparative centrifuge Avanti J-30, JA-25.5 rotor (Beckman). The supernatant was carefully separated from the insoluble matter (pellet), and loaded onto an $8 \mathrm{ml}$ of $50 \% \mathrm{Ni}^{2+}$-Agarose slurry (Qiagen) preequilibrated with lysis buffer. The mix was incubated for $1 \mathrm{~h}$ at an Intelli Mixer RM-2. The resin was then washed with 3-4 CV (column volume) of the same buffer. His-tagged recombinant protein was eluted with 3-4 CV of elution buffer containing $500 \mathrm{mM}$ imidazole. $1 \mathrm{ml}$ fractions were collected. The presence of the protein of interest in the collected fractions was checked by SDS-PAGE gel (Section 4.11.1). The fractions containing the poly (U)-polymerase protein were pooled together and dialyzed in D-tube dialyzer (MWCO $3.5 \mathrm{kDa}$ ) (Merck KGaA) in storage buffer (Table 8). The concentration of the protein was assessed by NanoDrop. The enzyme was aliquoted and stored at $-20^{\circ} \mathrm{C}$. Enzyme was active, as assessed by the Poly(U)-polymerase enzymatic reaction (Section 4.14.1).

\subsubsection{Poly(U)-polymerase reaction}

Reactions were carried out in NEB2 buffer provided by New England Biolabs (NEB) containing Tris- $\mathrm{HCl}(10 \mathrm{mM}), \mathrm{NaCl}(50 \mathrm{mM}), \mathrm{MgCl}_{2}(10 \mathrm{mM}), \mathrm{DTT}(1 \mathrm{mM}), \mathrm{pH}$ 7.9. Reactions contained Poly(U)polymerase (1.5 $\mu \mathrm{g}$ enzyme $/ 100 \mathrm{pmol} \mathrm{mRNA}$ ) (Section 4.14), UTP (8 mM), $\mathrm{MgCl}_{2}$ (7 mM), mRNAs

$\left(5^{\mathrm{Q}} \mathrm{RBe}_{24 \mathrm{e}}, 5^{*} \mathrm{RBe}_{24 \mathrm{e}}, 5^{\mathrm{Q}} \mathrm{RBS}_{18}\right)$ or its unlabeled counterparts (IBA) $(20 \mu \mathrm{M})$ in the presence of RNase inhibitor (1.6 units/ $\mu$ ) (RiboLock, Fermentas). Reactions were incubated for $100 \mathrm{~min}$ at $37{ }^{\circ} \mathrm{C}$ and purified according to the protocol provided by the manufacturer using the RNeasy Maxi Kit columns (Qiaqen). The eluted mRNA fractions were pooled and ethanol precipitated 4.15.1. Alternatively, the mRNA $5^{\mathrm{Q}} \mathrm{RBS}_{18 \mathrm{w}}$ and its unlabeled counterpart were extended enzymatically at $49^{\circ} \mathrm{C}$ and in the presence of $4 \%$ DMSO for $100 \mathrm{~min}$. 


\subsection{General RNA protocols}

\subsubsection{Ethanol precipitation}

mRNA was precipitated by addition of $1 / 10(\mathrm{v} / \mathrm{v}) \mathrm{NaCl}(3 \mathrm{M})$ and 3 volumes of absolute ethanol for $1 \mathrm{~h}$ at $-20^{\circ} \mathrm{C}$. After centrifugation for $45 \mathrm{~min}, 12000 \mathrm{rpm}$ at $4^{\circ} \mathrm{C}$ (Eppendorf $5810 \mathrm{R}$ ), the mRNA pellet was washed with 1 volume of $80 \%$ ethanol and centrifuged for $10 \mathrm{~min}, 12000 \mathrm{rpm}$ at $4^{\circ} \mathrm{C}$. The supernatant was discarded and the remaining RNA pellet was dried for 10 min under the hood and resuspended in water.

\subsubsection{TCA precipitation}

Time point samples after translation on the quench flow and incubation with $\mathrm{KOH}(250 \mu \mathrm{l})$ (Section 4.21.1) were precipitated by addition of 10\% TCA $(500 \mu \mathrm{l})$ and further incubated for $30 \mathrm{~min}$ at $4^{\circ} \mathrm{C}$. Reactions were filtered through a nitrocellulose filter presoaked with $5 \%$ TCA. The filter was washed with 5\% TCA (5 ml) and then 30\% isopropanol $(5 \mathrm{ml})$. Filters were dissolved in Quickszint 361 scintillation cocktail $(10 \mathrm{ml})$ and subjected to scintillation counting.

\subsection{Aminoacylation of Phe-tRNA}

Phenylalanine-specific aminoacyl-tRNA synthetase (PheRS) from E. coli was purified in house by T. Uhlendorf. tRNA ${ }^{\text {Phe }}$ was purified by Olaf Geintzer. A typical aminoacylation of tRNA ${ }^{\text {Phe }}$ reaction contained ATP (3mM), $\left[{ }^{14} \mathrm{C}\right]$ Phe $(60 \mu \mathrm{M})$ (380 DPM/pmol), tRNA ${ }^{\text {Phe }}(0.8 \mu \mathrm{M}), \mathrm{Mg}^{2+}(3 \mathrm{mM}), \mathrm{DTT}(1 \mathrm{mM})$ and PheRS $(1 \mu \mathrm{M})$. After $15 \mathrm{~min}$ of incubation at $37^{\circ} \mathrm{C}$ Phe-tRNA product was detected by Trichloroacetic acid (TCA) precipitation and subsequent radioactivity scintillation counting (Section 4.15.2).

When the PheRS reaction was used to supply aminoacylated tRNA ${ }^{\text {Phe }}$ for multiple rounds of elongation assay, a 2 -fold concentrated reaction containing the same components as above was mixed with the elongation machinery and incubated for $2 \mathrm{~min}$ at $37^{\circ} \mathrm{C}$. Subsequently it was mixed with an $70 \mathrm{~S} \mathrm{IC}\left(\mathrm{RBS}_{20 \mathrm{e}}(\mathrm{UUC})_{78} \mathrm{mRNA}\right)$. End point time points were stopped with $5 \mu \mathrm{L}$ of $\mathrm{KOH}(5 \mathrm{M})$ and hydrolyzed at $37^{\circ} \mathrm{C}$ for $30 \mathrm{~min}$. The nascent peptides were precipitated with TCA and subjected to scintillation counting (Section 4.15.2).

\subsection{7. $S 13(A l x 488)$ reconstitution to $\Delta 30 S$ subunit ribosomal subunits}

Reconstitution of purified 30S $\Delta \mathrm{S} 13$ ribosomal subunit and S13(Alx488) (kindly provided by Dr. R. Belardinelli) was carried out in HEPES (50 mM), pH 7.5, $\mathrm{MgCl}_{2}(20 \mathrm{mM}), \mathrm{KCl}(400 \mathrm{mM}), \beta-$ mercaptoethanol $(6 \mathrm{mM})$, and 1.75 fold molar excess of S13(Alx488) over the 30S $\Delta$ S13. The reaction was incubated for $60 \mathrm{~min}$ at $47^{\circ} \mathrm{C}$ light protected. The $30 \mathrm{~S}$ subunits were purified by ultracentrifugation through a $30 \%$ sucrose cushion in the same buffer. Pellets were gently resupended in TAKM7. The absorption of the Alx488 dye $\left(\varepsilon_{495}=73000 \mathrm{M}^{-1} \mathrm{~cm}^{-1}\right)$, measured at the NanoDrop, was used to estimate the concentration of the reconstituted ribosomes. Reconstitution efficiency was between 90-100 \% measured by the ratio between the pmol of S13(Alx488) and pmol of 30 s subunit. 


\subsection{Preparation of components used for in vitro translation}

$70 \mathrm{~S}$ ribosomes from $E$. coli MRE 600, initiation factors (IF1, IF2, IF3), fMet-tRNA ${ }^{\text {fMet }}$, EF-Tu, EFTs and EF-G were prepared as described (Gromadski et al., 2002; Milon et al., 2007; Rodnina, 1994; Rodnina et al., 1999; Rodnina and Wintermeyer, 1995; Wieden et al., 2002). [ $\left.{ }^{14} \mathrm{C}\right]$ Lys-tRNA ${ }^{\text {Lys }}(0.24 \mu \mathrm{M})$ was a kind gift of Dr. Caliskan. BodipyFL $\left[{ }^{3} \mathrm{H}\right] \mathrm{fMet}-\mathrm{tRNA}{ }^{\mathrm{fMet}}$ was prepared as described (Mittelstaet et al., 2013).

\subsection{S initiation complex formation and purification}

Reaction mixture $(1.5 \mathrm{ml})$ in TAKM7 contained 70S $(1 \mu \mathrm{M})$, mRNA $\left.(1.5 \mu \mathrm{M}), \mathrm{fl}^{3} \mathrm{H}\right]$ Met-tRNA ${ }^{\mathrm{fMet}}$ (3 $\mu \mathrm{M})(2500 \mathrm{dpm} / \mathrm{pmol})$, initiation factors IF1, IF2 and IF3 (2 $\mu \mathrm{M}$ each) and GTP (0.5 mM). After incubation for $30 \mathrm{~min}$ at $37^{\circ} \mathrm{C}$, the mixture was layered on a $500 \mathrm{ml}$ of $40 \%$ sucrose cushion in TAKM7 in a Beckman Coulter Tube (11 x 34, $2.2 \mathrm{ml}$, ultra-clear) (Beckman Coulter). The run was performed for $2 \mathrm{~h}, 55000 \mathrm{rpm}$ at $4^{\circ} \mathrm{C}$ (Beckman Coulter Optima ultracentrifuge), in a TLS 55 rotor (Beckman Coulter). The pelleted 70S IC complexes were resuspended in TAKM7. Ribosome concentrations were calculated from absorption measurements on the basis of 23 pmol/A260 unit. The mRNA concentration in the complex was calculated by the absorption of the dye at $542 \mathrm{~nm}$. The $\left.\mathrm{f}^{3} \mathrm{H}\right] \mathrm{Met}-$ tRNA $^{\text {fMet }}$ radioactivity was counted using a liquid scintillation analyzer (TriCarb, Perkin Elmer); and the data was used to estimate the tRNA concentration in the complex taking into account the specific activity of $\left[{ }^{3} \mathrm{H}\right] \mathrm{fMet}$. All the values collected were used to estimate the molar ratio between the three components reflecting the efficiency of 70S IC formation.

4.19.1. Initiation complex efficiency measured by nitrocellulose filter binding

70S $(0.15 \mu \mathrm{M})$ or $30 \mathrm{~S}$ subunit $\left.(0.15 \mu \mathrm{M}), \mathrm{f}^{3} \mathrm{H}\right] \mathrm{Met}^{\mathrm{tRNA}} \mathrm{fMet}^{\mathrm{f}}(0.45 \mu \mathrm{M})(2500 \mathrm{dpm} / \mathrm{pmol})$, initiation factors IF1, IF2 and IF3 $(0.3 \mu \mathrm{M}$ each) and GTP $(0.5 \mathrm{mM})$ were incubated with different model mRNAs $(0.45 \mu \mathrm{M})$ (Table 11). After incubation $50 \mu \mathrm{l}$ aliquots were layered on a nitrocellulose filters with $45 \mu \mathrm{m}$ pore size (Sartorius, Göttingen) which were subsequently washed with the same buffer. Filters were dissolved in $10 \mathrm{ml}$ liquid scintillation cocktail (Quickszint 361; Zinsser Analytic) and the radioactivity in disintegrations per minute $(\mathrm{dpm})$ associated with the filter was measured using a TriCarb counter (Perkin Elmer). The efficiency of 70S IC or 30S IC formation was estimated as the molar ratio between the $\left.\mathrm{f}^{3} \mathrm{H}\right]$ Met-tRNA ${ }^{\mathrm{fMet}}$ counted on each filter and ribosome present into each aliquot.

\subsection{Translation elongation machinery}

Typical ternary complex (TC) for the stopped flow experiments contained DTT (2 mM), GTP (2 $\mathrm{mM}$ ), phosphoenolpyruvate (3 $\mathrm{mM}$ ) (Roche), pyruvate kinase ( $2 \%, \mathrm{v} / \mathrm{v})$ (Roche), elongation factor Tu (EF-Tu) $(3 \mu \mathrm{M})$ and elongation factor G (EF-G) $(1 \mu \mathrm{M})$ incubated for $15 \mathrm{~min}$ at $37^{\circ} \mathrm{C}$. The Phe-tRNA ${ }^{\text {Phe }}$ $(1.5 \mu \mathrm{M})$ was subsequently added and the mix was incubated for further $2 \mathrm{~min}$ at $37^{\circ} \mathrm{C}$ just before the start of the experiment. For the translation of $70 \mathrm{~S} \mathrm{IC}\left(5^{*} \mathrm{RBS}_{20 \mathrm{e}}(\mathrm{U})_{250}\right.$ visualized on the TRIS Tricine gel the mixture contained the same components except different concentration of EF-Tu (12.6 $\mu \mathrm{M})$, Phe$\operatorname{tRNA}^{\text {Phe }}(8 \mu \mathrm{M})$, EF-G $(2 \mu \mathrm{M})$. 


\subsection{Rapid kinetic techniques}

All reactions were done at $37^{\circ} \mathrm{C}$, unless stated otherwise.

\subsubsection{Quench Flow}

Time courses were performed in a quench flow apparatus (KinTek Laboratories, Inc.). Equal volumes of two reactants were mixed rapidly and incubated for variable time before the reaction was stopped by addition of a quencher $(0.5 \mathrm{M} \mathrm{KOH})$. The mix was incubated for 30 min at $37^{\circ} \mathrm{C}$ in order to hydrolase the RNA. The sample was TCA precipitated and subjected to scintillation counting (Section 4.15.2). Data was analyzed by a one-exponential equation with Prism (GraphPad software).

\subsubsection{Stopped Flow}

Stopped-flow experiments were performed using a SX-20MV apparatus (Applied Photophysics, Leatherhead, UK). Fluorescence donors (Alx488 or ATTO488) were excited at $465 \mathrm{~nm}$ and the fluorescence emission signal was monitored after passing through a cut off filter of $500 \mathrm{~nm}$ (KV500). Samples were prepared in $800 \mu \mathrm{l}$ TAKM7 buffer and centrifuged $3 \mathrm{~min}$ at $13000 \mathrm{rpm}$ prior to loading. In a single experiment, $60 \mu \mathrm{l}$ of each sample reaction were rapidly mixed and 1000 data points were collected. Time courses were analyzed either by exponential fitting or numerical integration analysis. Standard errors were calculated from fitting of the average derived from 7-10 time courses for each reaction. Graphs were plotted and analyzed in GraphPad Prism (GraphPad, San Diego, CA). The following equations were used to fit exponentially the data.

One-exponential equation: $F=F 0+A \exp (-k a p p \times t)$ with a time constant $k_{\text {app }}$ at time $\mathrm{t}, \mathrm{F}$, the amplitude of the signal change $A$ and the final signal $\mathrm{F} 0$.

Second-order exponential equation: $F=F 0+A 1 \exp (-k a p p 1 \times t)+A 2 \exp (-k a p p 2 \times t)$ was used when a second phase in the fluorescence trace appeared, with a rate constant $k_{\text {app2 }}$ at time $\mathrm{t}, \mathrm{F}$ and a second amplitude change $A 2$. For a one-step reversible binding mechanism, association $\left(k_{\text {on }}\right)$ and dissociation $\left(\mathrm{k}_{\text {off }}\right)$ rate constants were estimated by linear fitting of the concentration dependence of the $k_{a p p 1}$ values. In cases where more than one exponential term was used to fit the time courses a global fit approach was utilized (Section 4.24). Fluorescence trace from Figure 17 (red) was fitted with a build-in equation from Table curve software (number 7939) (Systat Software). The fit output from the program was subtracted from the fluorescence trace itself in order to improve signal to noise ratio.

\subsection{First and second rounds of initiation reaction}

Before the experiment took place, the wild type 30S subunit or 30S (S13Alx488) subunit were activated with the addition of $\mathrm{Mg}^{2+}$ to a final concentration of $21 \mathrm{mM}$ at $37{ }^{\circ} \mathrm{C}$ for 30 minutes. Subsequently the 30 S subunit were mixed with 2-fold molar excess of IF1, IF2 and IF3 and GTP (0.5 $\mathrm{mM}$ ) in TAKM7. When IF3(Alx488) was used the molar ratio over the 30 S subunit was 1.2 fold excess. The components were incubated further $20-30 \mathrm{~min}$ at $37^{\circ} \mathrm{C}$. The formed $30 \mathrm{~S} \mathrm{PIC}$ was rapidly mixed at the stopped flow with $5 \mathrm{Q}$ labeled mRNAs or used in the second round initiation reaction. For the second round of initiation, synchronized and purified 70S IC (Section 4.19) with 5'-end labeled mRNAs $(0.05 \mu \mathrm{M})$ were rapidly mixed at the stopped flow machine with the 30S PIC $(0.1 \mu \mathrm{M})$, carrying 
fluorescence donor labeled proteins (S13Alx488 or IF3Alx488) and the elongation machinery, formed accordingly at $37^{\circ} \mathrm{C}$ for $30 \mathrm{~min}$ (Sections 4.20 ).

\subsection{RNA-RNA hybridization assay}

Unlabeled (asRNA12) and 3'-end labeled with Alx488 anti-sense RNA (asRNA12*) were ordered from IBA (Göttingen). The sequence of the oligonucleotide $\left(5^{\prime} \rightarrow 3^{\prime}\right)$ is CAUAGUAUACCU. $\mathrm{RBS}_{\mathrm{e} 20}(\mathrm{UUC})_{78}$ mRNA was prepared by T7 RNA-polymerase in vitro transcription reaction as described (Section 4.12).

\subsubsection{Electrophoretic Mobility Shift Assay (EMSA).}

To study the asRNA12* binding assay under equilibrium, we mixed constant concentrations of asRNA12* $(0.05 \mu \mathrm{M})$ with increasing concentrations of target $\mathrm{RBS}_{20 \mathrm{e}}(\mathrm{UUC})_{78}$ mRNA in HiFi buffer (Figure 19). The reaction was incubated for $30 \mathrm{~min}$ at $37^{\circ} \mathrm{C}$ in a Thermo-cycler PeqStar. After that it was mixed with loading buffer (native PAGE) and electrophoretically separated on a native PAGE (Section 4.11.4). Pictures of the gels were taken at Phosphorimager Fuji Film Fla 7000 (GE Healthcare, Germany). The gel was analyzed by Image J software $(\mathrm{NIH})$ where the fraction bound was calculated as the sum of the fluorescence of the free and the bound divided by the fluorescence of the bound. The fraction bound was then plotted in Graph Pad Prism and analyzed by a one-site specific binding function: $Y=B \min +B \max * X /(K d+X)$ where, Bmax is the maximum specific binding, Bmin is the minimum specific binding, $X$ is the mRNA concentration and $K_{d}$ is the equilibrium binding constant.

\subsection{2. asRNA12*-mRNA association kinetics measured at the stopped flow apparatus}

Stopped-flow experiments were performed as described (Section 4.21.2). Samples were prepared in $600 \mu \mathrm{l} \mathrm{HiFi} \mathrm{buffer,} \mathrm{incubated} \mathrm{at} 37^{\circ} \mathrm{C}$ for $10 \mathrm{~min}$. Constant concentration of asRNA12* was rapidly mixed with increasing concentrations of target $\mathrm{RBS}_{20 \mathrm{e}}(U U \mathrm{UC})_{78} \mathrm{mRNA}$. The fluorescence change of the asRNA12* was followed in time. Fluorescence time courses were fitted exponentially with a second order exponential equation (Section 4.21.2). The association $\left(\mathrm{k}_{\text {on }}\right)$ and dissociation ( $\left.\mathrm{k}_{\text {off }}\right)$ rate constants were estimated by linear fitting of the concentration dependence of the $k_{a p p 1}$ values while $\mathrm{k}_{\text {app2 }}$ was fitted with an equation $Y=\operatorname{Vmax} * X /(K m+X)$ where $V \max$ as the maximum velocity, $X$ as the mRNA concentration and $K m$ as the apparent affinity constant. 


\subsection{Kinetic modeling using numerical integration.}

Global fitting approach was needed to dissect multistep processes combined in a single model, resulting in amplitude and rate constants information for each step. All models were created on KinTek Explorer (Johnson et al., 2009). Typically the data modeled was FRET or fluorescence change traces obtained from the stopped flow. Various models were used for the global fitting of traces in Section 2.3, monitoring the first initiation event with FRET donors 30S(Alx488) subunit or IF3(Alx488). Summary of the models is found in Table 18.

Table 18. Summary of models used in the global fit of traces from the first round of initiation.

Time courses were modeled as a reversible binding reaction between mRNAs abbreviated as (A) and the 30S PIC carrying fluorescence $\left(\mathrm{B}^{*}\right)$ resulting in $30 \mathrm{~S} \mathrm{PIC}\left(\mathrm{C}^{*}\right)$. Subsequent irreversible rearrangement steps $\left(\mathrm{D}^{*}\right)$ and $\left(\mathrm{E}^{*}\right)$ were present in the model with IF3(Alx488) as donor in the reaction. The observables were assigned to each fluorescence species. The reference table and figure where the models were used are also specified.

\begin{tabular}{|c|c|c|c|}
\hline FRET pair & Model input & $\begin{array}{c}\text { Fluorescence } \\
\text { observables }\end{array}$ & $\begin{array}{c}\text { Used in } \\
\text { Figure/Table }\end{array}$ \\
\hline $5^{\mathrm{a}}$ mRNAs / 30S(S13488) PIC & $A+B^{*} \leftrightarrow C^{*}$ & $\mathrm{~b}(\mathrm{~B})+\mathrm{c}(\mathrm{C})$ & Figure 9 /Table 2 \\
\hline $\begin{array}{c}5^{\mathrm{Q}^{\mathrm{RBS}}}{ }_{18 \mathrm{e}}(\mathrm{U})_{250} \mathrm{mRNA} / \\
30 \mathrm{~S}(\mathrm{IF} 3(\mathrm{Al} \times 488) \mathrm{PIC}\end{array}$ & $A+B^{*} \leftrightarrow C^{*} \rightarrow D^{*}$ & $\mathrm{~b}(\mathrm{~B})+\mathrm{c}(\mathrm{C})+\mathrm{d}(\mathrm{D})$ & Figure 10A / Table 3 \\
\hline $\begin{array}{c}5^{\mathrm{O}} \mathrm{RBS}_{20 \mathrm{e}}(\mathrm{UUC})_{78} \mathrm{mRNA} / \\
30 \mathrm{~S}(\mathrm{IF} 3(\mathrm{Al} \times 488) \mathrm{PIC}\end{array}$ & $\mathrm{A}+\mathrm{B}^{*} \leftrightarrow \mathrm{C}^{*} \rightarrow \mathrm{D}^{*} \rightarrow \mathrm{E}^{*}$ & $\begin{array}{c}\mathrm{b}(\mathrm{B})+\mathrm{c}(\mathrm{C})+\mathrm{d}(\mathrm{D}) \\
+\mathrm{e}(\mathrm{E})\end{array}$ & Figure 10B / Table 3 \\
\hline
\end{tabular}




\section{References}

Adhin, M.R., and van Duin, J. (1990). Scanning model for translational reinitiation in eubacteria. J Mol Biol 213, 811-818.

Antoun, A., Pavlov, M.Y., Lovmar, M., and Ehrenberg, M. (2006). How initiation factors maximize the accuracy of tRNA selection in initiation of bacterial protein synthesis. Mol Cell 23, 183-193.

Arava, Y. (2009). Compaction of polyribosomal mRNA. RNA Biol 6, 399-401.

Arava, Y., Wang, Y., Storey, J.D., Liu, C.L., Brown, P.O., and Herschlag, D. (2003). Genome-wide analysis of mRNA translation profiles in Saccharomyces cerevisiae. Proc Natl Acad Sci USA 100, 38893894.

Baltzinger, M., and Holler, E. (1982). Catalytic mechanism of phenylalanyl-tRNA synthetase of Escherichia coli K10. Conformational change and tRNAPhe phenylalanylation are concerted. Biochemistry 21, 2467-2476.

Bentele, K., Saffert, P., Rauscher, R., Ignatova, Z., and Bluthgen, N. (2013). Efficient translation initiation dictates codon usage at gene start. Mol Syst Biol 9, 675.

Boelens, R., and Gualerzi, C.O. (2002). Structure and function of bacterial initiation factors. Curr Protein Pept Sci 3, 107-119.

Brandt, F., Carlson, L.A., Hartl, F.U., Baumeister, W., and Grunewald, K. (2010). The three-dimensional organization of polyribosomes in intact human cells. Mol Cell 39, 560-569.

Brandt, F., Etchells, S.A., Ortiz, J.O., Elcock, A.H., Hartl, F.U., and Baumeister, W. (2009). The native 3D organization of bacterial polysomes. Cell 136, 261-271.

Caliskan, N., Peske, F., and Rodnina, M.V. (2015). Changed in translation: mRNA recoding by -1 programmed ribosomal frameshifting. Trends Biochem Sci 40, 265-274.

Canonaco, M.A., Calogero, R.A., and Gualerzi, C.O. (1986). Mechanism of translational initiation in prokaryotes. Evidence for a direct effect of IF2 on the activity of the $30 \mathrm{~S}$ ribosomal subunit. FEBS Lett 207, 198-204.

Carter, A.P., Clemons, W.M., Jr., Brodersen, D.E., Morgan-Warren, R.J., Hartsch, T., Wimberly, B.T., and Ramakrishnan, V. (2001). Crystal structure of an initiation factor bound to the 30S ribosomal subunit. Science 291, 498-501.

Chang, B., Halgamuge, S., and Tang, S.L. (2006). Analysis of SD sequences in completed microbial genomes: non-SD-led genes are as common as SD-led genes. Gene 373, 90-99.

Chen, H., Bjerknes, M., Kumar, R., and Jay, E. (1994). Determination of the optimal aligned spacing between the Shine-Dalgarno sequence and the translation initiation codon of Escherichia coli mRNAs. Nucleic Acids Res 22, 4953-4957. 
Christensen, A.K., and Bourne, C.M. (1999). Shape of large bound polysomes in cultured fibroblasts and thyroid epithelial cells. Anat Rec 255, 116-129.

Chu, D., Kazana, E., Bellanger, N., Singh, T., Tuite, M.F., and von der Haar, T. (2014). Translation elongation can control translation initiation on eukaryotic mRNAs. EMBO J 33, 21-34.

Corbin, R.W., Paliy, O., Yang, F., Shabanowitz, J., Platt, M., Lyons, C.E., Jr., Root, K., McAuliffe, J., Jordan, M.I., Kustu, S., et al. (2003). Toward a protein profile of Escherichia coli: comparison to its transcription profile. Proc Natl Acad Sci USA 100, 9232-9237.

Cukras, A.R., and Green, R. (2005). Multiple effects of S13 in modulating the strength of intersubunit interactions in the ribosome during translation. J Mol Biol 349, 47-59.

Cunha, C.E., Belardinelli, R., Peske, F., Holtkamp, W., Wintermeyer, W., and Rodnina, M.V. (2013). Dual use of GTP hydrolysis by elongation factor $\mathrm{G}$ on the ribosome. Translation 1, e24315.

Darfeuille, F., Unoson, C., Vogel, J., and Wagner, E.G. (2007). An antisense RNA inhibits translation by competing with standby ribosomes. Mol Cell 26, 381-392.

de Smit, M.H., and van Duin, J. (1990). Secondary structure of the ribosome binding site determines translational efficiency: a quantitative analysis. Proc Natl Acad Sci USA 87, 7668-7672.

de Smit, M.H., and van Duin, J. (2003). Translational Standby Sites: How Ribosomes May Deal with the Rapid Folding Kinetics of mRNA. J Mol Biol 331, 737-743.

Dennis, P.P., and Bremer, H. (1974). Differential rate of ribosomal protein synthesis in Escherichia coli B/r. J Mol Biol 84, 407-422.

Diaconu, M., Kothe, U., Schlunzen, F., Fischer, N., Harms, J.M., Tonevitsky, A.G., Stark, H., Rodnina, M.V., and Wahl, M.C. (2005). Structural basis for the function of the ribosomal L7/12 stalk in factor binding and GTPase activation. Cell 121, 991-1004.

Dressaire, C., Gitton, C., Loubiere, P., Monnet, V., Queinnec, I., and Cocaign-Bousquet, M. (2009). Transcriptome and proteome exploration to model translation efficiency and protein stability in Lactococcus lactis. PLoS Comput Biol 5, e1000606.

Dunkle, J.A., and Cate, J.H. (2010). Ribosome structure and dynamics during translocation and termination. Annu Rev Biophys 39, 227-244.

Duval, M., Korepanov, A., Fuchsbauer, O., Fechter, P., Haller, A., Fabbretti, A., Choulier, L., Micura, R., Klaholz, B.P., Romby, P., et al. (2013). Escherichia coli ribosomal protein S1 unfolds structured mRNAs onto the ribosome for active translation initiation. PLoS Biol 11, e1001731.

Espah Borujeni, A., Channarasappa, A.S., and Salis, H.M. (2014). Translation rate is controlled by coupled trade-offs between site accessibility, selective RNA unfolding and sliding at upstream standby sites. Nucleic Acids Res 42, 2646-2659. 
Garcia, C., Fortier, P.L., Blanquet, S., Lallemand, J.Y., and Dardel, F. (1995a). 1H and 15N resonance assignments and structure of the $\mathrm{N}$-terminal domain of Escherichia coli initiation factor 3 . Eur J Biochem 228, 395-402.

Garcia, C., Fortier, P.L., Blanquet, S., Lallemand, J.Y., and Dardel, F. (1995b). Solution structure of the ribosome-binding domain of $E$. coli translation initiation factor IF3. Homology with the U1A protein of the eukaryotic spliceosome. J Mol Biol 254, 247-259.

Goodman, D.B., Church, G.M., and Kosuri, S. (2013). Causes and effects of N-terminal codon bias in bacterial genes. Science 342, 475-479.

Goyal, A., Belardinelli, R., Maracci, C., Milon, P., and Rodnina, M.V. (2015). Directional transition from initiation to elongation in bacterial translation. Nucleic Acids Res 43, 10700-10712.

Gromadski, K.B., Daviter, T., and Rodnina, M.V. (2006). A uniform response to mismatches in codonanticodon complexes ensures ribosomal fidelity. Mol Cell 21, 369-377.

Gromadski, K.B., Wieden, H.J., and Rodnina, M.V. (2002). Kinetic mechanism of elongation factor Tscatalyzed nucleotide exchange in elongation factor Tu. Biochemistry 41, 162-169.

Gualerzi, C.O., and Pon, C.L. (2015). Initiation of mRNA translation in bacteria: structural and dynamic aspects. Cell Mol Life Sci 72, 4341-4367.

Gualerzi, C.O., Severini, M., Spurio, R., La Teana, A., and Pon, C.L. (1991). Molecular dissection of translation initiation factor IF2. Evidence for two structural and functional domains. J Biol Chem 266, 16356-16362.

Guimaraes, J.C., Rocha, M., and Arkin, A.P. (2014). Transcript level and sequence determinants of protein abundance and noise in Escherichia coli. Nucleic Acids Res 42, 4791-4799.

Han, Y., Gao, X., Liu, B., Wan, J., Zhang, X., and Qian, S.B. (2014). Ribosome profiling reveals sequenceindependent post-initiation pausing as a signature of translation. Cell Res 24, 842-851.

Heyer, E.E., and Moore, M.J. (2016). Redefining the Translational Status of 80 S Monosomes. Cell 164, 757-769.

Hoang, L., Fredrick, K., and Noller, H.F. (2004). Creating ribosomes with an all-RNA 30S subunit P site. Proc Natl Acad Sci USA 101, 12439-12443.

Ingolia, N.T. (2014). Ribosome profiling: new views of translation, from single codons to genome scale. Nat Rev Genet 15, 205-213.

Ingolia, N.T., Brar, G.A., Rouskin, S., McGeachy, A.M., and Weissman, J.S. (2012). The ribosome profiling strategy for monitoring translation in vivo by deep sequencing of ribosome-protected mRNA fragments. Nat Protoc 7, 1534-1550.

Ito, K., Uno, M., and Nakamura, Y. (2000). A tripeptide 'anticodon' deciphers stop codons in messenger RNA. Nature 403, 680-684. 
Jacobson, L.A., and Baldassare, J.C. (1976). Association of messenger ribonucleic acid with $70 \mathrm{~S}$ monosomes from down-shifted Escherichia coli. J Bacteriol 127, 637-643.

Jacques, N., and Dreyfus, M. (1990). Translation initiation in Escherichia coli: old and new questions. Mol Microbiol 4, 1063-1067.

Jia, Y., and Patel, S.S. (1997). Kinetic mechanism of GTP binding and RNA synthesis during transcription initiation by bacteriophage T7 RNA polymerase. J Biol Chem 272, 30147-30153.

Johnson, K.A., Simpson, Z.B., and Blom, T. (2009). Global Kinetic Explorer: A new computer program for dynamic simulation and fitting of kinetic data. Anal Biochem 387, 20-29.

Julian, P., Milon, P., Agirrezabala, X., Lasso, G., Gil, D., Rodnina, M.V., and Valle, M. (2011). The CryoEM structure of a complete $30 \mathrm{~S}$ translation initiation complex from Escherichia coli. PLoS Biol 9, e1001095.

Keasling, J.D. (2010). Manufacturing Molecules Through Metabolic Engineering. Science 330, 13551358.

Keiler, K.C. (2015). Mechanisms of ribosome rescue in bacteria. Nat Rev Microbiol 13, 285-297.

Kennell, D., and Riezman, H. (1977). Transcription and translation initiation frequencies of the Escherichia coli lac operon. J Mol Biol 114, 1-21.

Kierzek, A.M., Zaim, J., and Zielenkiewicz, P. (2001). The effect of transcription and translation initiation frequencies on the stochastic fluctuations in prokaryotic gene expression. J Biol Chem 276, 8165-8172.

Korostelev, A.A. (2011). Structural aspects of translation termination on the ribosome. RNA 17, 14091421.

Kosuri, S., Goodman, D.B., Cambray, G., Mutalik, V.K., Gao, Y., Arkin, A.P., Endy, D., and Church, G.M. (2013). Composability of regulatory sequences controlling transcription and translation in Escherichia coli. Proc Natl Acad Sci USA 110, 14024-14029.

Kudla, G., Murray, A.W., Tollervey, D., and Plotkin, J.B. (2009). Coding-Sequence Determinants of Gene Expression in Escherichia coli. Science 324, 255-258.

La Teana, A., Gualerzi, C.O., and Brimacombe, R. (1995). From stand-by to decoding site. Adjustment of the mRNA on the $30 \mathrm{~S}$ ribosomal subunit under the influence of the initiation factors. RNA 1, 772782.

La Teana, A., Pon, C.L., and Gualerzi, C.O. (1996). Late events in translation initiation. Adjustment of fMet-tRNA in the ribosomal P-site. J Mol Biol 256, 667-675.

Lackner, D.H., Beilharz, T.H., Marguerat, S., Mata, J., Watt, S., Schubert, F., Preiss, T., and Bahler, J. (2007). A network of multiple regulatory layers shapes gene expression in fission yeast. Mol Cell 26, 145-155. 
Laemmli, U.K. (1970). Cleavage of structural proteins during the assembly of the head of bacteriophage T4. Nature 227, 680-685.

Lakowicz, J.R. (2016 ). Principles of Fluorescence Spectroscopy 3edn (Springer US).

Laursen, B.S., Sorensen, H.P., Mortensen, K.K., and Sperling-Petersen, H.U. (2005). Initiation of protein synthesis in bacteria. Microbiol Mol Biol Rev 69, 101-123.

Lee, P.S., Shaw, L.B., Choe, L.H., Mehra, A., Hatzimanikatis, V., and Lee, K.H. (2003). Insights into the relation between mRNA and protein expression patterns: II. Experimental observations in Escherichia coli. Biotechnol Bioeng 84, 834-841.

Lee, T.H., Lapidus, L.J., Zhao, W., Travers, K.J., Herschlag, D., and Chu, S. (2007). Measuring the folding transition time of single RNA molecules. Biophys J 92, 3275-3283.

Li, G.W. (2015). How do bacteria tune translation efficiency? Curr Opin Microbiol 24, 66-71.

Li, G.W., Burkhardt, D., Gross, C., and Weissman, J.S. (2014). Quantifying absolute protein synthesis rates reveals principles underlying allocation of cellular resources. Cell 157, 624-635.

Liu, W., Shin, D., Tor, Y., and Cooperman, B.S. (2013). Monitoring translation with modified mRNAs strategically labeled with isomorphic fluorescent guanosine mimetics. ACS Chem Biol 8, 2017-2023.

Lu, P., Vogel, C., Wang, R., Yao, X., and Marcotte, E.M. (2007). Absolute protein expression profiling estimates the relative contributions of transcriptional and translational regulation. Nat Biotechnol 25, 117-124.

MacDougall, D.D., and Gonzalez, R.L., Jr. (2015). Translation initiation factor 3 regulates switching between different modes of ribosomal subunit joining. J Mol Biol 427, 1801-1818.

Marzi, S., Myasnikov, A.G., Serganov, A., Ehresmann, C., Romby, P., Yusupov, M., and Klaholz, B.P. (2007). Structured mRNAs regulate translation initiation by binding to the platform of the ribosome. Cell 130, 1019-1031.

Mehra, A., Lee, K.H., and Hatzimanikatis, V. (2003). Insights into the relation between mRNA and protein expression patterns: I. Theoretical considerations. Biotechnol Bioeng 84, 822-833.

Melnikov, S., Ben-Shem, A., Garreau de Loubresse, N., Jenner, L., Yusupova, G., and Yusupov, M. (2012). One core, two shells: bacterial and eukaryotic ribosomes. Nat Struct Mol Biol 19, 560-567.

Miller, O.L., Jr., Hamkalo, B.A., and Thomas, C.A., Jr. (1970). Visualization of bacterial genes in action. Science 169, 392-395.

Milon, P., Carotti, M., Konevega, A.L., Wintermeyer, W., Rodnina, M.V., and Gualerzi, C.O. (2010). The ribosome-bound initiation factor 2 recruits initiator tRNA to the 30S initiation complex. EMBO Rep 11, 312-316.

Milon, P., Konevega, A.L., Gualerzi, C.O., and Rodnina, M.V. (2008). Kinetic checkpoint at a late step in translation initiation. Mol Cell 30, 712-720. 
Milon, P., Konevega, A.L., Peske, F., Fabbretti, A., Gualerzi, C.O., and Rodnina, M.V. (2007). Transient kinetics, fluorescence, and FRET in studies of initiation of translation in bacteria. Methods Enzymol 430, 1-30.

Milon, P., Maracci, C., Filonava, L., Gualerzi, C.O., and Rodnina, M.V. (2012). Real-time assembly landscape of bacterial 30 S translation initiation complex. Nat Struct Mol Biol 19, 609-615.

Milon, P., and Rodnina, M.V. (2012). Kinetic control of translation initiation in bacteria. Crit Rev Biochem Mol Biol 47, 334-348.

Mitarai, N., Sneppen, K., and Pedersen, S. (2008). Ribosome collisions and translation efficiency: optimization by codon usage and mRNA destabilization. J Mol Biol 382, 236-245.

Mittelstaet, J., Konevega, A.L., and Rodnina, M.V. (2013). A kinetic safety gate controlling the delivery of unnatural amino acids to the ribosome. J Am Chem Soc 135, 17031-17038.

Moll, I., Hirokawa, G., Kiel, M.C., Kaji, A., and Blasi, U. (2004). Translation initiation with $70 \mathrm{~S}$ ribosomes: an alternative pathway for leaderless mRNAs. Nucleic Acids Res 32, 3354-3363.

Myasnikov, A.G., Afonina, Z.A., Menetret, J.F., Shirokov, V.A., Spirin, A.S., and Klaholz, B.P. (2014). The molecular structure of the left-handed supra-molecular helix of eukaryotic polyribosomes. Nat Commun 5, 5294.

$\mathrm{Na}$, D., Lee, S., and Lee, D. (2010). Mathematical modeling of translation initiation for the estimation of its efficiency to computationally design mRNA sequences with desired expression levels in prokaryotes. BMC Syst Biol 4, 71.

Nakagawa, S., Niimura, Y., Miura, K., and Gojobori, T. (2010). Dynamic evolution of translation initiation mechanisms in prokaryotes. Proc Natl Acad Sci USA 107, 6382-6387.

O'Donnell, S.M., and Janssen, G.R. (2001). The initiation codon affects ribosome binding and translational efficiency in Escherichia coli of $\mathrm{cl}$ mRNA with or without the 5' untranslated leader. J Bacteriol 183, 1277-1283.

Ogle, J.M., Carter, A.P., and Ramakrishnan, V. (2003). Insights into the decoding mechanism from recent ribosome structures. Trends Biochem Sci 28, 259-266.

Passalacqua, K.D., Varadarajan, A., Ondov, B.D., Okou, D.T., Zwick, M.E., and Bergman, N.H. (2009). Structure and complexity of a bacterial transcriptome. J Bacteriol 191, 3203-3211.

Peske, F., Rodnina, M.V., and Wintermeyer, W. (2005). Sequence of steps in ribosome recycling as defined by kinetic analysis. Mol Cell 18, 403-412.

Petrelli, D., LaTeana, A., Garofalo, C., Spurio, R., Pon, C.L., and Gualerzi, C.O. (2001). Translation initiation factor IF3: two domains, five functions, one mechanism? EMBO J 20, 4560-4569.

Pfeffer, S., Brandt, F., Hrabe, T., Lang, S., Eibauer, M., Zimmermann, R., and Forster, F. (2012). Structure and 3D arrangement of endoplasmic reticulum membrane-associated ribosomes. Structure 20, 1508-1518. 
Picard, F., Milhem, H., Loubiere, P., Laurent, B., Cocaign-Bousquet, M., and Girbal, L. (2012). Bacterial translational regulations: high diversity between all mRNAs and major role in gene expression. BMC Genomics 13, 528.

Porschke, D. (1974). Thermodynamic and kinetic parameters of an oligonucleotide hairpin helix. Biophys Chem 1, 381-386.

Qin, X., Ahn, S., Speed, T.P., and Rubin, G.M. (2007). Global analyses of mRNA translational control during early Drosophila embryogenesis. Genome Biol 8, R63.

Ramakrishnan, V. (2002). Ribosome structure and the mechanism of translation. Cell 108, 557-572.

Rauzan, B., McMichael, E., Cave, R., Sevcik, L.R., Ostrosky, K., Whitman, E., Stegemann, R., Sinclair, A.L., Serra, M.J., and Deckert, A.A. (2013). Kinetics and thermodynamics of DNA, RNA, and hybrid duplex formation. Biochemistry 52, 765-772.

Rodnina, M. (1994). Purification of $\mathrm{fMet}^{-\mathrm{tRNA}} \mathrm{fMet}^{\mathrm{f}}$ by Fast Protein Liquid Chromatography. Anal Biochem 219, 380-381.

Rodnina, M.V., Savelsbergh, A., Katunin, V.I., and Wintermeyer, W. (1997). Hydrolysis of GTP by elongation factor $\mathrm{G}$ drives tRNA movement on the ribosome. Nature 385, 37-41.

Rodnina, M.V., Savelsbergh, A., Matassova, N.B., Katunin, V.I., Semenkov, Y.P., and Wintermeyer, W. (1999). Thiostrepton inhibits the turnover but not the GTPase of elongation factor $\mathrm{G}$ on the ribosome. Proc Natl Acad Sci USA 96, 9586-9590.

Rodnina, M.V., and Wintermeyer, W. (1995). GTP consumption of elongation factor Tu during translation of heteropolymeric mRNAs. Proc Natl Acad Sci USA 92, 1945-1949.

Rodnina, M.V., and Wintermeyer, W. (2011). The ribosome as a molecular machine: the mechanism of tRNA-mRNA movement in translocation. Biochem Soc Trans 39, 658-662.

Rudorf, S., Thommen, M., Rodnina, M.V., and Lipowsky, R. (2014). Deducing the kinetics of protein synthesis in vivo from the transition rates measured in vitro. PLoS Comput Biol 10, e1003909.

Salis, H.M., Mirsky, E.A., and Voigt, C.A. (2009). Automated design of synthetic ribosome binding sites to control protein expression. Nat Biotechnol 27, 946-950.

Savelsbergh, A., Katunin, V.I., Mohr, D., Peske, F., Rodnina, M.V., and Wintermeyer, W. (2003). An elongation factor G-induced ribosome rearrangement precedes tRNA-mRNA translocation. Mol Cell $11,1517-1523$.

Schagger, H., and von Jagow, G. (1987). Tricine-sodium dodecyl sulfate-polyacrylamide gel electrophoresis for the separation of proteins in the range from 1 to $100 \mathrm{kDa}$. Anal Biochem 166, 368379.

Schmeing, T.M., and Ramakrishnan, V. (2009). What recent ribosome structures have revealed about the mechanism of translation. Nature 461, 1234-1242. 
Seo, S.W., Yang, J., and Jung, G.Y. (2009). Quantitative correlation between mRNA secondary structure around the region downstream of the initiation codon and translational efficiency in Escherichia coli. Biotechnol Bioeng 104, 611-616.

Seo, S.W., Yang, J.S., Kim, I., Yang, J., Min, B.E., Kim, S., and Jung, G.Y. (2013). Predictive design of mRNA translation initiation region to control prokaryotic translation efficiency. Metab Eng 15, 67-74.

Sette, M., Spurio, R., van Tilborg, P., Gualerzi, C.O., and Boelens, R. (1999). Identification of the ribosome binding sites of translation initiation factor IF3 by multidimensional heteronuclear NMR spectroscopy. RNA 5, 82-92.

Sette, M., van Tilborg, P., Spurio, R., Kaptein, R., Paci, M., Gualerzi, C.O., and Boelens, R. (1997). The structure of the translational initiation factor IF1 from E.coli contains an oligomer-binding motif. EMBO J 16, 1436-1443.

Shapiro, A.L., Vinuela, E., and Maizel, J.V., Jr. (1967). Molecular weight estimation of polypeptide chains by electrophoresis in SDS-polyacrylamide gels. Biochem Biophys Res Commun 28, 815-820.

Shine, J., and Dalgarno, L. (1974). The 3'-terminal sequence of Escherichia coli $16 S$ ribosomal RNA: complementarity to nonsense triplets and ribosome binding sites. Proc Natl Acad Sci USA 71, 13421346.

Skorski, P., Leroy, P., Fayet, O., Dreyfus, M., and Hermann-Le Denmat, S. (2006). The highly efficient translation initiation region from the Escherichia coli rpsA gene lacks a shine-dalgarno element. J Bacteriol 188, 6277-6285.

Sorensen, M.A., and Pedersen, S. (1991). Absolute in vivo translation rates of individual codons in Escherichia coli. The two glutamic acid codons GAA and GAG are translated with a threefold difference in rate. J Mol Biol 222, 265-280.

Steitz, J.A., and Jakes, K. (1975). How ribosomes select initiator regions in mRNA: base pair formation between the $3^{\prime}$ terminus of $16 \mathrm{~S}$ rRNA and the mRNA during initiation of protein synthesis in Escherichia coli. Proc Natl Acad Sci USA 72, 4734-4738.

Storz, G., Vogel, J., and Wassarman, K.M. (2011). Regulation by small RNAs in bacteria: expanding frontiers. Mol Cell 43, 880-891.

Studer, S.M., and Joseph, S. (2006). Unfolding of mRNA secondary structure by the bacterial translation initiation complex. Mol Cell 22, 105-115.

Studer, S.M., and Joseph, S. (2007). Binding of mRNA to the bacterial translation initiation complex. Methods Enzymol 430, 31-44.

Takyar, S., Hickerson, R.P., and Noller, H.F. (2005). mRNA helicase activity of the ribosome. Cell 120, 49-58.

Tsai, A., Petrov, A., Marshall, R.A., Korlach, J., Uemura, S., and Puglisi, J.D. (2012). Heterogeneous pathways and timing of factor departure during translation initiation. Nature 487, 390-393. 
Tuller, T., Carmi, A., Vestsigian, K., Navon, S., Dorfan, Y., Zaborske, J., Pan, T., Dahan, O., Furman, I., and Pilpel, Y. (2010a). An evolutionarily conserved mechanism for controlling the efficiency of protein translation. Cell 141, 344-354.

Tuller, T., Waldman, Y.Y., Kupiec, M., and Ruppin, E. (2010b). Translation efficiency is determined by both codon bias and folding energy. Proc Natl Acad Sci USA 107, 3645-3650.

Tuller, T., Waldman, Y.Y., Kupiec, M., and Ruppin, E. (2010c). Translation efficiency is determined by both codon bias and folding energy. Proc Natl Acad Sci U S A 107, 3645-3650.

Underwood, K.A., Swartz, J.R., and Puglisi, J.D. (2005). Quantitative polysome analysis identifies limitations in bacterial cell-free protein synthesis. Biotechnol Bioeng 91, 425-435.

Valleriani, A., Ignatova, Z., Nagar, A., and Lipowsky, R. (2010). Turnover of messenger RNA: Polysome statistics beyond the steady state. Epl 89, 58003-58003.

Voss, N.R., Gerstein, M., Steitz, T.A., and Moore, P.B. (2006). The geometry of the ribosomal polypeptide exit tunnel. J Mol Biol 360, 893-906.

Wagner, E.G., and Flardh, K. (2002). Antisense RNAs everywhere? Trends Genet 18, 223-226.

Welch, M., Govindarajan, S., Ness, J.E., Villalobos, A., Gurney, A., Minshull, J., and Gustafsson, C. (2009). Design parameters to control synthetic gene expression in Escherichia coli. PLoS One 4, e7002.

Wieden, H.J., Gromadski, K., Rodnin, D., and Rodnina, M.V. (2002). Mechanism of elongation factor (EF)-Ts-catalyzed nucleotide exchange in EF-Tu. Contribution of contacts at the guanine base. J Biol Chem 277, 6032-6036.

Wimberly, B.T., Brodersen, D.E., Clemons, W.M., Jr., Morgan-Warren, R.J., Carter, A.P., Vonrhein, C., Hartsch, T., and Ramakrishnan, V. (2000). Structure of the $30 \mathrm{~S}$ ribosomal subunit. Nature 407, 327339.

Wintermeyer, W., Peske, F., Beringer, M., Gromadski, K.B., Savelsbergh, A., and Rodnina, M.V. (2004). Mechanisms of elongation on the ribosome: dynamics of a macromolecular machine. Biochem Soc Trans 32, 733-737.

Youngman, E.M., McDonald, M.E., and Green, R. (2008). Peptide release on the ribosome: mechanism and implications for translational control. Annu Rev Microbiol 62, 353-373.

Yusupova, G., Jenner, L., Rees, B., Moras, D., and Yusupov, M. (2006). Structural basis for messenger RNA movement on the ribosome. Nature 444, 391-394.

Yusupova, G.Z., Yusupov, M.M., Cate, J.H.D., and Noller, H.F. (2001). The path of messenger RNA through the ribosome. Cell 106, 233-241.

Yvon, M., Chabanet, C., and Pelissier, J.P. (1989). Solubility of peptides in trichloroacetic acid (TCA) solutions. Hypothesis on the precipitation mechanism. Int J Pept Protein Res 34, 166-176. 
Zouridis, H., and Hatzimanikatis, V. (2007). A model for protein translation: polysome selforganization leads to maximum protein synthesis rates. Biophys J 92, 717-730.

Zuker, M. (2003). Mfold web server for nucleic acid folding and hybridization prediction. Nucleic Acids Res 31, 3406-3415.

Zuo, E.T., Tanious, F.A., Wilson, W.D., Zon, G., Tan, G.S., and Wartell, R.M. (1990). Effect of Base-Pair Sequence on the Conformations and Thermally Induced Transitions in Oligodeoxyribonucleotides Containing Only at Base-Pairs. Biochemistry 29, 4446-4456.

Zur, H., and Tuller, T. (2012). Strong association between mRNA folding strength and protein abundance in S. cerevisiae. EMBO Rep 13, 272-277. 


\section{Acknowledgments}

I sincerely thank Prof. Dr. Marina Rodnina for her guidance, patience and professionalism. Her supervision helped me to become a better scientist. I thank my thesis committee members, Prof. Dr. Heinz Neumann and Prof. Dr. Holger Stark, for their valuable input during fruitful thesis committee discussions. I would like to express my gratitude to Dr. Riccardo Belardinelli for his constant support and hour-long discussions, for naming me lentissima and contributing with jokes even if I was not even close to laughter. Thank you, Dr. Pohl Milon for initiating this project and being a strict mentor. All the lab members made me feel welcomed in the lab: Michael, Tanja, Sandra, Olaf, Theo, Manuela, Christina, Ant and Dimitra. Thank you, Raffa, for being an awesome bench neighbor and mocking me when I overdose with ordering my desk. For all the cheerful lunch talks and cocktails I am thankful to Neva, Aki, Heena, Carlos, Michael, Albena and Michi. Goran do not forget P ten.

A huge thank you, to Steffen Burckhardt and Kerstin Grueniger, for being so organized and truly friendly. Dear Steffen, I will never forget our trip to Jerusalem and the amazing culture nights you helped us organize. Göttingen feels like home because of my lovely AKB family. Siv, I could not imagine having a better roomie, Marta, I appreciate all the free coffee and your advices, Victor, thank you for teaching me enthusiasm and salsa, Paola, (Queen P) your laughter is unforgettable and Mateusz, for the rainbow of emotions you bring to my life. My sincere gratitude to my family, Tatiana, Andrei and Yosif. You supported me every second along the way. Thank you, Alexander Rabe, for your kindness, love, support and optimism. 


\section{Abbreviations}

30 IC

$30 S$ PIC

70S EC

70S IC

aa

aa-tRNA

Alx488

anti-SD

APS

ATP

CTD

dNTP

dpm

EF

FRET

GMP

GTP

i.e.

IF

IPTG

$k_{+\mathrm{i}} 2^{\text {nd }}$ UUC

$k_{+\mathrm{i}} 2^{\text {nd }}$ UUCPost

$k_{+\mathrm{i}} 2^{\text {nd }} \mathrm{UUU}$

$k_{+\mathrm{i}} 2^{\text {nd }}$ UUU*

$k_{+\mathrm{i}} 2^{\text {nd }}$ UUUPost

$k_{+2} 2^{\text {nd }}$ UUUPost*

$\boldsymbol{k}_{\text {app }}$
30S initiation complex

305 preinitiation complex

70S elongation complex

70S initiation complex

Amino acid

Aminoacyl-tRNA

Alexa488 dye

Anti-Shine-Dalgarno

Ammonium peroxodisulfate

Adenosine triphosphate

C-terminal domain

(deoxy)nucleoside triphosphate

Disintegrations per minute

Elongation factor

Fluorescence resonance energy transfer

Guanosine monophosphate

Guanosine triphosphate

id est ("it is")

Initiation factor

Isopropyl- $\beta$-D-thiogalactopyranoside

Rate constant of second ribosome association to $5^{\mathrm{Q}} \mathrm{RBS}_{20 \mathrm{e}}(\mathrm{UUC})_{78}$ mRNA

Rate constant of second ribosome association to a post elongation 70S IC

$\left(5^{\mathrm{Q}} \mathrm{RBS}_{20 \mathrm{e}}(\mathrm{UUC})_{78} \mathrm{mRNA}\right)$

Rate constant of second ribosome association to $5^{\mathrm{Q}} \mathrm{RBS}_{18 \mathrm{e}}(\mathrm{U})_{250} \mathrm{mRNA}$

Rate constant of second ribosome association to $5^{*} \mathrm{RBS}_{18 \mathrm{e}}(\mathrm{U})_{250} \mathrm{mRNA}$

Rate constant of second ribosome association to a post elongation 70S IC

$\left(5^{\mathrm{Q}} \mathrm{RBS}_{18 \mathrm{e}}(\mathrm{U})_{250} \mathrm{mRNA}\right)$

Rate constant of second ribosome association to a post elongation 70S IC

$\left(5^{*} \operatorname{RBS}_{18 \mathrm{e}}(U)_{250} \mathrm{mRNA}\right)$

Apparent rate constant 


\begin{tabular}{|c|c|}
\hline$k_{\mathrm{e}} 1^{\text {st }} \mathrm{UUC}$ & Elongation rate of the first $70 \mathrm{SEC}$ with $5^{\mathrm{a}} \mathrm{RBS}_{20 \mathrm{e}}(\mathrm{UUC})_{78} \mathrm{mRNA}$ \\
\hline$k_{\mathrm{e}} 1^{\text {st }} \mathrm{UUU}$ & Elongation rate of the first 70S EC with poly(U)-extended mRNAs \\
\hline $\mathbf{k}_{\text {obs }}$ & Observable rate \\
\hline $\mathbf{k}_{\text {off }}$ & Dissociation rate constant \\
\hline $\mathbf{k}_{\text {on }}$ & Association rate constant \\
\hline $\min$ & Minute \\
\hline mRNA & Messenger RNA \\
\hline MW & Molecular weight \\
\hline $\mathrm{nm}$ & Nanometer \\
\hline ORF & Open reading frame \\
\hline PAGE & Polyacrylamide gel electrophoresis \\
\hline PCR & Polymerase chain reaction \\
\hline PEP & Phosphoenolpyruvate \\
\hline PheRS & Phe Aminoacyl-tRNA synthetase \\
\hline PK & Pyruvate kinase \\
\hline PTC & Peptidyl transferase center \\
\hline RRF & Ribosome recycling factor \\
\hline rRNA & Ribosomal RNA \\
\hline $\mathbf{S}$ & Svedberg unit \\
\hline $\mathbf{s}$ & Second \\
\hline s.d. & Standard deviation \\
\hline s.e.m. & Standard error of the mean \\
\hline SD & Shine-Dalgarno \\
\hline SDS & Sodium dodecyl sulfate \\
\hline TC & Ternary complex \\
\hline TEMED & $\mathrm{N}, \mathrm{N}, \mathrm{N}^{\prime}, \mathrm{N}^{\prime}$-Tetramethylethylendiamine \\
\hline$t_{\mathrm{f}} 2^{\mathrm{nd}}$ & Frequency of second translation initiation \\
\hline tRNA & Transfer RNA \\
\hline UTR & Untranslated region \\
\hline $\mathbf{v} / \mathbf{v}$ & volume/volume \\
\hline$w / v$ & weight/volume \\
\hline
\end{tabular}




\section{List of figures}

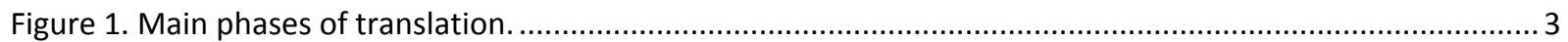

Figure 2. Overall architecture of the $50 \mathrm{~S}$ and $30 \mathrm{~S}$ subunits with bacterial-specific moieties. ............................. 5

Figure 3. Comparison between prokaryotic and eukaryotic polysomal orientation............................................ 10

Figure 4. Synthesis and activity testing of the model $5^{\prime}$-end labeled mRNAs. ....................................................13

Figure 5. In vitro transcribed model mRNAs are active in translation initiation. ............................................... 16

Figure 6. FRET between 5'-end labeled mRNAs with poly(U) extensions and IF3(Alx488) bound to 30S PIC or

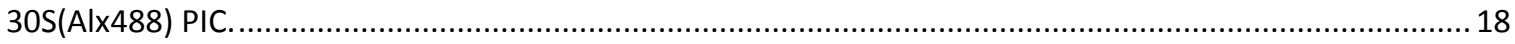

Figure 7. Fluorescence change of $5 * \mathrm{RBS}_{18 \mathrm{e}}(\mathrm{U})_{250}$ mRNA upon binding to the $30 \mathrm{~S} \mathrm{PIC...................................20}$

Figure 8. FRET between $5{ }^{\mathrm{a} B \mathrm{RS}_{20}}$ (UUC) 78 mRNA and IF3(Alx488) bound to the $30 \mathrm{SPIC}$ or $30 \mathrm{~S}$ (Alx488) PIC....... 22

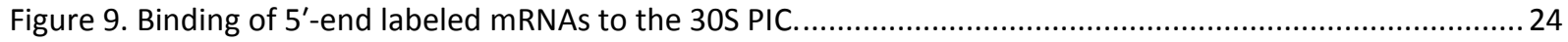

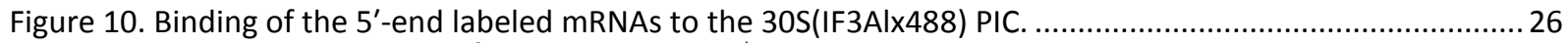

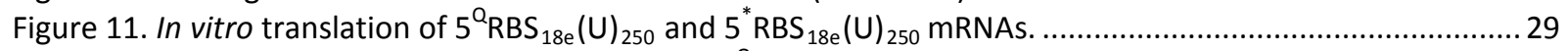

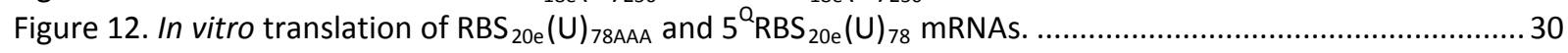

Figure 13. The first step of polysome formation in vitro in a minimal translation system .....................................33

Figure 14. Kinetic models for second round initiation. ............................................................................. 37

Figure 15. Co- and post- translational monitoring of 30S(Alx488) PIC recruitment to $5^{\mathrm{Q}} \mathrm{RBS}_{20 \mathrm{e}}(\mathrm{UUC})_{78} \mathrm{mRNA}_{\text {.... }} 40$

Figure 16. Co- and post- translational monitoring of $30 \mathrm{~S} \mathrm{PIC} \mathrm{recruitment} \mathrm{to} 5^{\mathrm{Q}} \mathrm{RBS}_{18 \mathrm{e}}(\mathrm{U})_{250}$ mRNA. ...................42

Figure 17. Visualizing the $5^{\prime}$-end-labeled mRNA during elongation and second round of initiation. .................... 45

Figure 18. Co-and post translationally recruitment to the $30 \mathrm{~S} \mathrm{PIC} \mathrm{to} \mathrm{the} 5 * \mathrm{RBS}_{18 \mathrm{e}}(\mathrm{U})_{250} \mathrm{mRNA}$........................ 46

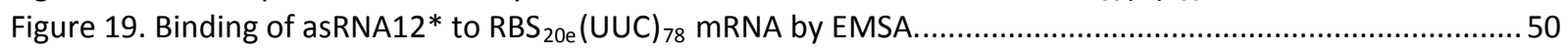

Figure 20. Fluorescence change of asRNA12* upon $\mathrm{RBS}_{20 \mathrm{e}}(\mathrm{UUC})_{78}$ mRNA binding. .........................................5 51

Figure 21. Co-and post translationally recruitment of asRNA12* to the $5^{\mathrm{a}^{\mathrm{RBS}}}{ }_{20 \mathrm{e}}(\mathrm{UUC})_{78}$ mRNA. .....................53

Figure 22. Structure of the $5^{\prime}$-end labeled model mRNAs produced by modified in vitro transcription reaction. 76

\section{List of tables}

Table 1. Summary of association rate constants between 30 S PIC and 5 '-end labeled mRNAs..........................25

Table 2. Summary of the elemental rate constants of interaction between 30S PIC and $55^{\prime}$-end labeled mRNAs. 25

Table 3. Summary of the elemental rate constants of interaction between 30S(IF3Alx488) PIC and 5'-end labeled mRNAs.

Table 4. Summary of rates of poly(Phe) synthesis. …….............................................................................. 31

Table 5. Summary of elemental rate constants obtained with global fit models from Figure 14........................ 48

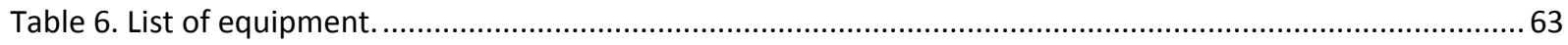

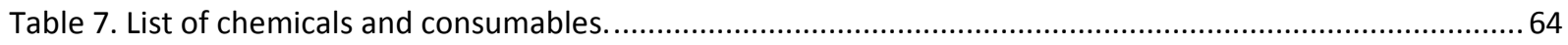

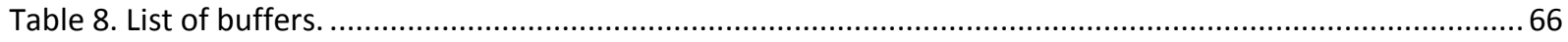

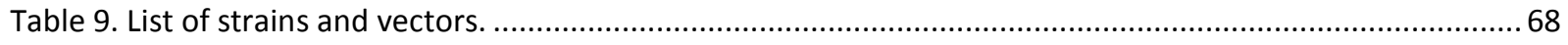

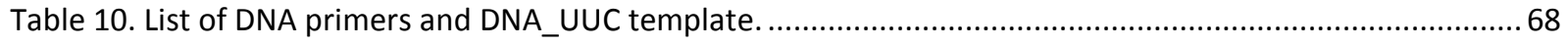

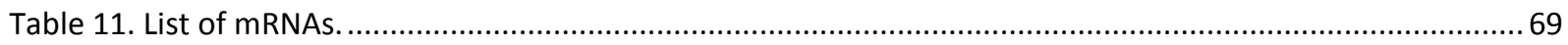

Table 12. $\Delta \mathrm{G}^{\circ}$ free energy calculations of RBS from model mRNAs.............................................................. 70

Table 13. Thermo-cycler program conditions for single stranded DNA_UUC.....................................................72

Table 14. Thermo-cycler program conditions for double stranded DNA_UUC..................................................72

Table 15. Three-stage site-directed mutagenesis. ............................................................................................. 73

Table 16. First step of thermo-cycler program conditions for site-directed mutagenesis.................................... 73

Table 17. Second step of thermo-cycler program conditions for site-directed mutagenesis................................73

Table 18. Summary of models used in the global fit of traces from the first round of initiation........................... 82 


\section{Curriculum Vitae}

Personal information

Name
Address
Telephone
E-mail
Nationality
Date of birth

EDUCATION

$04 / 2012-05 / 2016$

$10 / 2010-03 / 2012$

$09 / 2006-07 / 2010$

$09 / 1999-06 / 2006$
Irena Yosifova Andreeva

Max Planck Institute for Biophysical Chemistry, Department of Physical Biochemistry, Am Fassberg 11

+495512012961

irenkandr@gmail.com / irena.andreeva@mpibpc.mpg.de

Bulgarian

$26 / 10 / 1987$

International Max Planck Research School in Molecular Biology

University of Göttingen, Germany

PhD

Max Planck Institute for Biophysical Chemistry, Department of Physical Biochemistry, Göttingen, Germany.

International Max Planck Research School in Molecular Biology University of Göttingen, Germany

Master of science, Molecular Biology

Max Planck Institute for Biophysical Chemistry, Department of Physical Biochemistry, Göttingen, Germany.

Overall grade of the Master's degree : A - excellent

Sofia University "St. Kliment Ohridski", Sofia, Bulgaria

Bachelor of Science, Molecular biology

Overall grade of the Bachelor's degree: A - excellent

"Vasil Levski" School, Sevlievo, Bulgaria

Graduated with a high school diploma in advanced English language study.

Overall grade : A - excellent 
EXTRACURRICULAR ACTIVITIES

2014-2016

$10 / 2012-09 / 2013$

$09 / 2011-10 / 2012$
Member of the PhD and Postdoc community at Max Planck Institute for Biophysical Chemistry.

$10^{\text {th }}$ Horizons in Molecular Biology

Central co-organizers of an international PhD symposium. Planning and coordinating all the meeting and the actions from the other groups

$\mathbf{9}^{\text {th }}$ Horizons in Molecular Biology

Co-organizer of an international PhD symposium. 